


\section{Selected Thermodynamic Properties for} Mixtures of R-32 (Difluoromethane), R-125 (Pentafluoroethane), R-134A $(1,1,1,2$-Tetrafluoroethane), R-143A (1,1,1-Trifluoroethane), R-41 (Fluoromethane), R-290 (Propane), and R-744 (Carbon Dioxide)

Cynthia D. Holcomb Joseph W. Magee Jennifer L. Scott Stephanie L. Outcalt William M. Haynes

Physical and Chemical Properties Division Chemical Science and Technology Laboratory National Institute of Standards and Technology 325 Broadway

Boulder, Colorado 80303-3328

December 1997

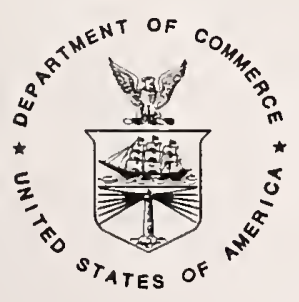


National Institute of Standards and Technology Technical Note Natl. Inst. Stand. Technol., Tech. Note 1397, 200 pages (December 1997) CODEN:NTNOEF

\section{U.S. GOVERNMENT PRINTING OFFICE \\ WASHINGTON: 1997}

For sale by the Superintendent of Documents, U.S. Government Printing Office, Washington, DC 20402-9325 


\section{TABLE OF CONTENTS}

LIST OF FIGURES

LIST OF TABLES

1. INTRODUCTION.

2. SIGNIFICANT RESULTS

2.1 Thermophysical Properties of R-32/125/134a and Its Constituent Binaries

2.1.1 R-32/134a

2.1 .2 R-32/125

$2.1 .3 \mathrm{R}-125 / 134 \mathrm{a}$ 4

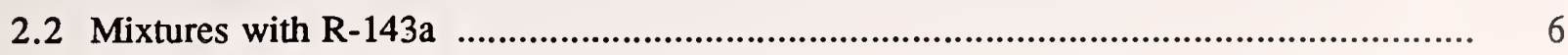

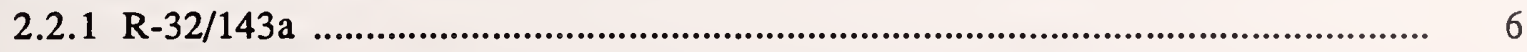

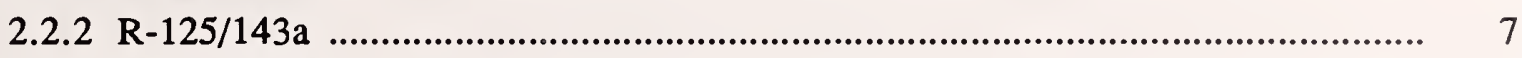

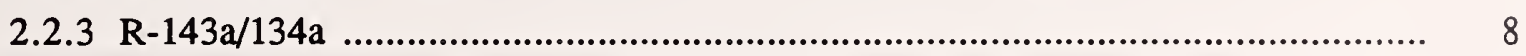

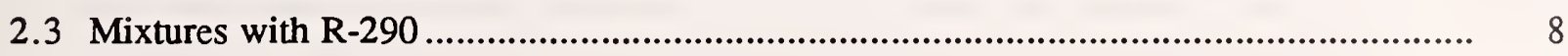

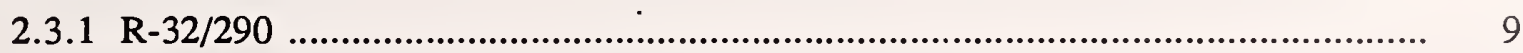

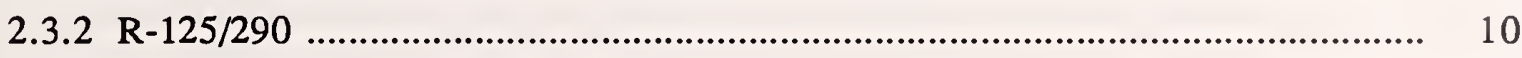

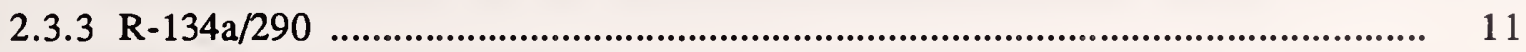

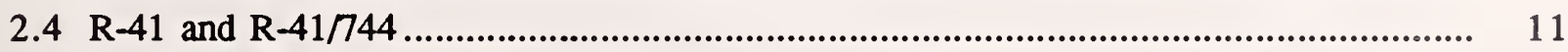

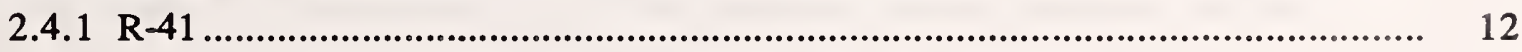

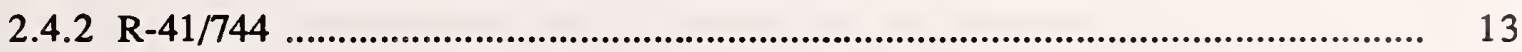

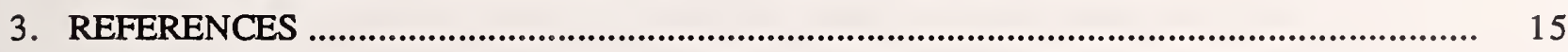

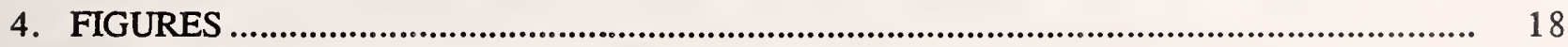

APPENDIX A. TABLES OF THERMOPHYSICAL PROPERTY DATA ............................. A-1

APPENDIX B. EXPERIMENTAL APPARATUS ....................................................... B-1

B.1 Vapor-Liquid Equilibrium Apparatus ............................................................. B-2

B.2 Bubble-Point and Near-Saturation $(p, p, T)$ Apparatus ......................................... B-2

B.3 Isochoric $(p, p, T)$ Apparatus ......................................................................... B

B.4 Adiabatic Constant Volume Calorimeter .......................................................... B-4

B.5 Spherical Resonator Speed of Sound Apparatus .............................................. B-4

APPENDIX C. ESTIMATES OF STATE-POINT UNCERTAINTIES ................................... C-1

APPENDIX D. GAS CHROMATOGRAPH CALIBRATION PROCEDURES ......................... D 1

APPENDIX E. REPRINTS OF PAPERS RELATED TO THE LEMMON-JACOBSEN

MODEL [1] AND REFPROP 6.0 [2] 


\section{LIST OF FIGURES}

Figure 1. Types of Phase Behavior for the Refrigerant Mixtures Studied in This Project.........

Figure 2. Comparison of Bubble-Point Pressures for the R-32/134a System; the Baseline is from the Lemmon-Jacobsen Model in REFPROP 6.0.

Figure 3. Comparison of Vapor Compositions for the R-32/134a System; the Baseline is from the Lemmon-Jacobsen Model in REFPROP 6.0.

Figure 4. Comparison of Densities for the R-32/134a System; the Baseline is from the Lemmon-Jacobsen Model in REFPROP 6.0.

Figure 5. Comparison of Bubble-Point Pressures for the R-32/125 System; the Baseline is from the Lemmon-Jacobsen Model in REFPROP 6.0

Figure 6. Comparison of Vapor Compositions for the R-32/125 System; the Baseline is from the Lemmon-Jacobsen Model in REFPROP 6.0

Figure 7. Comparison of Densities for the R-32/125 System; the Baseline is from the Lemmon-Jacobsen Model in REFPROP 6.0...

Figure 8. Comparison of Bubble-Point Pressures for the R-125/134a System; the Baseline is from the Lemmon-Jacobsen Model in REFPROP 6.0.

Figure 9. Comparison of Vapor Compositions for the R-125/134a System; the Baseline is from the Lemmon-Jacobsen Model in REFPROP 6.0.

Figure 10. Comparison of Densities for the R-125/134a System; the Baseline is from the Lemmon-Jacobsen Model in REFPROP 6.0.

Figure 11. Comparison of Bubble-Point Pressures for the R-32/125/134a System; the Baseline is from the Lemmon-Jacobsen Model in REFPROP 6.0

Figure 12. Comparison of Vapor Compositions for the R-32/125/134a System; the Baseline is from the Lemmon-Jacobsen Model in REFPROP 6.0.

Figure 13. Comparison of Densities for the R-32/125/134a System; the Baseline is from the Lemmon-Jacobsen Model in REFPROP 6.0

Figure 14. Comparison of Bubble-Point Pressures for the R-32/143a System; the Baseline is from the Lemmon-Jacobsen Model in REFPROP 6.0.

Figure 15. Comparison of Vapor Compositions for the R-32/143a System; the Baseline is from the Lemmon-Jacobsen Model in REFPROP 6.0.

Figure 16. Comparison of Densities for the R-32/143a System; the Baseline is from the Lemmon-Jacobsen Model in REFPROP 6.0 .

Figure 17. Comparison of Bubble-Point Pressures for the R-125/143a System; the Baseline is from the Lemmon-Jacobsen Model in REFPROP 6.0

Figure 18. Comparison of Vapor Compositions for the R-125/143a System; the Baseline is from the Lemmon-Jacobsen Model in REFPROP 6.0.

Figure 19. Range of Measured Temperatures and Pressures for Isochoric ( $, \rho, T)$ Data for a Mixture of R-125/143a with $\times(\mathrm{R}-125)=0.49996$ Mole Fraction

(0.58812 Mass Fraction). 
Figure 20. Comparison of Densities for the R-125/143a System; the Baseline is from the Lemmon-Jacobsen Model in REFPROP 6.0

Figure 21. Comparison of Bubble-Point Pressures for the R-143a/134a System; the Baseline is from the Lemmon-Jacobsen Model in REFPROP 6.0.

Figure 22. Comparison of Vapor Compositions for the R-143a/134a System; the Baseline is from the Lemmon-Jacobsen Model in REFPROP 6.0.

Figure 23. Comparison of Densities for the R-143a/134a System; the Baseline is from the Lemmon-Jacobsen Model in REFPROP 6.0.

Figure 24. Comparison of Bubble-Point Pressures for the R-32/290 System; the Baseline is from the Lemmon-Jacobsen Model in REFPROP 6.0

Figure 25. Comparison of Vapor Compositions for the R-32/290 System; the Baseline is from the Lemmon-Jacobsen Model in REFPROP 6.0.

Figure 26. Comparison of Densities for the R-32/290 System; the Baseline is from the Lemmon-Jacobsen Model in REFPROP 6.0.

Figure 27. Comparison of Bubble-Point Pressures for the R-125/290 System; the Baseline is from the Lemmon-Jacobsen Model in REFPROP 6.0

Figure 28. Comparison of Vapor Compositions for the R-125/290 System; the Baseline is from the Lemmon-Jacobsen Model in REFPROP 6.0.

Figure 29. Comparison of Densities for the R-125/290 System; the Baseline is from the Lemmon-Jacobsen Model in REFPROP 6.0

Figure 30. Comparison of Bubble-Point Pressures for the R-134a/290 System; the Baseline is from the Lemmon-Jacobsen Model in REFPROP 6.0

Figure 31. Comparison of Vapor Compositions for the R-134a/290 System; the Baseline is from the Lemmon-Jacobsen Model in REFPROP 6.0.

Figure 32. Comparison of Densities for the R-134a/290 System; the Baseline is from the Lemmon-Jacobsen Model in REFPROP 6.0

Figure 33. Comparison of Vapor Pressures for R-41; the Baseline is from Equation (1)

Figure 34. Range of Measured Temperatures and Pressures for Isochoric $(p, p, T)$ Data for $R-41$.

Figure 35. Comparison of Densities for R-41; the Baseline is from the MBWR Equation of State in REFPROP 6.0.

Figure 36. Comparison of the Isochoric Heat Capacity Data at Saturation and in the SinglePhase Liquid Region for R-41; the Baseline is from the MBWR Equation of State in REFPROP 6.0

Figure 37. Comparison of the Vapor Speed of Sound Data for R-41; the Baseline is from the MBWR Equation of State in REFPROP 6.0.

Figure 38. Comparison of Bubble-Point Pressures for the R-41/744 System; the Baseline is from the Lemmon-Jacobsen Model in REFPROP 6.0. 
Figure 39. Comparison of Vapor Compositions for the R-41/744 System; the Baseline is from the Lemmon-Jacobsen Model in REFPROP 6.0.

Figure 40. Range of Measured Temperatures and Pressures for Isochoric $(p, p, T)$ Data for a Mixture of $R-41 / 744$ with $x(R-41)=0.49982$ Mole Fraction (0.43591 Mass Fraction). 58

Figure 41. Comparison of Isochoric $(p, p, T)$ Data for the Equimolar Mixture of R-41/744; the Baseline is from the Lemmon-Jacobsen Model in REFPROP 6.0 .

Figure B1. Schematic Diagram of the Dynamic Phase Equilibrium Apparatus.......................... B-6

Figure B2. Schematic Diagram of the Bubble-Point and Near-Saturation (p,p,T) Apparatus ...... B-7

Figure B3. Schematic Diagram of the Isochoric $(\mathrm{p}, \mathrm{\rho}, \mathrm{T})$ Apparatus .................................. B-8

Figure B4. Schematic Diagram of the Calorimeter ................................................... B-9

Figure B5. Schematic Diagram of the Spherical Resonator Speed of Sound Apparatus.............. B-10 


\section{LIST OF TABLES}

Table 1. Summary of the Refrigerant Systems Studied, the Properties Measured for Each System, and the Molecular Weights of the Pure Components.

Table 2. Summary of the Experimental Uncertainties for the Apparatus Used in This Project.

Table 3. Vapor-Liquid Equilibrium Data for R-32/134a Mixtures from 280 to $340 \mathrm{~K}$ $\left(44\right.$ to $\left.152^{\circ} \mathrm{F}\right)$

Table 4. Near-Saturation (p,p,T) Data for R-32/134a Mixtures from 279 to $340 \mathrm{~K}$ (43 to $152^{\circ} \mathrm{F}$ )

Table 5. Vapor-Liquid Equilibrium Data for R-32/125 Mixtures from 280 to $340 \mathrm{~K}$ (44 to $\left.152^{\circ} \mathrm{F}\right)$.

Table 6. Near-Saturation (p,p,T) Data for R-32/125 Mixtures from 279 to $341 \mathrm{~K}$ (43 to $\left.154^{\circ} \mathrm{F}\right)$

Table 7. Vapor-Liquid Equilibrium Data for R-125/134a Mixtures from 280 to $340 \mathrm{~K}$ $\left(44\right.$ to $\left.152^{\circ} \mathrm{F}\right)$

Table 8. Bubble-Point Pressures for R-125/134a Mixtures from 280 to $340 \mathrm{~K}$ $\left(45\right.$ to $\left.153^{\circ} \mathrm{F}\right)$

Table 9. Near-Saturation (p, $\rho, T)$ Data for R-125/134a Mixtures from 280 to $342 \mathrm{~K}$ (44 to $\left.157^{\circ} \mathrm{F}\right)$

Table 10. Vapor-Liquid Equilibrium Data for R-32/125/134a Mixtures from 280 to $340 \mathrm{~K}$ $\left(44\right.$ to $\left.152^{\circ} \mathrm{F}\right)$

Table 11. Bubble-Point Pressures for R-32/125/134a Mixtures from 221 to $345 \mathrm{~K}$ $\left(-62\right.$ to $\left.162^{\circ} \mathrm{F}\right)$.

Table 12. Near-Saturation (p,p,T) Data for R-32/125/134a Mixtures from 244 to $346 \mathrm{~K}$ $\left(-21\right.$ to $\left.163^{\circ} \mathrm{F}\right)$

Table 13. Vapor-Liquid Equilibrium Data for R-32/143a Mixtures from 280 to $340 \mathrm{~K}$ (44 to $152^{\circ} \mathrm{F}$ )

Table 14. Near-Saturation (p,p,T) Data for R-32/143a Mixtures from 279 to $340 \mathrm{~K}$ (43 to $152^{\circ} \mathrm{F}$ )

Table 15. Vapor-Liquid Equilibrium Data for R-125/143a Mixtures from 280 to $326 \mathrm{~K}$ (44 to $\left.127^{\circ} \mathrm{F}\right)$

Table 16. Bubble-Point Pressures for R-125/143a Mixtures from 280 to $325 \mathrm{~K}$ $\left(45\right.$ to $\left.125^{\circ} \mathrm{F}\right)$

Table 17. Near-Saturation (p,p,T) Data for R-125/143a Mixtures from 280 to $328 \mathrm{~K}$ (44 to $131^{\circ} \mathrm{F}$ ).

Table 18. Isochoric (p,p,T) Data from 200 to $400 \mathrm{~K}\left(-100\right.$ to $\left.260^{\circ} \mathrm{F}\right)$ for a Mixture of $\mathrm{R}-125 / 143 \mathrm{a}$ with $\mathrm{x}(\mathrm{R}-125)=0.49996$ Mole Fraction (0.58812 Mass Fraction). 
Table 19. Isochoric Heat Capacities $\left(\mathrm{C}_{\mathrm{v}}\right)$ from 205 to $344 \mathrm{~K}\left(-90\right.$ to $\left.160^{\circ} \mathrm{F}\right)$ for a Mixture of R-125/143a with $x(R-125)=0.49996$ Mole Fraction (0.58812 Mass Fraction).

Table 20. Vapor-Liquid Equilibrium Data for R-143a/134a Mixtures from 280 to $340 \mathrm{~K}$ (45 to $152^{\circ} \mathrm{F}$ ).

Table 21. Bubble-Point Pressures for R-143a/134a Mixtures from 281 to $340 \mathrm{~K}$ (46 to $153^{\circ} \mathrm{F}$ ).

Table 22. Near-Saturation (p, $\rho, T$ ) Data for R-143a/134a Mixtures from 280 to $343 \mathrm{~K}$ $\left(45\right.$ to $\left.158^{\circ} \mathrm{F}\right)$.

Table 23. Vapor-Liquid Equilibrium Data for R-32/290 Mixtures from 280 to $341 \mathrm{~K}$ ( 44 to $154^{\circ} \mathrm{F}$ ). ("LL" indicates possible liquid-liquid immiscibility).

Table 24. Near-Saturation (p,p,T) Data for R-32/290 Mixtures from 278 to $341 \mathrm{~K}$ $\left(42\right.$ to $\left.153^{\circ} \mathrm{F}\right)$ A-43

Table 25. Vapor-Liquid Equilibrium Data for R-125/290 Mixtures from 280 to $364 \mathrm{~K}$ $\left(44\right.$ to $\left.195^{\circ} \mathrm{F}\right)$

Table 26. Near-Saturation (p,p,T) Data for R-125/290 Mixtures from 280 to $326 \mathrm{~K}$ (44 to $128^{\circ} \mathrm{F}$ ).

Table 27. Vapor-Liquid Equilibrium Data for R-134a/290 Mixtures from 279 to $357 \mathrm{~K}$ (43 to $182^{\circ} \mathrm{F}$ ). ("LL" indicates possible liquid-liquid immiscibility).

Table 28. Near-Saturation ( $p, p, T)$ Data for R-134a/290 Mixtures from 278 to $357 \mathrm{~K}$ $\left(40\right.$ to $183^{\circ} \mathrm{F}$ ).

Table 29. Vapor Pressures for R-41 from 252 to $312 \mathrm{~K}$ ( -6 to $102^{\circ} \mathrm{F}$ ) Measured Using the Vapor-Liquid Equilibrium Apparatus.

Table 30. Vapor Pressures for $\mathrm{R}-41$ from 170 to $317 \mathrm{~K}\left(-154\right.$ to $\left.111^{\circ} \mathrm{F}\right)$ Measured Using the Isochoric (p,p,T) Apparatus.

Table 31. Near-Saturation ( $p, \rho, T$ ) Data for R-41 from 274 to $296 \mathrm{~K}$ (34 to $73^{\circ} \mathrm{F}$ ). A-55

Table 32. Comparisons of Critical Point Parameters for R-41. A-56

Table 33. Isochoric (p,p,T) Data for $\mathrm{R}-41$ from 132 to $400 \mathrm{~K}\left(-222\right.$ to $\left.260^{\circ} \mathrm{F}\right)$ A-57

Table 34. Saturated Liquid Densities for R-41 from 131 to $309 \mathrm{~K}\left(-224\right.$ to $\left.96^{\circ} \mathrm{F}\right)$

Extrapolated from Isochoric $(\mathrm{p}, \mathrm{p}, \mathrm{T})$ Data A-70

Table 35. Isochoric Heat Capacities $\left(\mathrm{C}_{\mathrm{v}}\right)$ for $\mathrm{R}-41$ from 148 to $343 \mathrm{~K}\left(-193\right.$ to $\left.157^{\circ} \mathrm{F}\right) \ldots . . . . . .$. A-71

Table 36. Two-Phase Heat Capacities for R-41 from 136 to $314 \mathrm{~K}\left(-215\right.$ to $\left.106^{\circ} \mathrm{F}\right)$. A-75

Table 37. Vapor Phase Speed of Sound Data for R-41 from 249.5 to $350 \mathrm{~K}$ $\left(-11\right.$ to $\left.170^{\circ} \mathrm{F}\right)$

Table 38. Vapor-Liquid Equilibrium Data for R-41/744 Mixtures from 218 to $290 \mathrm{~K}$ $\left(-68\right.$ to $\left.62^{\circ} \mathrm{F}\right)$ 
Table 39. Isochoric (p,p,T) Data from 192 to $400 \mathrm{~K}\left(-114\right.$ to $\left.260^{\circ} \mathrm{F}\right)$ for a Mixture of $\mathrm{R} 41 / 744$ with $x(R-41)=0.49982$ Mole Fraction (0.43591 Mass Fraction). A-81

Table D1. Summary of the Gas Chromatograph Settings, the Separation Columns, and the Standard Reference Mixtures Used for Each Refrigerant System. D-4 



\title{
SELECTED THERMODYNAMIC PROPERTIES FOR MIXTURES OF R-32 (DIFLUOROMETHANE), R-125 (PENTAFLUOROETHANE), R-134A (1,1,1,2- TETRAFLUOROETHANE), R-143A (1,1,1-TRIFLUOROETHANE), R-41 (FLUOROMETHANE), R-290 (PROPANE), AND R-744 (CARBON DIOXIDE)
}

\author{
Cynthia D. Holcomb \\ Joseph W. Magee \\ Jennifer L. Scott \\ Stephanie L. Outcalt \\ William M. Haynes \\ Physical and Chemical Properties Division \\ Chemical Science and Technology Laboratory \\ National Institute of Standards and Technology \\ Boulder, Colorado 80303
}

\begin{abstract}
Numerous fluids and fluid mixtures have been identified as promising altematives to the HCFC and CFC refrigerants R-22, R-22/115, and R-13, but, for many of them, reliable thermodynamic data are not available. Thermophysical property measurements were carried out on one pure fluid, ten binary mixtures, and one temary mixture which are potential HCFC alternatives. Vapor-liquid equilibrium, near-saturation density, $(\mathrm{p}, \rho, \mathrm{T})$, heat capacity, and vapor-phase speed of sound data were measured over wide ranges of temperature and pressure. The systems studied include R-41, R-32/134a; R-32/125; R-125/134a; R-32/143a; R-125/143a; R143a/134a; R-32/290; R-125/290; R-134a/290; R-41/744; and R-32/125/134a. The new data compliment the existing data and help to resolve problems and differences that exist in and between existing data sets. The measured data were compared to selected literature results, where available, and to predictions from REFPROP 6.0.
\end{abstract}

Keywords: alternative refrigerants; vapor-liquid equilibria; pressure-volumetemperature; vapor speed of sounds; refrigerant mixtures

\section{INTRODUCTION}

Alternative refrigerants have become increasingly important to industrial applications as the ozone-depleting refrigerants are being phased out under the requirements of the Montreal Protocol. The main objective of this project was to measure the data needed to refine the models used by engineers for evaluating new refrigerants and refrigerant mixtures and for designing refrigeration cycles with these new fluids. To meet this objective, several tasks were addressed: (1) measure properties of pure fluids and mixture properties identified as replacements for specific fluids, (2) investigate the behavior of propane-containing mixtures (propane has been suggested as an additive to enhance oil solubility), and 3) provide data needed to test the ability of models to predict multicomponent mixture properties and complex phase behavior. The data from this project provide property information on previously unstudied systems, supplement existing data sets, resolve 
problems and differences between existing data sets, and refine models used in equipment design. Ten binary mixtures, one ternary, and one pure fluid were studied in this project.

Knowledge of the phase behavior of a fluid is important in determining if that fluid will be a suitable replacement for a pure refrigerant or refrigerant mixture. Azeotropic mixtures are important because they behave more like pure fluids which require simpler refrigeration cycle designs. A system exhibiting liquid-liquid immiscibility and azeotropic behavior may also be exploited in a refrigeration cycle. It was important to gather information on systems that might exhibit liquid-liquid immiscibility for two reasons. The first was to provide the data needed to examine the behavior of these systems in a refrigeration cycle. The second was to provide test data for implementing algorithms in predictive packages that can adequately represent liquid-liquid immiscibility.

The phase behavior for the systems measured in this report are classified as either Type I or Type II systems. Figure 1 shows generic examples of these two types of phase behavior. Type I systems have a continuous critical line and can have an azeotrope; the azeotrope can be either a positive pressure or a negative pressure azeotrope. All three subclasses of Type I systems were observed in this study. R-32/134a, R-125/134a, R-32/143a, and R-41/744 are nonazeotropic systems with the simplest type of phase behavior. R-32/125 and R-143a/134a are Type I systems with positive pressure azeotropes. R-125/143a is a Type I system with a negative pressure azeotrope. Type II systems have a continuous critical line with liquid-liquid immiscibility. Type II systems also can have azeotropes, and the liquid-liquid region can either encompass the azeotrope or the azeotrope can be outside the liquid-liquid region. R-32/290, R-125/290, and R-134a/290 are all believed to be Type II systems where the liquid-liquid immiscibility region encompasses the azeotrope. The azeotrope persists into the critical region, but the liquid-liquid region disappears around $310 \mathrm{~K}\left(98^{\circ} \mathrm{F}\right)$.

A full summary of the data taken on each system is presented in Table 1; tables of the thermophysical property data are presented in Appendix A. The experimental uncertainties of these measurements are reported in Table 2. The temperature scale used in all of the measurements was ITS-90. The descriptions of the apparatus used for the measurements in this project are presented in Appendix B. Appendix C describes how the state-point uncertainties were estimated. Appendix D summarizes the gas chromatograph calibration procedures and settings. Appendix E contains reprints of the papers describing the models [1] and predictive package [2] used for comparing the data sets.

\section{SIGNIFICANT RESULTS}

\subsection{Thermophysical Properties of R-32/125/134a and Its Constituent Binaries}

Property measurements of the ternary R-32/125/134a system are important in meeting the objectives of this project. This ternary is a possible replacement for R-22 and/or R-22/115, and the ternary results can be used to test the capability of the Helmholtz energy model of Lemmon and Jacobsen [1]. This model is used to calculate the thermodynamic properties of mixtures in REFPROP 
6.0 [2] and to predict the thermophysical properties for a ternary system based on the interaction parameters of its constituent binaries. The constituent binaries of $\mathrm{R}-32 / 125 / 134 \mathrm{a}$ are also potential replacements for $\mathrm{R}-22$ and/or R-22/115.

\subsubsection{R-32/134a}

$\mathrm{R}-32 / 134 \mathrm{a}$ is a Type I mixture with no azeotrope. It is one of the least complicated systems to model, but it is an important mixture for ternary calculations. The data for the R-32/134a system cover five isotherms from 279 to $340 \mathrm{~K}$ ( 43 to $152^{\circ} \mathrm{F}$ ). Forty-eight vapor-liquid equilibrium and 44 near-saturation $(p, p, T)$ measurements were made. These data, presented in Tables 3 and 4 , have been compared to five other data sets available in the literature. The deviations between the data and the values predicted from the Lemmon-Jacobsen model are presented in Figures 2 through 4. In Figure 2 , the deviations between the bubble-point pressures and the predicted values are presented. The data from this work agree with the data of Nagel and Bier [3] within $\pm 1 \%$. Most of the data of Higashi [4] and of Widiatmo et al. [5] also agree with the data of this work within $\pm 1 \%$ except for a few points. The data of Fujiwara et al. [6] are 3\% lower than any of the other data sets. The data of Deifbaugh and Morrison [7] that are at similar compositions agree within $\pm 0.5 \%$ with the data of this work.

The scatter in the data might appear large compared to the experimental uncertainties quoted in Table 2. A distinction must be made between the experimental uncertainty of a specific parameter measurement (such as temperature, pressure, or composition) and the state-point uncertainty. The state point is system dependent and is defined as the equilibrium bubble-point pressure and vapor composition at a given liquid composition and temperature. Each of the parameters $(\mathrm{P}, \mathrm{T}, \mathrm{x}, \mathrm{y})$ has an experimental uncertainty associated with the measurement of that property. However, the state-point uncertainty is a function of the uncertainties of each of these four parameters as well as the dependences between them. The experimental uncertainty of the bubble-point pressure state point is a function of the uncertainty of the temperature measurement, the liquid composition measurement, the pressure measurement, and the relation of the bubble-point pressure with temperature and liquid composition for the specific system under study. The state-point uncertainties are different for each system and vary with temperature and composition. A detailed discussion of estimates for the statepoint uncertainties is presented in Appendix C. The bubble-point pressure state-point uncertainty for the $\mathrm{R}-32 / 134 \mathrm{a}$ system at temperatures from 280 to $340 \mathrm{~K}$ ( 44 to $152^{\circ} \mathrm{F}$ ) ranges from \pm 0.22 to $\pm 0.30 \%$.

In Figure 3, the vapor compositions of the data sets are compared. In general, the four data sets agree within \pm 0.015 mole fraction R-32. The data of Fujiwara et al. [6] are systematically 0.015 mole fraction R-32 lower than the predictions of the Lemmon-Jacobsen model in REFPROP 6.0. The vapor-composition state-point uncertainty ranges from \pm 0.006 to \pm 0.013 mole fraction $R-32$ for the $\mathrm{R}-32 / 134 \mathrm{a}$ system at temperatures from 280 to $340 \mathrm{~K}$ (44 to $152^{\circ} \mathrm{F}$ ). As with the bubble-point pressure state-point uncertainty, a similar estimate of the state-point uncertainty of the vapor 
composition can be calculated. A detailed discussion of the estimate of the vapor-composition statepoint uncertainty is presented in Appendix C.

The deviations for the near-saturation $(p, \rho, T)$ data for $R-32 / 134 a$ are presented in Figure 4 . The liquid densities agree within $\pm 1.0 \%$ of the predicted values from the Lemmon-Jacobsen model in REFPROP 6.0 . The vapor densities agree within $\pm 2 \%$ of the predicted values and most of the data of Weber and Defibaugh [8]. The liquid-density state-point uncertainty for the R-32/134a system at temperatures from 279 to $340 \mathrm{~K}\left(43\right.$ to $152^{\circ} \mathrm{F}$ ) ranges from \pm 0.22 to $\pm 0.26 \%$. The vapor-density state-point uncertainty for the R-32/134a system at temperatures from 309 to $340 \mathrm{~K}$ (97 to $152^{\circ} \mathrm{F}$ ) ranges from \pm 0.32 to $\pm 0.79 \%$. As with the bubble-point pressure state-point uncertainty, a similar estimate of the state-point uncertainty of the liquid and vapor densities can be calculated. A detailed discussion for the estimate of the density state-point uncertainties is presented in Appendix C.

\subsubsection{R-32/125}

$\mathrm{R}-32 / 125$ is a Type I mixture with a slight positive pressure azeotrope. The data for the R$32 / 125$ system cover five isotherms from 279 to $341 \mathrm{~K}$ (43 to $154^{\circ} \mathrm{F}$ ). Thirty vapor-liquid equilibrium and 45 near-saturation $(\mathrm{p}, \rho, \mathrm{T})$ measurements were made. These data, presented in Tables 5 and 6, were compared to five other data sets available in the literature. The deviations between the data and the values predicted from the Lemmon-Jacobsen model in REFPROP 6.0 are presented in Figures 5 through 7. In Figure 5, the deviations between the bubble-point pressures and the predicted values are presented. The data from this work agree with the data of Nagel and Bier [3] and that of Widiatmo et al. [9] within $\pm 1 \%$ except for one point on the $325 \mathrm{~K}\left(125^{\circ} \mathrm{F}\right)$ isotherm. Except for two points, the data of Higashi [10] also agree with the data of this work within $\pm 1 \%$. The data of Deifbaugh and Morrison [7] agree within $\pm 0.5 \%$ with the data of this work that is at a similar composition. The data of Fujiwara et al. [6] are $2 \%$ higher than any of the other data sets. The bubble-point pressure state-point uncertainty for the R-32/125 system at temperatures from 280 to $340 \mathrm{~K}$ ( 44 to $152^{\circ} \mathrm{F}$ ) ranges from \pm 0.15 to $\pm 0.19 \%$.

In Figure 6, the vapor compositions of the data sets are compared. In general, the four data sets agree within \pm 0.013 mole fraction $R-32$. The vapor-composition state-point uncertainty ranges from \pm 0.008 to \pm 0.009 mole fraction $\mathrm{R}-32$ for the $\mathrm{R}-32 / 125$ system at temperatures from 280 to $340 \mathrm{~K}$ (44 to $152^{\circ} \mathrm{F}$ ).

The deviations for the near-saturation $(p, \rho, T)$ data for $R-32 / 125$ are presented in Figure 7 . The liquid densities agree within $\pm 1 \%$ of the predicted values from the Lemmon-Jacobsen model in REFPROP 6.0. The vapor densities agree within $\pm 2 \%$ of the predicted values and the data of Weber and Defibaugh [8]. The liquid-density state-point uncertainty for the $\mathrm{R}-32 / 125$ system at temperatures from 279 to $340 \mathrm{~K}$ ( 43 to $152^{\circ} \mathrm{F}$ ) ranges from \pm 0.22 to $0.25 \%$. The vapor-density statepoint uncertainty for the R-32/125 system at temperatures from 294 to $341 \mathrm{~K}$ (70 to $154^{\circ} \mathrm{F}$ ) ranges from \pm 0.34 to $\pm 0.90 \%$. 


\subsubsection{R-125/134a}

$\mathrm{R}-125 / 134 \mathrm{a}$ is a Type I mixture with no azeotrope. The data for the $\mathrm{R}-125 / 134$ a system cover five isotherms from 280 to $342 \mathrm{~K}$ (44 to $157^{\circ} \mathrm{F}$ ). Thirty vapor-liquid equilibrium and 17 nearsaturation $(p, p, T)$ measurements were made. Ten bubble-point pressure measurements on standard mixtures were also made. The data are presented in Tables 7 through 9 . Bubble-point pressure measurements on standard mixtures were included for this system because of difficulties involved with the gas chromatograph (GC) calibration. The bubble-point pressure measurements eliminate the uncertainty introduced by sampling and analysis to determine the liquid composition. These measurements represent an independent verification of the bubble-point measurements from the vapor-liquid equilibrium measurements, and can be used to check the validity of the GC calibration. The data were compared to two other data sets available in the literature. The deviations between the data and the predicted values from the Lemmon-Jacobsen model are presented in Figures 8 through 10. In Figure 8, the deviations between the bubble-point pressures and the predicted values are presented. The data from this work agree with the data of Nagel and Bier [3] within $\pm 2 \%$. Except for two points, the data of Higuchi and Higashi [11] agree with the data of this work within $\pm 2 \%$. The bubble-point pressure state-point uncertainty for the R-125/134a system at temperatures from 280 to $340 \mathrm{~K}$ (44 to $152^{\circ} \mathrm{F}$ ) ranges from \pm 0.23 to $\pm 0.30 \%$.

In Figure 9, the vapor compositions of the data sets are compared. In general, the three data sets agree within \pm 0.018 mole fraction $R-125$. The vapor-composition state-point uncertainty ranges from \pm 0.006 to \pm 0.012 mole fraction $\mathrm{R}-125$ for the $\mathrm{R}-125 / 134 \mathrm{a}$ system at temperatures from 280 to $340 \mathrm{~K}$ (44 to $152^{\circ} \mathrm{F}$ ).

The deviations for the near-saturation $(p, p, T)$ data for $\mathrm{R}-125 / 134 \mathrm{a}$ are presented in Figure 10. The liquid densities agree within $\pm 1 \%$ of the predicted values from the Lemmon-Jacobsen model in REFPROP 6.0 . The vapor densities agree within $\pm 2 \%$ of the predicted values and most of the data of Weber and Defibaugh [8]. The liquid-density state-point uncertainty for the R-125/134a system at temperatures from 280 to $340 \mathrm{~K}$ ( 44 to $153^{\circ} \mathrm{F}$ ) ranges from \pm 0.21 to $\pm 0.24 \%$. The vapor-density state-point uncertainty for the R-125/134a system at temperatures from 296 to $342 \mathrm{~K}$ ( 73 to $157^{\circ} \mathrm{F}$ ) ranges from \pm 0.51 to $\pm 1.08 \%$.

\subsubsection{R-32/125/134a}

The data for the R-32/125/134a system cover five isotherms from 280 to $340 \mathrm{~K}$ (44 to $152^{\circ} \mathrm{F}$ ) with some additional measurements at temperatures from 221 to $345 \mathrm{~K}\left(-62\right.$ to $\left.162^{\circ} \mathrm{F}\right)$ that were obtained under a project funded by ICI. Twenty-four vapor-liquid equilibrium and 43 nearsaturation $(p, \rho, T)$ measurements were made. Thirty-four bubble-point measurements on standard mixtures were performed to determine the reliability of the GC calibration procedure for a ternary mixture. The data are presented in Tables 10 through 12 . The data were compared to the other data set available in the literature. The deviations between the data and the predicted values from the 
Lemmon-Jacobsen model are presented in Figures 11 through 13. In Figure 10, the deviations between the experimental bubble-point pressures and predicted values are presented. The data from this work agree with the data of Nagel and Bier [3] and of Higashi [12] within $\pm 3 \%$. The bubblepoint pressure state-point uncertainty for the R-32/125/134a system at temperatures from 280 to 340 $\mathrm{K}$ (44 to $152^{\circ} \mathrm{F}$ ) ranges from \pm 0.15 to $\pm 0.30 \%$.

In Figure 12, the vapor compositions of the data sets are compared. In general, the three data sets agree within \pm 0.018 mole fraction $R-32$. The vapor-composition state-point uncertainty ranges from \pm 0.006 to \pm 0.013 mole fraction $R-32$ for the $R-32 / 125 / 134$ a system at temperatures from 280 to $340 \mathrm{~K}$ (44 to $152^{\circ} \mathrm{F}$ ).

The deviations for the near-saturation $(\mathrm{p}, \mathrm{\rho}, \mathrm{T})$ data for $\mathrm{R}-32 / 125 / 134 \mathrm{a}$ are presented in Figure 13. The liquid densities agree within $\pm 1 \%$ of the predicted values from the Lemmon-Jacobsen model in REFPROP 6.0 . The vapor densities agree within $\pm 2 \%$ of the predicted values and most of the data of Gillis et al. [13]. The liquid-density state-point uncertainty for the R-32/125/134a system at temperatures from 244 to $346 \mathrm{~K}\left(-21\right.$ to $\left.163^{\circ} \mathrm{F}\right)$ ranges from \pm 0.21 to $\pm 0.26 \%$. The vapor-density state-point uncertainty for the $\mathrm{R}-32 / 125 / 134 \mathrm{a}$ system at temperatures from 313 to $343 \mathrm{~K}$ (103 to $158^{\circ} \mathrm{F}$ ) ranges from \pm 0.32 to $\pm 1.08 \%$.

The Lemmon-Jacobsen model accurately predicted the phase behavior and densities of the ternary using only the binary interaction parameters. The mode1 did not require any additional parameters specifically for the ternary mixture. This result confirms that, for this system, the Lemmon-Jacobsen model can be used to predict multicomponent mixture properties when the model uses mixture parameters for the constituent binaries which have been fit to experimental data.

\subsection{Mixtures with R-143a}

Three mixtures containing R-143a were studied. These mixtures are potential substitutes for R22 and /or R-22/115, and the data for these systems with different types of phase behavior can be used to test mixture models.

\subsubsection{R-32/143a}

$\mathrm{R}-32 / 143 \mathrm{a}$ is a Type I system with no azeotrope. The data for the R-32/143a system cover five isotherms from 279 to $340 \mathrm{~K}$ (43 to $152^{\circ} \mathrm{F}$ ). Twenty-nine vapor-liquid equilibrium and 49 nearsaturation $(p, \rho, T)$ measurements were made. The data are presented in Tables 13 and 14. In Figure 14, the bubble-point pressures are compared. The bubble-point pressures of this work agree with the predicted values from the Lemmon-Jacobsen model within $\pm 0.7 \%$. The data of Fujiwara et al. [6] are 2 to $3 \%$ higher than the data from this work. The bubble-point pressure state-point uncertainty for R$32 / 143 \mathrm{a}$ at temperatures from 280 to $340 \mathrm{~K}$ ( 44 to $152^{\circ} \mathrm{F}$ ) ranges from \pm 0.14 to $\pm 0.20 \%$.

In Figure 15, the vapor compositions are compared. The data of Fujiwara et al. [6] and this work agree within \pm 0.025 mole fraction $\mathrm{R}-32$ of the predicted values of the Lemmon-Jacobsen model 
in REFPROP 6.0. The vapor-composition state-point uncertainty for $\mathrm{R}-32 / 143 \mathrm{a}$ at temperatures from 280 to $340 \mathrm{~K}$ ( 44 to $152^{\circ} \mathrm{F}$ ) ranges from \pm 0.007 to \pm 0.010 mole fraction $\mathrm{R}-32$.

In Figure 16, the liquid and vapor near-saturation $(p, \rho, T)$ data are compared to the predicted values from the Lemmon-Jacobsen model in REFPROP 6.0. The liquid densities agree within $\pm 1 \%$ except for the $340 \mathrm{~K}\left(152^{\circ} \mathrm{F}\right)$ isotherm which is close to the critical point of $\mathrm{R}-143 \mathrm{a}$. The vapor densities for the two isotherms closest to the critical region also show larger deviations. The liquiddensity state-point uncertainty for the R-32/143a system at temperatures from 279 to $340 \mathrm{~K}$ (43 to $152^{\circ} \mathrm{F}$ ) ranges from \pm 0.21 to $\pm 0.24 \%$. The vapor-density state-point uncertainty for the $R-32 / 143 \mathrm{a}$ system at temperatures from 294 to $340 \mathrm{~K}$ ( 70 to $152^{\circ} \mathrm{F}$ ) ranges from \pm 0.27 to $\pm 0.69 \%$.

\subsubsection{R-125/143a}

$\mathrm{R}-125 / 143 \mathrm{a}$ is a Type I system with a weak negative pressure azeotrope. The data for the R$125 / 143$ a system cover four isotherms from 280 to $328 \mathrm{~K}\left(44\right.$ to $131^{\circ} \mathrm{F}$ ). Twenty-five vapor-liquid equilibrium and 14 near-saturation $(p, \rho, T)$ measurements were made. Eleven bubble-point measurements on standard mixtures were performed to determine the reliability of the GC calibration procedure for this binary mixture. The data are presented in Tables 15 through 17 . The single-phase data for the R-125/143a system cover 15 isochores from 200 to $400 \mathrm{~K}$ ( -100 to $260^{\circ} \mathrm{F}$ ) at pressures up to $35 \mathrm{MPa}$ (5100 psi). Both gas- and liquid-phase $(\mathrm{p}, \mathrm{\rho}, \mathrm{T})$ data were measured, as well as liquidphase heat capacity data. The data are presented in Tables 18 and 19. Two-hundred eighty-one isochoric $(p, \rho, T)$ data points and 120 isochoric heat capacity measurements were made.

Figure 17 shows the comparison of the bubble-point pressures for R-125/143a to the predicted values from the Lemmon-Jacobsen model. The compositions were difficult to measure because the vapor pressure curves of these two components are very similar. The experimental uncertainty of the composition measurements for this system is approximately twice that of the other systems in this study. The experimental uncertainty of the measured composition is \pm 0.008 mole fraction R-143a. The data from this work fall between the data of Takashima and Higashi [14] and those of Nagel and Bier [15]. The bubble-point pressure state-point uncertainty for R-125/143a at temperatures from 280 to $326 \mathrm{~K}$ (44 to $127^{\circ} \mathrm{F}$ ) ranges from \pm 0.15 to $\pm 0.18 \%$.

Figure 18 shows the comparison of the vapor compositions for $\mathrm{R}-125 / 143 \mathrm{a}$ to the values predicted from the Lemmon-Jacobsen model. The vapor compositions for the three data sets agree within \pm 0.011 mole fraction $\mathrm{R}-125$. The vapor-composition state-point uncertainty for the $\mathrm{R}$ $125 / 143 \mathrm{a}$ system at temperatures from 280 to $326 \mathrm{~K}$ ( 44 to $127^{\circ} \mathrm{F}$ ) ranges from \pm 0.011 to \pm 0.012 mole fraction R-143a.

The ranges of temperature and pressure for the isochoric $(p, \rho, T)$ data are shown in Figure 19. Figure 20 shows the comparison of the liquid and vapor near-saturation $(p, p, T)$ and the isochoric $(p, p, T)$ data to the predicted values from the Lemmon-Jacobsen model. The near-saturation $(p, \rho, T)$ liquid densities agree with the model within $\pm 0.8 \%$, and the near-saturation $(p, \rho, T$ ) vapor densities agree with the model within $\pm 0.75 \%$. The liquid-phase isochoric $(p, \rho, T$ ) data agree with the model 
within $\pm 0.25 \%$, and the vapor-phase isochoric $(p, \rho, T)$ data agree with the model and the data of Weber and Defibaugh [8] within $\pm 0.85 \%$. The liquid-density state-point uncertainty for the nearsaturation ( $p, p, T$ ) data for the R-125/143a system at temperatures from 280 to $325 \mathrm{~K}$ (44 to $125^{\circ} \mathrm{F}$ ) ranges from \pm 0.24 to $\pm 0.27 \%$. The vapor-density state-point uncertainty for the near-saturation $(p, \rho, T)$ data for the $\mathrm{R}-125 / 143 \mathrm{a}$ system at temperatures from 296 to $328 \mathrm{~K}$ (74 to $131^{\circ} \mathrm{F}$ ) ranges from \pm 0.48 to $\pm 0.60 \%$.

\section{2 .3 R-143a/134a}

$\mathrm{R}-143 \mathrm{a} / 134 \mathrm{a}$ is a Type I system with no azeotrope. The data for the R-143a/134a system cover five isotherms from 280 to $343 \mathrm{~K}$ ( 45 to $158^{\circ} \mathrm{F}$ ). Twenty-nine vapor-liquid equilibrium and 17 nearsaturation $(p, \rho, T)$ measurements were made. Eleven bubble-point measurements on standard mixtures were performed to determine the reliability of the GC calibration procedure for this binary mixture. The data are presented in Tables 20 through 22.

Figure 21 shows comparisons of the bubble-point pressures for R-143a/134a with the predicted values from the Lemmon-Jacobsen model. The bubble-point pressures agree with those of Nagel and Bier [15] within $\pm 2 \%$. The bubble-point pressure state-point uncertainty for the R-143a/134a system at temperatures from 280 to $340 \mathrm{~K}$ ( 44 to $152^{\circ} \mathrm{F}$ ) ranges from \pm 0.20 to $\pm 0.25 \%$.

Figure 22 shows comparisons of the vapor compositions for R-125/143a with the predicted values from the Lemmon-Jacobsen model. The vapor compositions agree with those of Nagel and Bier [15] within \pm 0.018 mole fraction R-143a. The vapor-composition state-point uncertainty for the $\mathrm{R}-143 \mathrm{a} / 134 \mathrm{a}$ system at temperatures from 280 to $340 \mathrm{~K}\left(45\right.$ to $152^{\circ} \mathrm{F}$ ) ranges from \pm 0.006 to \pm 0.011 mole fraction R-143a.

Figure 23 shows comparisons of the liquid and vapor near-saturation $(p, \rho, T)$ data with the values predicted from the Lemmon-Jacobsen model. The liquid densities agree with the predicted values within $\pm 1 \%$. The liquid-density state-point uncertainty for the $\mathrm{R}-143 \mathrm{a} / 134 \mathrm{a}$ system at temperatures from 280 to $340 \mathrm{~K}\left(45\right.$ to $153^{\circ} \mathrm{F}$ ) ranges from \pm 0.22 to $\pm 0.24 \%$. The vapor-density state-point uncertainty for the $\mathrm{R}-143 \mathrm{a} / 134 \mathrm{a}$ system at temperatures from 312 to $343 \mathrm{~K}$ (102 to $158^{\circ} \mathrm{F}$ ) ranges from \pm 0.38 to $\pm 0.73 \%$. Additional data in the moderate temperature and pressure range are needed to determine the accuracy of the near-saturation vapor-phase $(p, \rho, T)$ data and to better optimize the fit.

\subsection{Mixtures with R-290}

There are two main reasons for studying refrigerant mixtures containing R-290 (propane). One of the difficulties with the chlorine-free alternative refrigerants is their immiscibility with the oils used in refrigeration cycles. The addition of R-290 to the mixture to enhance oil solubility is under investigation. In order to model multicomponent systems that contain R-290, the mixture parameters for binary systems containing R-290 are required. Another reason for studying R-290 is the complex 
phase behavior exhibited by R-290 mixtures allows the models to be rigorously tested. These systems have very strong positive azeotropes and possible liquid-liquid immiscibility. They provide a very stringent test for the REFPROP 6.0 model and its ability to calculate properties for polar/nonpolar mixtures with three phases in equilibrium.

Although the Lemmon-Jacobsen model used in REFPROP 6.0 is capable of predicting liquidliquid immiscibility, the algorithms implementing it in REFPROP 6.0 do not consider this behavior. Because of the complexity of this phase behavior, more experimental data are required to model the two separate liquid phases. Accurate liquid- and gas-phase (p,p,T) data and a knowledge of the compositions of the two liquid phases and gas phase in equilibrium are necessary for accurately determining the interaction parameters that can be used to model this phase behavior. Unfortunately, the measurements scheduled for these systems included near-saturation $(p, \rho, T)$ data, but not isochoric $(\mathrm{p}, \mathrm{p}, \mathrm{T})$ data. The vapor-liquid equilibrium apparatus was not designed to separate and to measure two distinct liquid phases. In the region where the liquid-liquid immiscibility occurs, no stable liquid densities or compositions can be recorded. The data available in the literature for these systems are limited, possibly because all three systems are in the process of being patented. The overall uncertainty of the measurements and the lack of data to optimize the model have resulted in deviations between the model and the data that are larger than for the other refrigerant systems.

\subsubsection{R-32/290}

$\mathrm{R}-32 / 290$ is a Type II system with a strong positive pressure azeotrope. It shows the most extreme phase behavior of the three propane systems studied. It is a mixture of a very polar molecule with a nonpolar molecule. The two molecules have strong repulsive interactions and exhibit a strong positive pressure azeotrope. At temperatures below $310 \mathrm{~K}\left(98^{\circ} \mathrm{F}\right)$, the liquid separates into two phases that were observed visually. The vapor-liquid equilibrium apparatus was not designed to measure two separate liquid phases, but the presence of two liquid phases is indicated by an unstable liquid composition and density for a constant vapor composition, bubble-point pressure, and vapor density. Measurements were made outside the liquid-liquid region where the liquid composition could be measured. A few measurements were taken to determine the vapor composition in equilibrium with the two liquid phases.

The data for the R-32/290 system cover five isotherms from 278 to $341 \mathrm{~K}$ (42 to $154^{\circ} \mathrm{F}$ ). Seventy-five vapor-liquid equilibrium and 50 near-saturation ( $p, \rho, T)$ measurements were made. The data are presented in Tables 23 and 24. There were no other data available for comparison for any of the properties measured for this system.

Figure 24 shows the comparison of the bubble-point pressures to the predicted values of the Lemmon-Jacobsen model in REFPROP 6.0. The data agree with the model within $\pm 5 \%$. The bubblepoint pressure state-point uncertainty for the R-32/290 system at temperatures from 280 to $340 \mathrm{~K}$ (44 to $153^{\circ} \mathrm{F}$ ) ranges from \pm 0.14 to $\pm 0.63 \%$. The uncertainties for the systems with propane are greater than for the other refrigerant systems studied because of the greater sensitivity of the bubble-point 
pressure to changes in composition. This sensitivity means that small uncertainties in the composition measurement correspond to much larger uncertainties in the bubble-point pressure.

Figure 25 shows the comparison of the vapor compositions to the predicted values from the Lemmon-Jacobsen model in REFPROP 6.0. The vapor compositions agree with the model within \pm 0.05 mole fraction $R-32$. The vapor-composition state-point uncertainty for the R-32/290 system at temperatures from 280 to $340 \mathrm{~K}$ ( 44 to $153^{\circ} \mathrm{F}$ ) ranges from \pm 0.015 to \pm 0.025 mole fraction $\mathrm{R}-32$. The state-point uncertainties are much larger because of the sensitivity of the equilibrium vapor composition to both temperature and liquid composition.

Figure 26 shows the comparison of the liquid and vapor near-saturation $(p, \rho, T)$ data to the predicted values from the Lemmon-Jacobsen model in REFPROP 6.0. The liquid and vapor densities agree with the predicted values within $\pm 7 \%$. The liquid-density state-point uncertainty for the $\mathrm{R}-32 / 290$ system at temperatures from 278 to $340 \mathrm{~K}$ (42 to $153^{\circ} \mathrm{F}$ ) ranges from \pm 0.23 to $\pm 0.33 \%$. The vapor-density state-point uncertainty for the R-32/290 system at temperatures from 296 to $341 \mathrm{~K}$ ( 73 to $153^{\circ} \mathrm{F}$ ) ranges from \pm 0.28 to $\pm 3.10 \%$.

\subsubsection{R-125/290}

$\mathrm{R}-125 / 290$ is a Type II system with a strong positive pressure azeotrope that may exhibit liquidliquid immiscibility at temperatures below $280 \mathrm{~K}\left(44^{\circ} \mathrm{F}\right)$. The data for the R-125/290 system cover eight isotherms from 280 to $364 \mathrm{~K}$ ( 44 to $195^{\circ} \mathrm{F}$ ). Sixty-three vapor-liquid equilibrium and 26 nearsaturation $(p, \rho, T)$ measurements were made. The data are presented in Tables 25 and 26.

In Figure 27, comparisons of the bubble-point pressures for the R-125/290 system with the predicted values from the Lemmon-Jacobsen model in REFPROP 6.0 are shown. The bubble-point pressures agree with values from the model within $\pm 4.5 \%$. The bubble-point pressure state-point uncertainty for the R-125/290 system at temperatures from 280 to $364 \mathrm{~K}$ ( 44 to $195^{\circ} \mathrm{F}$ ) ranges from \pm 0.15 to $\pm 0.42 \%$.

In Figure 28, comparisons of the vapor compositions for the R-125/290 system to the predicted values of the Lemmon-Jacobsen model in REFPROP 6.0 are shown. The vapor compositions agree with the predicted values within \pm 0.04 mole fraction $R-125$. The vapor-composition state-point uncertainty for the R-125/290 system at temperatures from 280 to $364 \mathrm{~K}$ (44 to $195^{\circ} \mathrm{F}$ ) ranges from \pm 0.006 to \pm 0.015 mole fraction $\mathrm{R}-125$.

In Figure 29, comparisons of the liquid and vapor near-saturation $(p, \rho, T)$ data to the predicted values of the Lemmon-Jacobsen model in REFPROP 6.0 are shown. The liquid densities agree with the model within $\pm 2 \%$, and the vapor densities agree within $\pm 3.5 \%$. The liquid-density state-point uncertainty for the R-125/290 system at temperatures from 280 to $325 \mathrm{~K}$ ( 44 to $125^{\circ} \mathrm{F}$ ) ranges from \pm 0.26 to $\pm 0.34 \%$. The vapor-density state-point uncertainty for the $\mathrm{R}-125 / 290$ system at temperatures from 294 to $326 \mathrm{~K}\left(69\right.$ to $128^{\circ} \mathrm{F}$ ) ranges from \pm 0.26 to $\pm 2.30 \%$. 
$\mathrm{R}-134 \mathrm{a} / 290$ is a Type II system with a strong positive pressure azeotrope. The data for the R$134 \mathrm{a} / 290$ system cover six isotherms from 278 to $357 \mathrm{~K}$ (42 to $\left.183^{\circ} \mathrm{F}\right)$. Seventy-two vapor-liquid equilibrium and 52 near-saturation $(p, \rho, T)$ measurements were made. The data are presented in Tables 27 and 28. Because of the liquid-liquid immiscibility, only qualitative comparisons can be made with the Lemmon-Jacobsen model.

Figure 30 shows the comparison of the bubble-point pressures to the predicted values of the Lemmon-Jacobsen model in REFPROP 6.0. The data of Kleiber [16] agree with the data from this work within a few percent. The data of Jadot and Frere [17] appears to be qualitatively different from our data and from the data of Kleiber [16]. The bubble-point pressure state-point uncertainty for the $\mathrm{R}-134 \mathrm{a} / 290$ system at temperatures from 280 to $357 \mathrm{~K}$ ( 44 to $183^{\circ} \mathrm{F}$ ) ranges from \pm 0.13 to $\pm 0.57 \%$.

Figure 31 shows the comparison of the vapor compositions to the predicted values of the Lemmon-Jacobsen model in REFPROP 6.0. The three data sets agree within \pm 0.09 mole fraction $R$ 134a. The vapor-composition state-point uncertainty for the $\mathrm{R}-134 \mathrm{a} / 290$ system at temperatures from 280 to $357 \mathrm{~K}$ ( 44 to $183^{\circ} \mathrm{F}$ ) ranges from \pm 0.005 to \pm 0.019 mole fraction $\mathrm{R}-134 \mathrm{a}$.

Figure 32 shows the comparison of the liquid and vapor near-saturation $(p, \rho, T)$ data to the predicted values from the Lemmon-Jacobsen model in REFPROP 6.0. The liquid densities agree with the model within $\pm 5 \%$, and the vapor densities show increasing deviations as the temperature increases. The liquid-density state-point uncertainty for the R-134a/290 system at temperatures from 278 to $356 \mathrm{~K}$ ( 40 to $181^{\circ} \mathrm{F}$ ) ranges from \pm 0.29 to $\pm 0.42 \%$. The vapor-density state-point uncertainty for the R-125/290 system at temperatures from 311 to $357 \mathrm{~K}\left(100\right.$ to $\left.183^{\circ} \mathrm{F}\right)$ ranges from \pm 0.24 to $\pm 2.06 \%$.

\subsection{R-41 and $R-41 / 744$}

$R-41$ is a possible substitute for $R-13$. While $R-23$ is most often considered for these applications, the long atmospheric lifetime and high global warming potential of R-23 leaves open the search for a more environmentally desirable fluid. Unfortunately, R-41 is a flammable fluid. R744 (carbon dioxide) is a nonflammable fluid, but its freezing point is too high to be used as a replacement for $\mathrm{R}-13$. The expectations that a mixture of $\mathrm{R}-41 / 744$ would have reduced flammability relative to pure $R-41$ and a lower freezing point than pure R-744 make this mixture an attractive possibility. An accurate equation of state exists for R-744 and was incorporated in REFPROP 6.0. A preliminary MBWR equation of state for R-41 was incorporated in REFPROP 6.0. Measurements on R-41 and R-41/744 were performed. Comparisons with predictions from REFPROP 6.0 were used to validate the data. 


\subsubsection{R-41}

A variety of single-phase and two-phase data was collected for R-41. Twenty vapor pressure measurements were made in the vapor-liquid equilibrium apparatus. Vapor pressure data were also measured in the isochoric $(p, \rho, T)$ apparatus. Thirty-one vapor pressure measurements were obtained with this apparatus. The vapor pressure data are presented in Tables 29 and 30. The vapor pressure data from this work were combined with the data of Oi et al. [18], and a vapor pressure correlation that is valid from the triple point to the critical point was developed. This equation is of the form,

$$
P_{\sigma}=P_{c} \cdot\left[\frac{a_{1} \tau+a_{2} \tau^{1.5}+a_{3} \tau^{3}+a_{4} \tau^{6}}{1-\tau}\right],
$$

$$
\begin{aligned}
& \text { where } \\
& \tau=1-\mathrm{T} / \mathrm{T}_{c}, \\
& \mathrm{~T}=\text { temperature, } \\
& \mathrm{T}_{c}=\text { critical temperature, } \\
& \mathrm{P}_{\sigma}=\text { vapor pressure, and } \\
& \mathrm{P}_{\mathrm{c}}=\text { critical pressure. }
\end{aligned}
$$

The critical temperature used in the fit is $317.28 \mathrm{~K}\left(111.4^{\circ} \mathrm{F}\right)$ (This equation requires the absolute scale temperatures. Therefore, degrees Fahrenheit must be converted to degrees Rankine by adding 459.7). The critical pressure used in the fit is $5.897 \mathrm{MPa}(855.3 \mathrm{psia})$. The coefficients $\mathrm{a}_{\mathrm{i}}$ are dimensionless and are as follows:

$$
\begin{aligned}
& a_{1}=-7.01707106 \\
& a_{2}=1.33436478 \\
& a_{3}=-1.78330695 \\
& a_{4}=-1.84394112
\end{aligned}
$$

Figure 33 shows comparisons of the two data sets from this work and the vapor pressures of Oi et al. [18] with the calculated values from eq. (1). The data agree within $\pm 0.3 \%$.

The critical point parameters used in eq. (1) were determined from the near-saturation vapor and liquid $(p, p, T)$ data and the vapor pressure data collected in this work. Twenty-four nearsaturation vapor and liquid $(p, p, T)$ data points were obtained. The data are presented in Table 31 . The vapor pressure data and near-saturation $(p, p, T)$ data were used to estimate the critical point parameters of R-41 using the method of Van Poolen et al. [19]. The critical point temperature is estimated to be $317.28 \pm 0.08 \mathrm{~K}\left(111.43 \pm 0.14^{\circ} \mathrm{F}\right)$. This temperature agrees with those of Bominaar et al. [20] and 
of Biwas et al. [21] within $\pm 0.12 \mathrm{~K}\left( \pm 0.22^{\circ} \mathrm{F}\right)$. The critical pressure is estimated to be $5.897 \pm 0.01$ $\mathrm{MPa}(855.3 \pm 1.4 \mathrm{psia})$. This critical pressure agrees within $\pm 0.27 \mathrm{MPa}( \pm 4.3 \mathrm{psia})$ with the critical pressures of Bominaar et al. [20] and of Biwas et al. [21]. The critical density is estimated to be 316.5 $\pm 1.5 \mathrm{~kg} / \mathrm{m}^{3}\left(19.74 \pm 0.9 \mathrm{lb} / \mathrm{ft}^{3}\right)$. The critical density agrees within $\pm 5.1 \mathrm{~kg} / \mathrm{m}^{3}\left( \pm 0.34 \mathrm{lb} / \mathrm{ft}^{3}\right)$ of the critical densities of Bominaar et al. [20] and of Biwas et al. [21]. A summary of the critical point parameters is presented in Table 32.

Liquid- and gas-phase $(\mathrm{p}, \mathrm{p}, \mathrm{T})$ measurements for $\mathrm{R}-41$ were taken along 17 isochores at temperatures from 132 to $400 \mathrm{~K}\left(-222\right.$ to $\left.260^{\circ} \mathrm{F}\right)$ at pressures up to $35 \mathrm{MPa}$ (5100 psi). Fourhundred forty-five isochoric $(p, \rho, T)$ measurements were obtained. The data are presented in Table 33. Saturated liquid densities for R-41 were estimated by extrapolating the isochoric ( $p, \rho, T)$ data to the vapor pressures calculated from eq. (1). These calculated saturated liquid densities are presented in Table 34. Figure 34 shows the range of temperatures and pressures covered by the isochoric $(p, p, T)$ data. Figure 35 compares the near-saturation $(p, \rho, T)$ liquid densities, the isochoric $(p, \rho, T)$ data, and the calculated saturated liquid densities from the isochoric $(p, \rho, T)$ data with calculated values from the MBWR equation in REFPROP 6.0. All of the data agree with the predicted values within $\pm 0.5 \%$, and the majority was fit to within approximately $0.2 \%$ except in close proximity to the triple point temperature and the critical temperature. The near-saturation densities agree with the predicted values within $\pm 0.3 \%$. The overall fit of the $(p, \rho, T)$ data has an average absolute deviation of $\pm 0.048 \%$ and a bias of $0.002 \%$.

Liquid- and gas-phase heat capacity measurements were taken for R-41 along 17 isochores at temperatures from 148 to $343 \mathrm{~K}\left(-193\right.$ to $\left.157^{\circ} \mathrm{F}\right)$ at pressures up to $33 \mathrm{MPa}$ (4800 psi). Onehundred twenty-two isochoric heat capacity measurements and 133 saturated-liquid heat capacity measurements were obtained. The data are presented in Tables 35 and 36 . Figure 36 compares the isochoric heat capacity data at saturation and in the single-phase liquid region with calculated values from the MBWR equation in REFPROP 6.0. The liquid-phase heat capacity data agree with the predictions within \pm 2.5 except near the critical point. The saturated heat capacity data agree with the predictions within $\pm 1.5 \%$ except near the critical point and near the triple point.

Vapor phase speed of sound measurements were made from 249.5 to $350 \mathrm{~K}$ ( -10.6 to $\left.170.3^{\circ} \mathrm{F}\right)$. Thirty-seven measurements were obtained. The data are presented in Table 37 . The experimental data agreed with the predictions within $\pm 0.82 \%$ with a bias of $0.17 \%$ and an average deviation of $\pm 0.25 \%$. Figure 37 compares the vapor speed of sound data with calculated values from the MBWR equation in REFPROP 6.0 .

\subsubsection{R-41/744}

$\mathrm{R}-41 / 744$ is a Type I system with no azeotrope. The data for the R-41/744 systems cover six isotherms from 218 to $290 \mathrm{~K}$ ( -68 to $62^{\circ} \mathrm{F}$ ). Thirty-seven vapor-liquid equilibrium points were recorded. The data are presented in Table 38. In Figure 38, the deviations between the bubble-point pressures and the predicted values are presented. The bubble-point pressure data agreed with the 
predicted values from the Lemmon-Jacobsen model within $\pm 1.5 \%$. The bubble-point pressure statepoint uncertainty for R-41/744 at temperatures from 218 to $290 \mathrm{~K}$ ( -68 to $62^{\circ} \mathrm{F}$ ) ranges from \pm 0.19 to $\pm 0.22 \%$. In Figure 39, the vapor compositions are compared to the predicted values of the Lemmon-Jacobsen model. No other data sets were available for comparison. The vapor compositions agree with the predicted values from the Lemmon-Jacobsen model within \pm 0.018 mole fraction of $R$ 41. The vapor-composition state-point uncertainty for the R-41/744 system at temperatures from 218 to $290 \mathrm{~K}\left(-68\right.$ to $\left.62^{\circ} \mathrm{F}\right)$ ranges from \pm 0.006 to \pm 0.011 mole fraction $\mathrm{R}-41$.

Isochoric $(p, \rho, T)$ data were also obtained for the $R-41 / 744$ system. Measurements were taken in both the gas and liquid phases. The data are reported in Table 39. Figure 40 shows the range of temperatures and pressures covered by the isochoric $(p, \rho, T)$ data. Figure 41 shows the comparison of the isochoric $(p, \rho, T)$ data to the predicted values from the Lemmon-Jacobsen model in REFPROP 6.0. The isochoric $(p, \rho, T)$ data agreed with the predicted values from the Lemmon-Jacobsen model within $\pm 1.0 \%$ except for two vapor-phase points.

The $\mathrm{R}-41 / 744$ system is a possible replacement for $\mathrm{R}-13$ if the freezing point of the mixture is significantly lower than the freezing point of pure R-744. Prior to this study, no published data were available for the solid-liquid equilibria of R-41/744 mixtures. Based on known behavior of similar mixtures, we expected the freezing points of R-41/744 mixtures to fall below that of pure R-744 whose triple point temperature is $216.59 \mathrm{~K}\left(-69.83^{\circ} \mathrm{F}\right)$. The triple point temperature of $\mathrm{R}-41$ was estimated to be $129.82 \pm 0.04 \mathrm{~K}\left(-226.01 \pm 0.07^{\circ} \mathrm{F}\right)$, as observed in the adiabatic calorimeter. The calculated freezing point of our equimolar mixture is approximately $186 \mathrm{~K}\left(-125^{\circ} \mathrm{F}\right)$, which is $13 \mathrm{~K}$ $\left(23.4^{\circ} \mathrm{F}\right)$ above the average of the triple point temperatures of $\mathrm{R}-41$ and $\mathrm{R}-744$.

To determine some bounds on the freezing point temperature for the equimolar R-41/744 mixture (0.499823 mole fraction R-41 (0.43591 mass fraction $R-41)$ ), we condensed the sample into a precooled PVT cell. In such experiments, the sample would condense to either a liquid or to a solid after it enters the cell, depending on the initial temperature of the PVT cell. This test required only minimal additional effort, since the PVT cell had to be filled to carry out PVT experiments. We carried out two filling experiments. The initial cell temperatures were $180 \mathrm{~K}$ and $170 \mathrm{~K}(-135.6$ and $-153.7^{\circ} \mathrm{F}$ ), both at a final pressure of $2 \mathrm{MPa}(290 \mathrm{psia})$. We determined that both samples were liquid phase by heating the samples and observing a steady rise of pressure of approximately $2 \mathrm{MPa} / \mathrm{K}$ (161 $\left.\mathrm{psia} /{ }^{\circ} \mathrm{F}\right)$. This technique has established that the freezing point of an equimolar mixture is less than $182.5 \mathrm{~K}\left(-131.2^{\circ} \mathrm{F}\right)$.

We then employed an adiabatic calorimeter to accurately measure the temperature at which solid precipitates from a liquid sample of the R-41/744 mixture. The calorimeter bomb was filled with a liquid sample $(57.907 \mathrm{~g})(0.1277 \mathrm{lb})$ at a final temperature and pressure of $(292.68 \mathrm{~K}, 7.50 \mathrm{MPa}$ $\left.\left(67.14^{\circ} \mathrm{F}, 1088 \mathrm{psia}\right)\right)$. This quantity of material leaves only a small vapor space above the liquid when it was subsequently cooled. The sample was cooled rapidly to $225 \mathrm{~K}\left(-55^{\circ} \mathrm{F}\right)$, then slowly to 95 $\mathrm{K}\left(-289^{\circ} \mathrm{F}\right)$. We observed the formation of a solid phase at a temperature of $125 \mathrm{~K}\left(-235^{\circ} \mathrm{F}\right)$, as indicated by a sharp break in a graph of the recorded temperatures versus times. We then heated the sample from $95 \mathrm{~K}\left(-289^{\circ} \mathrm{F}\right)$ to about $115 \mathrm{~K}\left(-253^{\circ} \mathrm{F}\right)$, then allowed the sample to equilibrate and 
measured the small heat leak. The heater power was then lowered to about $15 \%$ of the normal level, and we continued to heat the sample to $135 \mathrm{~K}\left(-217^{\circ} \mathrm{F}\right)$. The freezing temperature was observed where the temperature reached a plateau value for the elapsed time needed to melt the solid phase. Three experiments were carried out. The elapsed time at the plateau temperature was about 640 minutes. The observed freezing temperatures were $124.98 \pm 0.02 \mathrm{~K}\left(-234.72 \pm 0.036^{\circ} \mathrm{F}\right), 124.97 \pm$ $0.02 \mathrm{~K}\left(-234.74 \pm 0.036^{\circ} \mathrm{F}\right)$, and $125.00 \pm 0.02 \mathrm{~K}\left(-234.69 \pm 0.036^{\circ} \mathrm{F}\right)$. Though two heater power levels were selected, no dependence on the applied power was seen. The observed enthalpies of fusion were $2.069 \pm 0.01 \mathrm{~kJ} \cdot \mathrm{mol}^{-1}(22.79 \pm 0.11 \mathrm{BTU} \cdot \mathrm{lb}-1)$ and $2.074 \pm 0.01 \mathrm{~kJ} \cdot \mathrm{mol}^{-1}(22.84 \pm 0.11$ BTU $\left.\cdot 1 b^{-1}\right)$, after corrections for energy to heat the empty calorimeter and for energy lost to parasitic heat leaks were applied.

The average freezing temperature of $124.98 \mathrm{~K}\left(-234.72^{\circ} \mathrm{F}\right)$ is $48 \mathrm{~K}\left(86.4^{\circ} \mathrm{F}\right)$ below the mole fraction average of the pure component triple point temperatures, and also is $5 \mathrm{~K}\left(9^{\circ} \mathrm{F}\right)$ lower than that of the lowest-melting pure substance in the mixture. This evidence implies that this binary mixture will have at least one eutectic composition. More extensive experimental and theoretical studies of solid-liquid transitions are needed to further elucidate this phenomenon.

The measurements on R-125/134a, R-32/125/134a, R-32/143a, R-125/143a, R-143a/134a, R$32 / 290, \mathrm{R}-125 / 290, \mathrm{R}-134 \mathrm{a} / 290, \mathrm{R}-41$, and $\mathrm{R}-41 / 744$ were supported in part by a grant from the U.S. Department of Energy, Office of Building Technology (Grant number DE-FG02-91CE23810: Materials Compatibilities and Lubricants Research on CFC-Refrigerant Substitutes) administered by the Air-Conditioning and Refrigeration Technology Institute (MCLR Project Number 660-50800). Federal funding supporting this project constitutes $93.57 \%$ of allowable costs. Funding from the air conditioning and refrigeration industry supporting the project consists of direct cost sharing of $6.43 \%$ of allowable costs; and significant in-kind contributions. The measurements on $\mathrm{R}-32 / 134 \mathrm{a}$ and R-32/125 were supported by a grant from the U.S. Department of Energy, Office of Building Technology (Grant number 93CE23808.001). We would like to thank the following companies for supplying high purity refrigerant samples: ICI for supplying R-32, DuPont and ICI for supplying R125, and AlliedSignal for supplying R-143a. We would also like to thank Michael J. Hiza for preparing the standard mixtures used in this work and Mark O. McLinden for determining the vapor pressure equation for $\mathrm{R}-41$.

\section{REFERENCES}

[1] Lemmon, E.W.; Jacobsen, R.T.; Thermodynamic properties of mixtures of refrigerants R-32, R125, R-134a, and R-152a. Conference Preprint, 13th Symposium on Thermophysical Properties, Boulder, CO, June 22-27, 1997, submitted for publication in Int. J. Thermophys.; 1997. 
[2] McLinden, M.O.; Klein, S.A. A next generation refrigerant properties database. Proc. 6th Int. Refrig. Conf. at Purdue, West Lafayette, IN, July 23-26, 1996, 409; 1996.

[3] Nagel M.; Bier, K. Vapour-liquid equilibrium of temary mixtures of the refrigerants R32, R125 and R134a. Int. J. Refrig. 18: 534; 1995.

[4] Higashi, Y. Vapor-liquid equilibrium, coexistence curve and critical locus for binary HFC32/HFC-134a. Int. J. Thermophys. 16(5): 1175; 1995.

[5] Widiatmo, J.V.; Sato, H.; Watanabe, K. Measurements of liquid densities of the binary HFC-32 +HFC-134a System. Fluid Phase Equilibria 99: 199; 1994.

[6] Fujiwara, K.; Momota, H.; Noguchi, M. Vapor-liquid equilibria of HFC-32 mixtures. Proc. 13th Japanese Sym. Thermophysical Properties A116: 61; 1992.

[7] Defibaugh, D.R.; Morrison, G. Interaction coefficients for 15 mixtures of flammable and nonflammable components, Int. J. Refr. 18(8): 518; 1995.

[8] Weber, L.; Defibaugh, D. R. The virial coefficients of five binary mixtures of fluorinated methanes and ethanes. Int. J. Thermophys. 15(5): 863; 1994.

[9] Widiatmo, J.V.; Sato, H.; and Watanabe, K. Bubble-point pressures and saturated-liquid densities for binary HFC-32 + HFC-125 system. High Temperatures - High Pressures 25: 677; 1993.

[10] Higashi, Y. Vapor-liquid equilibrium, coexistence curve and critical locus for binary HFC32/125. Proc. 19th Int. Congress of Refrigeration, Netherlands IVa: 297; 1995.

[11] Higuchi, M.; Higashi, Y. Measurements of the vapor-liquid equilibrium for binary R125/134a mixture. Proc. 16th Japanese Symp. Thermophysical Properties, 16: 5; 1995.

[12] Higashi, Y. Vapor-liquid equilibrium and critical point for the R32/125/134a mixture. Presented at the AIChE Spring Meeting, New Orleans, LA; February 1996.

[13] Gillis, K.A.; Hurly, J.J.; Schmidt, J.W. Equation of state and ideal-gas heat capacity of a gaseous mixture of 1,1,1,2-tetrafluoroethane, pentafluoroethane, and difluoromethane. Int. J. Thermophys. 18(3): 655; 1997.

[14] Takashima, H.; Higashi, Y. Vapor-liquid equilibrium, coexistence curve and critical locus for binary HFC-125/143a. Proc. 16th Japanese Symp. Thermophysical Properties, 16: 9; 1995.

[15] Nagel M.; Bier, K. Vapour-liquid equilibrium of ternary mixtures of the refrigerants R125, R143a and R134a. Int. J. Refrig. 19, 264 (1996).

[16] Kleiber, M., Vapor-liquid equilibria of binary refrigerant mixtures containing propylene or R134a, Fluid Phase Equilibria 92: 149; 1994.

[17] Jadot, R.; Frere, M. Simulation of liquid-vapor equilibria of hydrofluorocarbon (HFC) mixtures by the UNIFAC model. High Temperatures - High Pressures 25: 491; 1993.

[18] Oi, T.; Shulman, J.; Popowicz, A.; Ishida, J. Vapor pressure isotope effects in liquid methyl fluoride. J. Phys. Chem. 87: 3153; 1983.

[19] Van Poolen, L.J.; Niesen, V.G.; Holcomb, C.D.; Outcalt, S.L. Critical densities from coexisting density data: application to refrigerants R22, R134a, and R124. Fluid Phase Equilibria 97: 97; 1994.

[20] Bominaar, S. A. R. C.; Biswas, S. N.; Trappeniers, N. J.; Ten Seldam, C.A. (p, $\left.V_{m}, T\right)$ Properties of methyl fluoride in the (gas+liquid) critical region. J. Chem. Thermodynami. 19: 959; 1987. 
[21] Biswas, S. N.; Ten Seldam, C. A.; Bominaar, S. A. R. C.; Trappeniers, N. J. Liquid-vapor coexistence curve of methyl fluoride in the critical region. Fluid Phase Equilibria 49: 1; 1989. 
6. FIGURES 


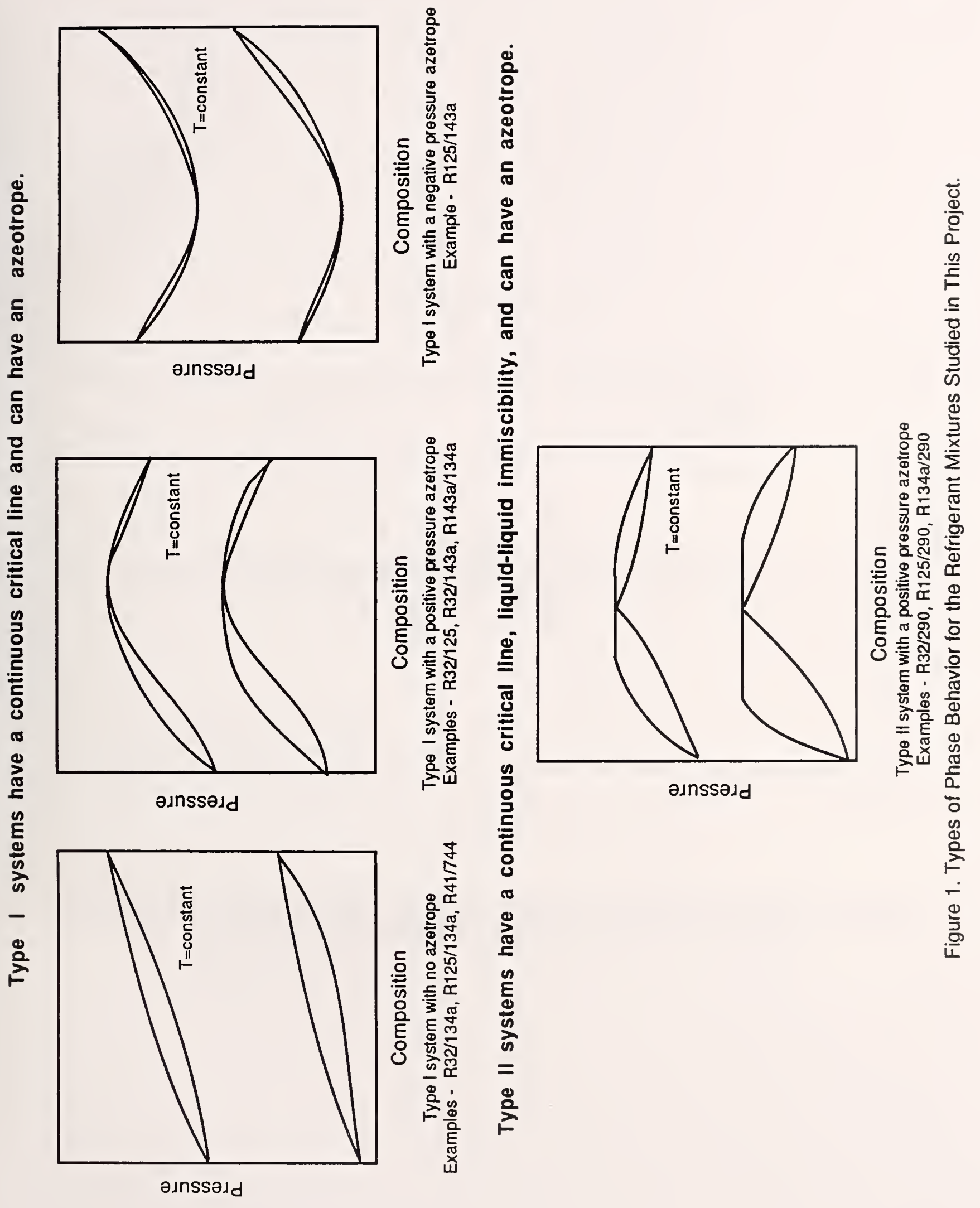






Figure 2. Comparison of Bubble-Point Pressures for the R-32/134a System; the Baseline is from the Lemmon-Jacobsen Model in REFPROP 6.0. 


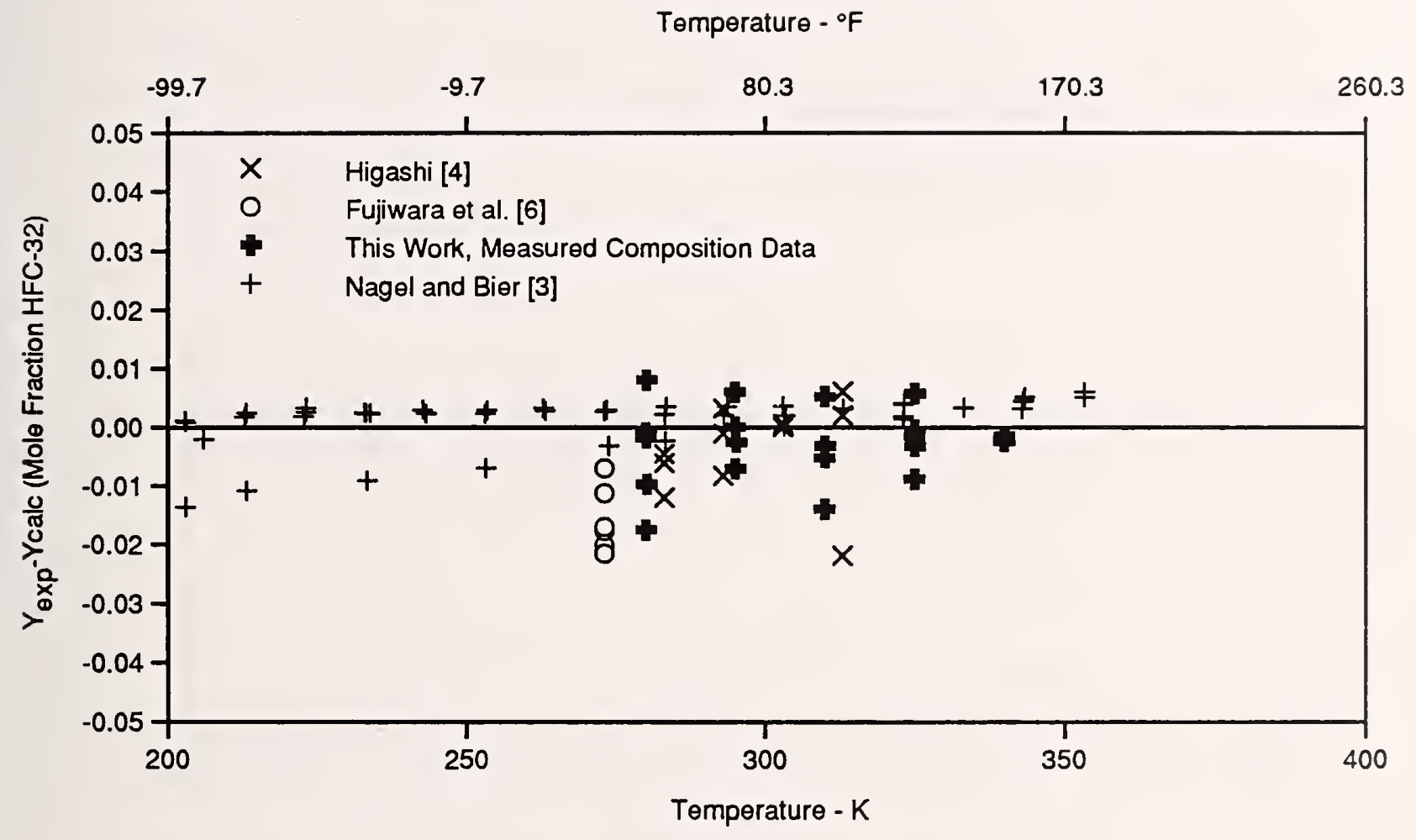

Figure 3. Comparison of Vapor Compositions for the R-32/134a System; the Baseline is from the Lemmon-Jacobsen Model in REFPROP 6.0. 


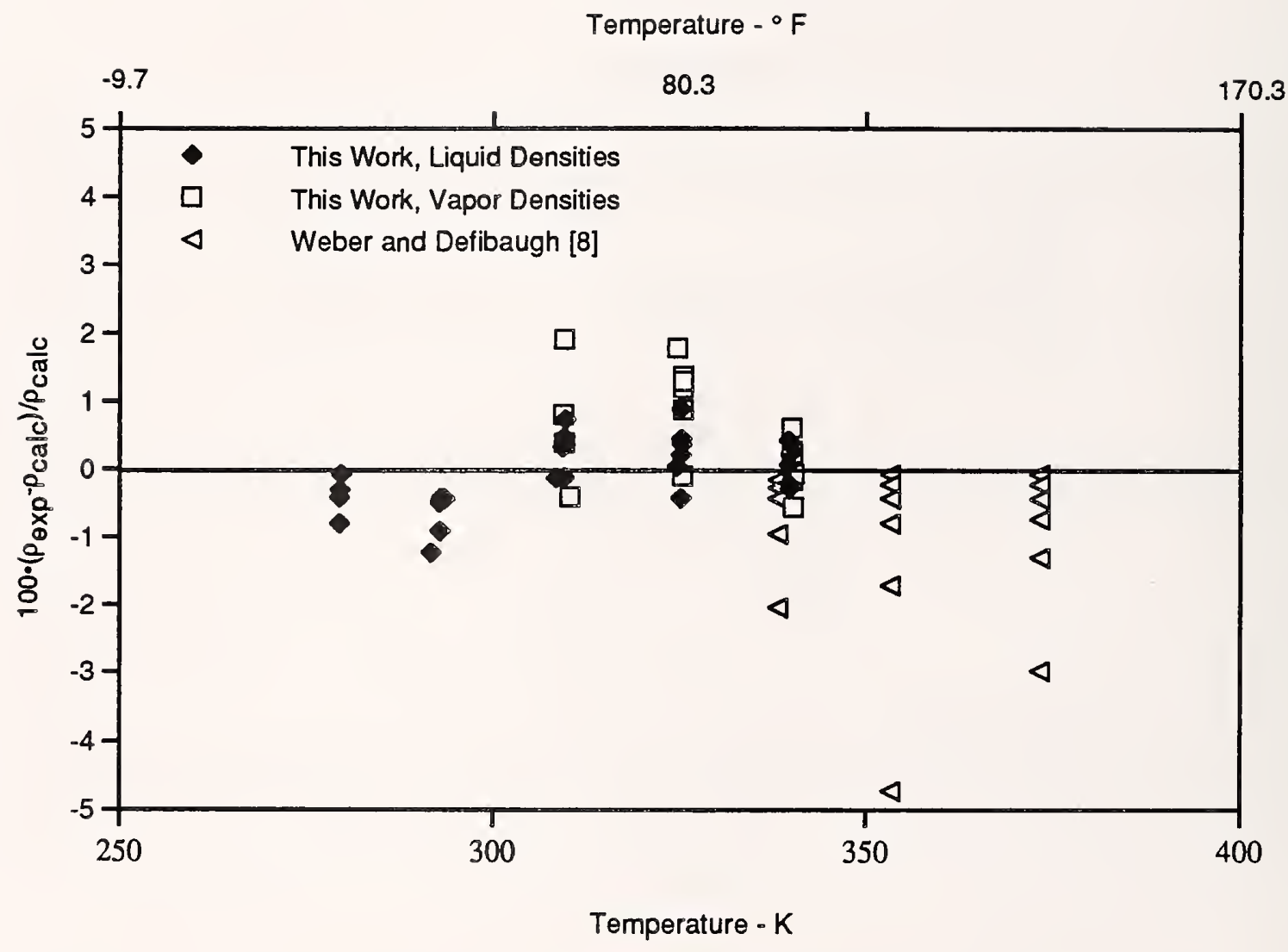

Figure 4. Comparison of Densities for the R-32/134a System; the Baseline is from the Lemmon-Jacobsen Model in REFPROP 6.0. 


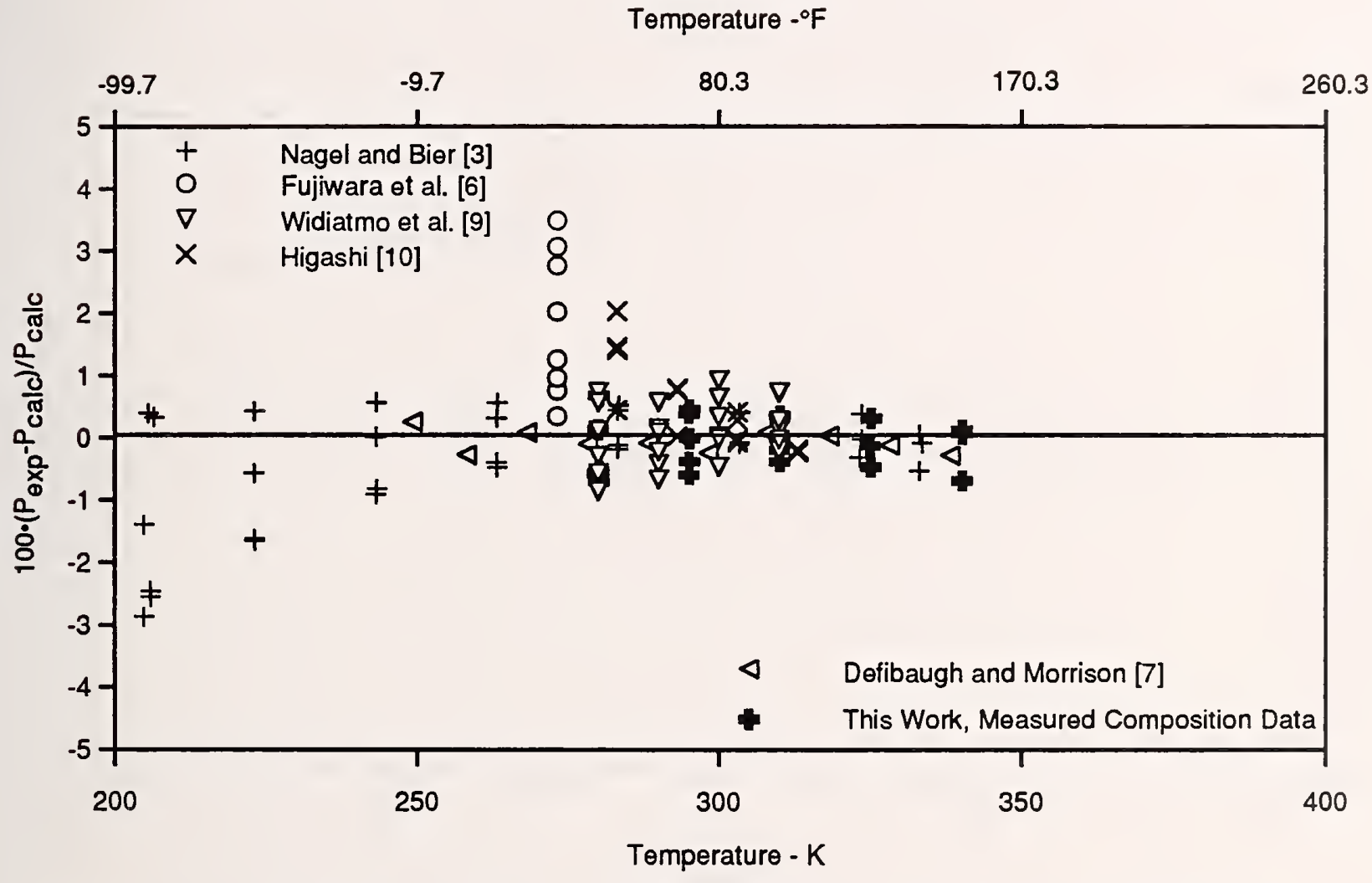

Figure 5. Comparison of Bubble-Point Pressures for the R-32/125 System; the Baseline is from the Lemmon-Jacobsen Model in REFPROP 6.0. 


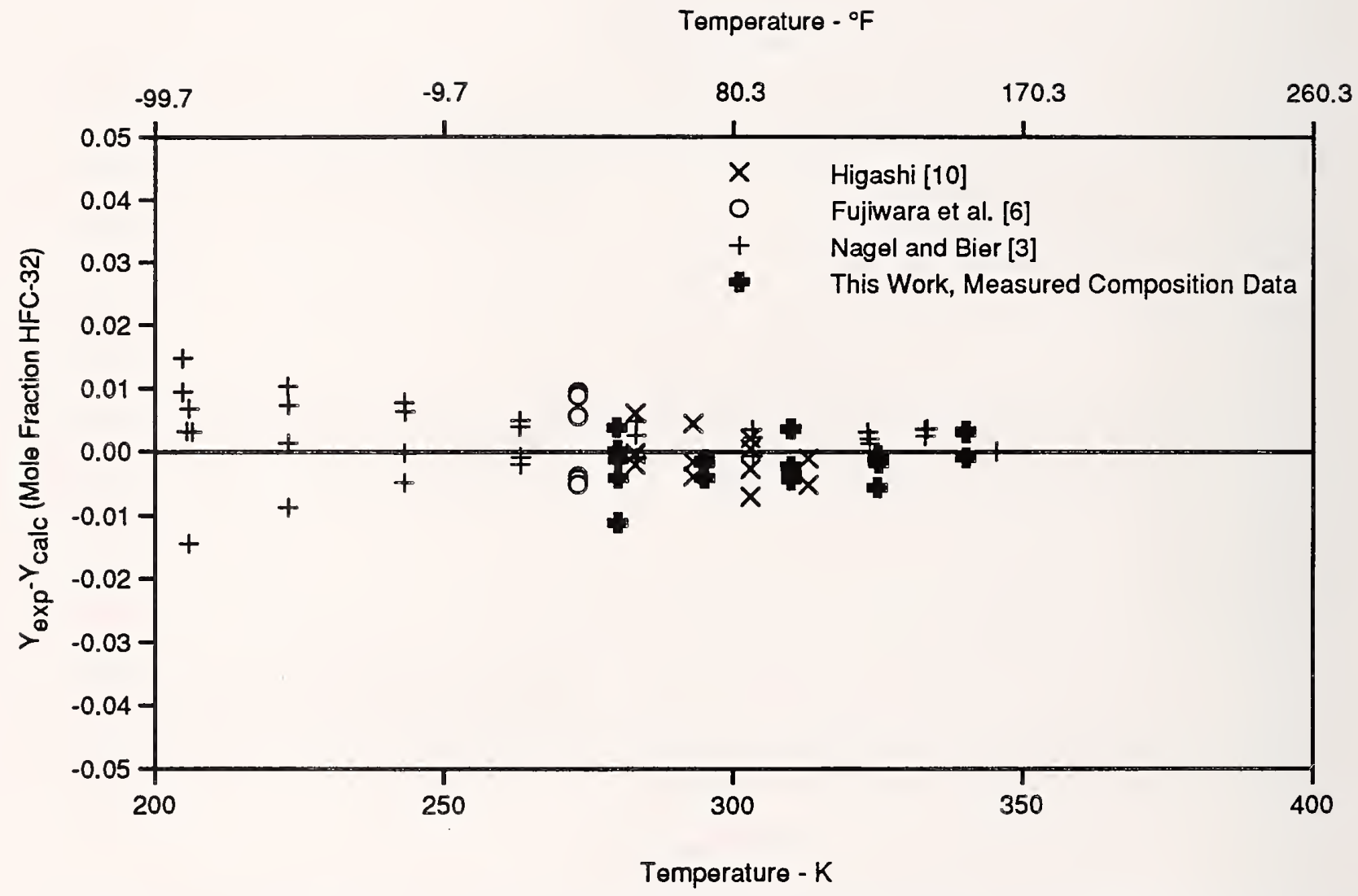

Figure 6. Comparison of Vapor Compositions for the R-32/125 System; the Baseline is from the Lemmon-Jacobsen Model in REFPROP 6.0. 
Temperature $-{ }^{\circ} \mathrm{F}$

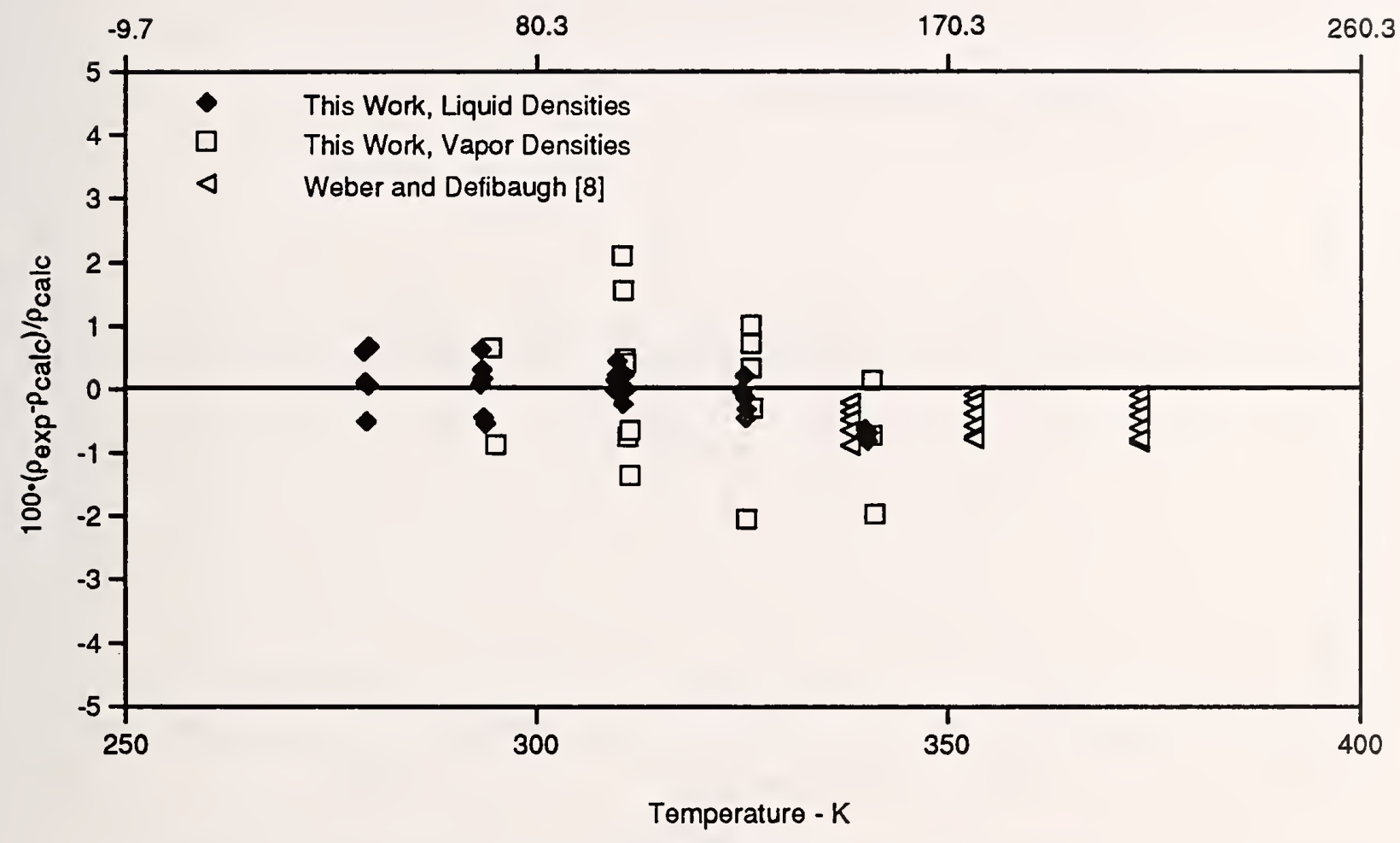

Figure 7. Comparison of Densities for the R-32/125 System; the Baseline is from the Lemmon-Jacobsen Model in REFPROP 6.0. 


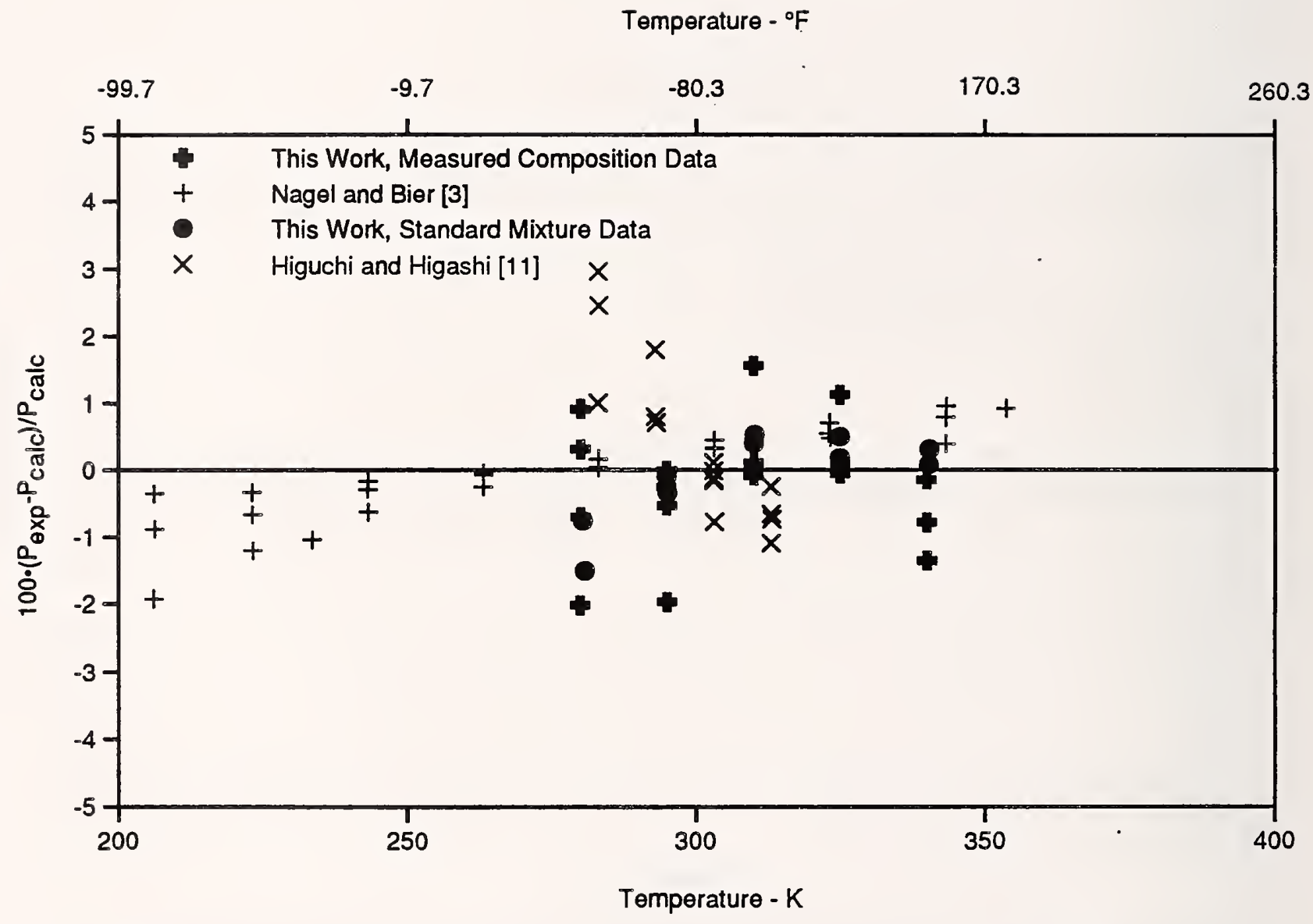

Figure 8. Comparison of Bubble-Point Pressures for the R-125/134a System; the Baseline is from the Lemmon-Jacobsen Model in REFPROP 6.0. 


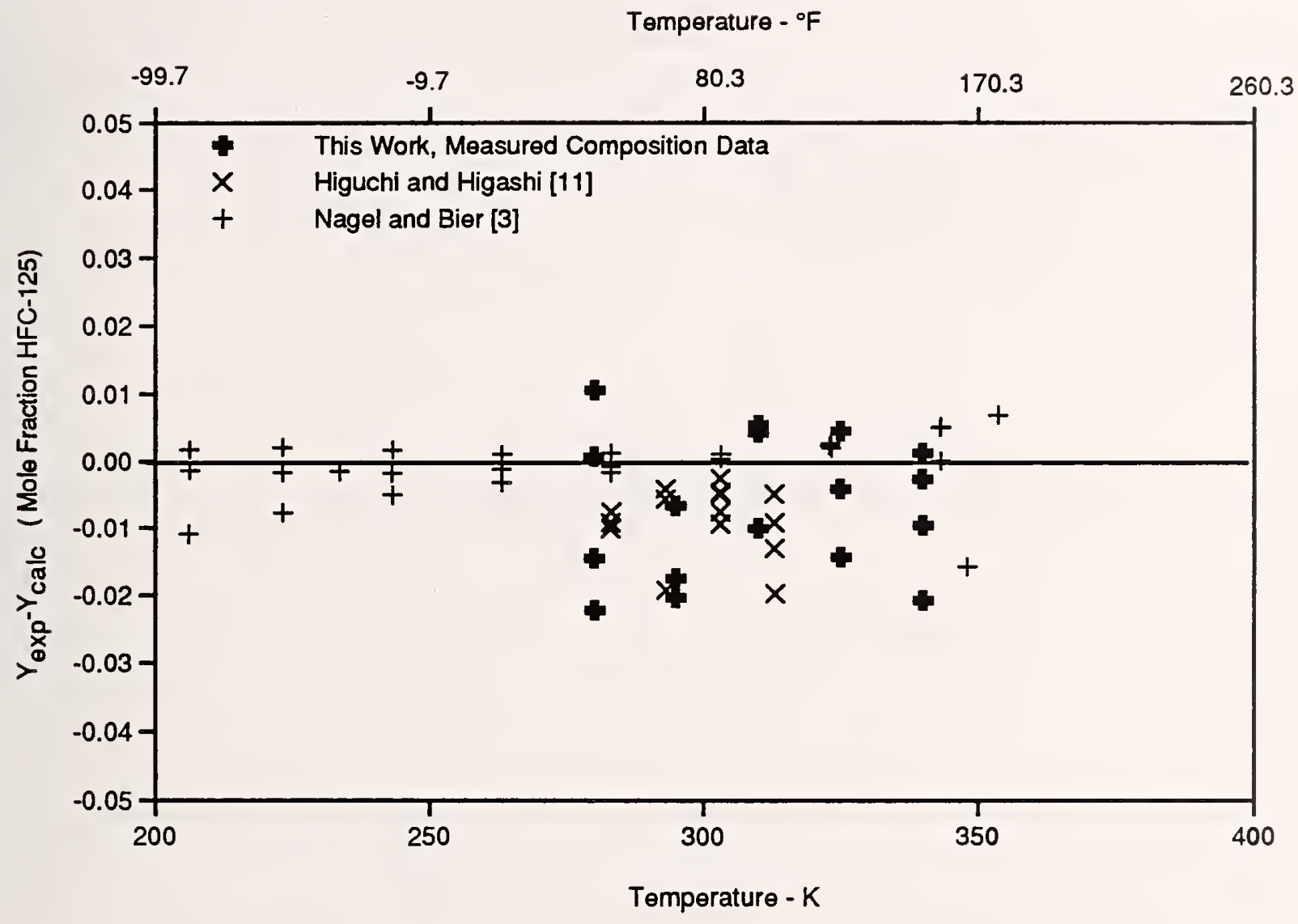

Figure 9. Comparison of Vapor Compositions for the R-125/134a System; the Baseline is from the Lemmon-Jacobsen Model in REFPROP 6.0. 


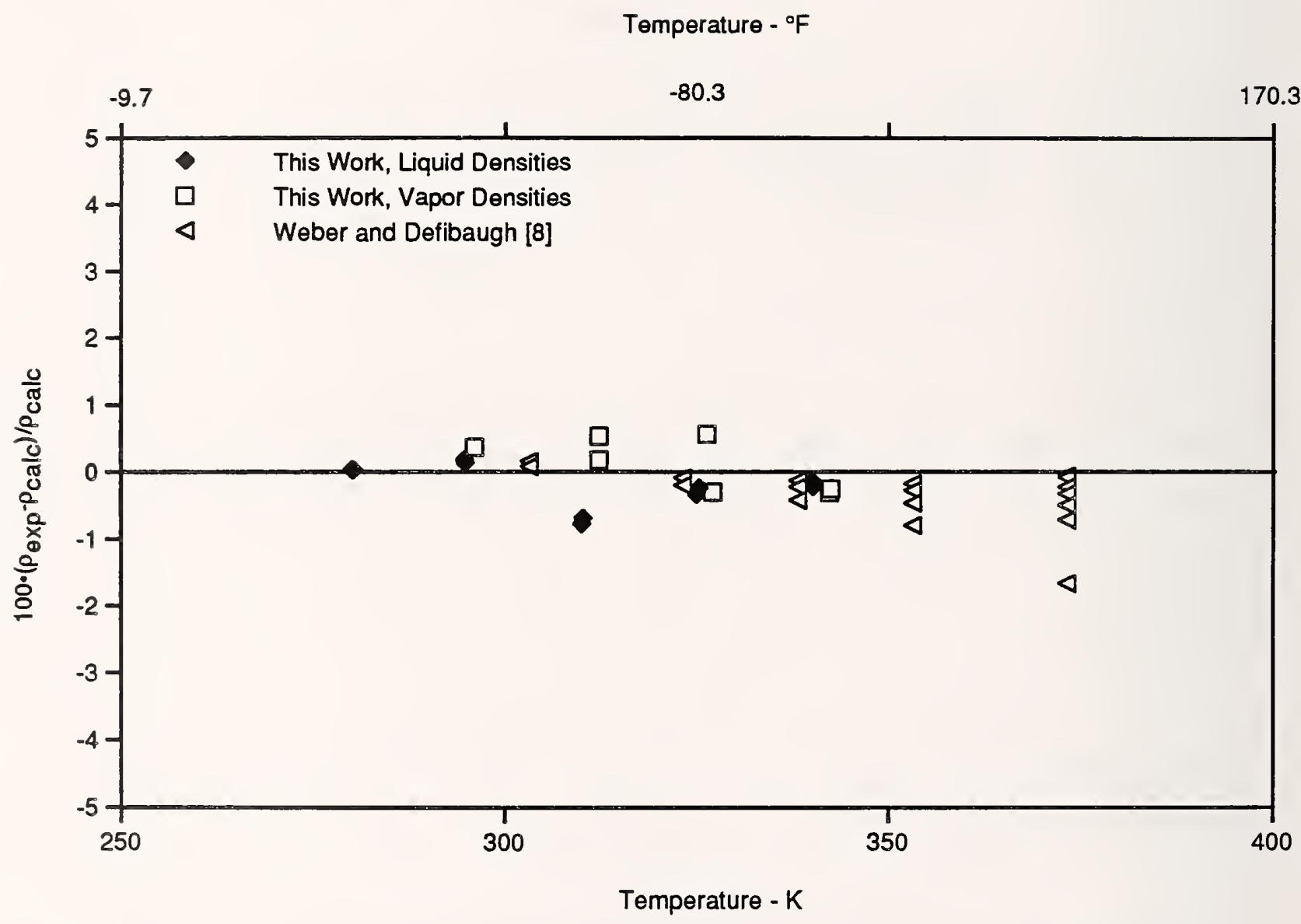

Figure 10. Comparison of Densities for the R-125/134a System; the Baseline is from the Lemmon-Jacobsen Model in REFPROP 6.0. 
Temperature $-{ }^{\circ} \mathrm{F}$

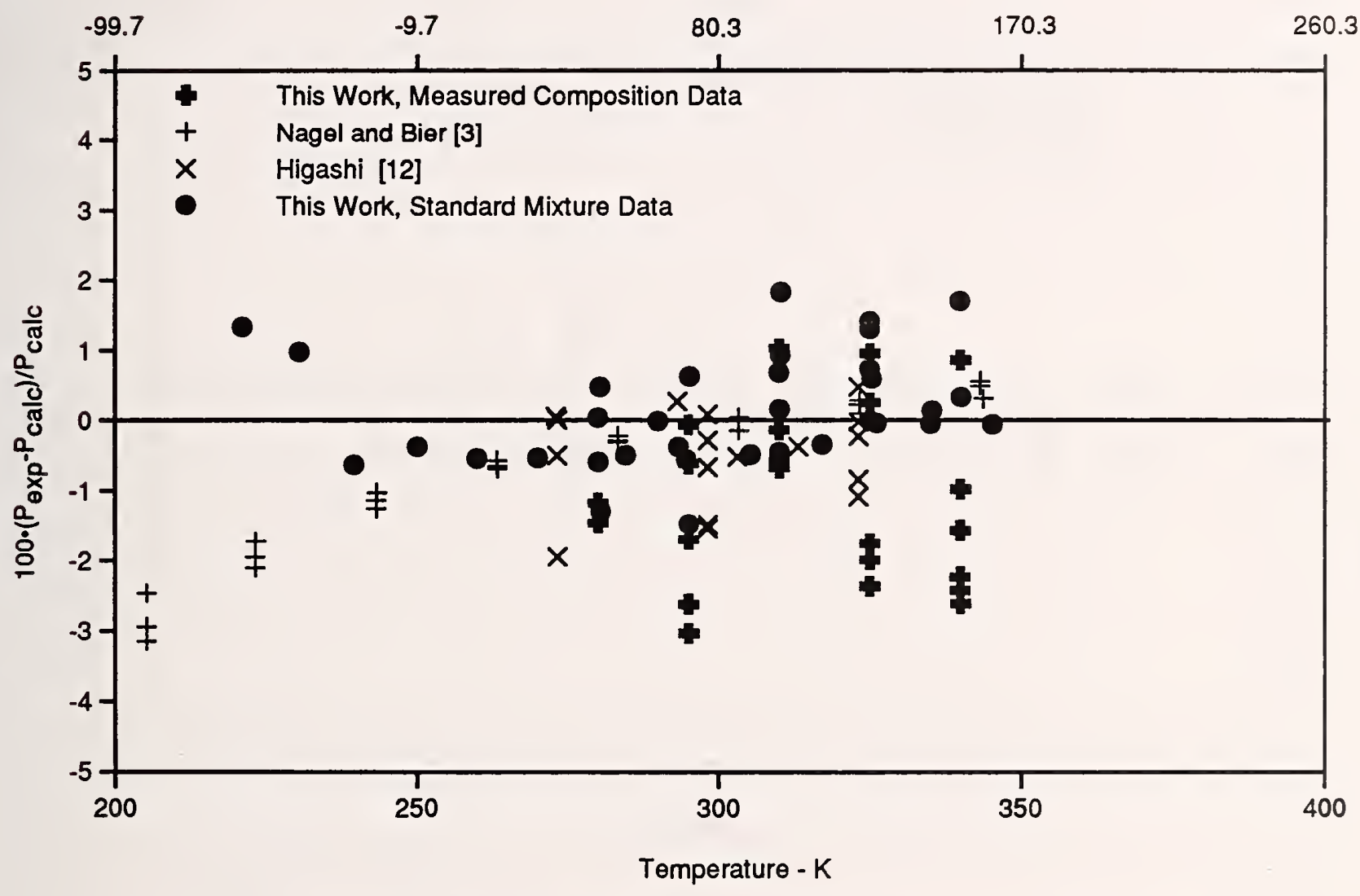

Figure 11. Comparison of Bubble-Point Pressures for the R-32/125/134a System; the Baseline is from the Lemmon-Jacobsen Model in REFPROP 6.0. 
Temperature - ${ }^{\circ} \mathrm{F}$

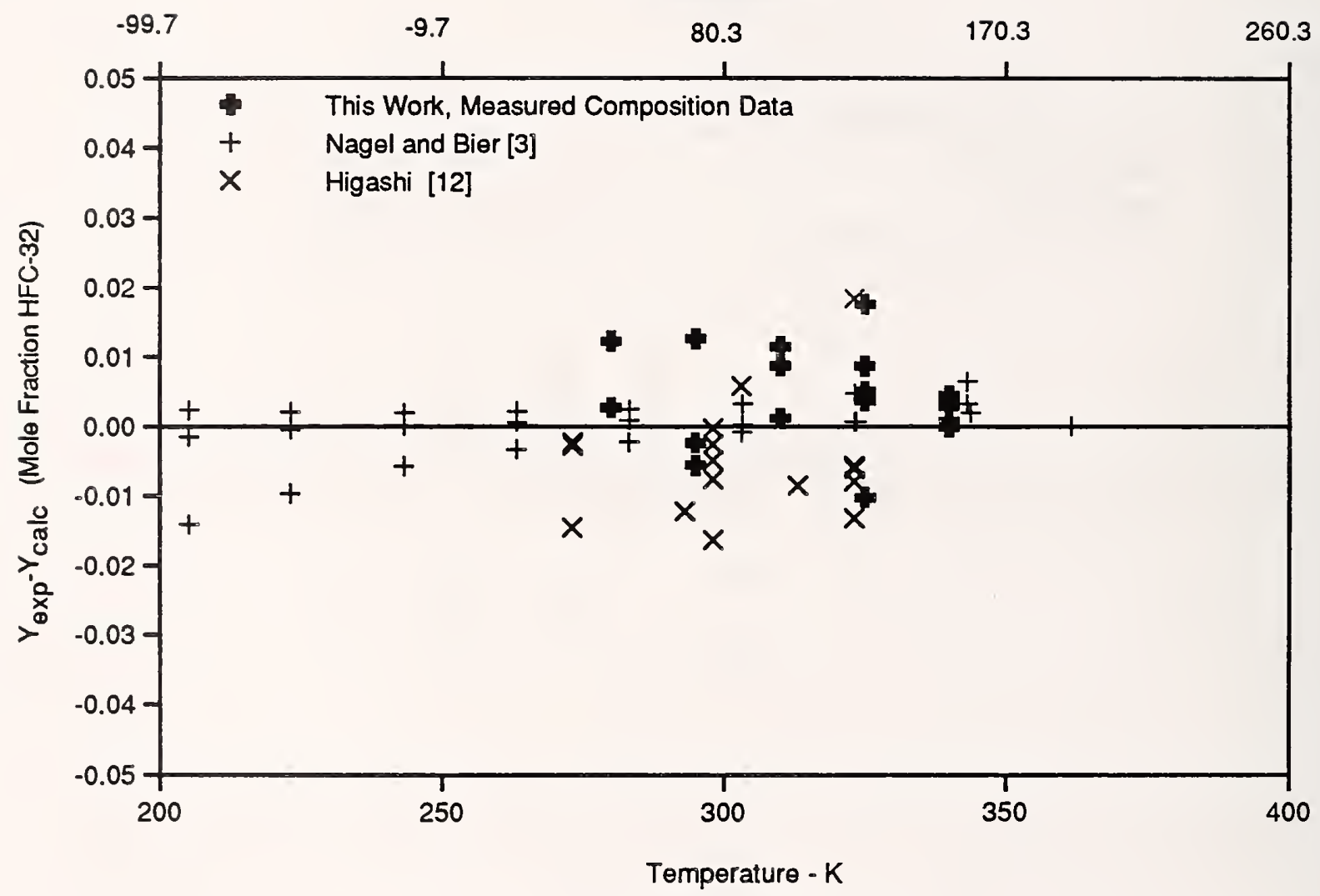

Figure 12. Comparison of Vapor Compositions for the R-32/125/134a System; the Baseline is from the Lemmon-Jacobsen Model in REFPROP 6.0. 
Temperature $-{ }^{\circ} \mathrm{F}$

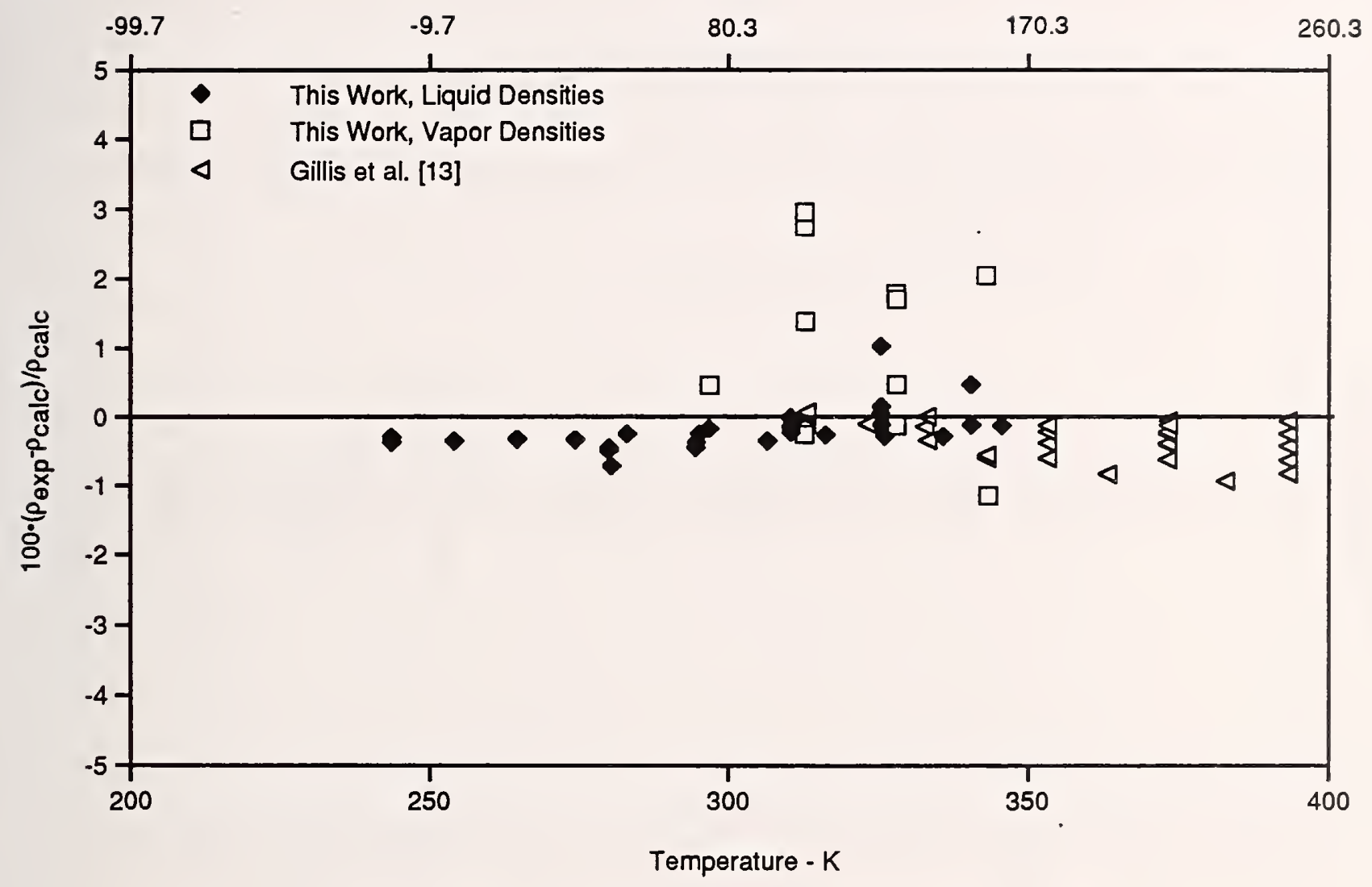

Figure 13. Comparison of Densities for the R-32/125/134a System; the Baseline is from the Lemmon-Jacobsen Model in REFPROP 6.0. 


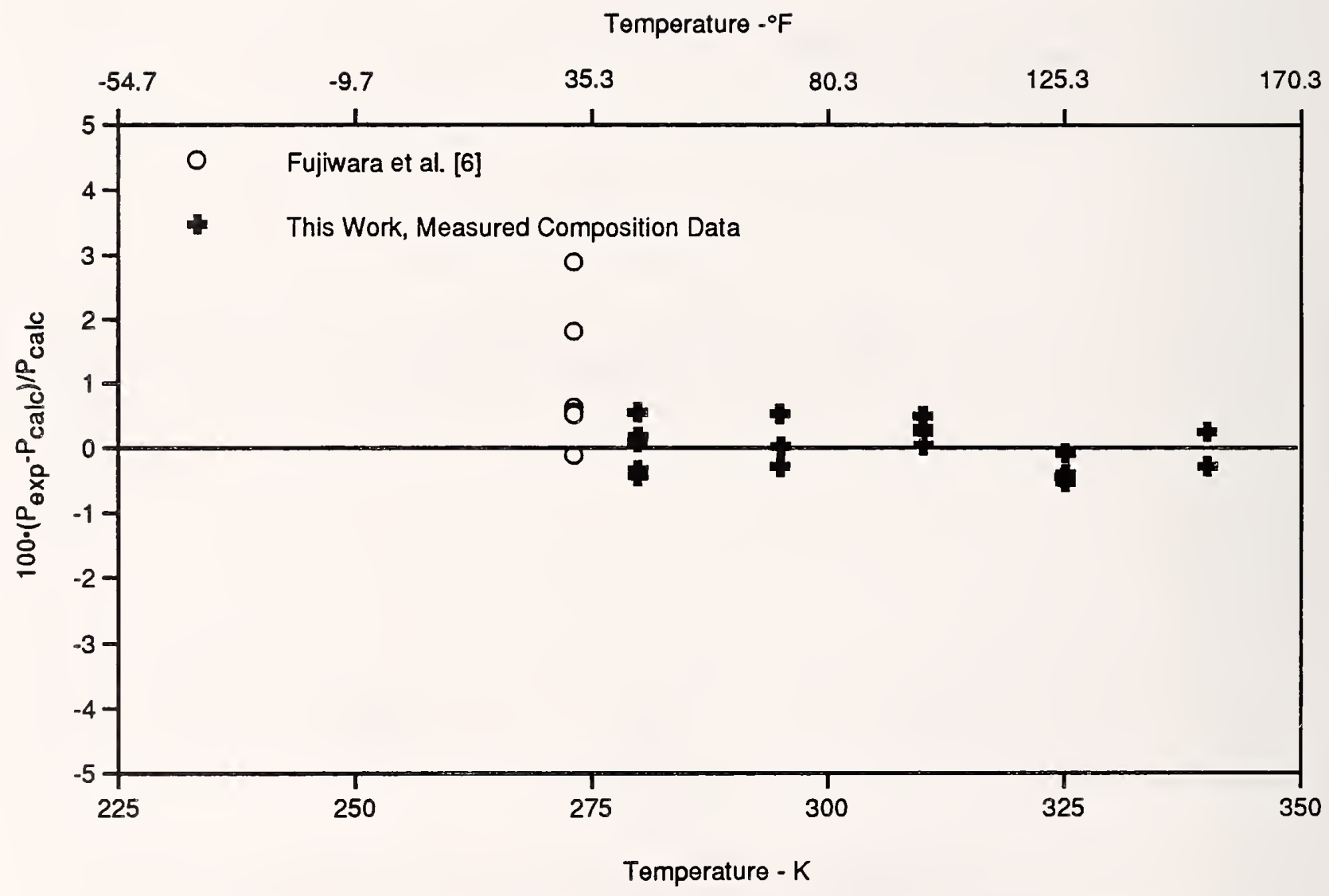

Figure 14. Comparison of Bubble-Point Pressures for the R-32/143a System; the Baseline is from the Lemmon-Jacobsen Model in REFPROP 6.0. 


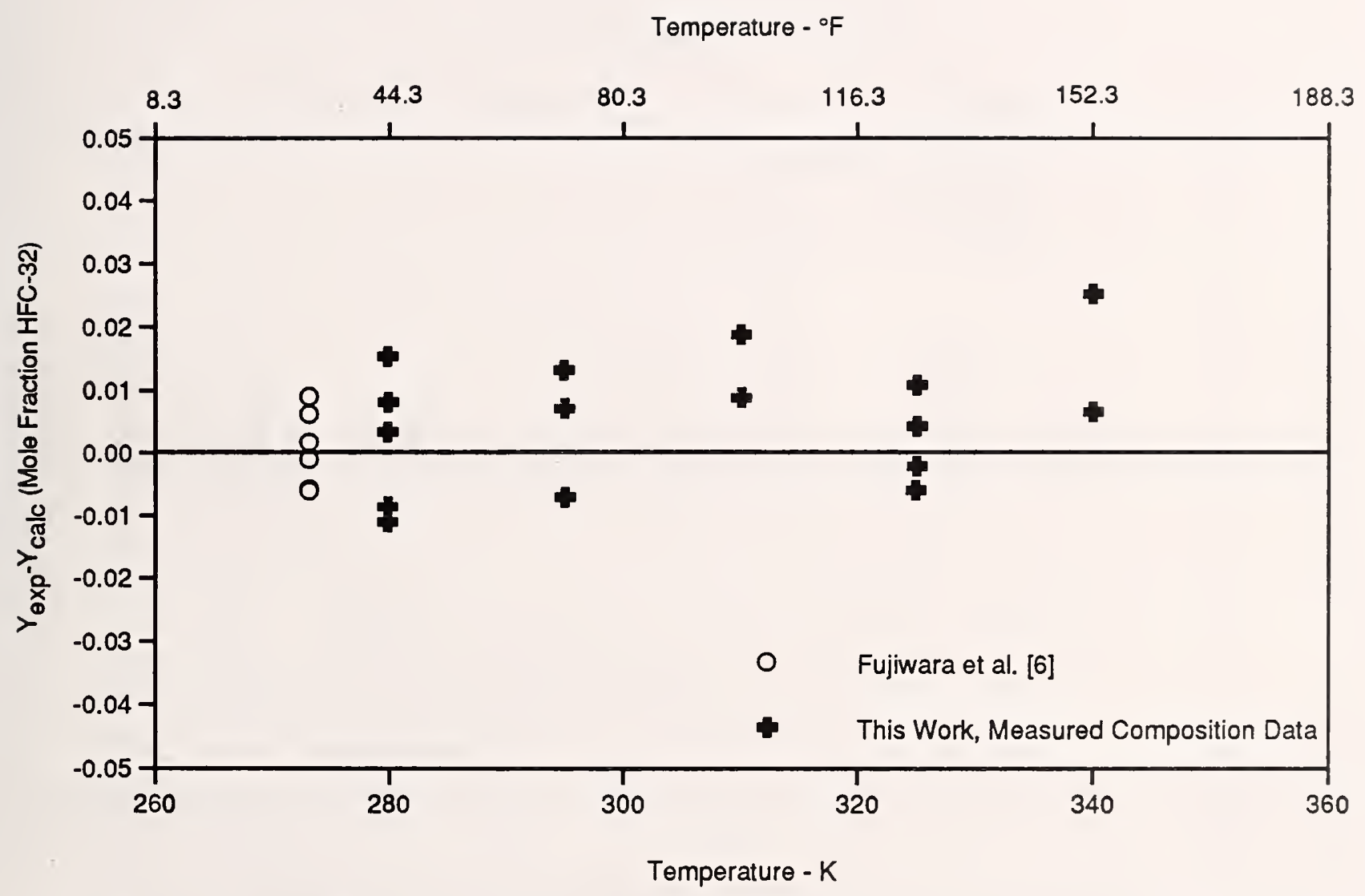

Figure 15. Comparison of Vapor Compositions for the R-32/143a System; the Baseline is from the Lemmon-Jacobsen Model in REFPROP 6.0. 


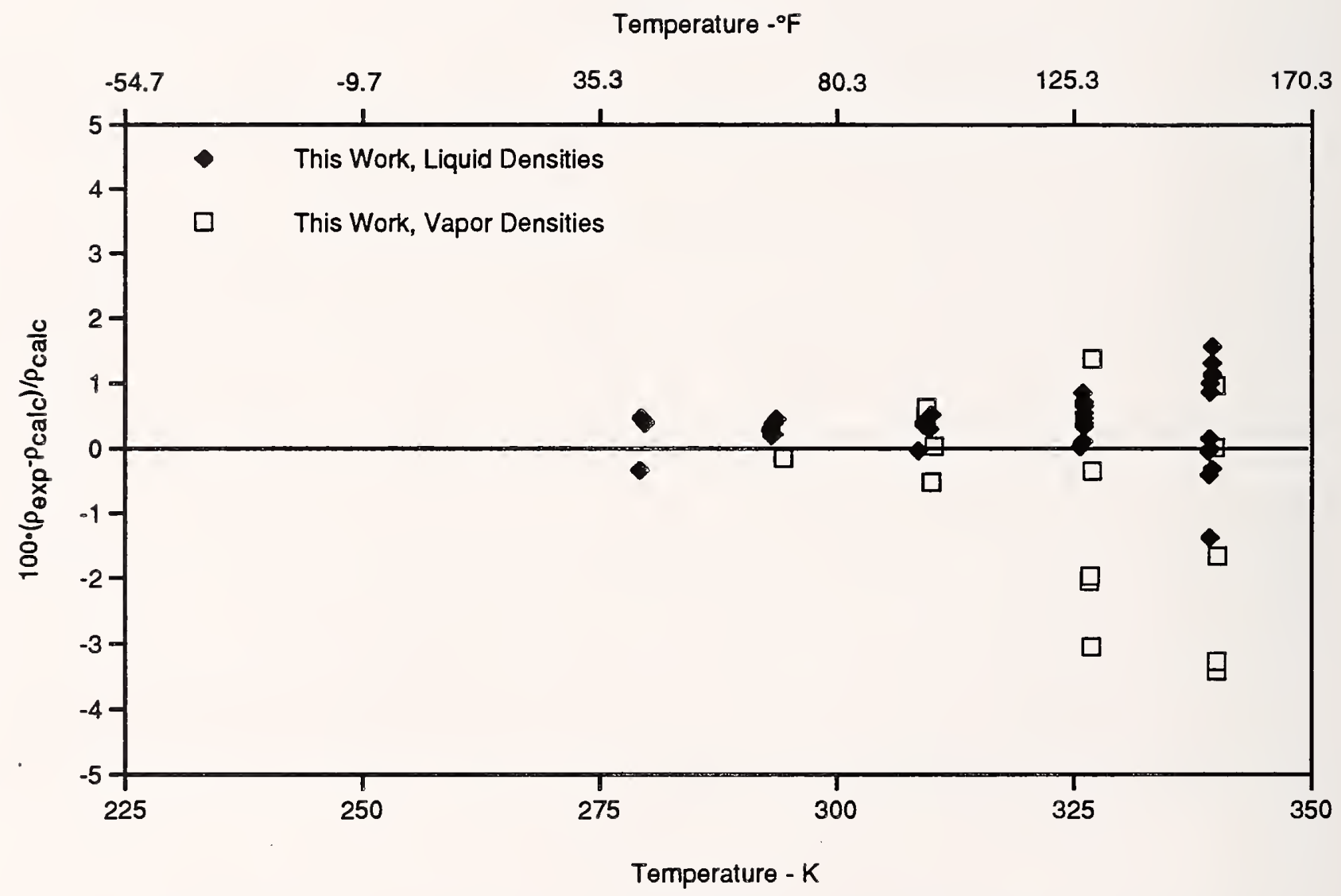

Figure 16. Comparison of Densities for the R-32/143a System; the Baseline is from the Lemmon-Jacobsen Model in REFPROP 6.0. 


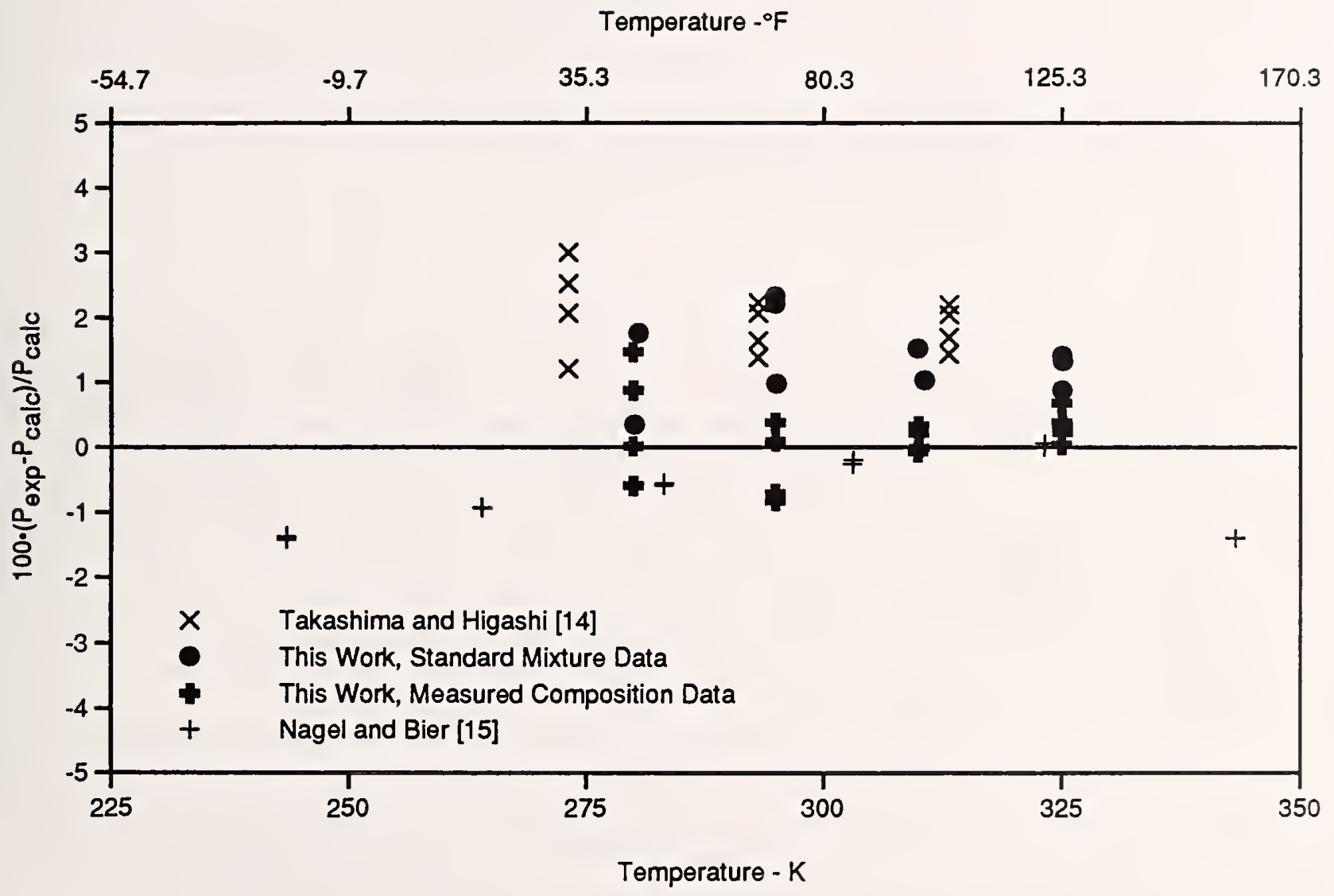

Figure 17. Comparison of Bubble-Point Pressures for the R-125/143a System; the Baseline is from the Lemmon-Jacobsen Model in REFPROP 6.0. 


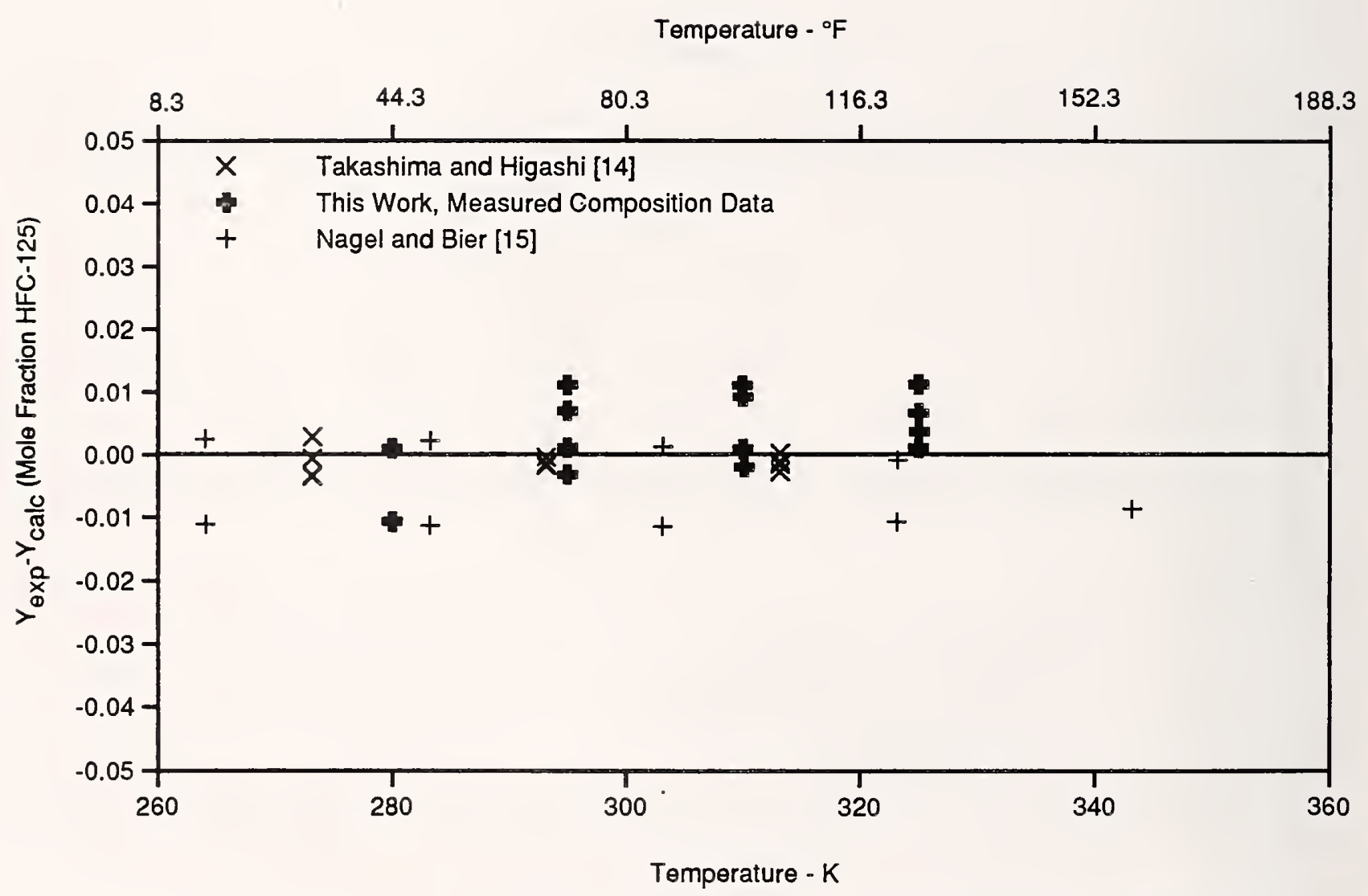

Figure 18. Comparison of Vapor Compositions for the R-125/143a System; the Baseline is from the Lemmon-Jacobsen Model in REFPROP 6.0. 
Temperature $-{ }^{\circ} \mathbf{F}$

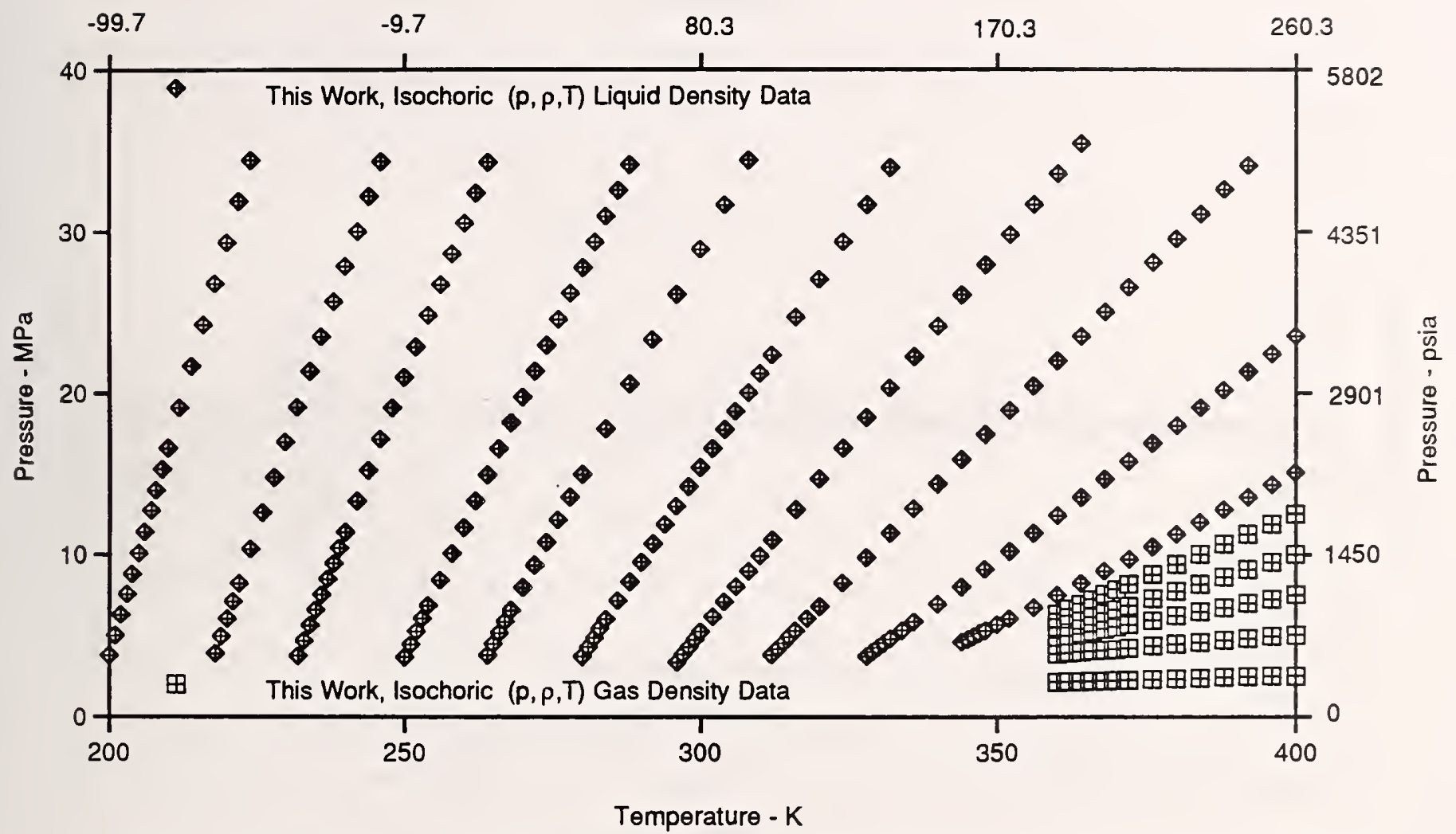

Figure 19. Range of Measured Temperatures and Pressures for Isochoric $(p, p, T)$ Data for a Mixture of $R-125 / 143 a$ with $\times(R-125)=0.49996$ Mole Fraction (0.58812 Mass Fraction). 


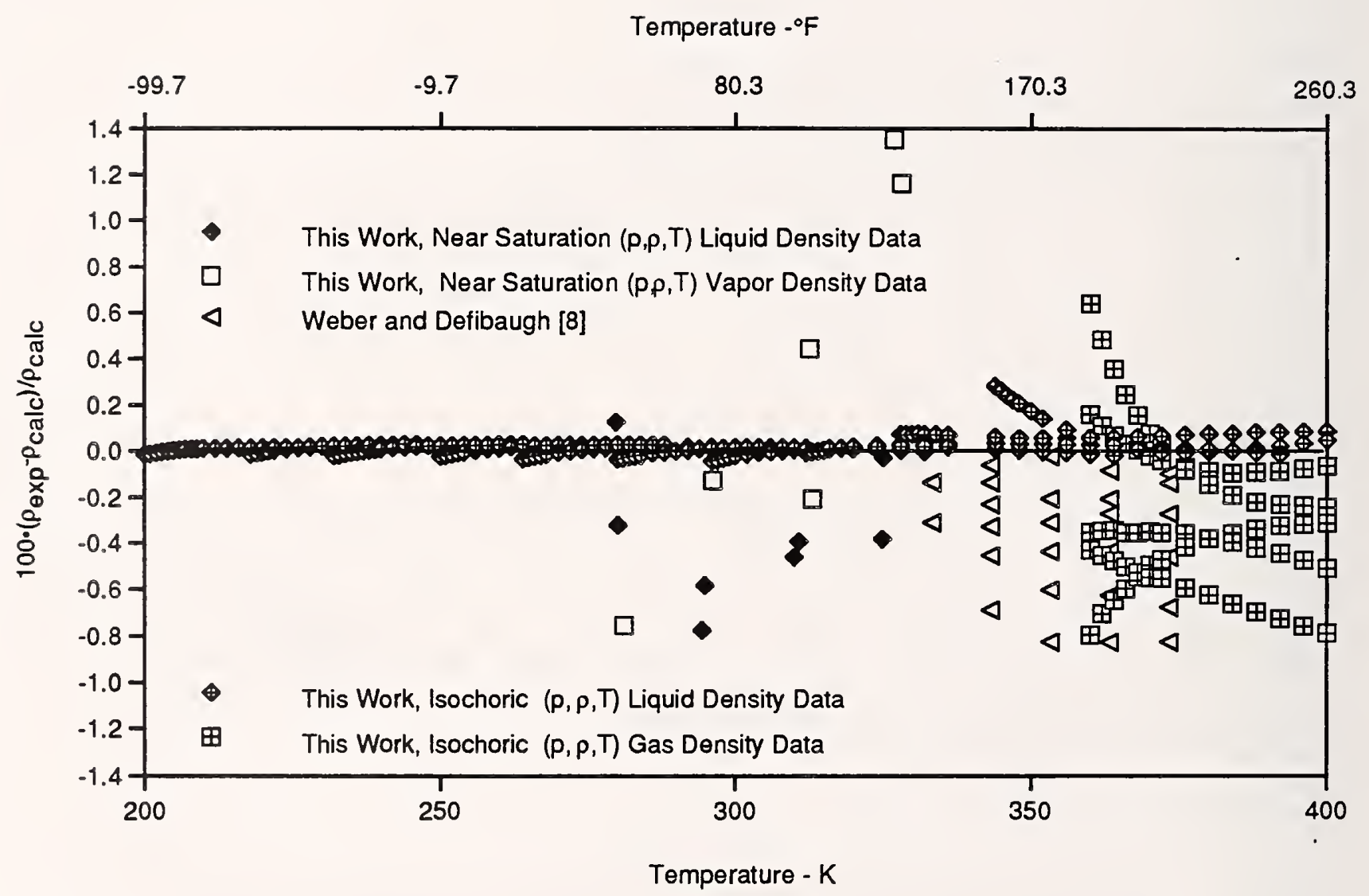

Figure 20. Comparison of Densities for the R-125/143a System; the Baseline is from the Lemmon-Jacobsen Model in REFPROP 6.0. 
Temperature - ${ }^{\circ} \mathbf{F}$

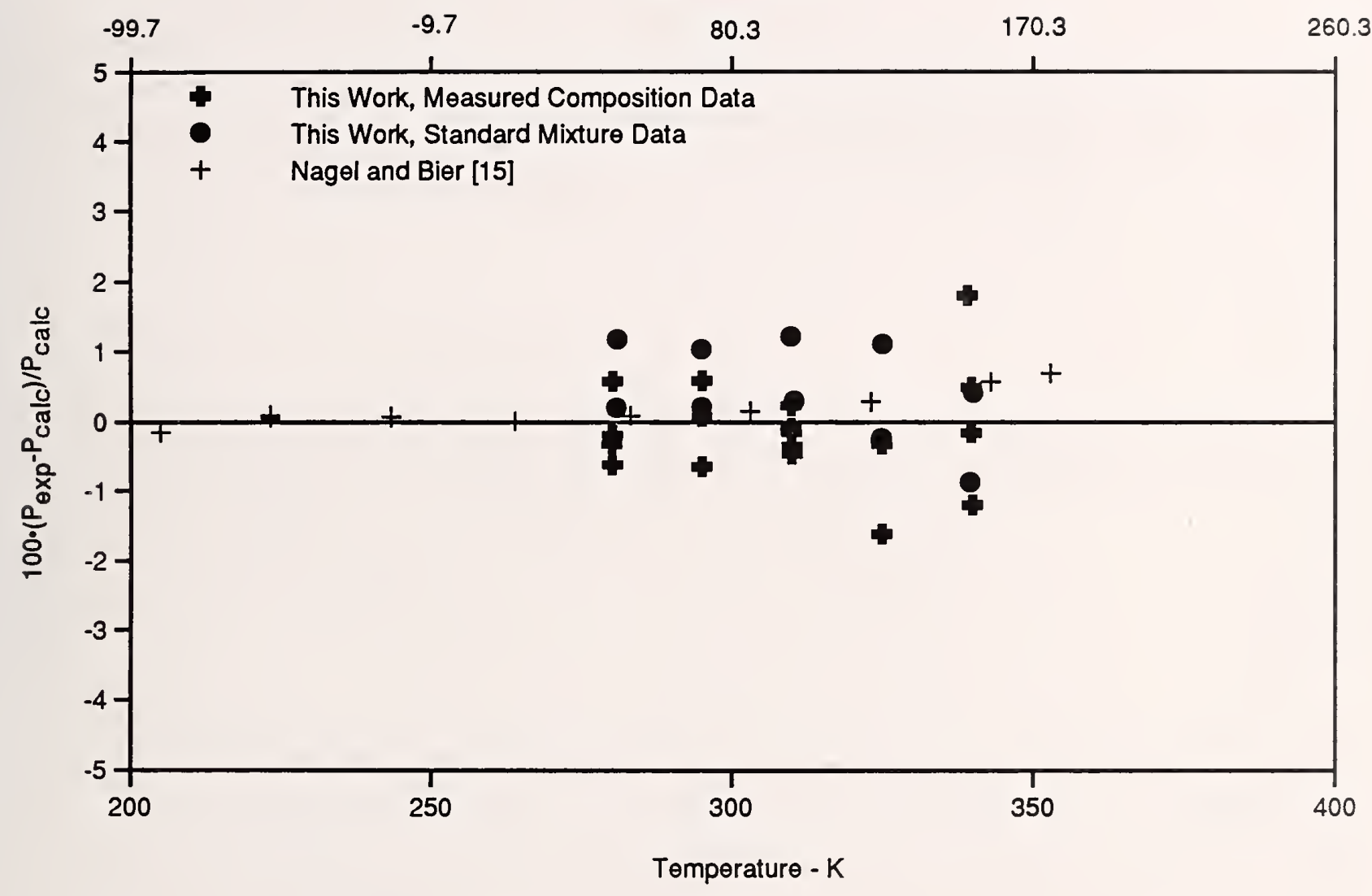

Figure 21. Comparison of Bubble-Point Pressures for the R-143a/134a System; the Baseline is from the Lemmon-Jacobsen Model in REFPROP 6.0. 
Temperature - ${ }^{\circ} \mathrm{F}$

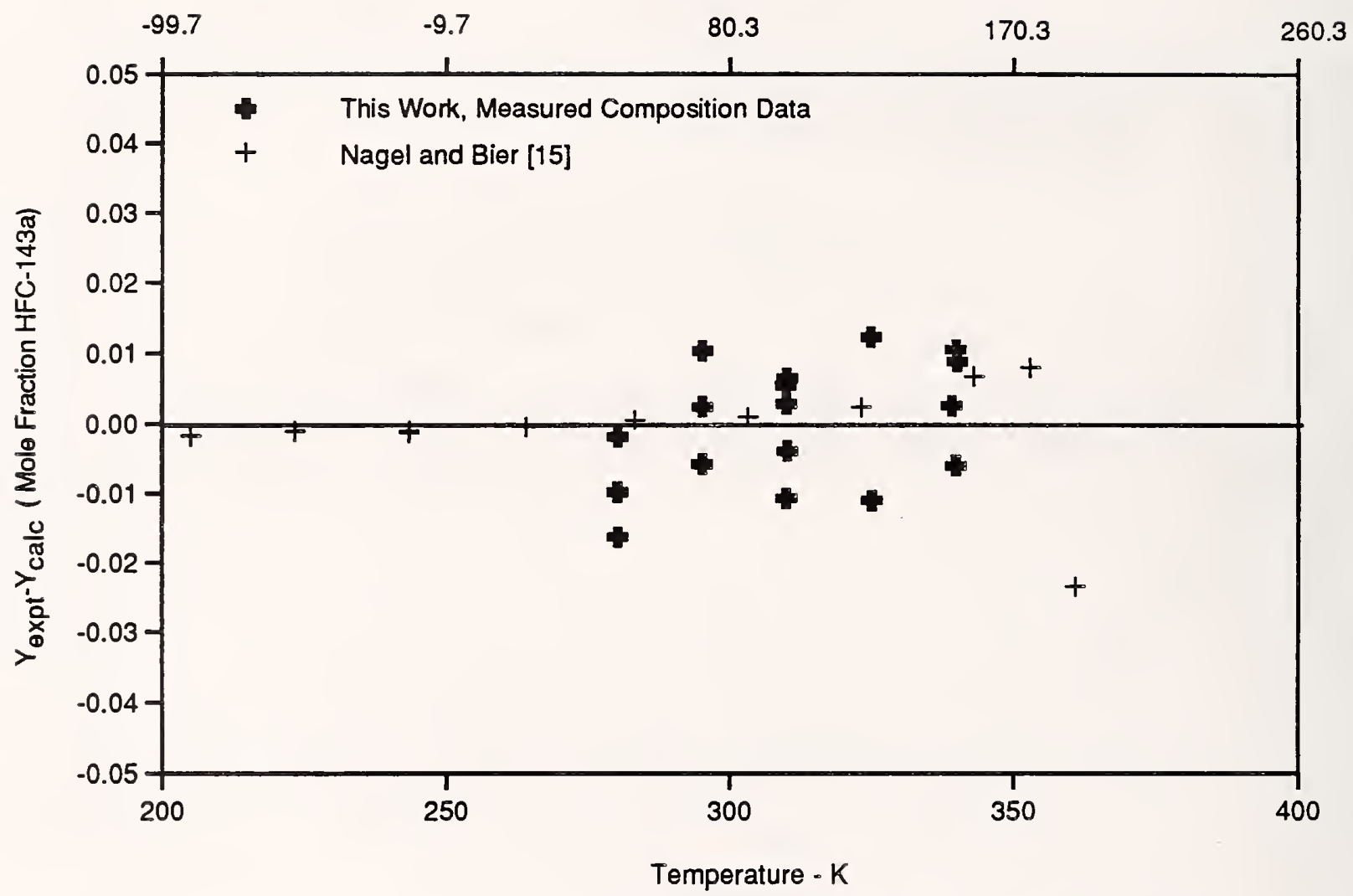

Figure 22. Comparison of Vapor Compositions for the R-143a/134a System; the Baseline is from the Lemmon-Jacobsen Model in REFPROP 6.0. 
Temperature - ${ }^{\circ} \mathrm{F}$

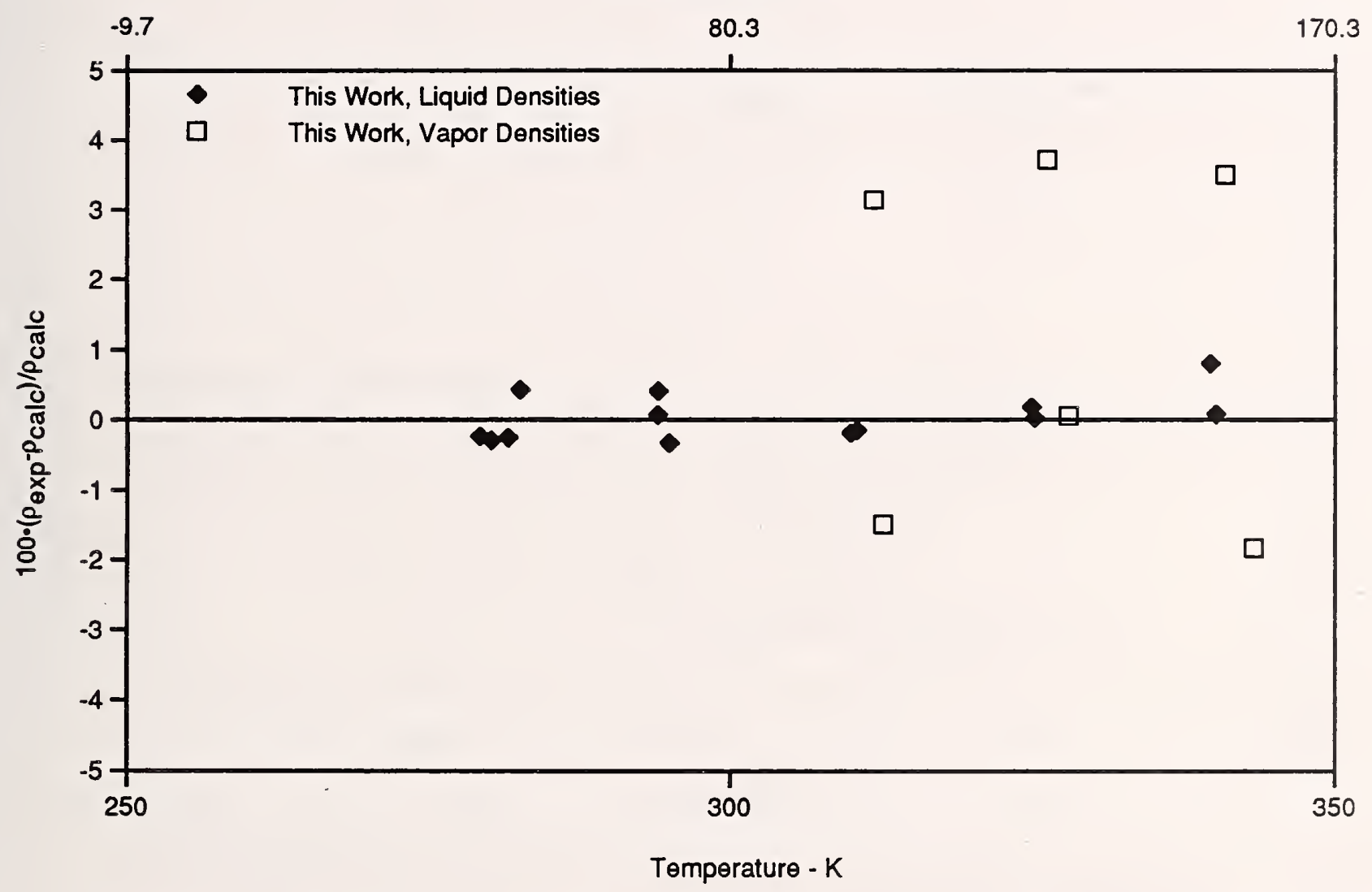

Figure 23. Comparison of Densities for the R-143a/134a System; the Baseline is from the Lemmon-Jacobsen Model in REFPROP 6.0. 


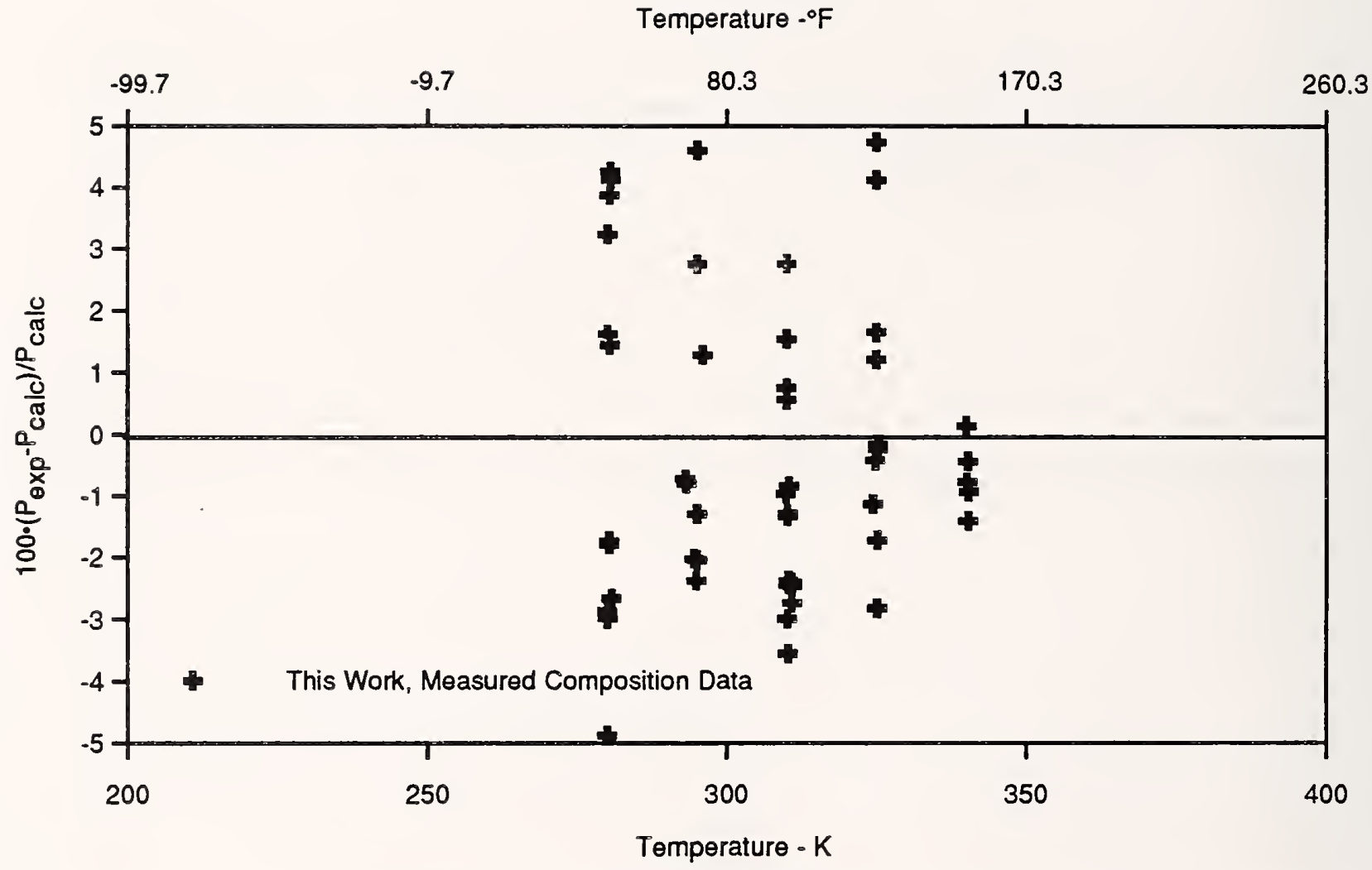

Figure 24. Comparison of Bubble-Point Pressures for the R-32/290 System; the Baseline is from the Lemmon-Jacobsen Model in REFPROP 6.0. 
Temperature - ${ }^{\circ} \mathrm{F}$

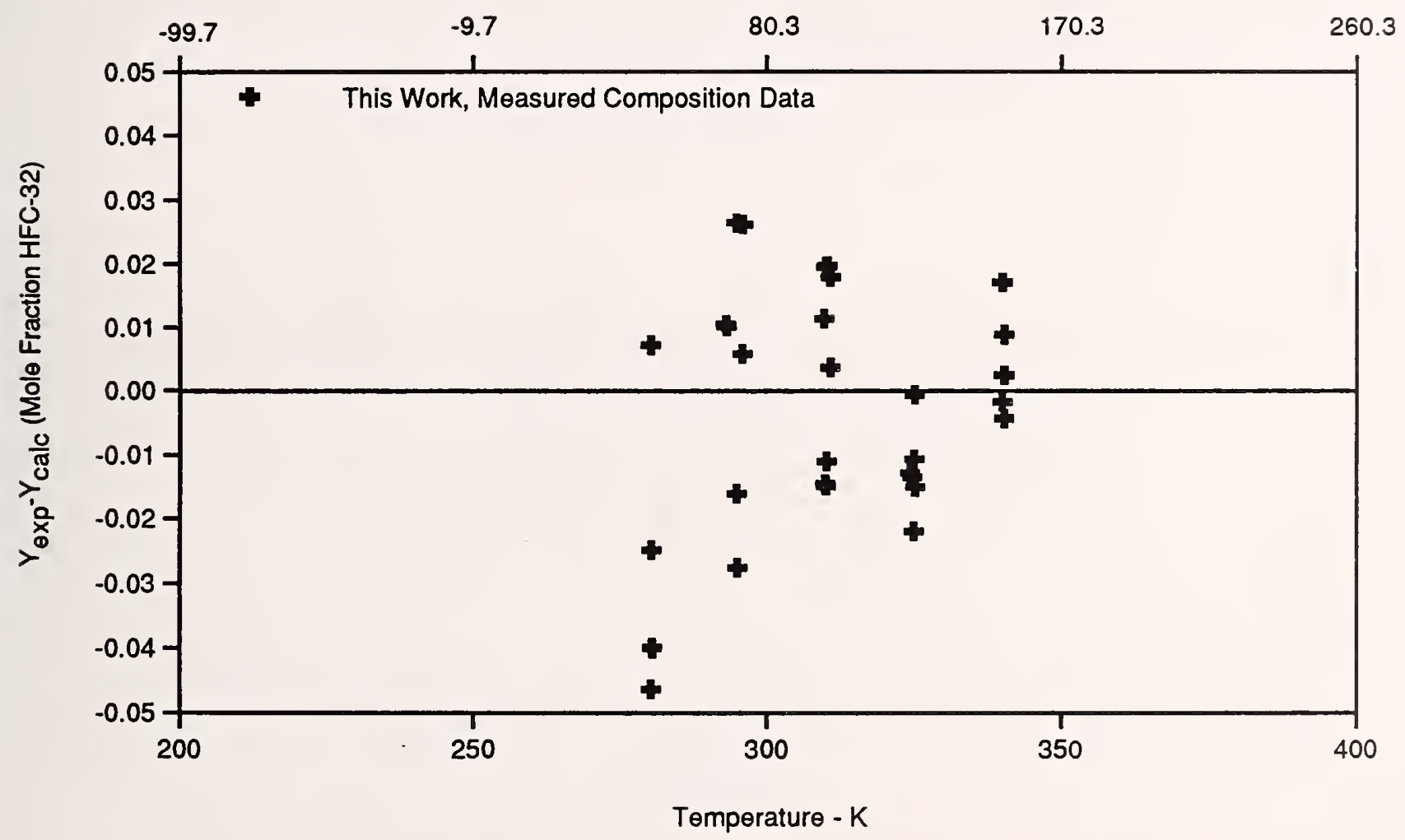

Figure 25. Comparison of Vapor Compositions for the R-32/290 System; the Baseline is from the Lemmon-Jacobsen Model in REFPROP 6.0. 


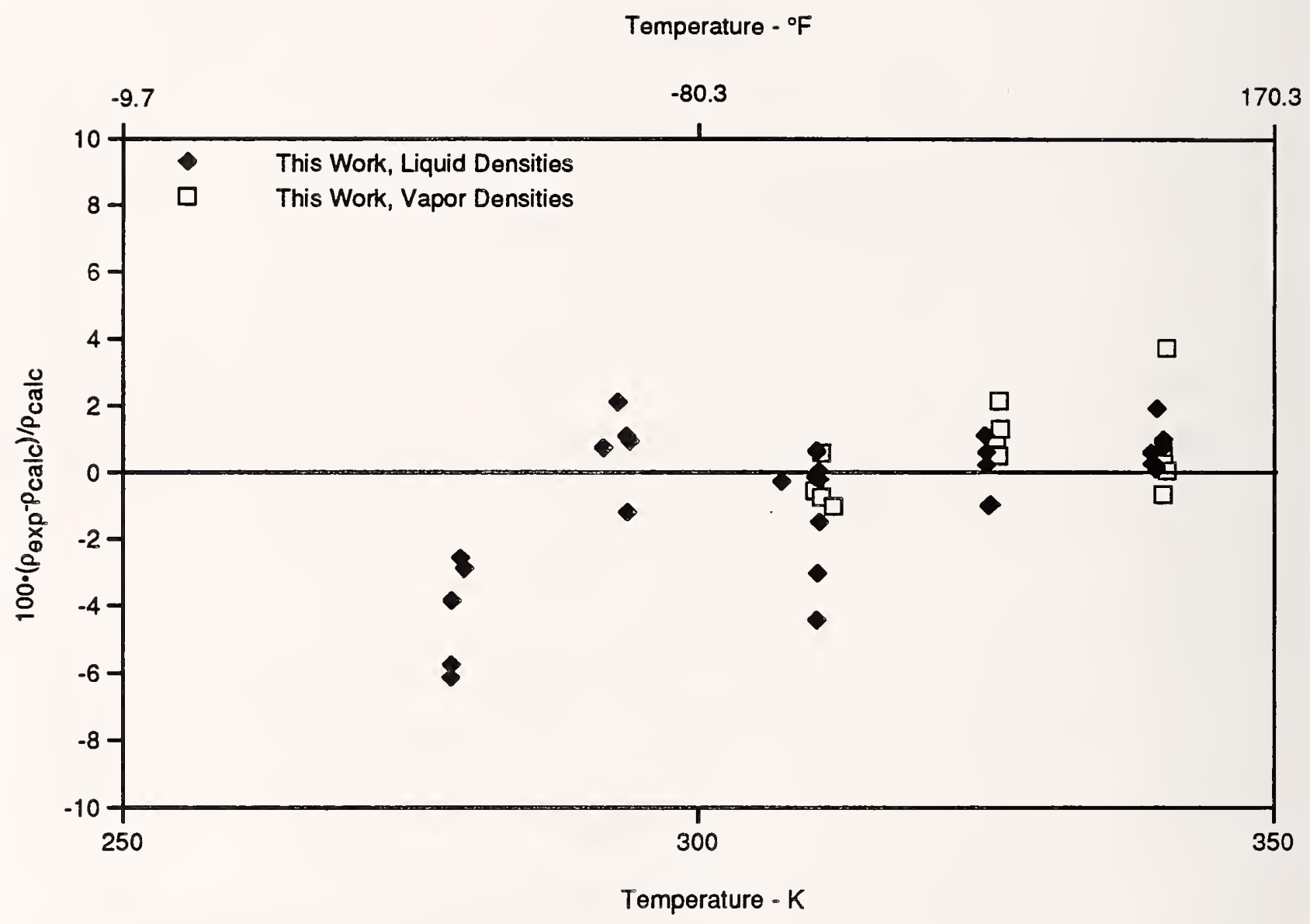

Figure 26. Comparison of Densities for the R-32/290 System; the Baseline is from the Lemmon-Jacobsen Model in REFPROP 6.0. 
Temperature $-{ }^{\circ} \mathrm{F}$

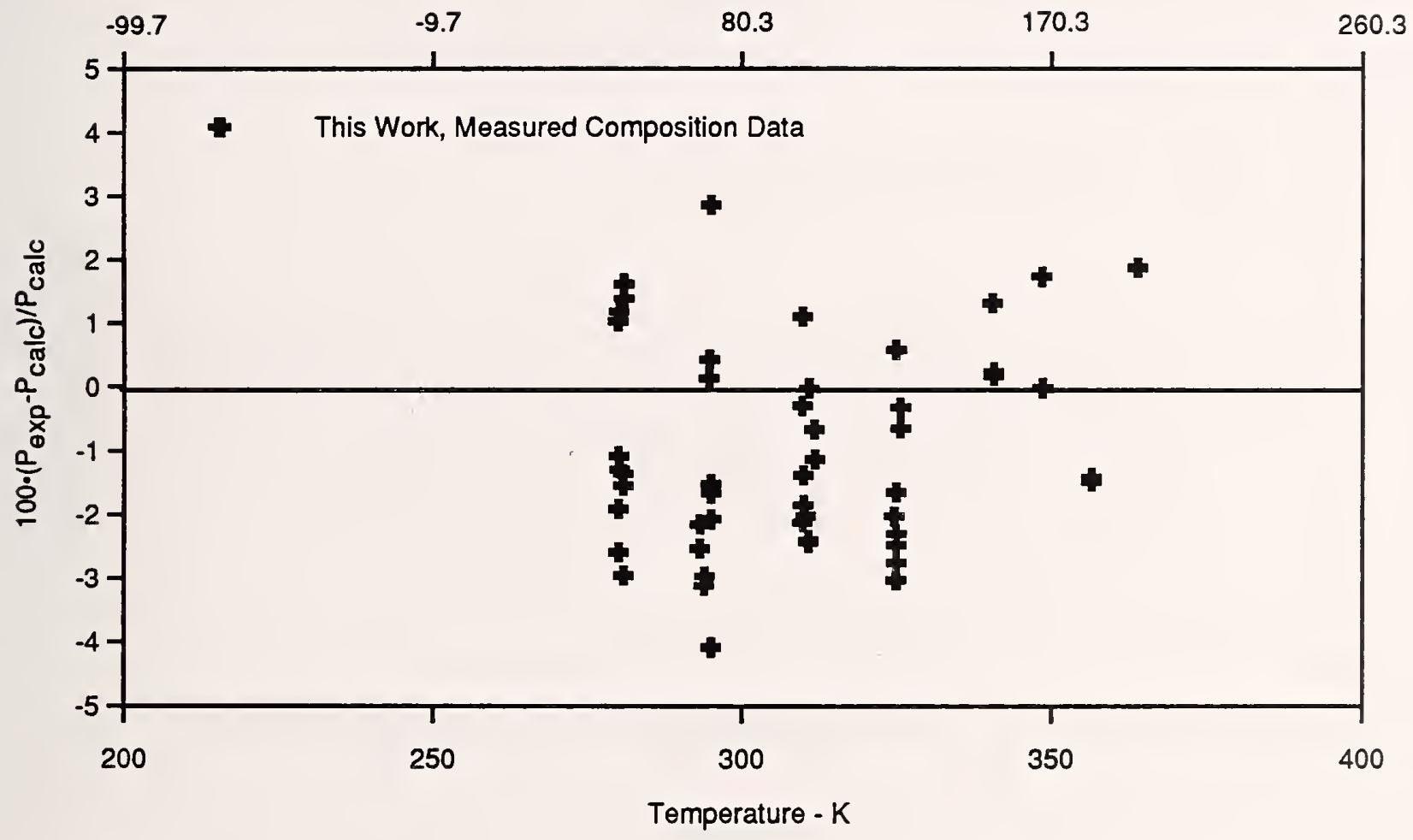

Figure 27. Comparison of Bubble-Point Pressures for the R-125/290 System; the Baseline is from the Lemmon-Jacobsen Model in REFPROP 6.0. 
Temperature - ${ }^{\circ} \mathrm{F}$

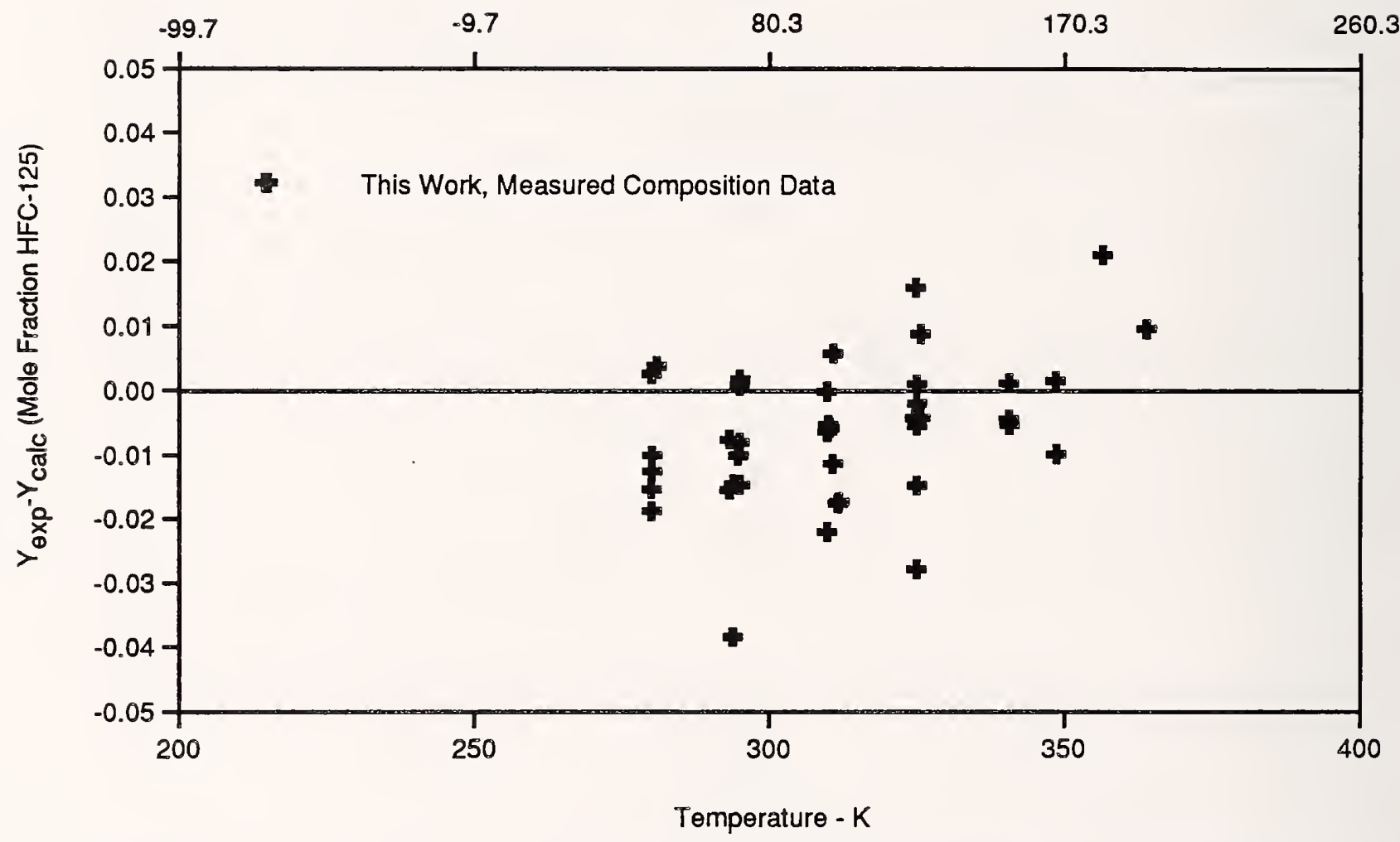

Figure 28. Comparison of Vapor Compositions for the R-125/290 System; the Baseline is from the Lemmon-Jacobsen Model in REFPROP 6.0. 
Temperature - ${ }^{\circ} \mathrm{F}$

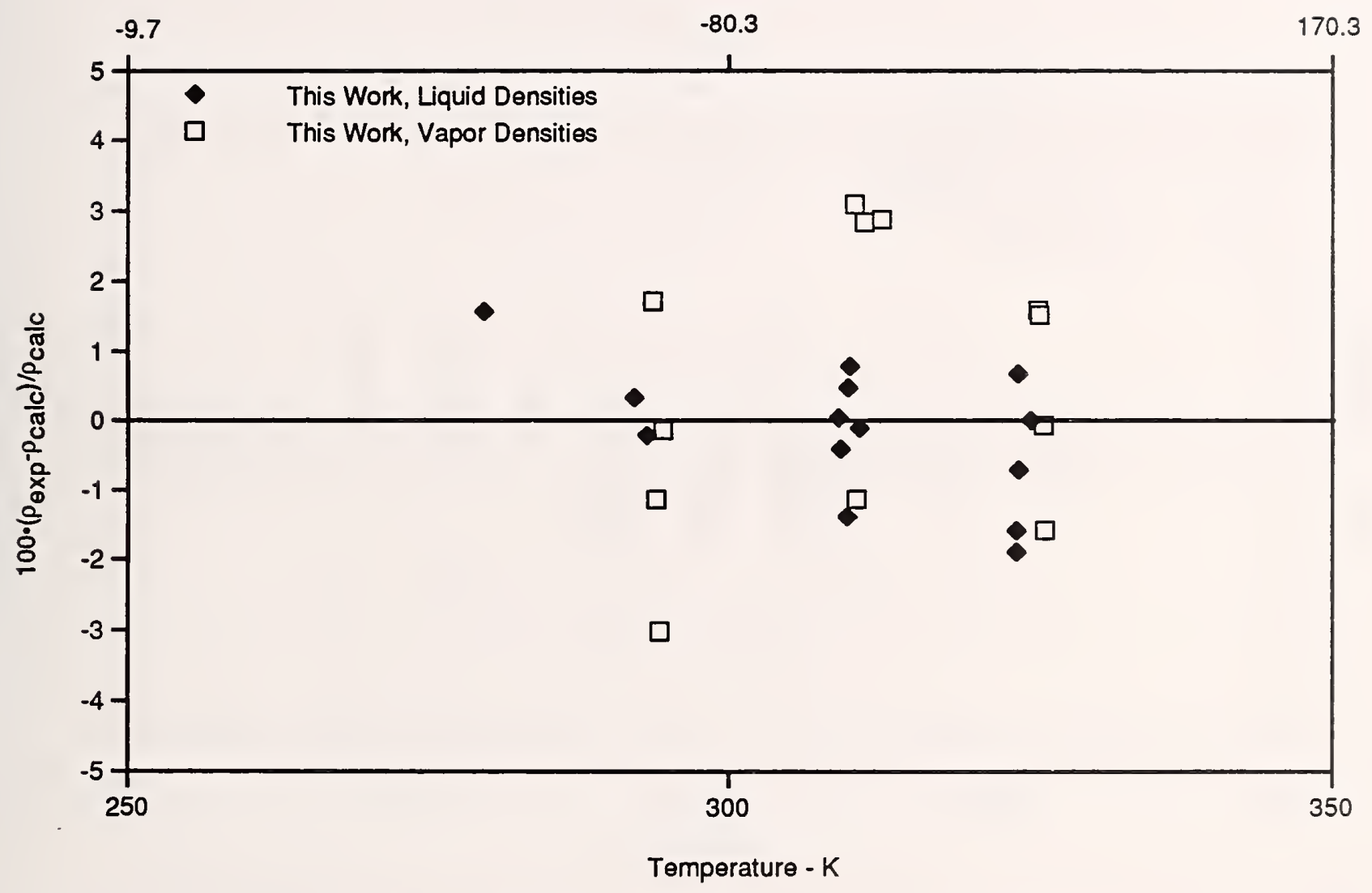

Figure 29. Comparison of Densities for the R-125/290 System; the Baseline is from the .Lemmon-Jacobsen Model in REFPROP 6.0. 


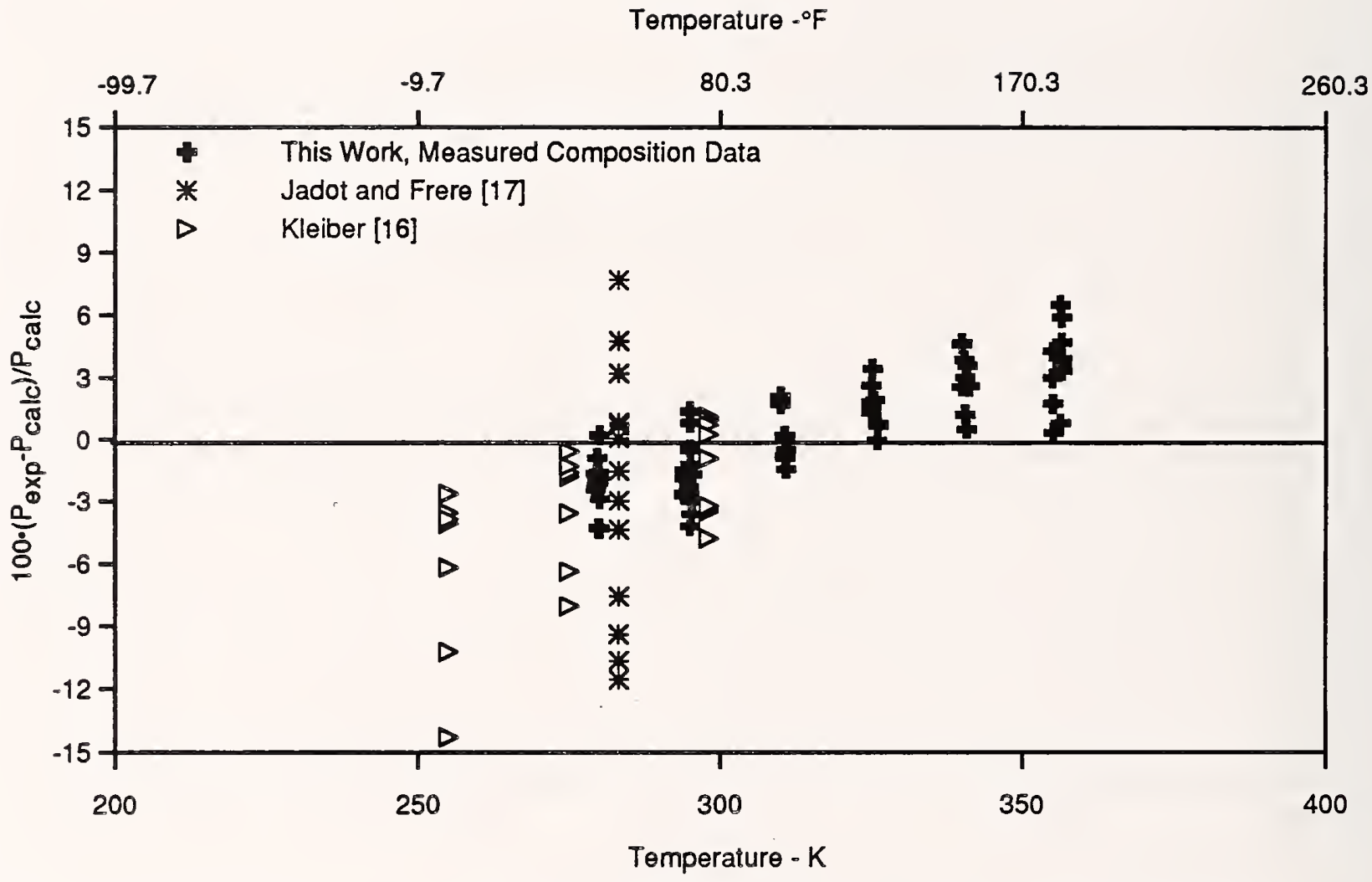

Figure 30. Comparison of Bubble-Point Pressures for the R-134a/290 System; the Baseline is from the Lemmon-Jacobsen Model in REFPROP 6.0. 


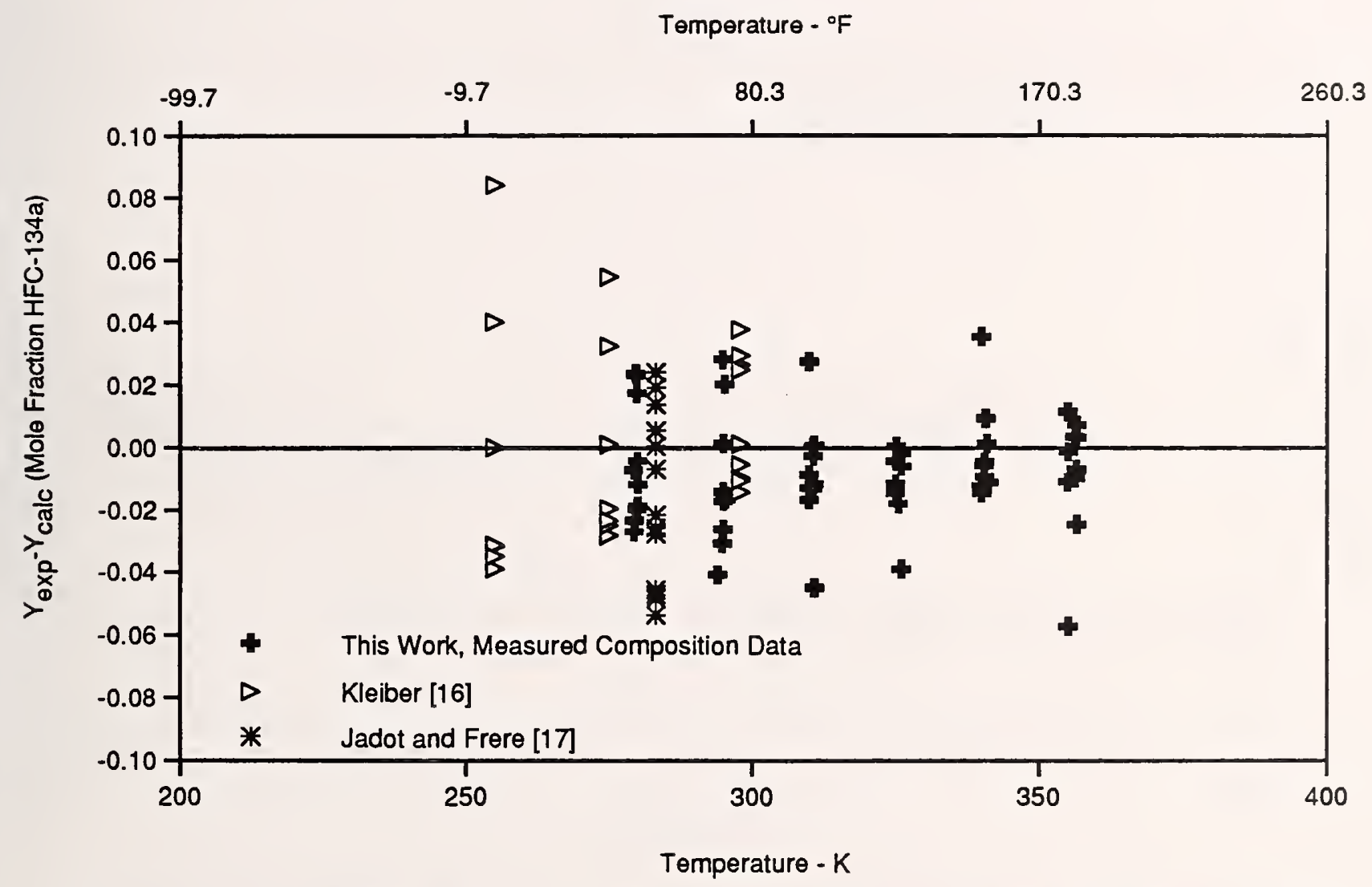

Figure 31. Comparison of Vapor Compositions for the R-134a/290 System; the Baseline is from the Lemmon-Jacobsen Model in REFPROP 6.0. 


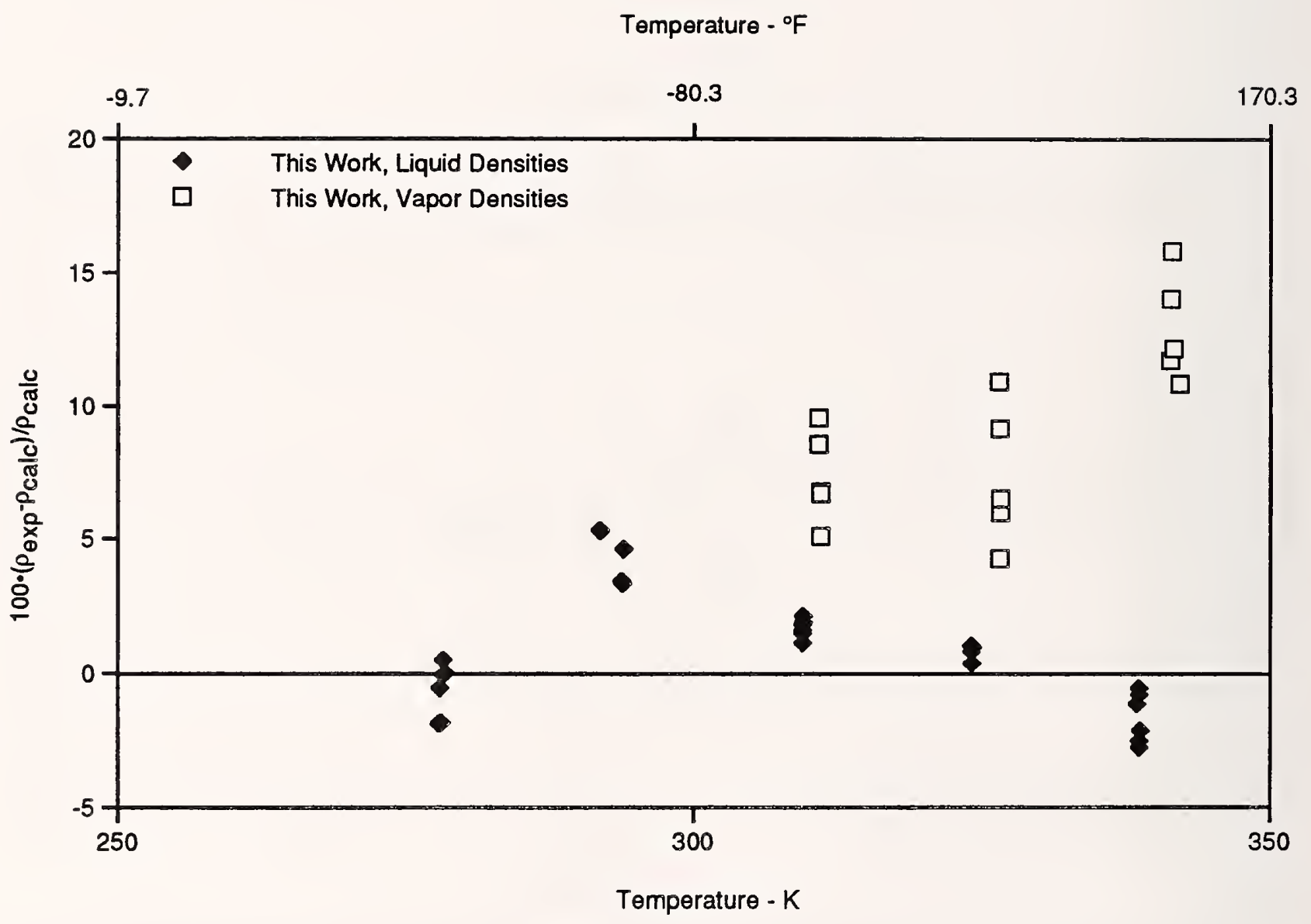

Figure 32. Comparison of Densities for the R-134a/290 System; the Baseline is from the Lemmon-Jacobsen Model in REFPROP 6.0. 


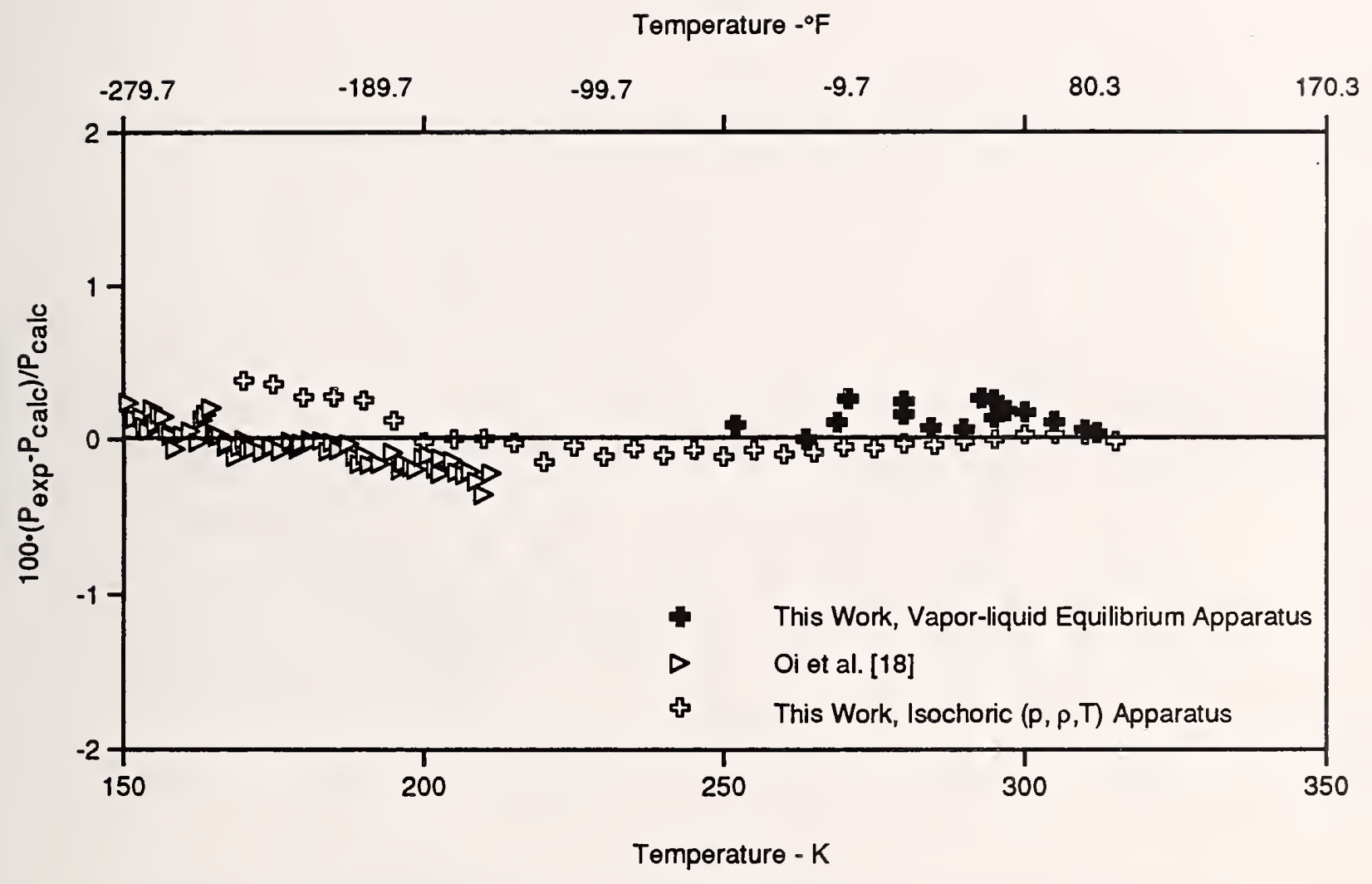

Figure 33. Comparison of Vapor Pressures for R-41; the Baseline is from Equation (1). 
Temperature - ${ }^{\circ} \mathrm{F}$

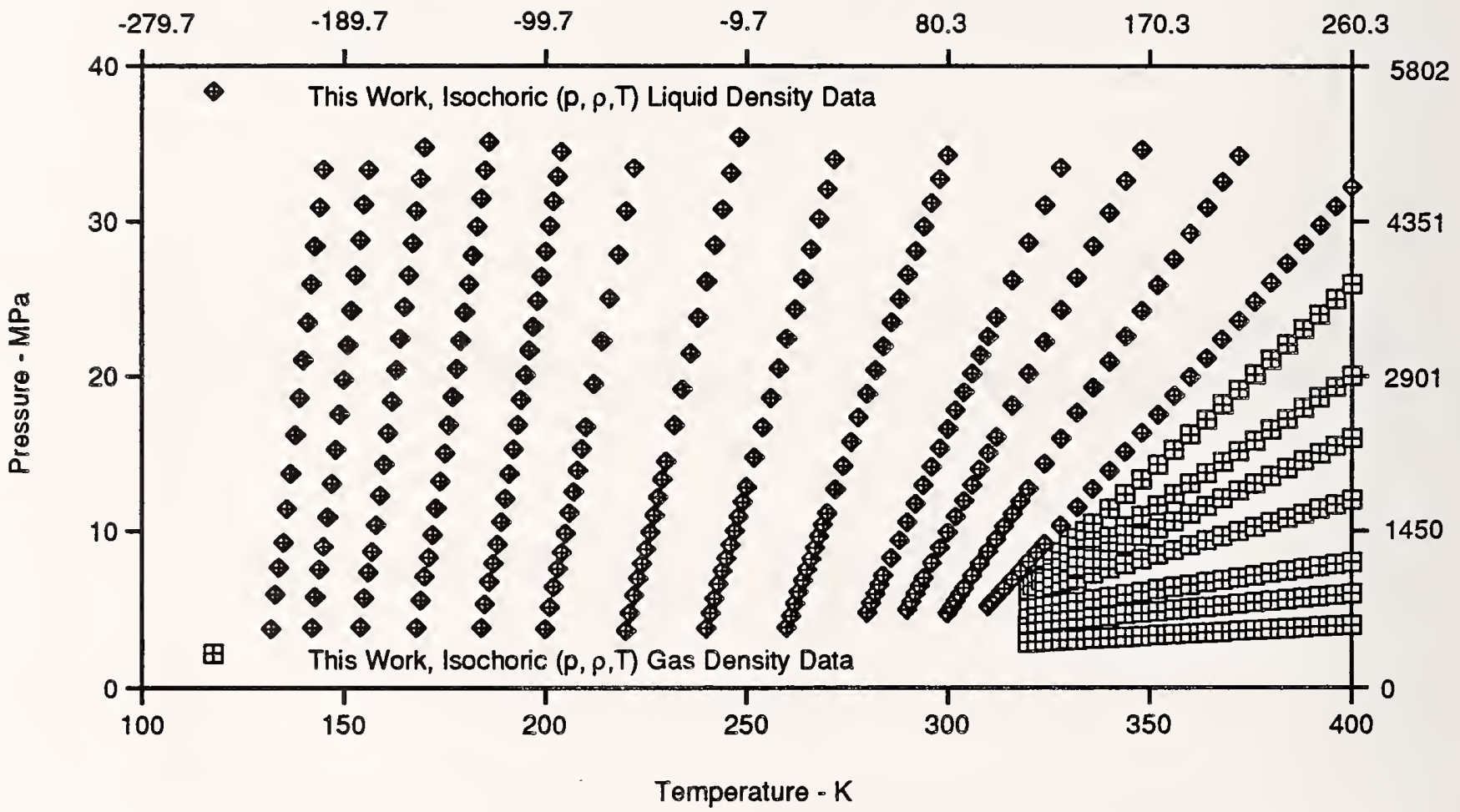

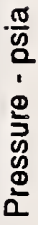

Figure 34. Range of Measured Temperatures and Pressures for Isochoric $(p \rho, T)$ Data for R-41. 
Temperature $-{ }^{\circ} \mathrm{F}$

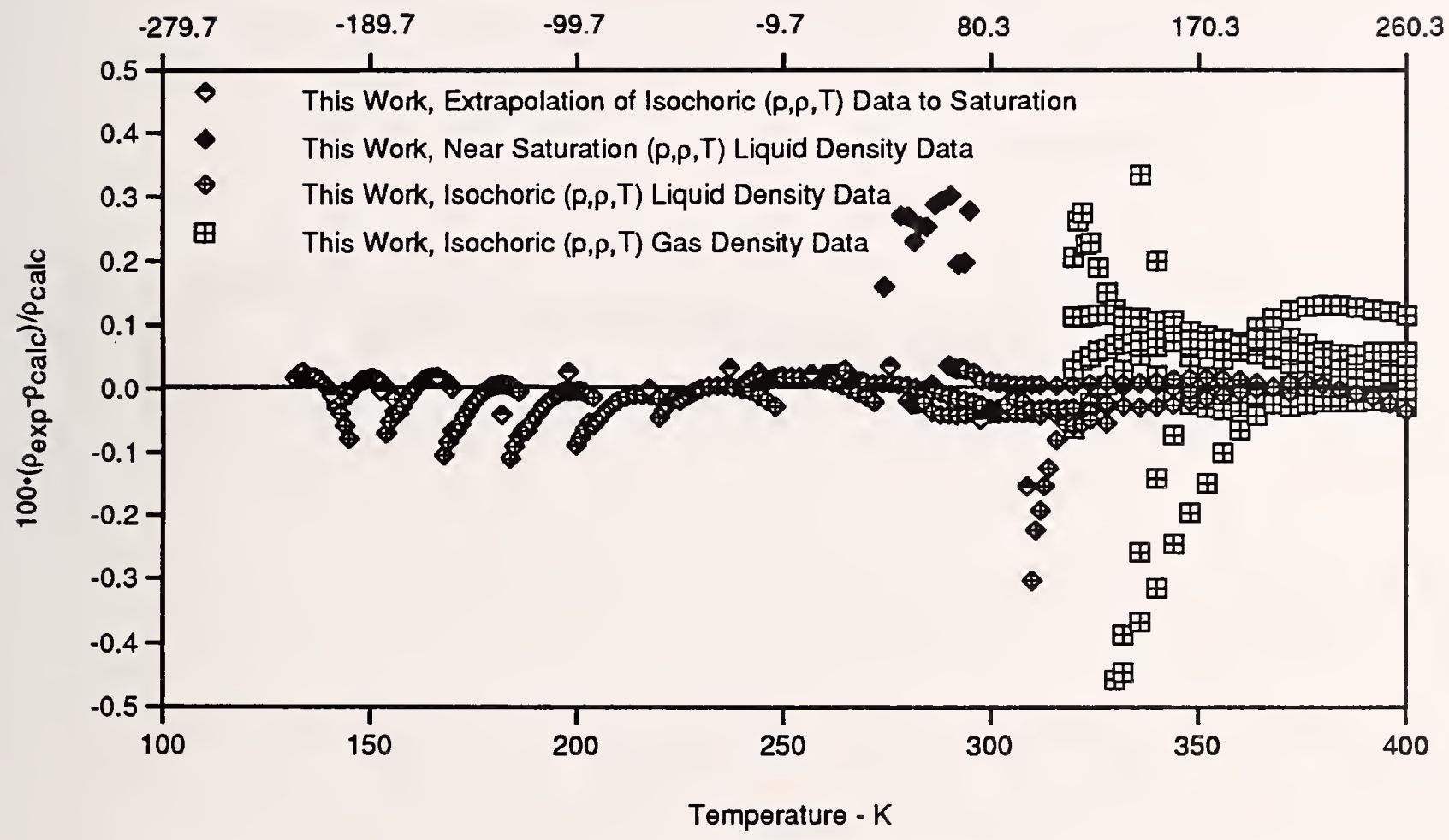

Figure 35. Comparison of Densities for R-41; the Baseline is from the MBWR Equation of State in REFPROP 6.0. 


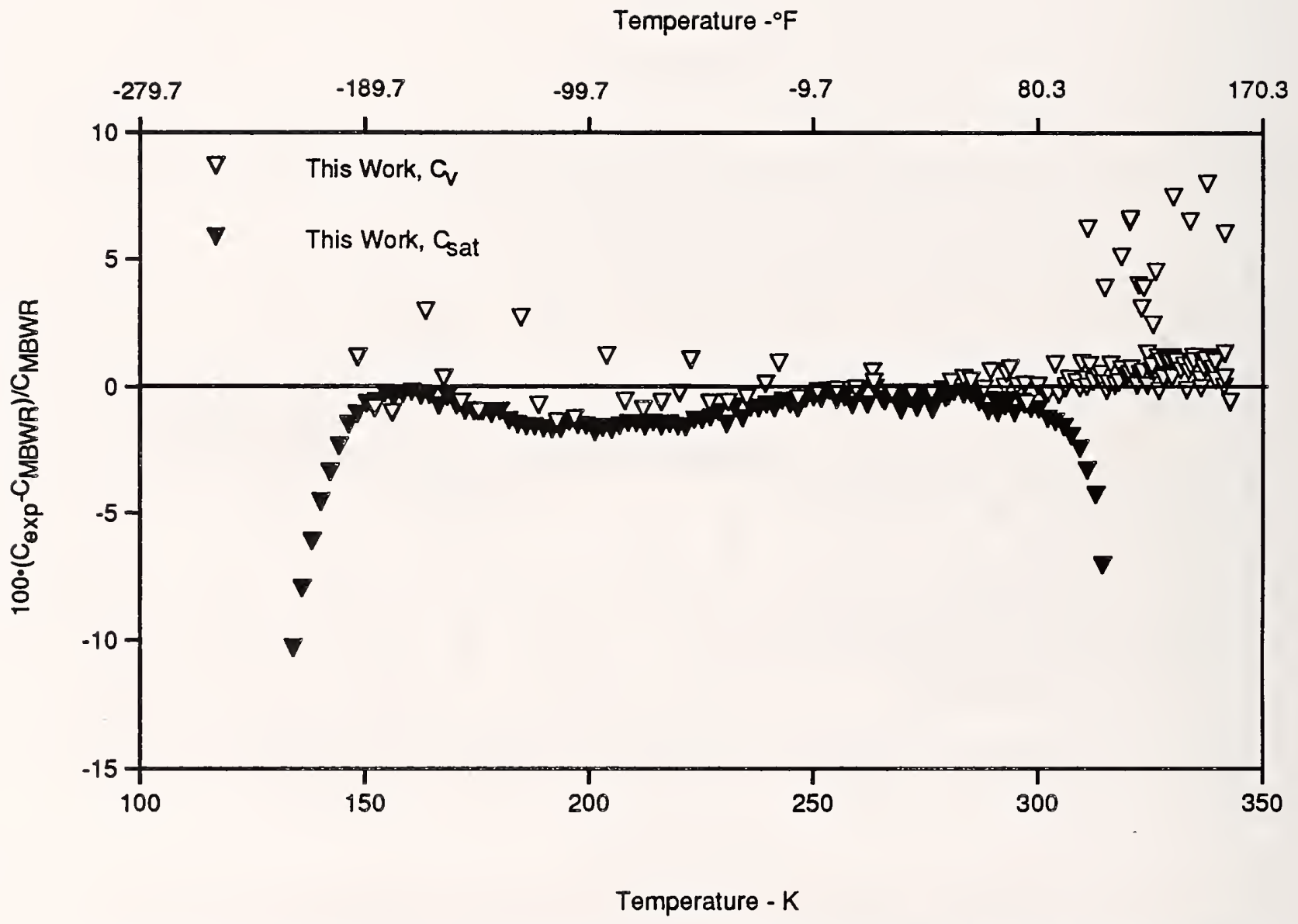

Figure 36. Comparison of the Isochoric Heat Capacity Data at Saturation and in the Single-Phase Liquid Region for R-41; the Baseline is from the MBWR Equation of State in REFPROP 6.0 . 
Temperature - ${ }^{\circ} \mathrm{F}$

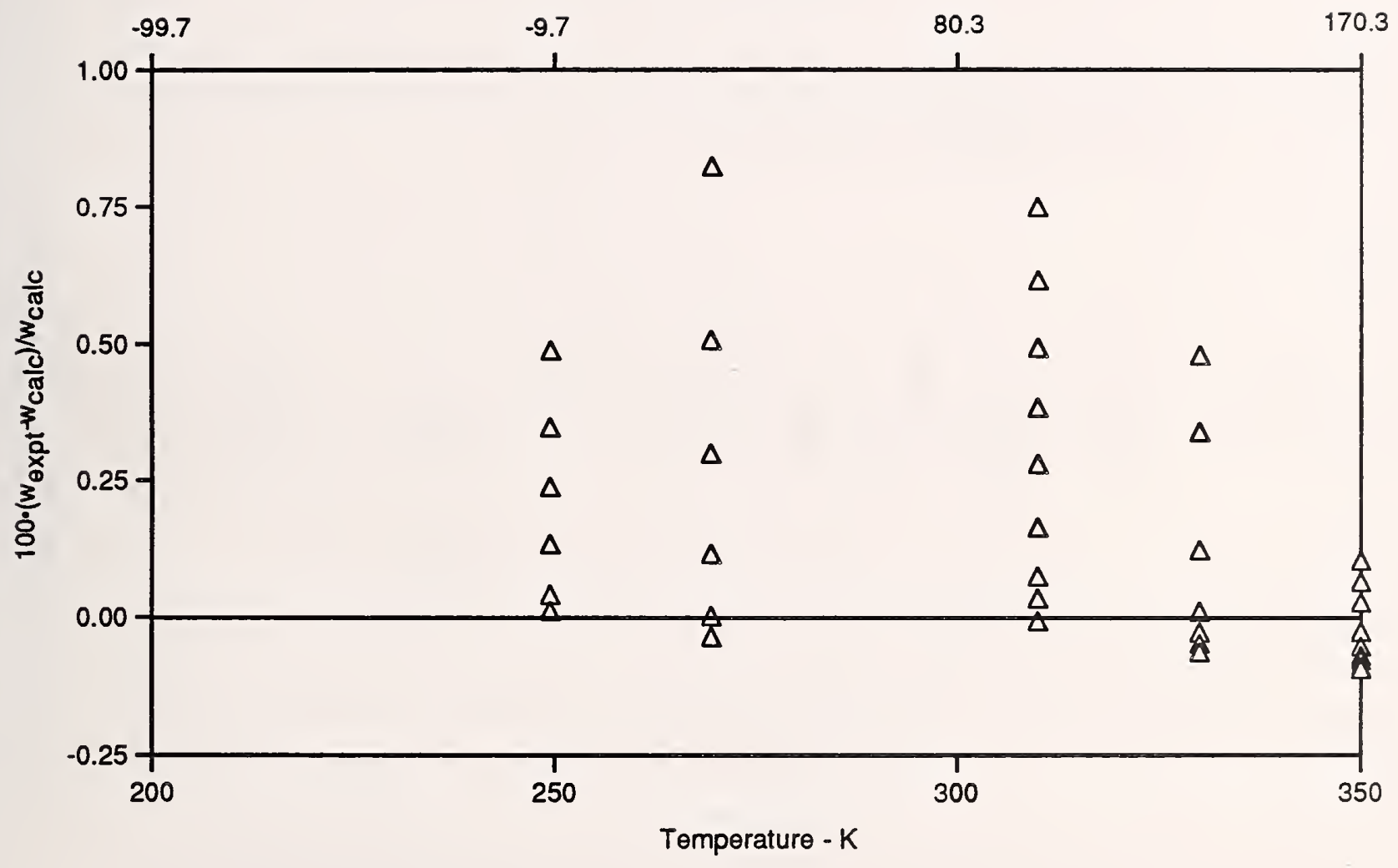

Figure 37. Comparison of the Vapor Speed of Sound Data for R-41; the Baseline is from the MBWR Equation of State in REFPROP 6.0. 
Temperature $-^{\circ} \mathrm{F}$

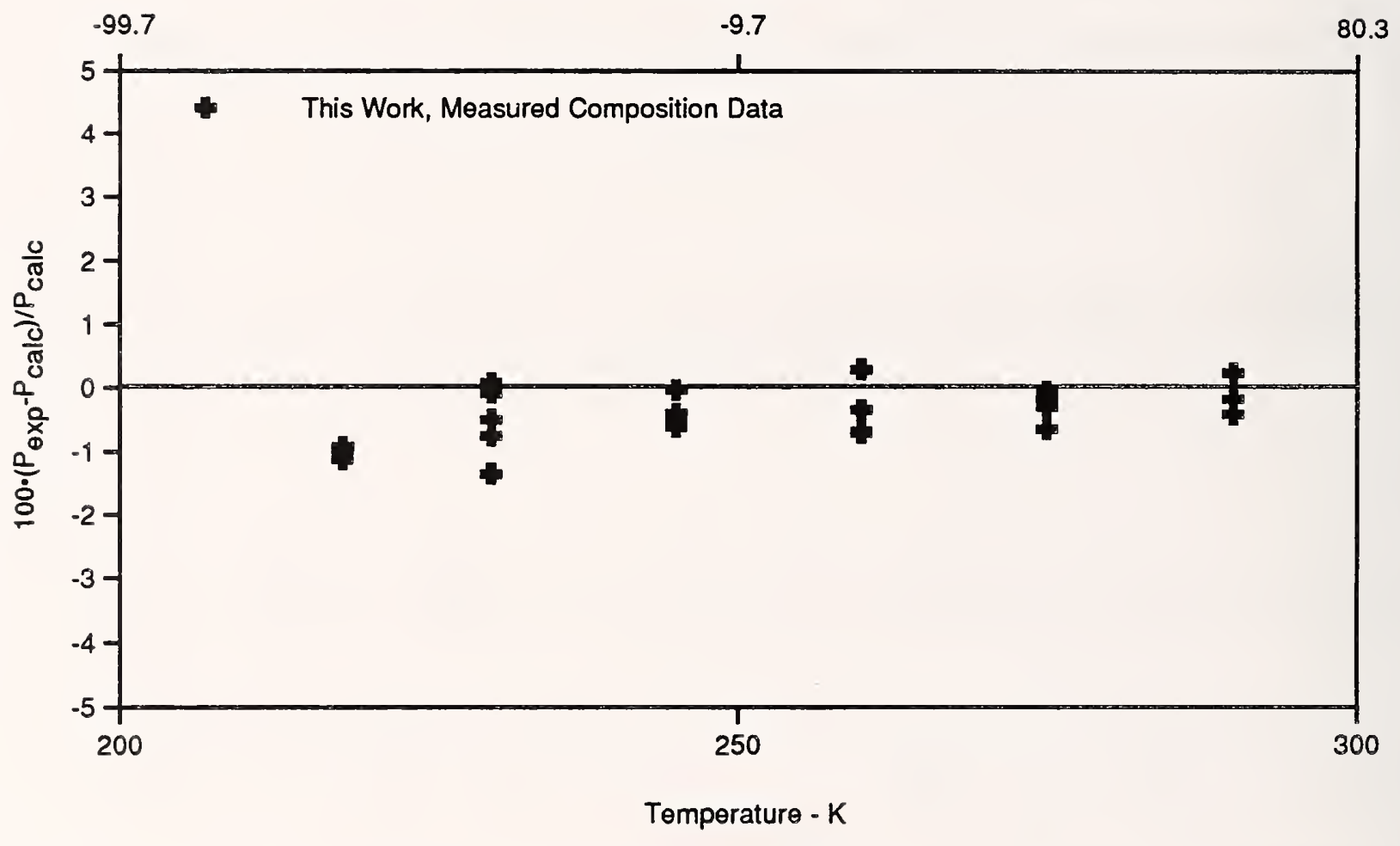

Figure 38. Comparison of Bubble-Point Pressures for the R-41/744 System; the Baseline is from the Lemmon-Jacobsen Model in REFPROP 6.0. 
Temperature - ${ }^{\circ} \mathrm{F}$

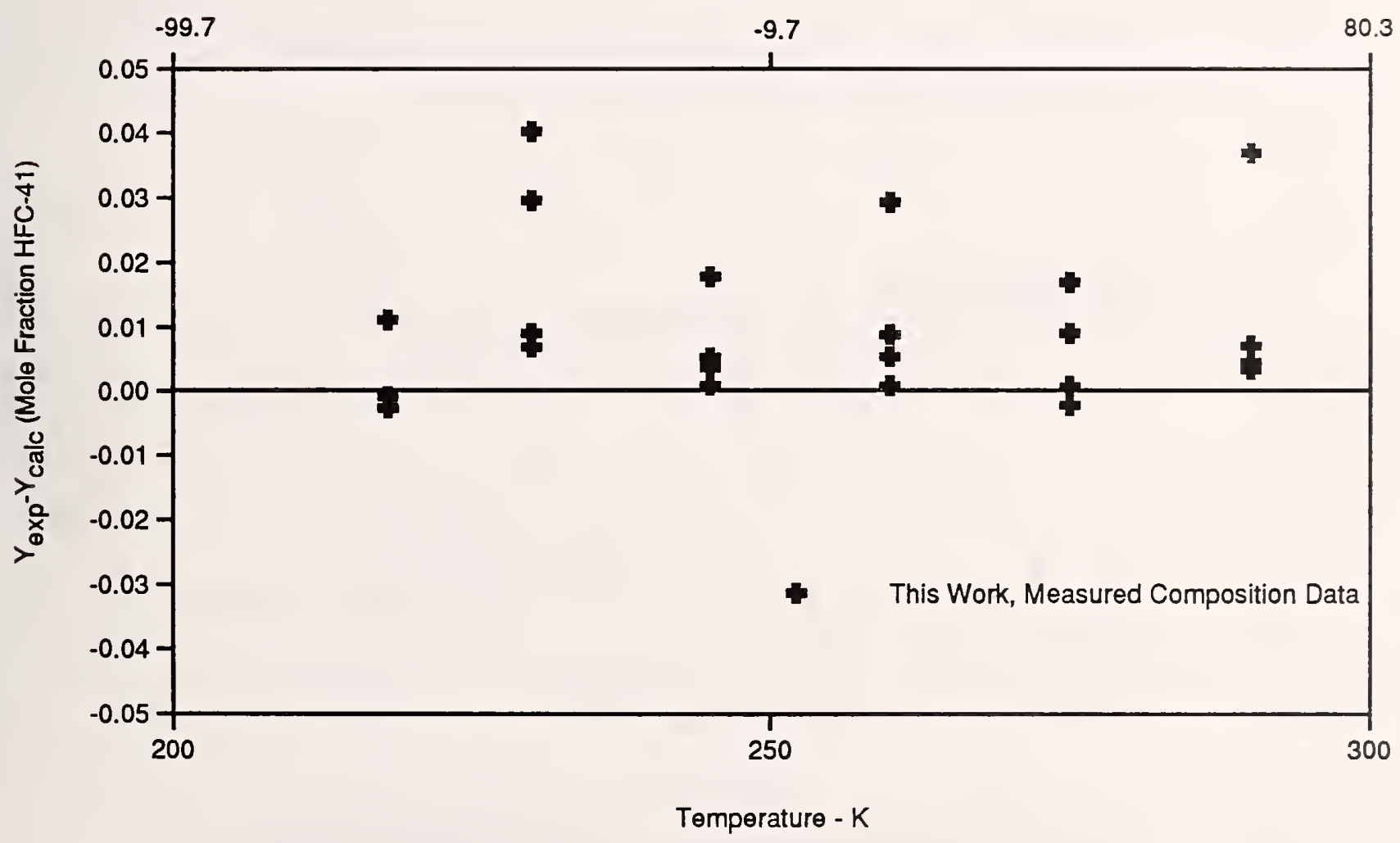

Figure 39. Comparison of Vapor Compositions for the R-41/744 System; the Baseline is from the Lemmon-Jacobsen Model in REFPROP 6.0. 


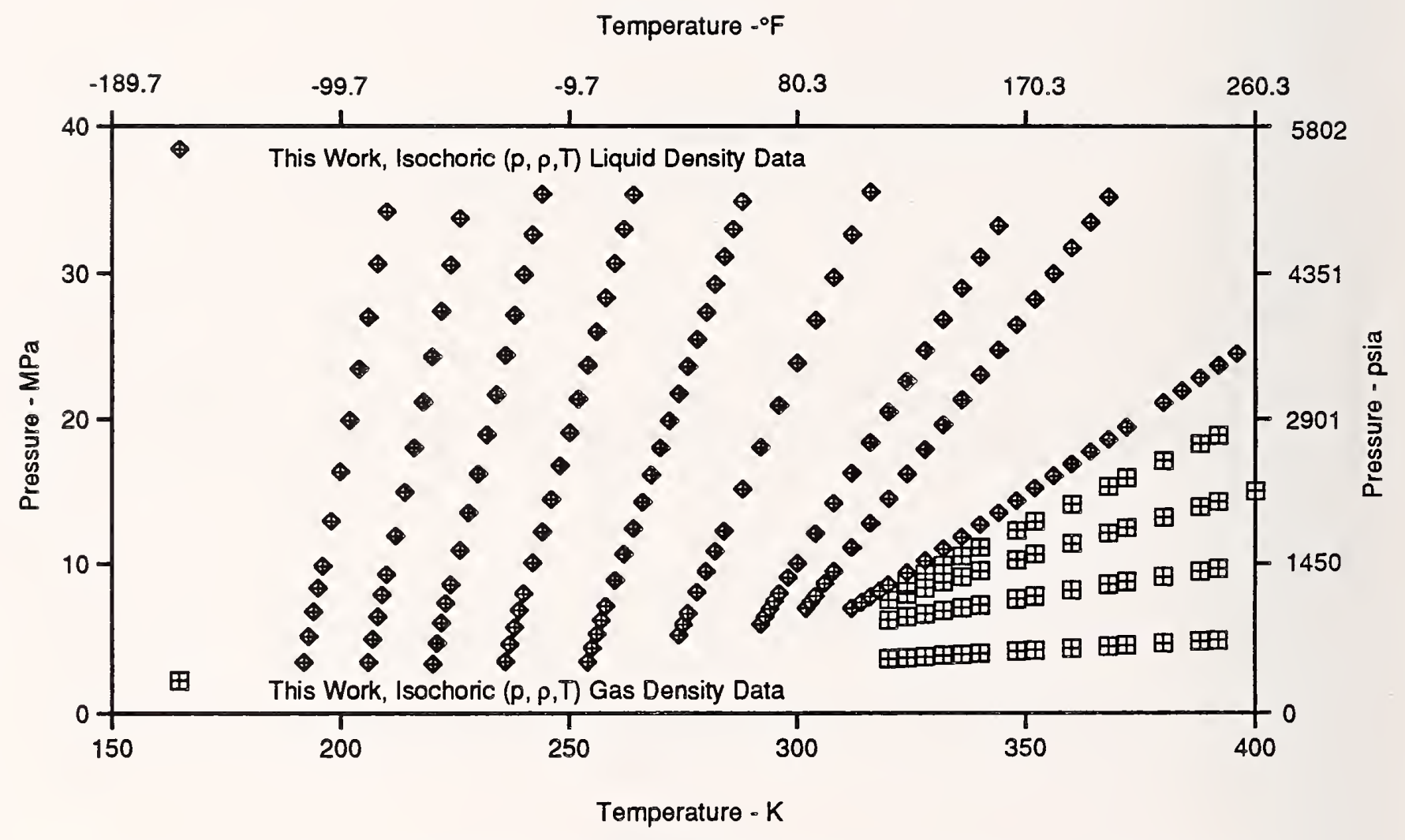

Figure 40. Range of Measured Temperatures and Pressures for Isochoric $(p, \rho, T)$ Data for a Mixture of R-41/744 with $\times(R-41)=0.49982$ Mole Fraction (0.43591 Mass Fraction). 


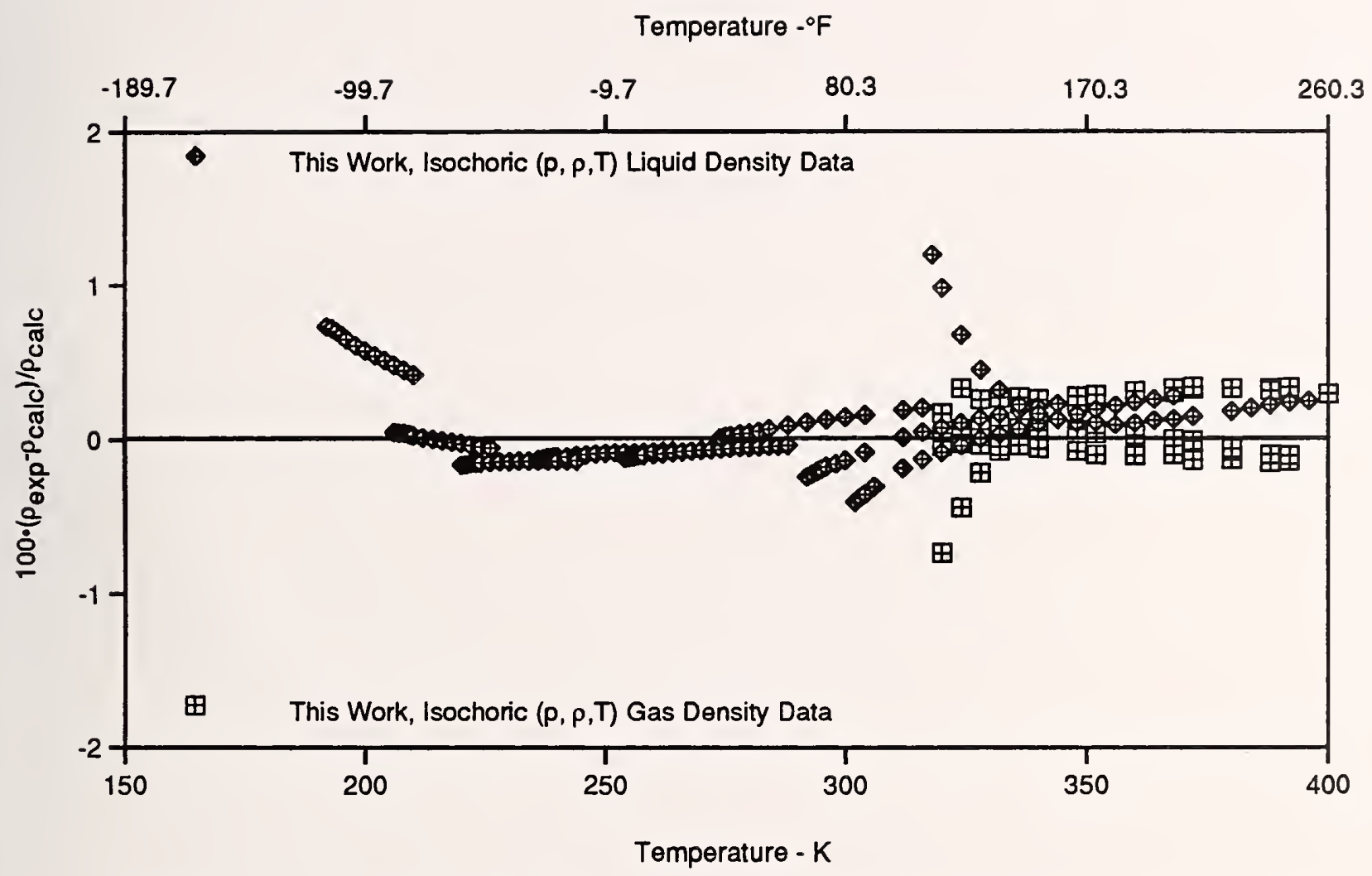

Figure 41. Comparison of Isochoric $(p p, T)$ Data for the Equimolar Mixture of R-41/744; the Baseline is from the Lemmon-Jacobsen Model in REFPROP 6.0. 


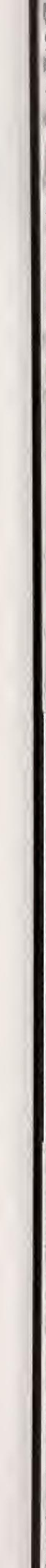


APPENDIX A:

TABLES OF THERMOPHYSICAL PROPERTY DATA 


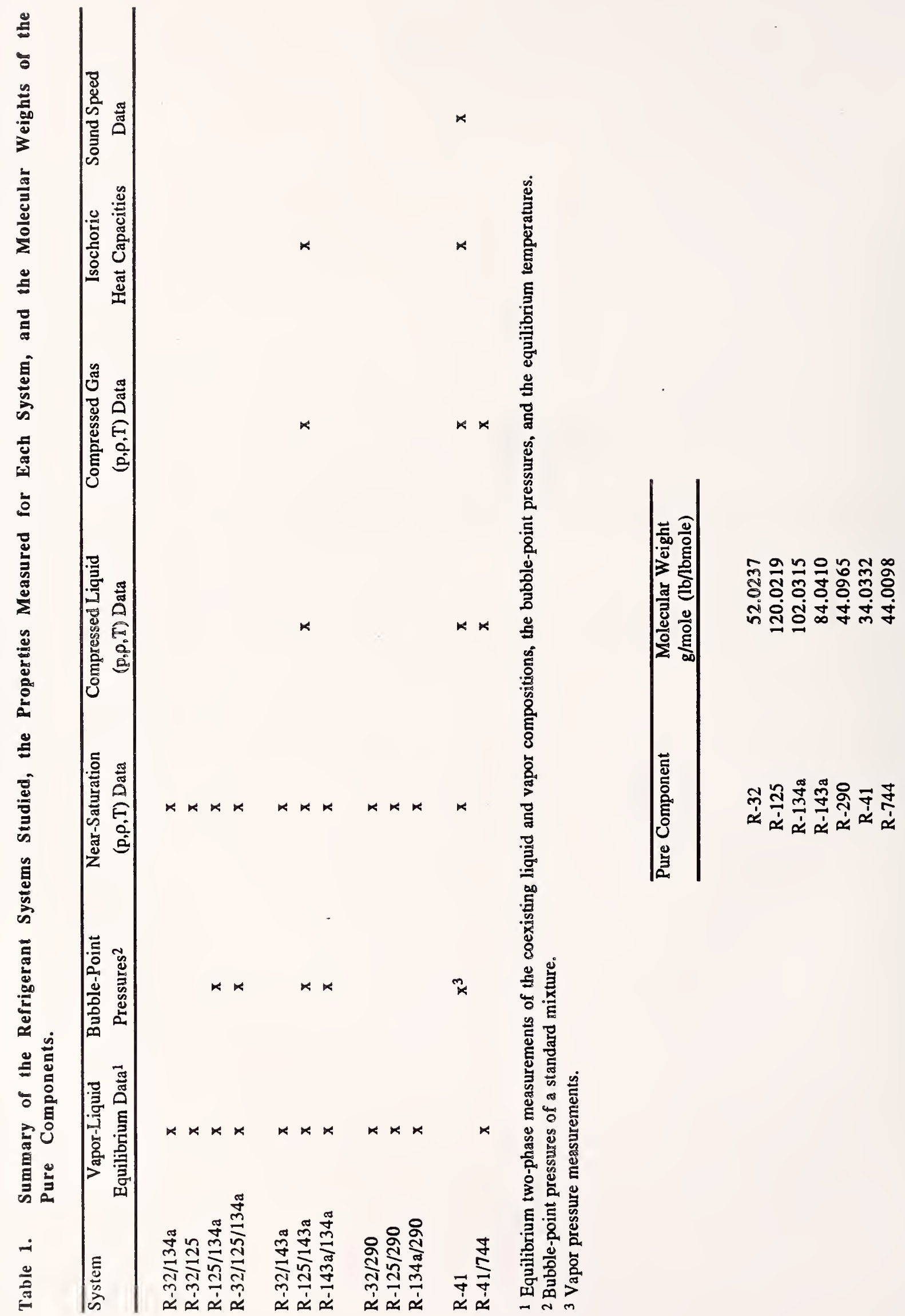




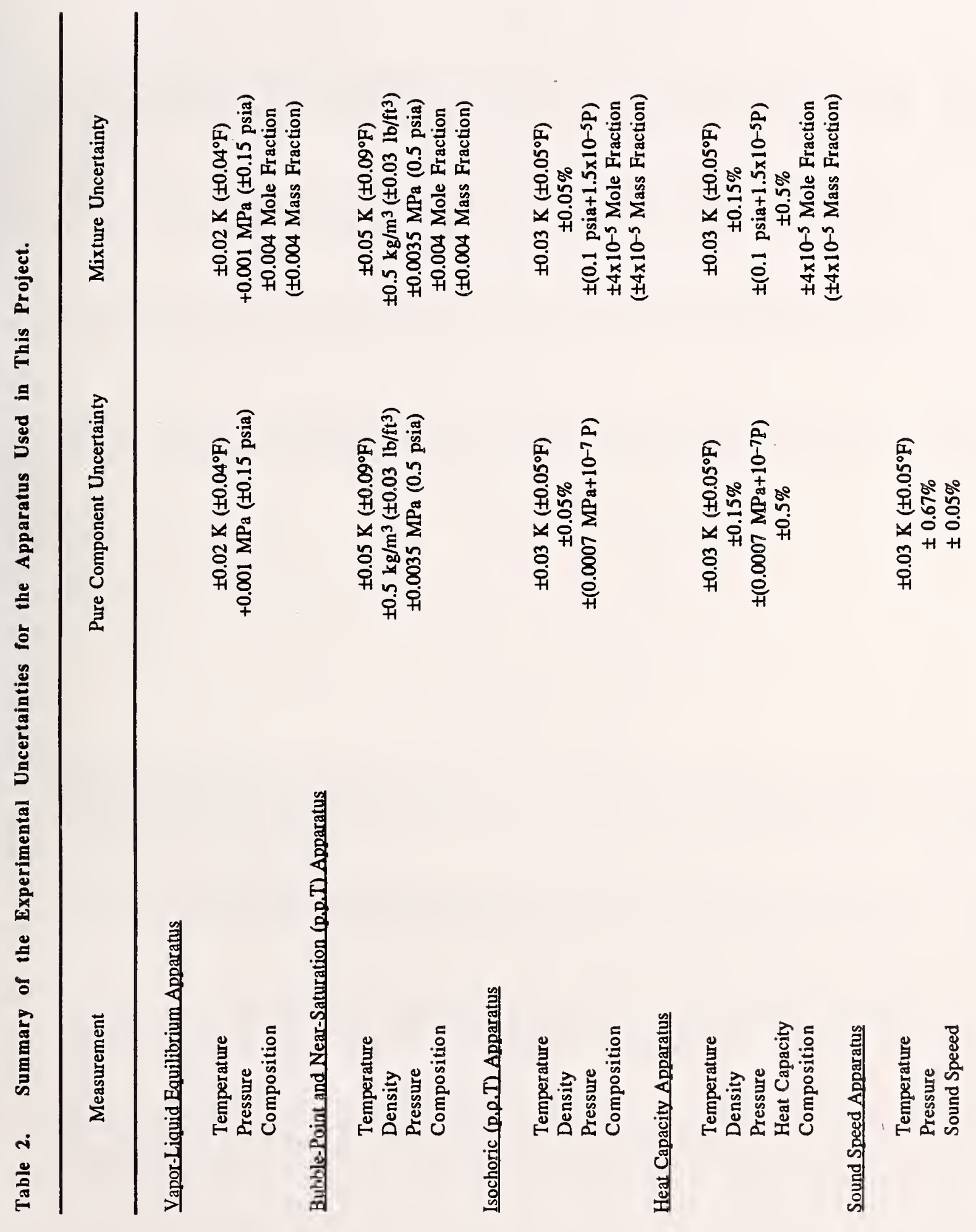




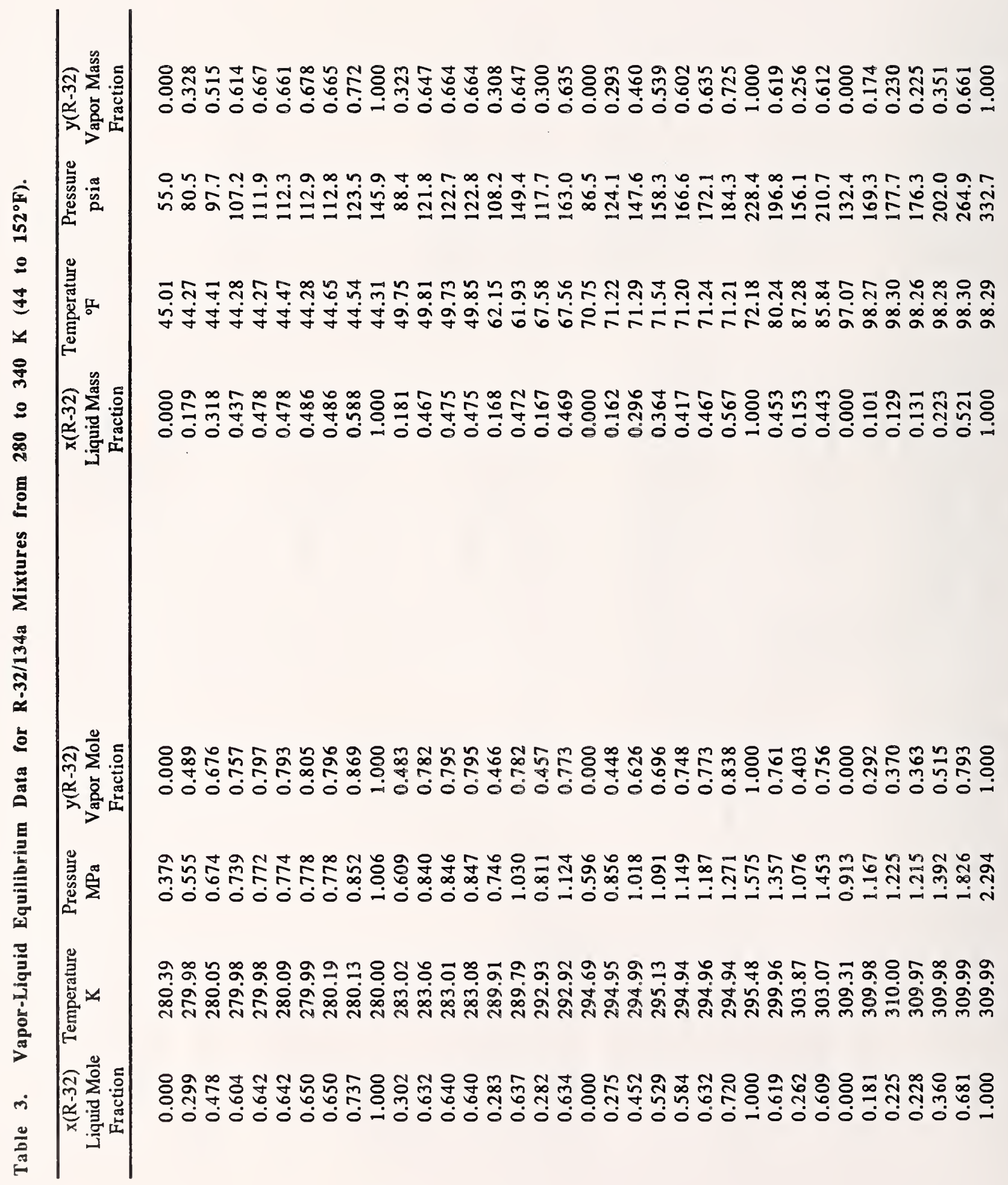




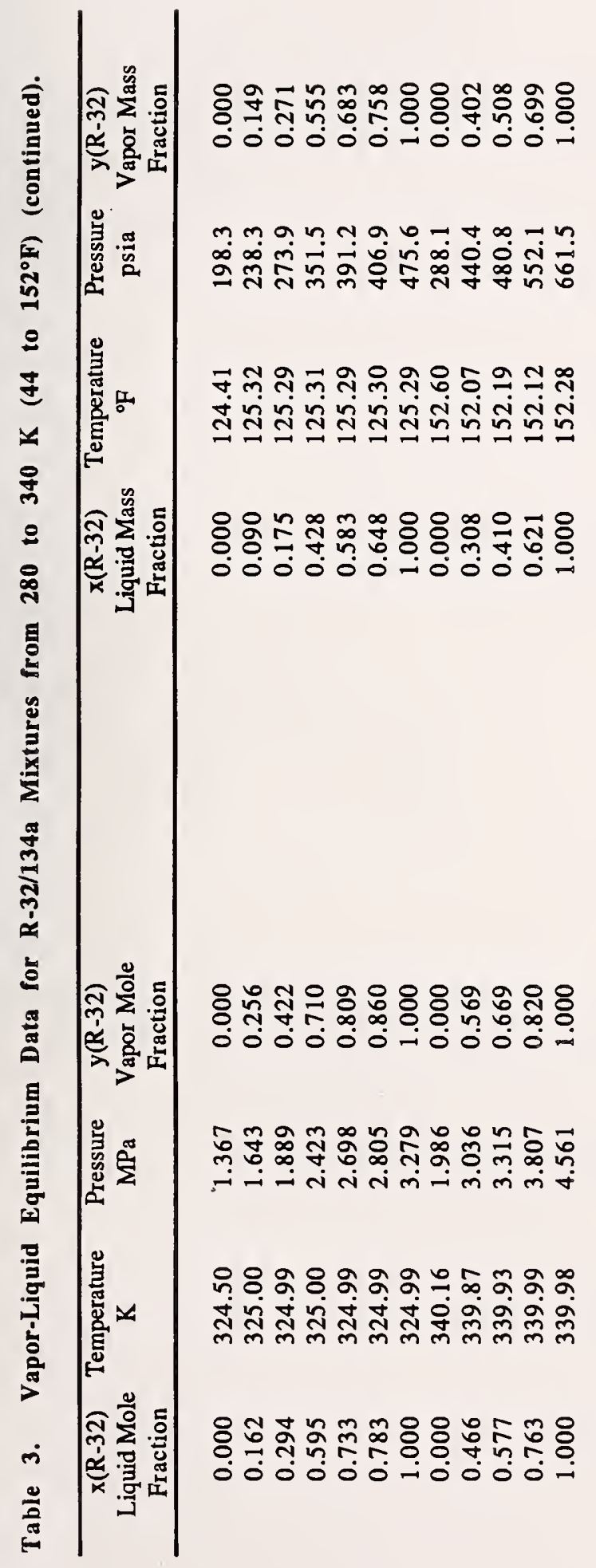




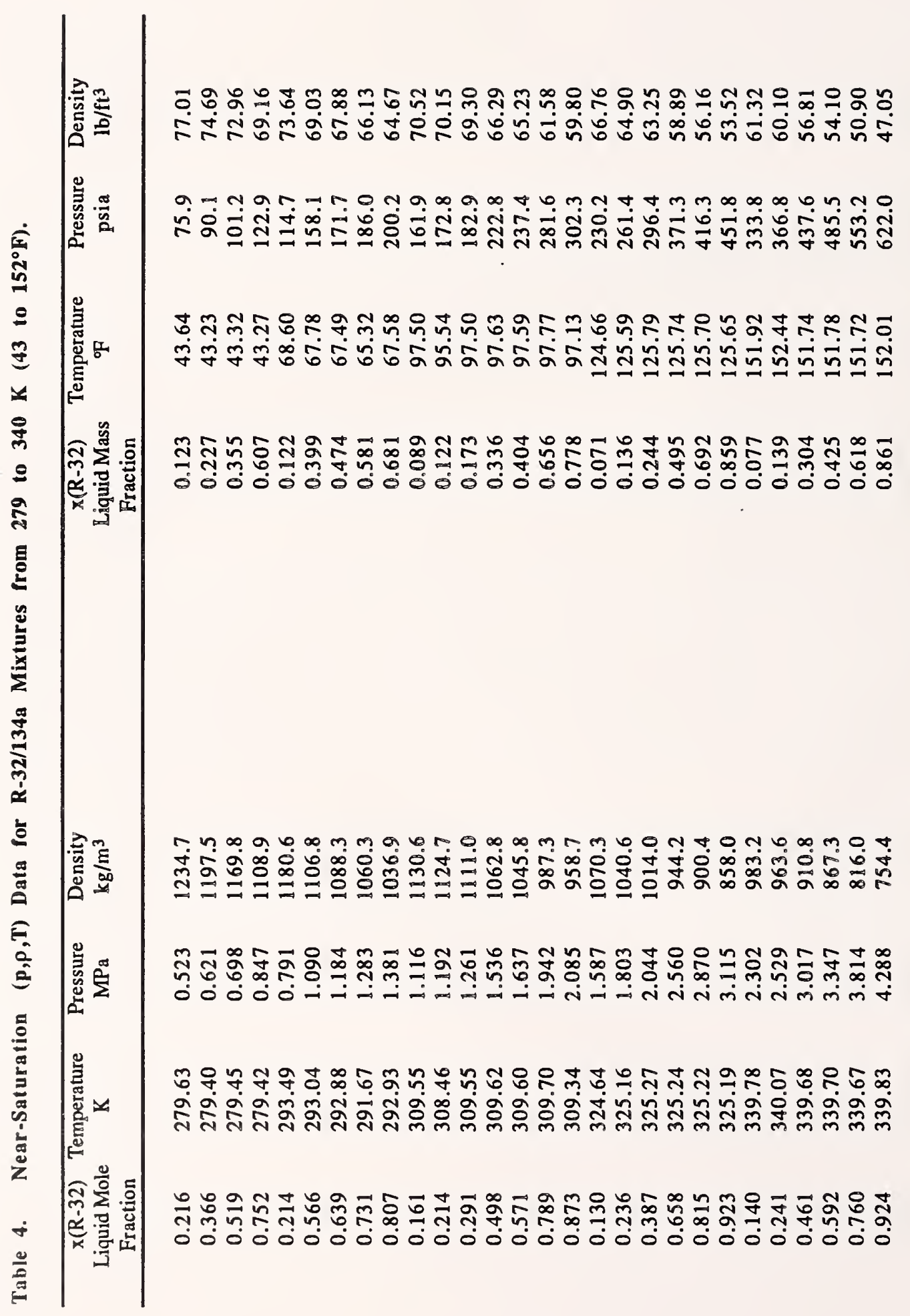




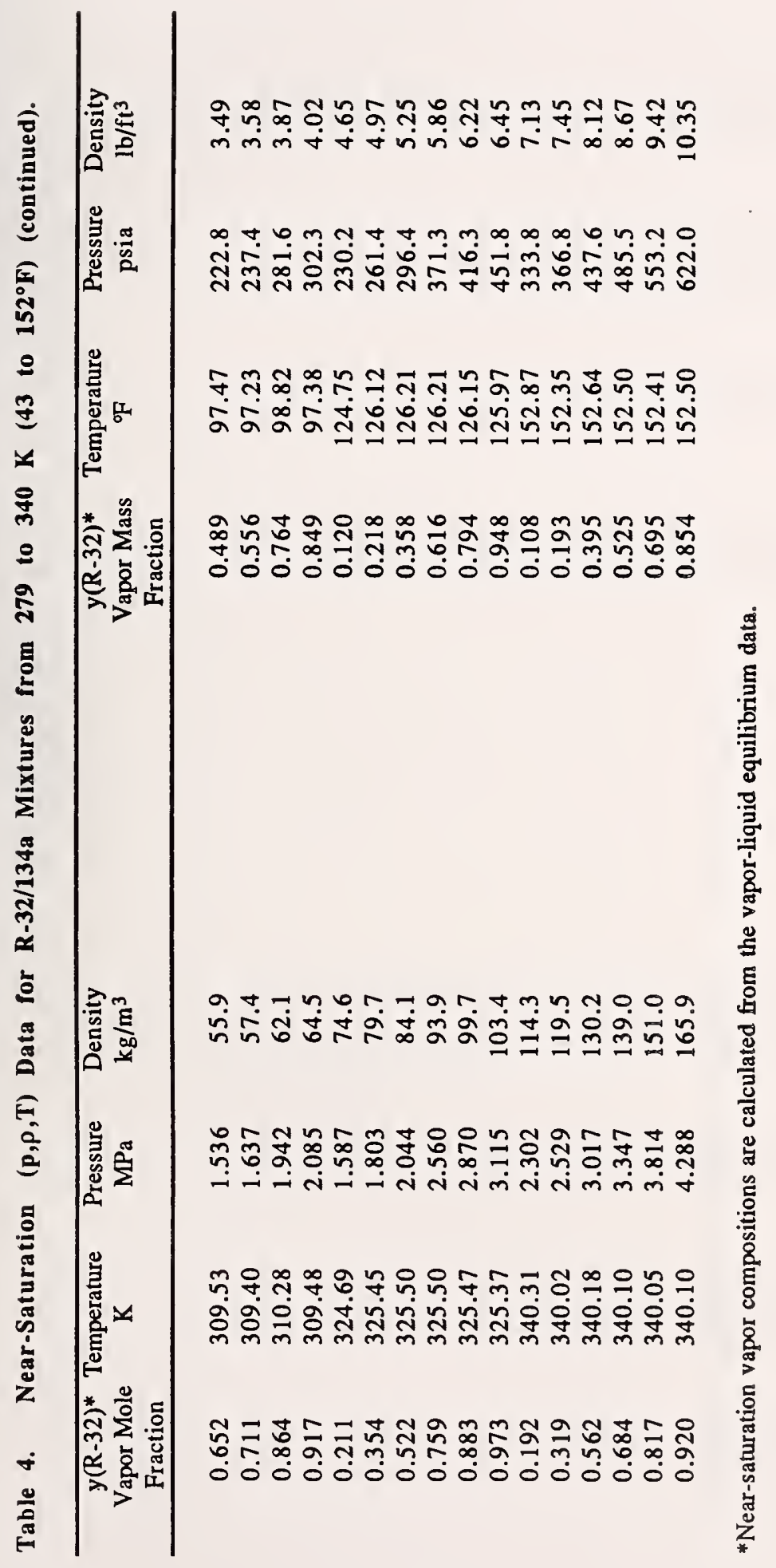




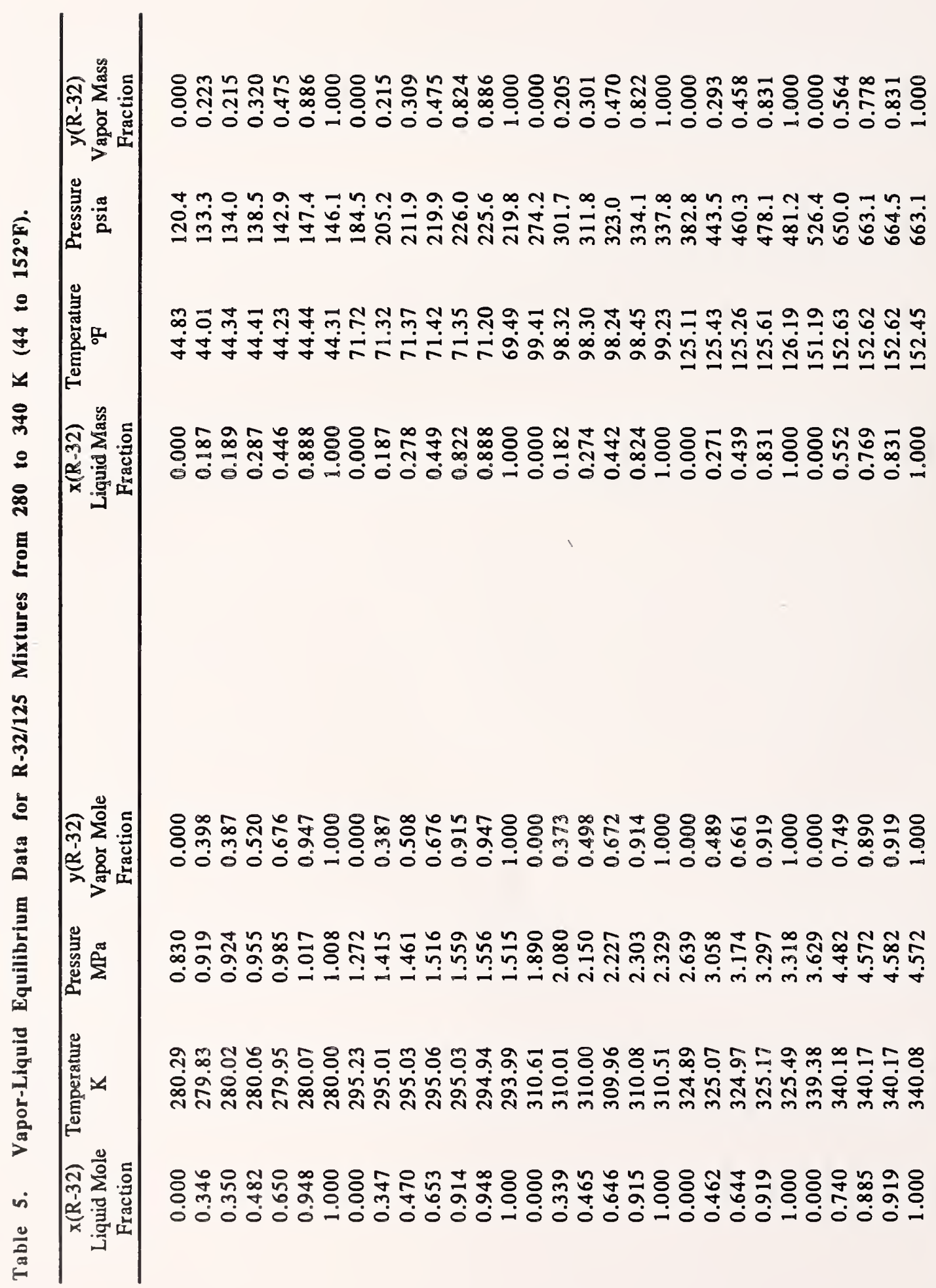




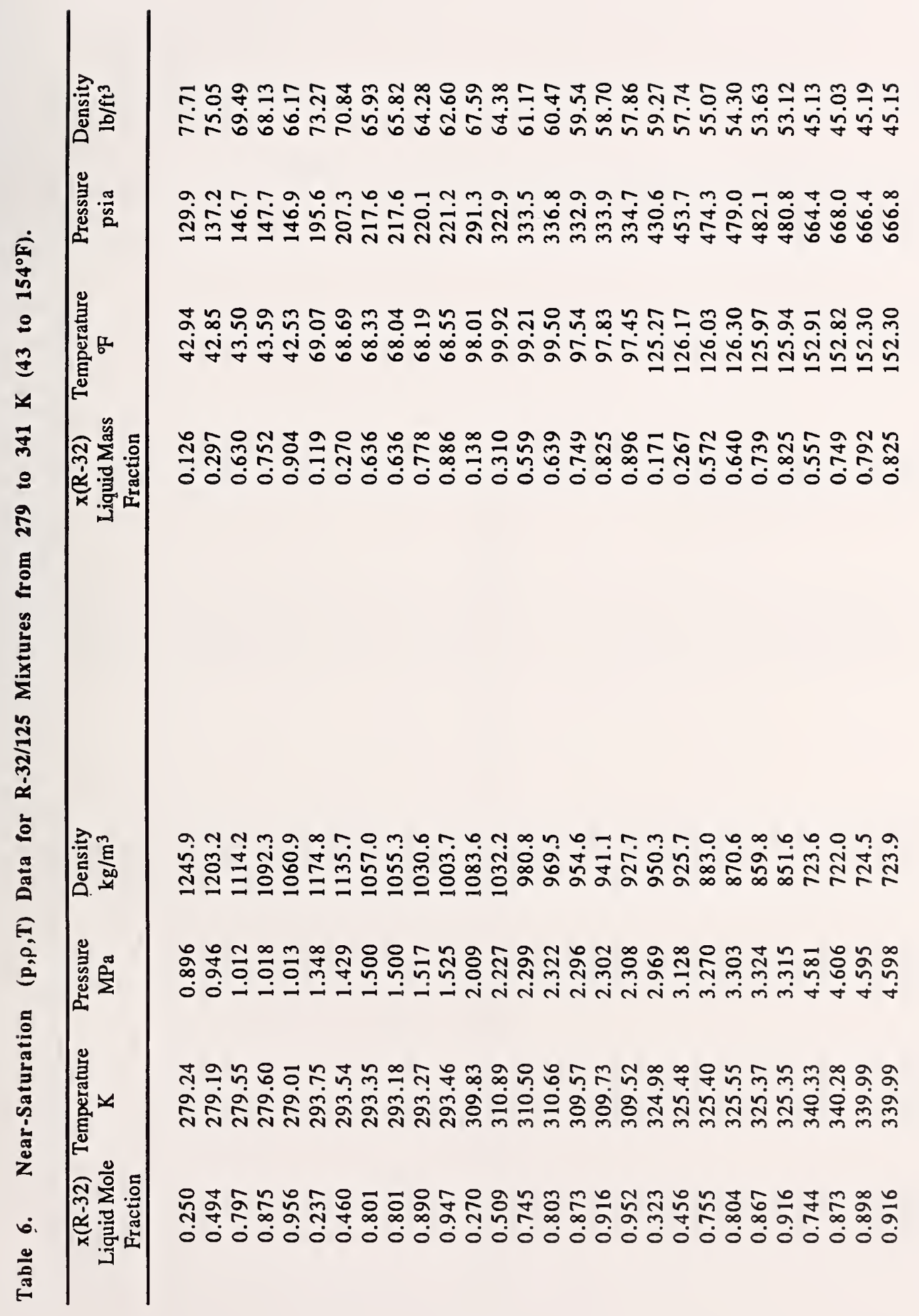




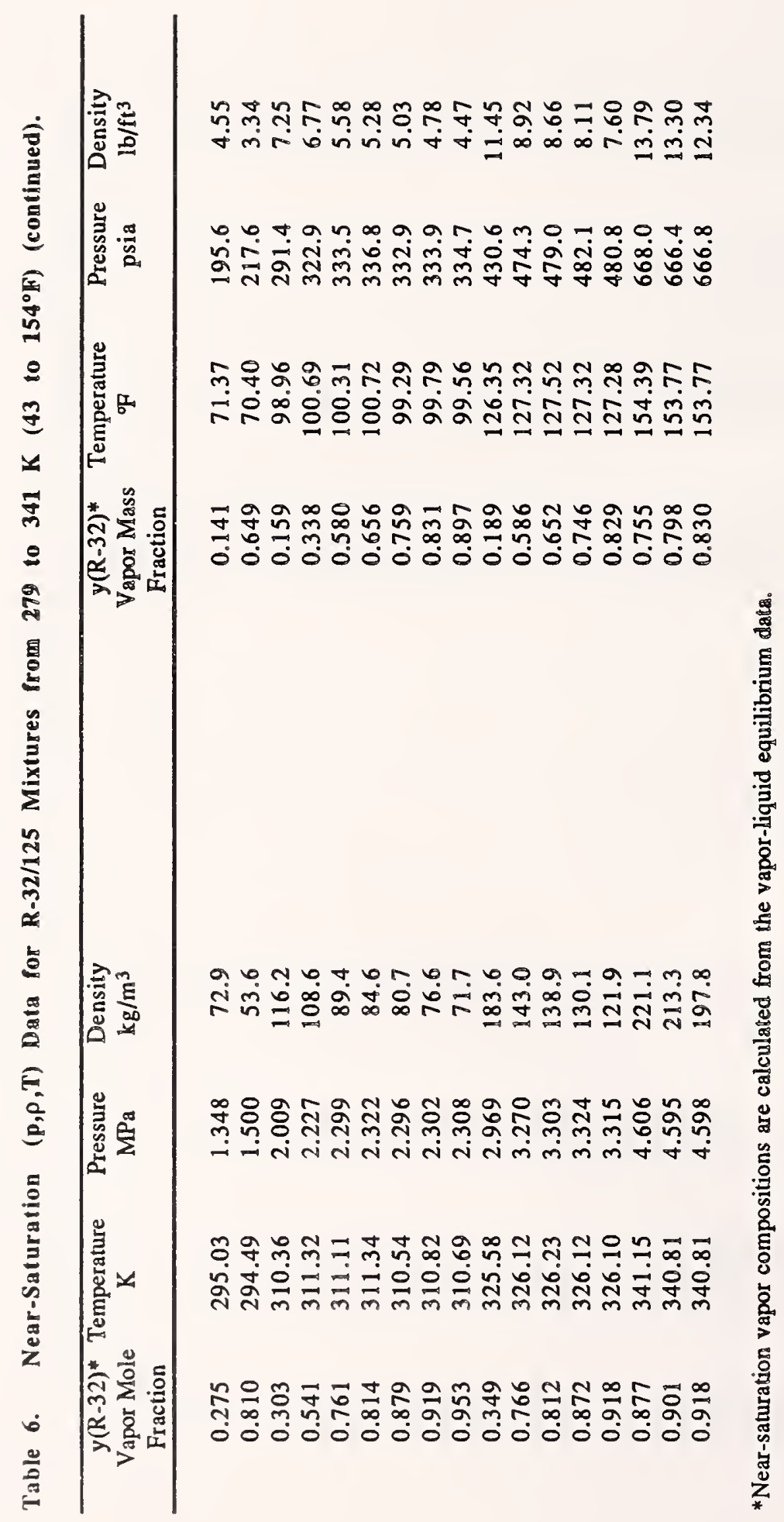




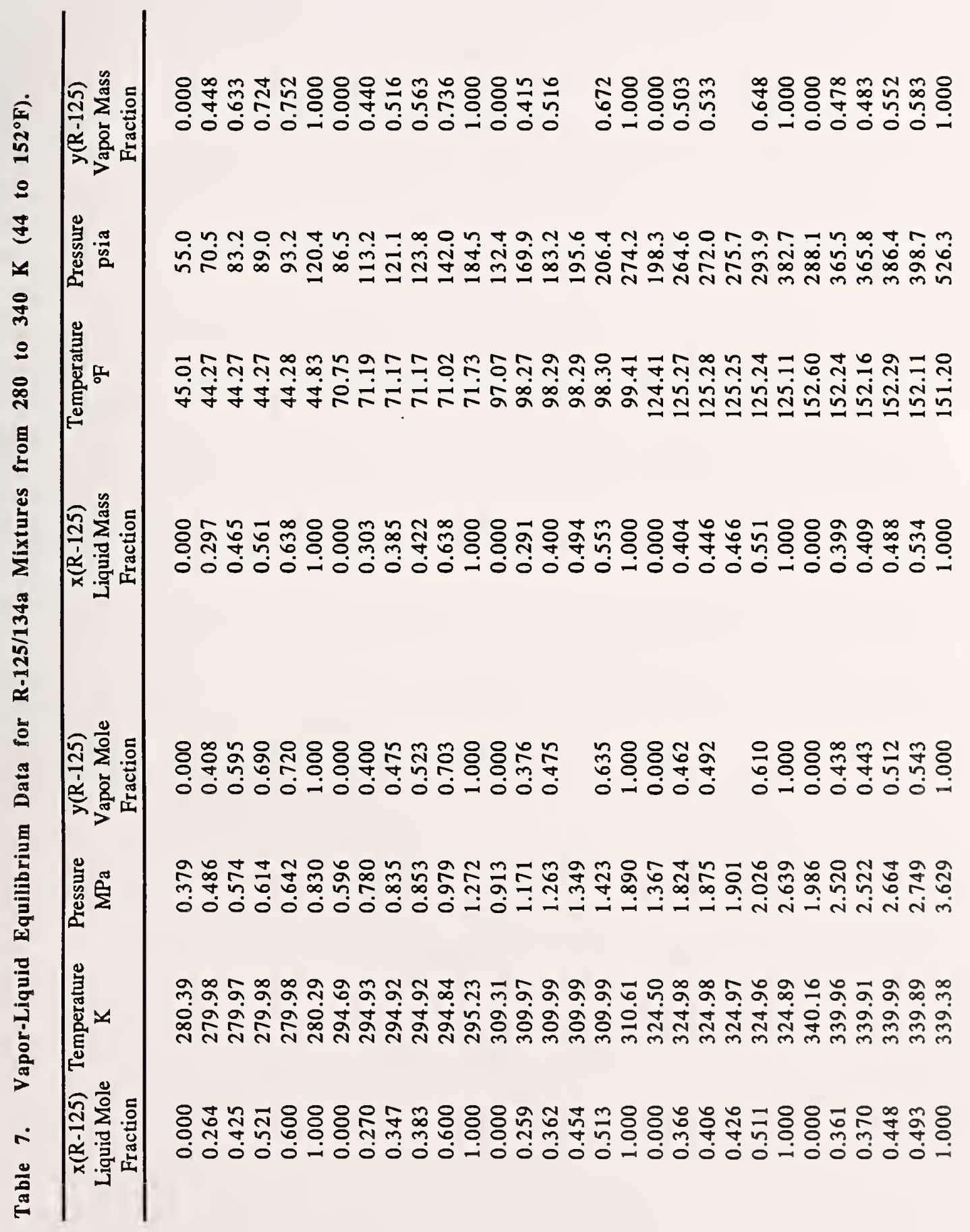




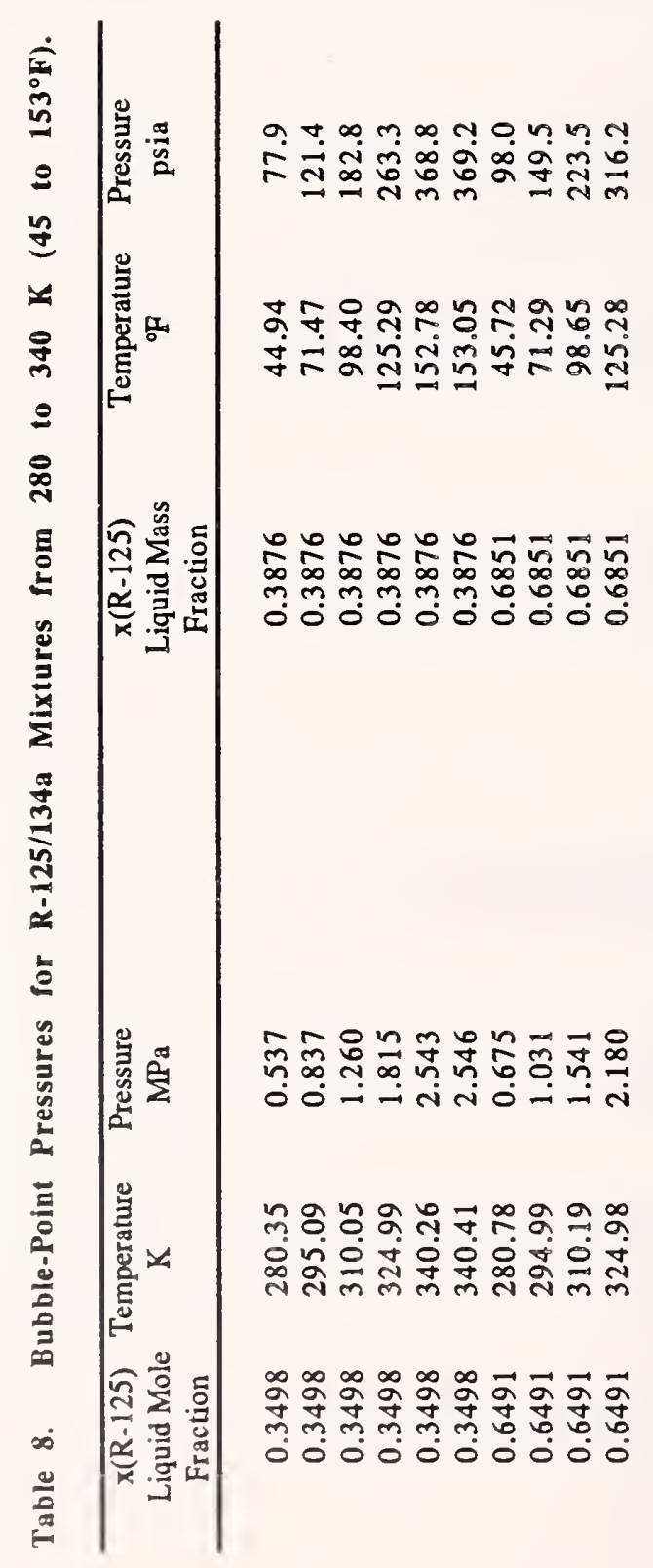




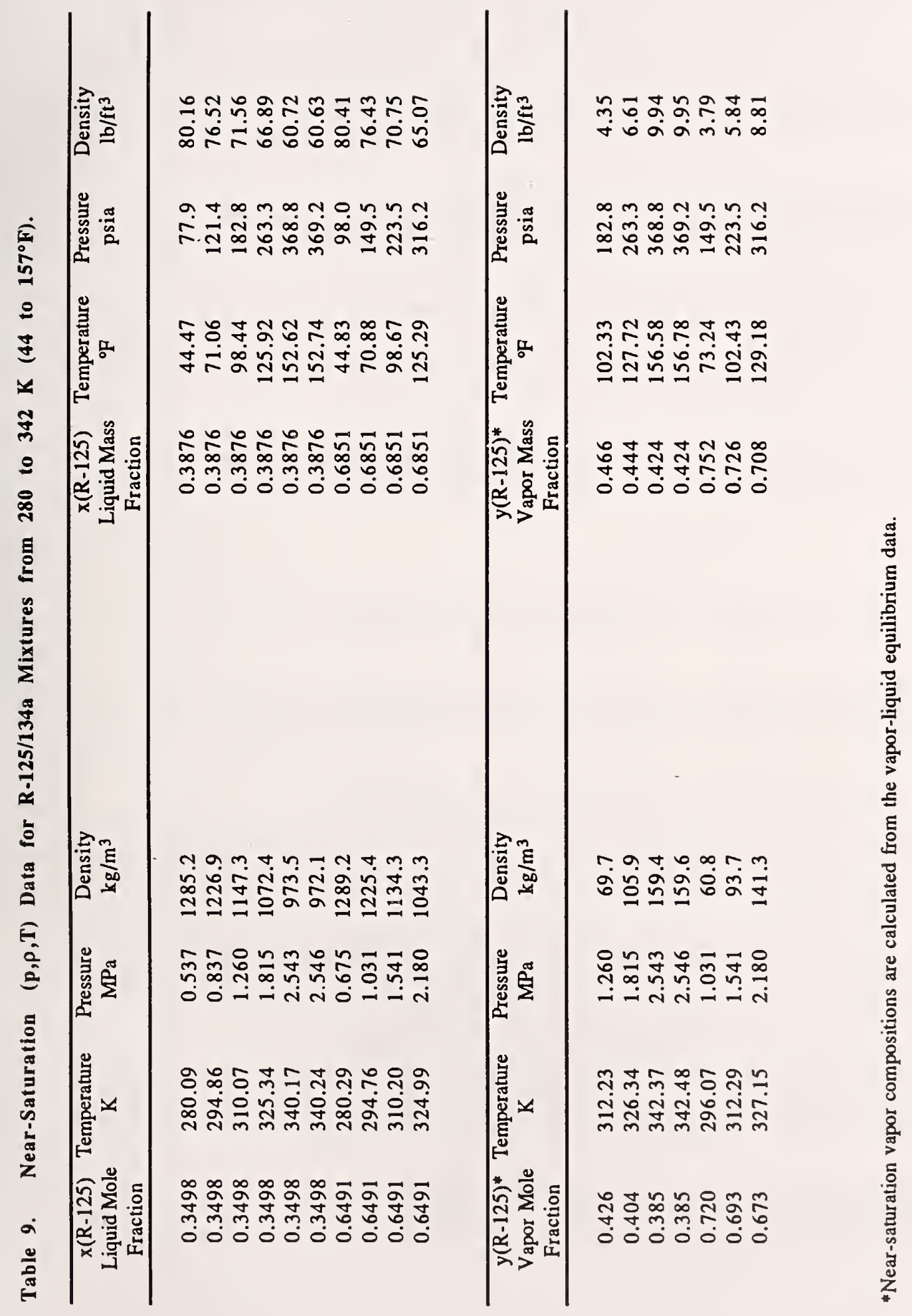




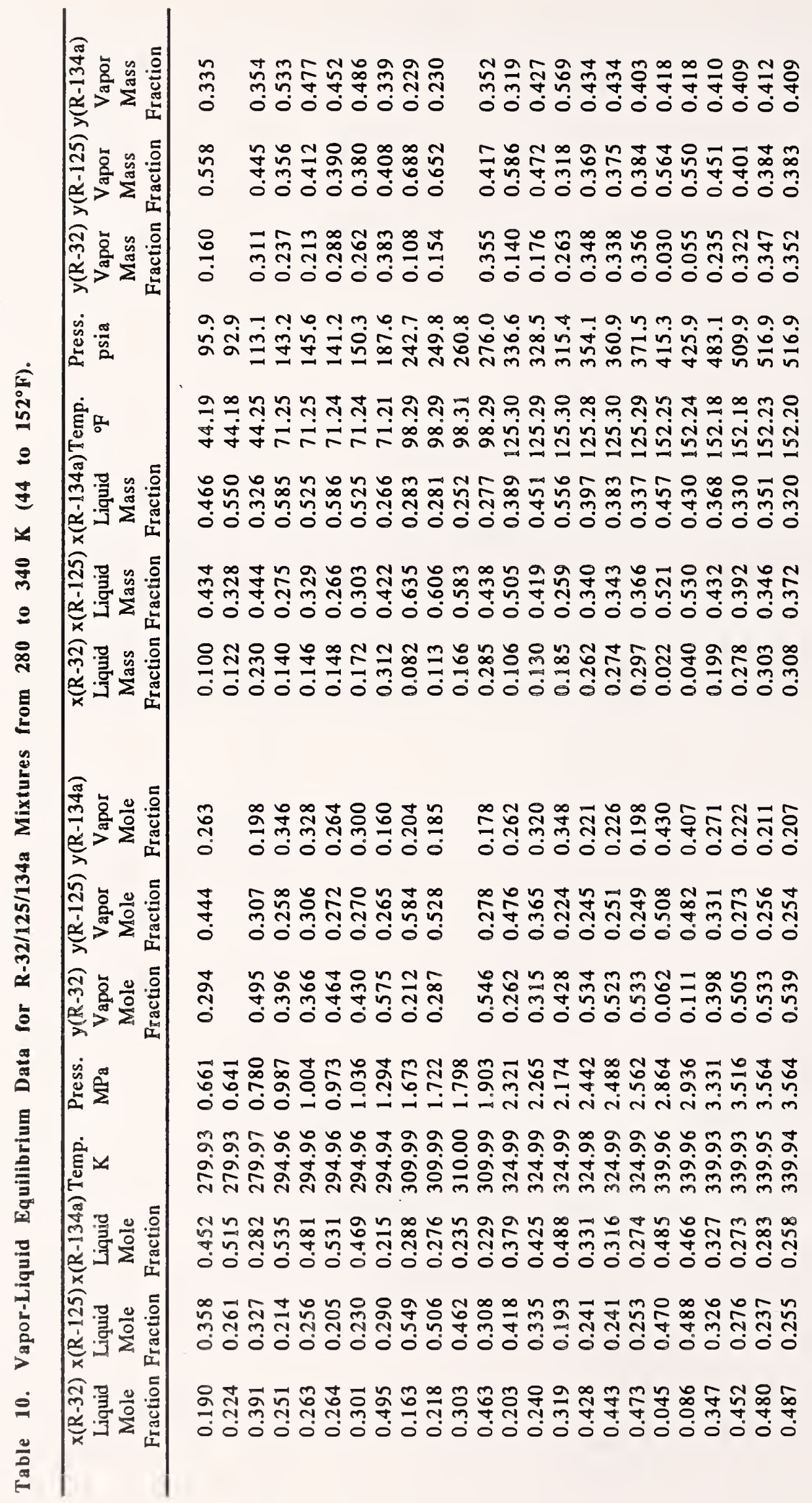


o

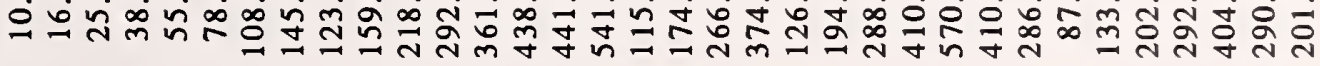

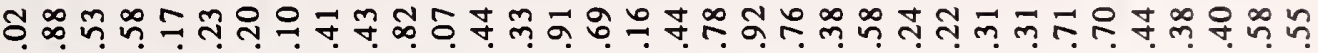

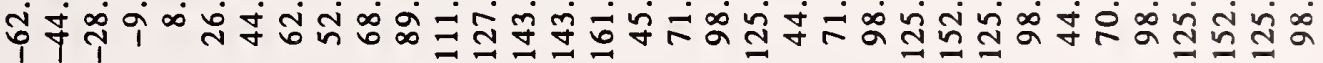

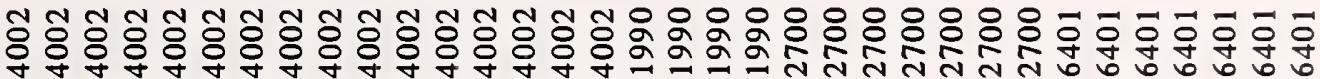

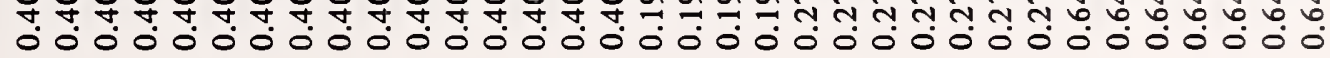

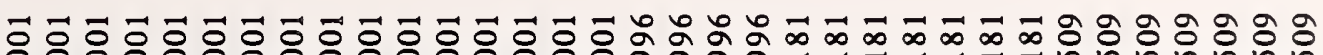

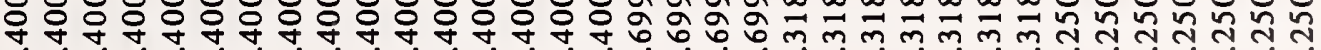

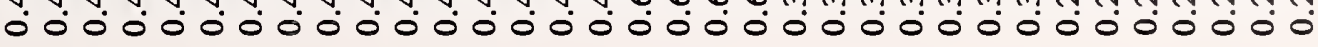

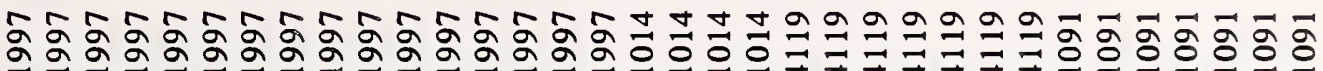

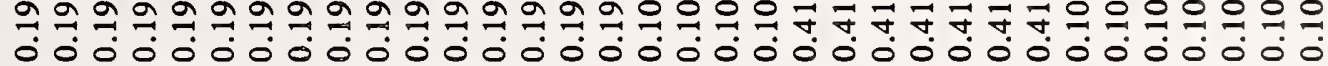

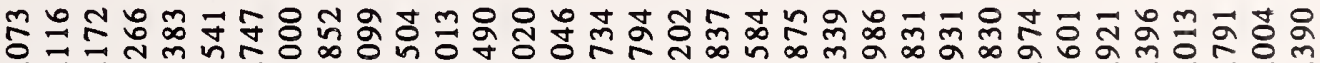

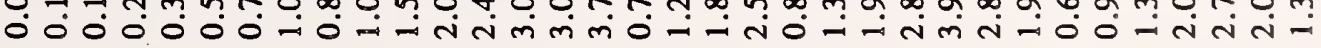

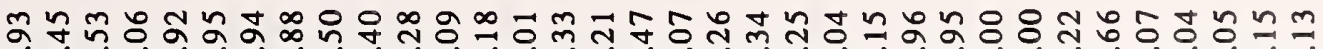

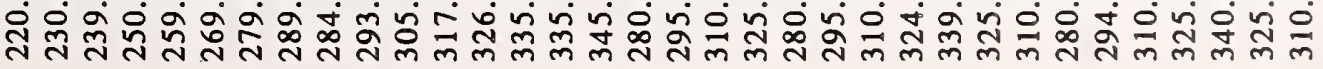

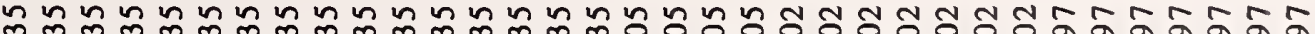

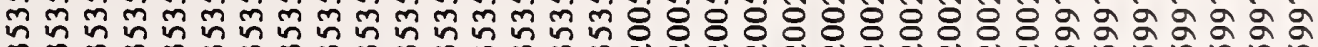

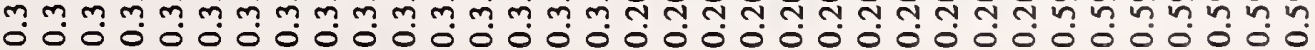

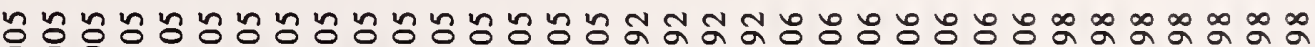

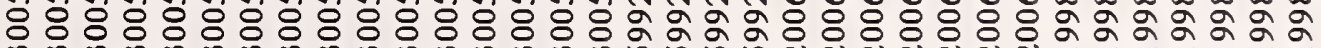

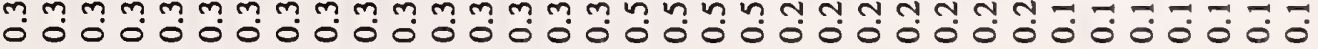

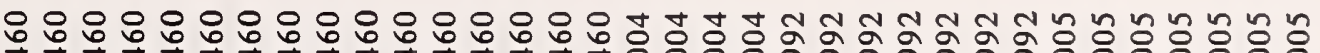

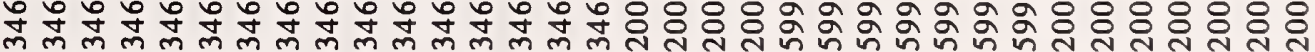
0000000000000000000000000000000000 







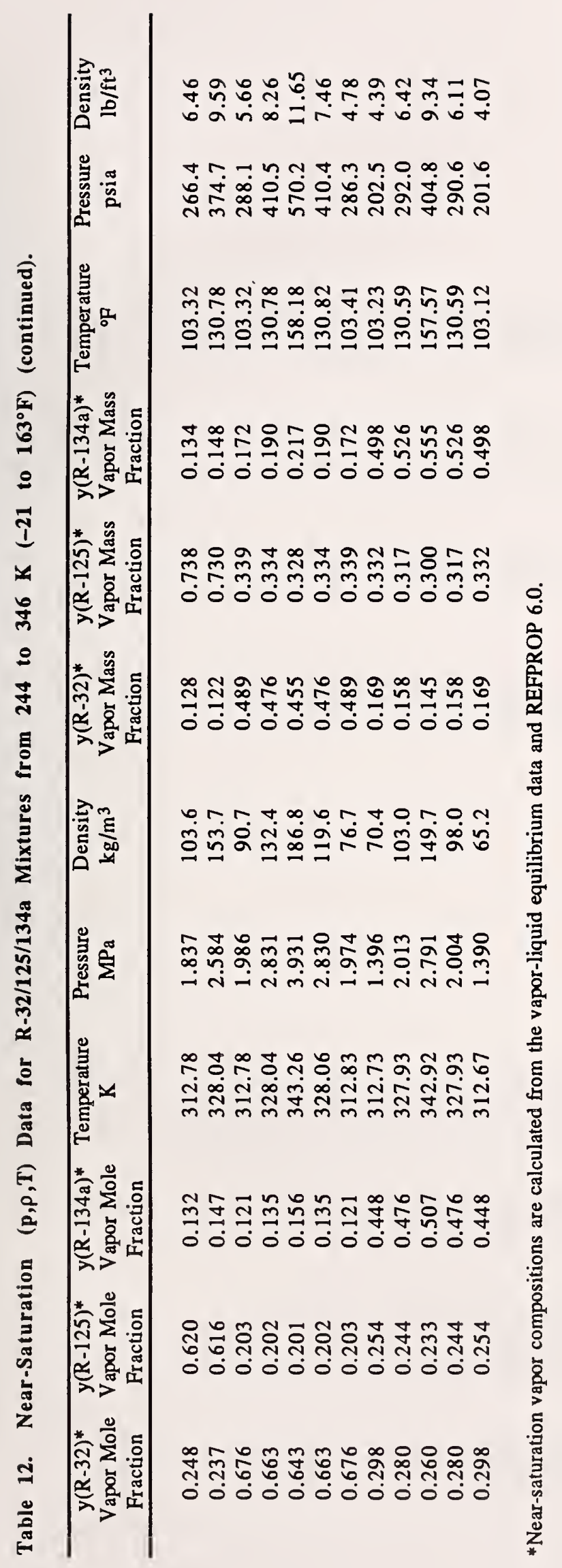




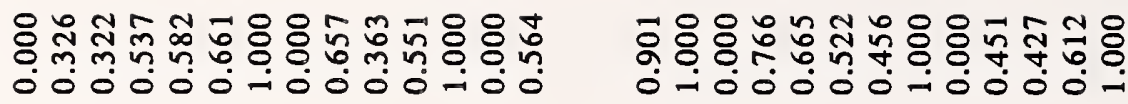

m

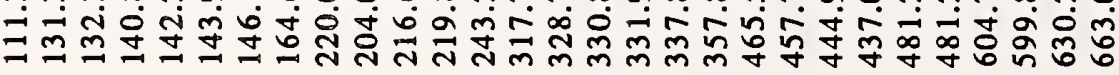

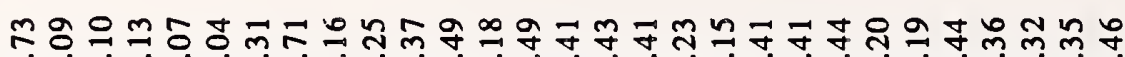

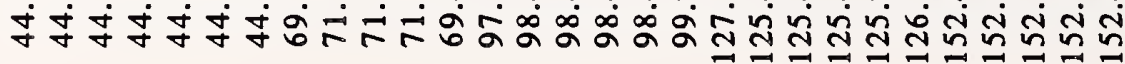

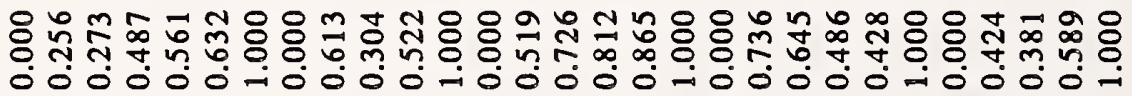

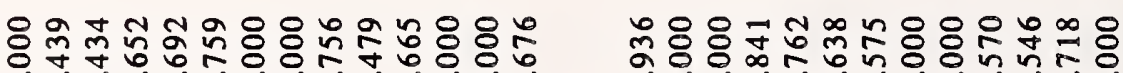

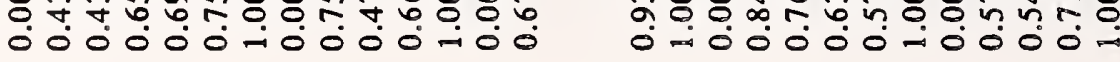

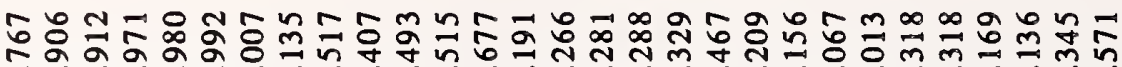

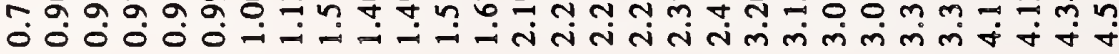

궁

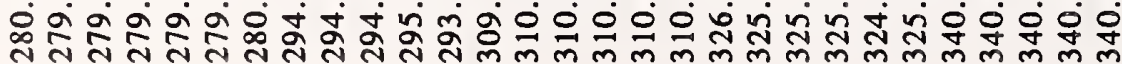

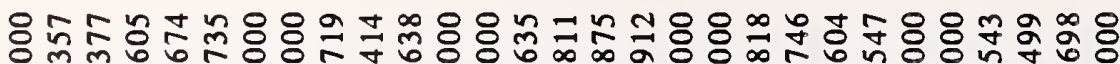

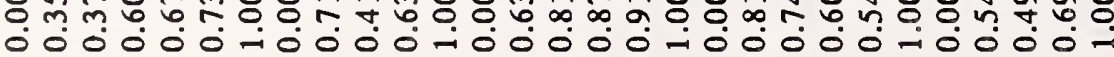




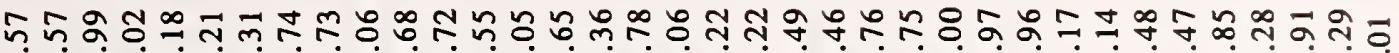
तु

a

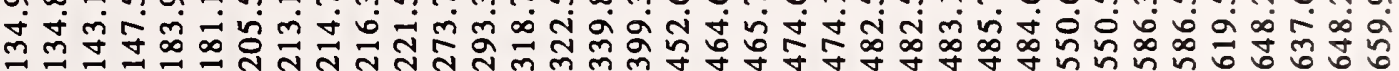

চ

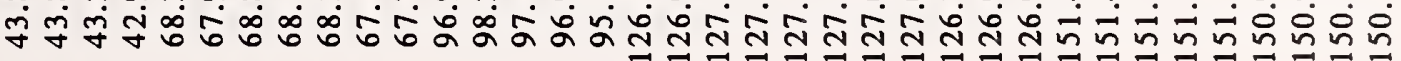

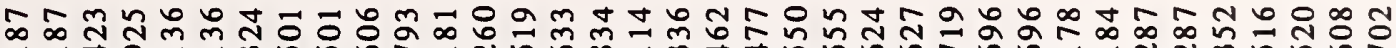

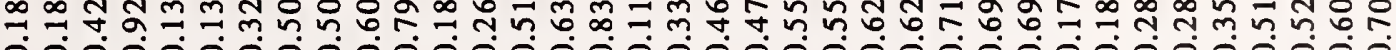

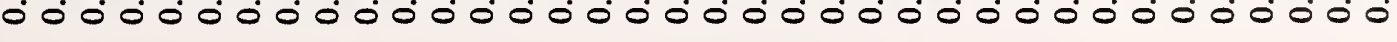

N

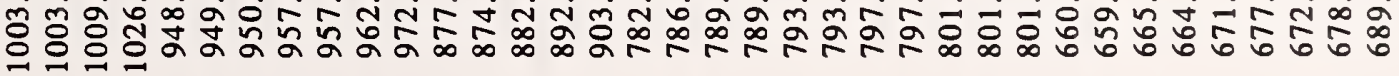

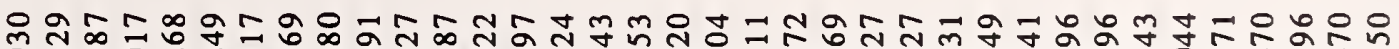
ŏ 0 ó

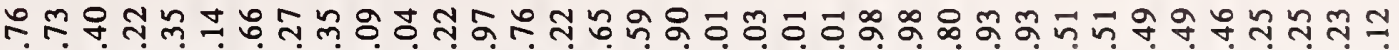

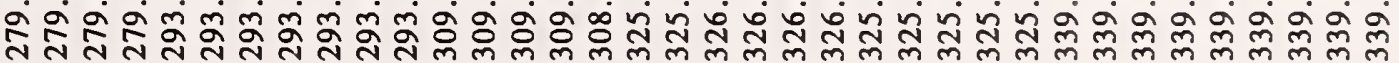

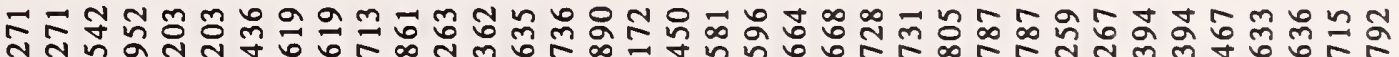

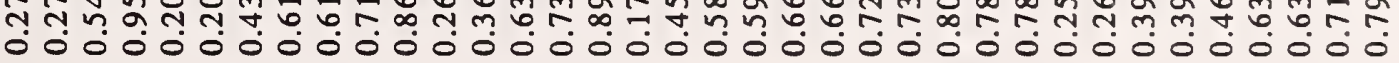




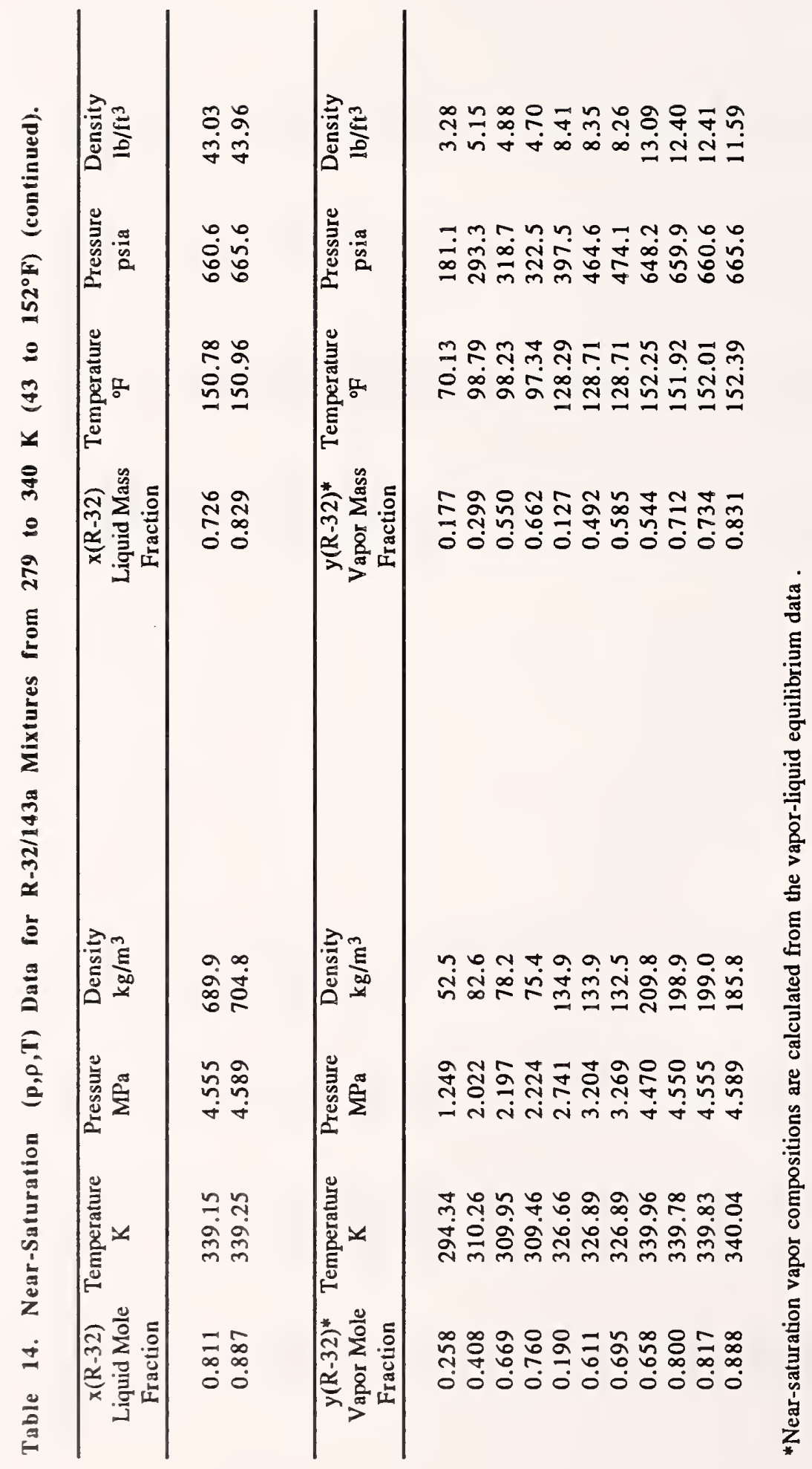




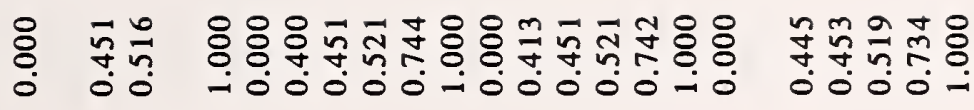

ง ๆ 0 0 0 t

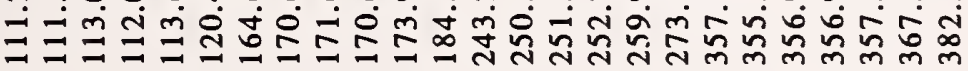

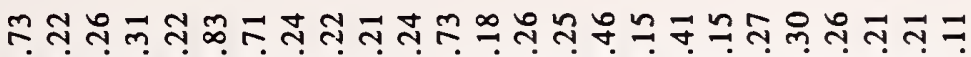

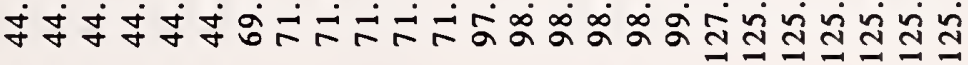

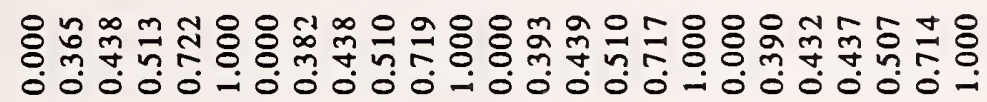

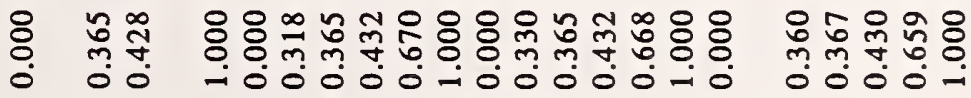

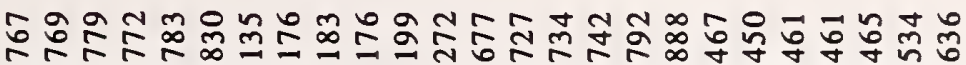

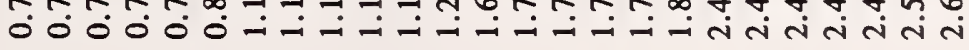

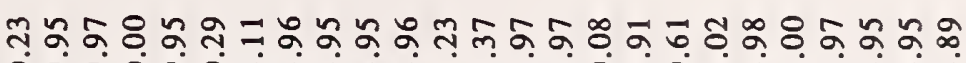

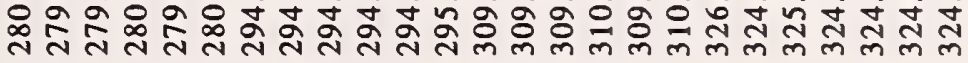

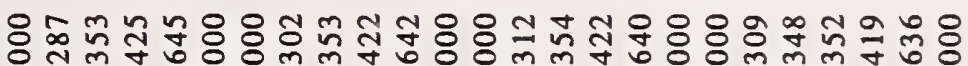

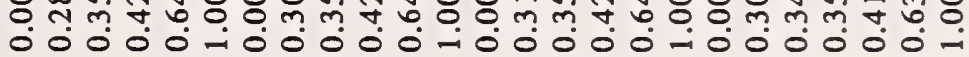




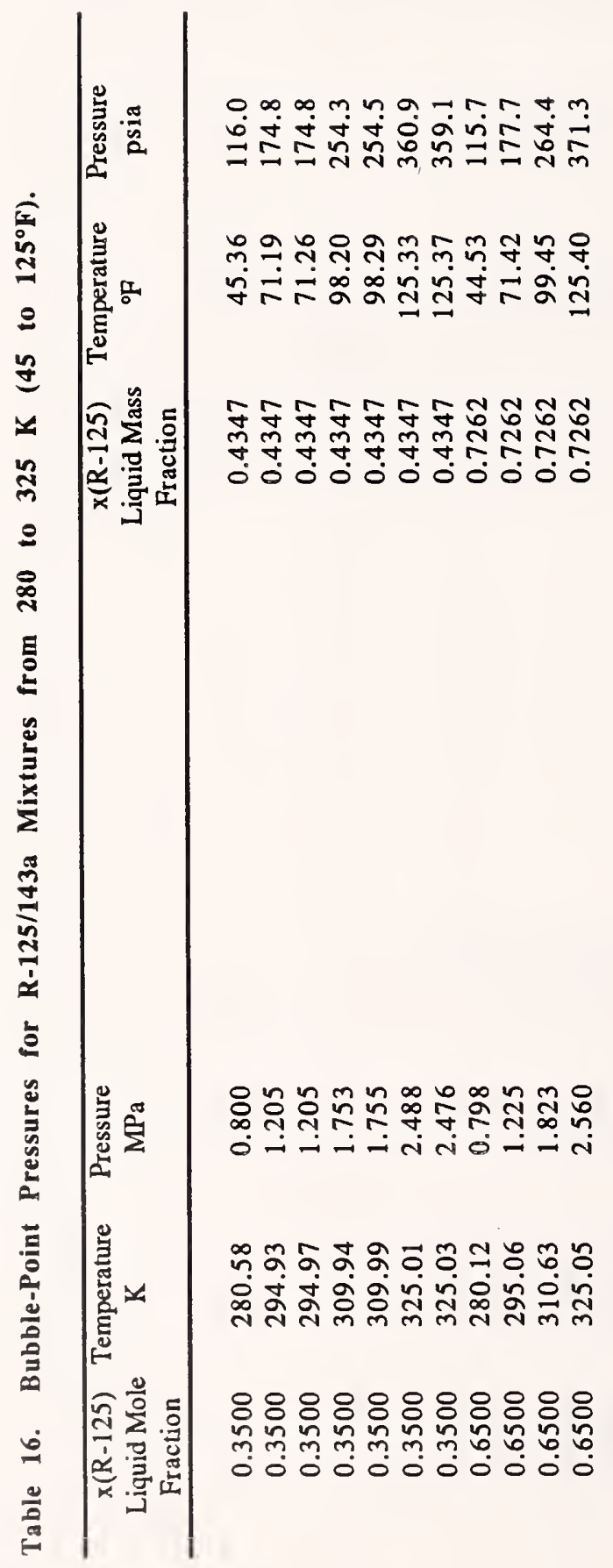




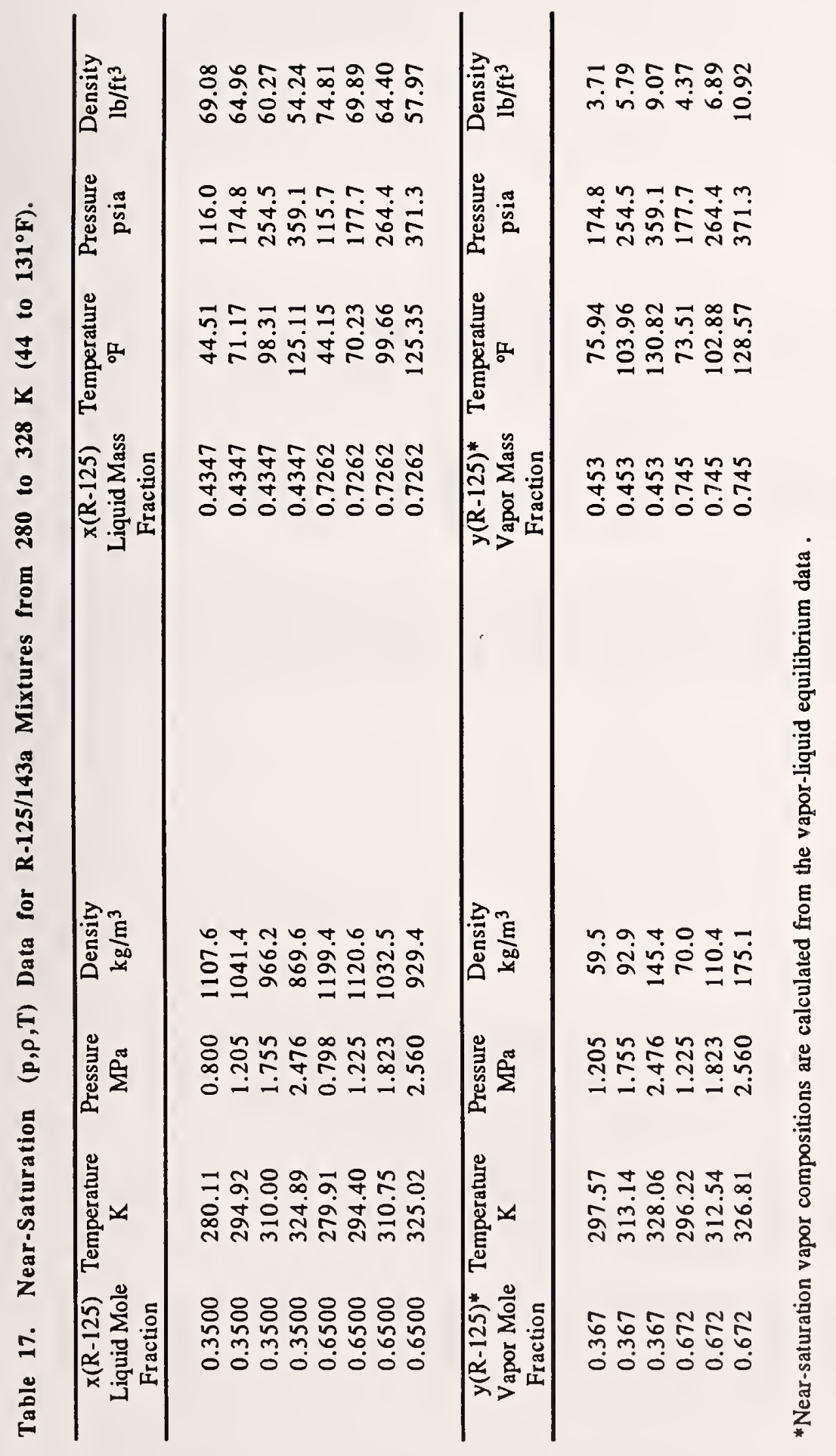




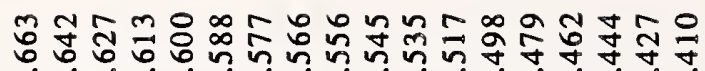

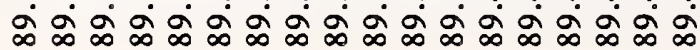

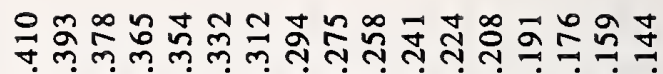
它

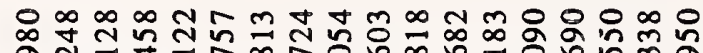

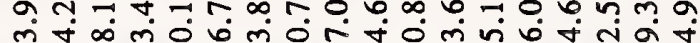

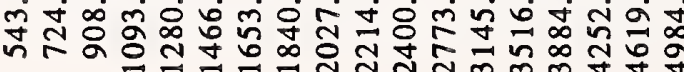

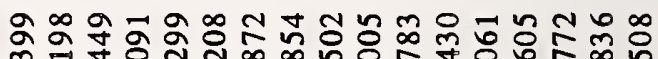
m.

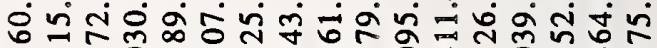

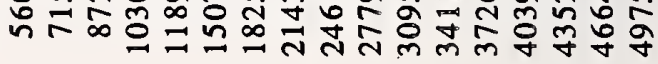

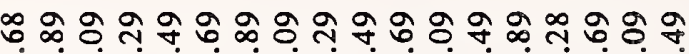

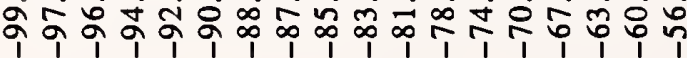

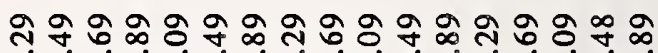
फ़

ํำ ம் nंn்

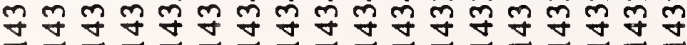

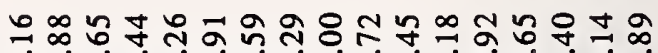
मंळें山்

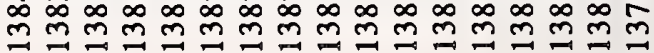

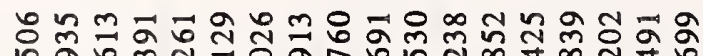

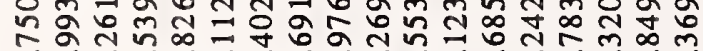

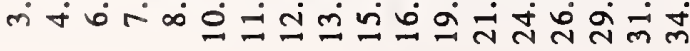

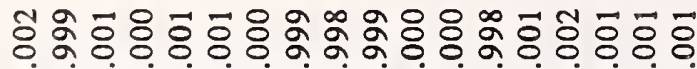

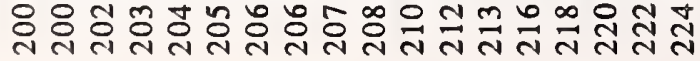

政

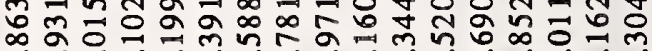

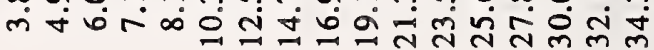

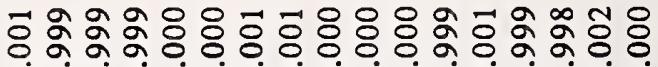

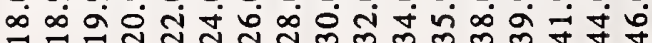
N 


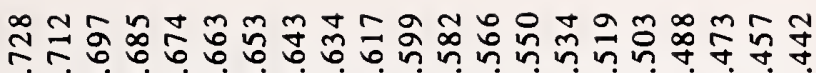

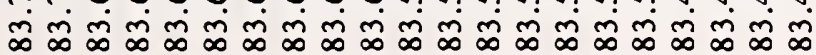

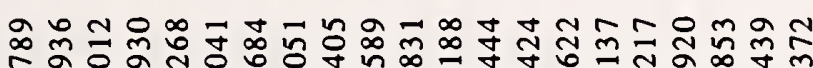

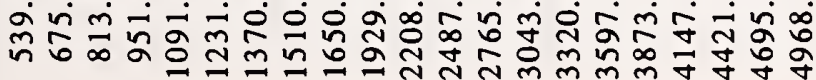

ᄋ 웜

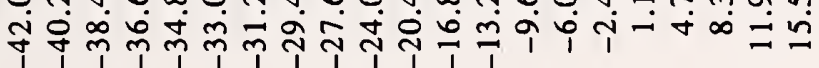

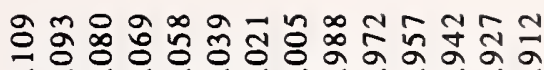

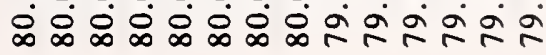

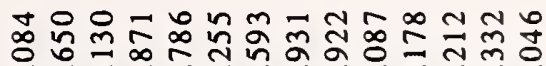

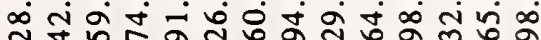
กี

ดิ

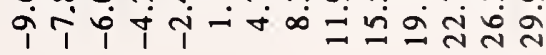

숭ํㅁำ

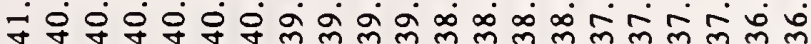

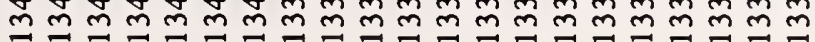

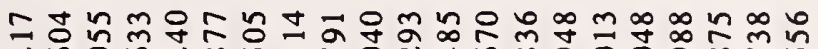

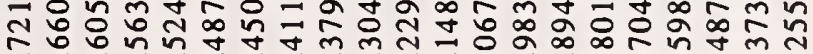
m

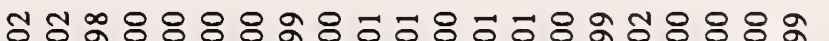

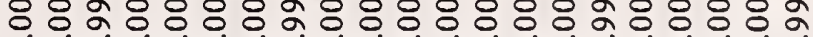

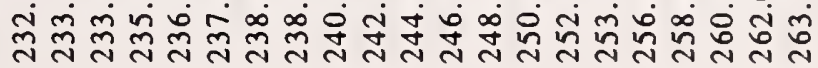

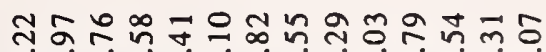
ஸ்

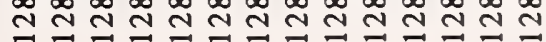

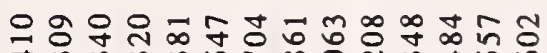

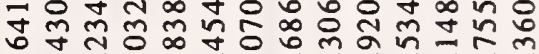

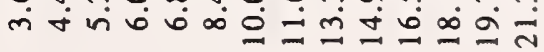

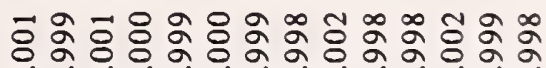

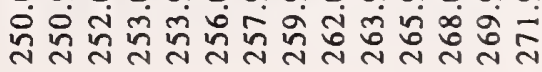




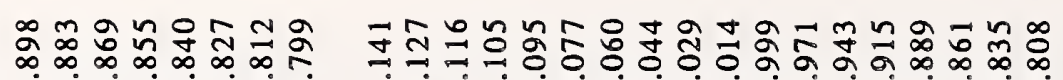

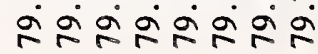

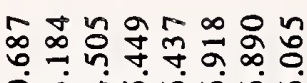
ல்

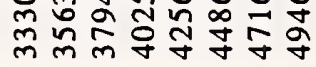

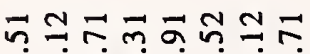

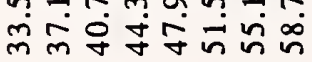

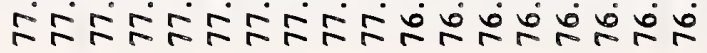

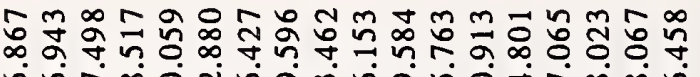

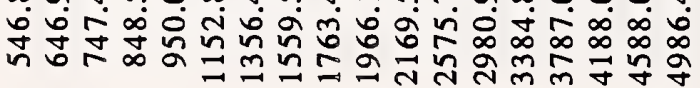

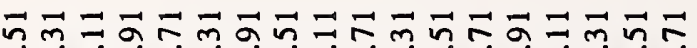

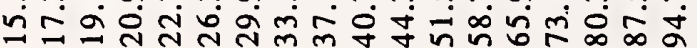

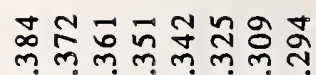
लिलिलm

은 ํํำ

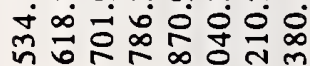

$\vec{m}=\vec{\sigma} \vec{\nabla} \vec{n} \exists \vec{\nabla} \vec{m}$

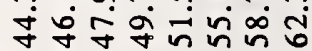

Ұำ iबi

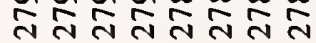
$\operatorname{cin}$ กงก

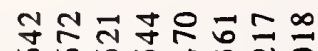

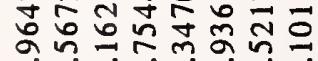
तี่ तั่

ลे 융ㅎㅇㅇㅇㅇㅇㅇㅇ

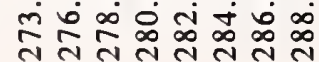

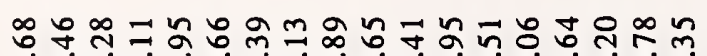

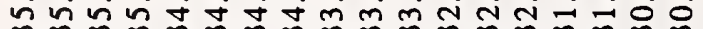

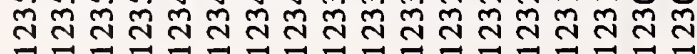

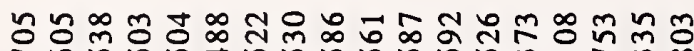

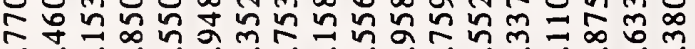

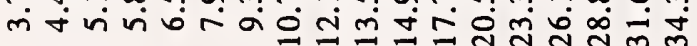

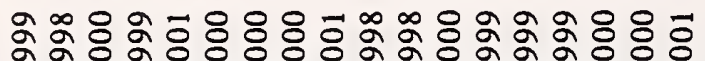

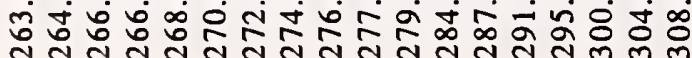

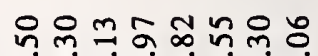

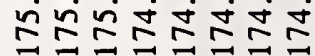
$\exists \Xi コ \Xi コ \Xi \Xi \Xi$

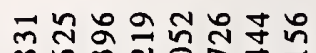

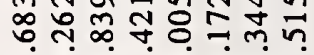

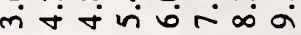

훙ㅇㅇㅇㅇㅇㅎㅎㅇㅇㅛ

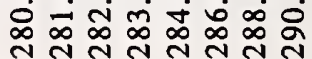




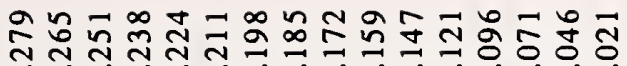

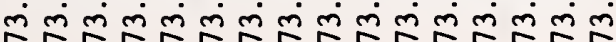

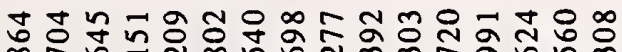
a $a$ a

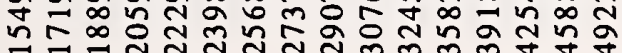

눙

究

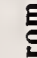

ㄴ.

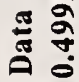

๙ ํำ

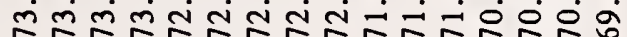
$\exists \Xi コ \Xi \Xi \Xi \Xi \Xi \Xi \Xi コ \Xi コ \Xi$

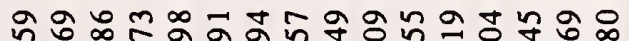
مै

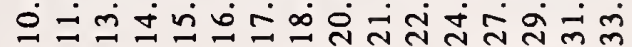

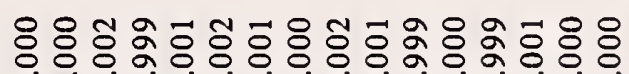

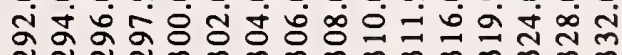

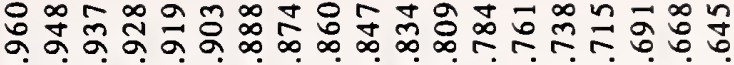

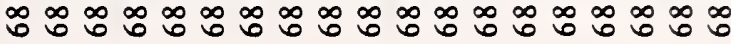

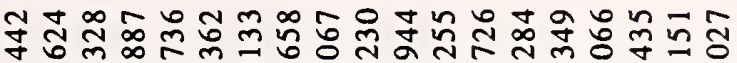

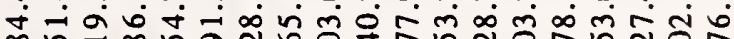

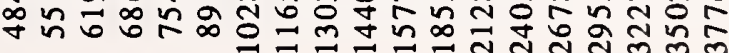

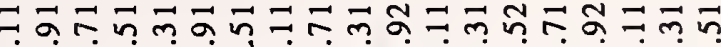

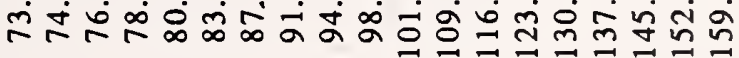

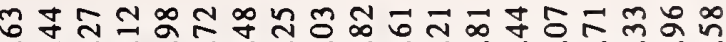

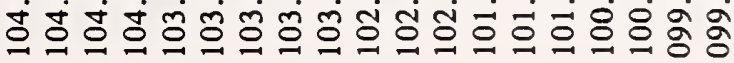

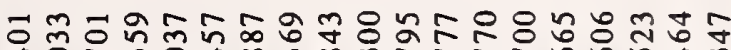
में क्ति

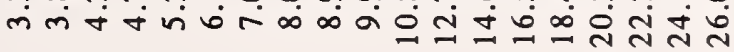

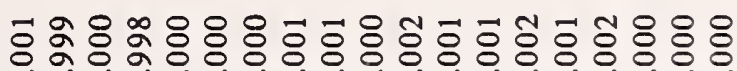

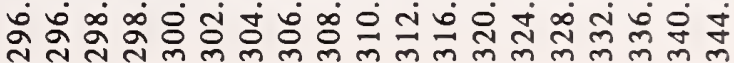




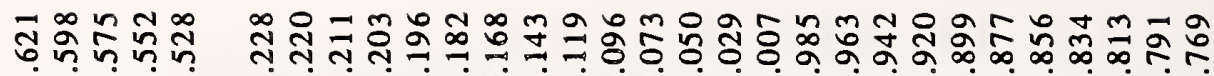

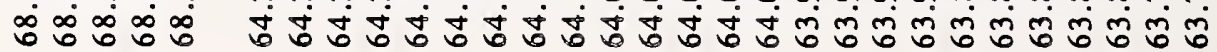

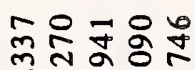

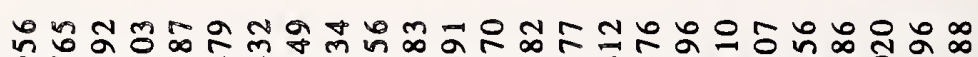
वं

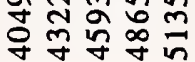

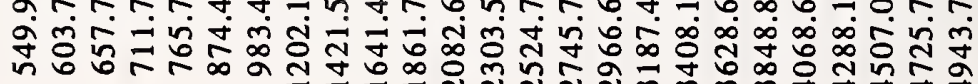

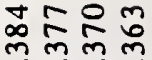
is $\sin$

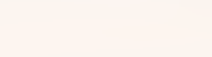

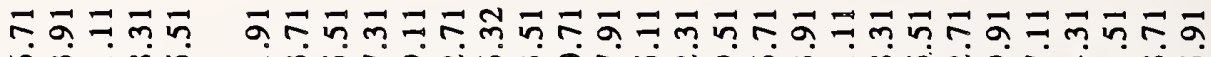

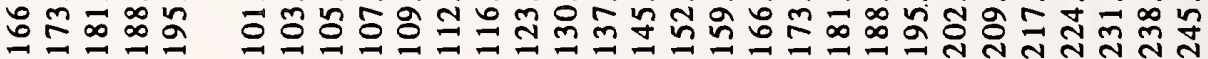

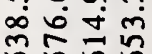

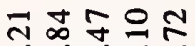
응ㅇㅇㅇㅇㅇㅇㅇㅇ 으으으응

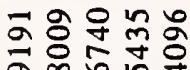
ते लेंm m

용ㅇㅇㅇ

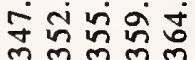

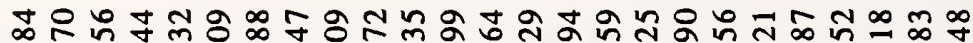

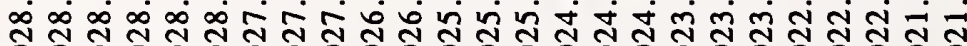

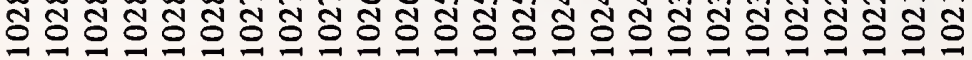

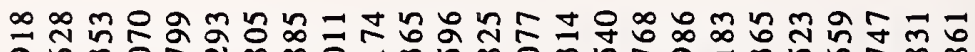

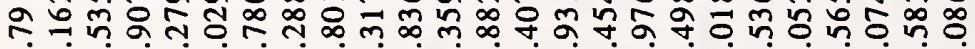

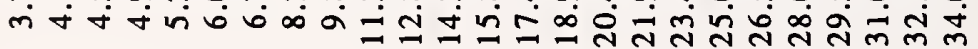

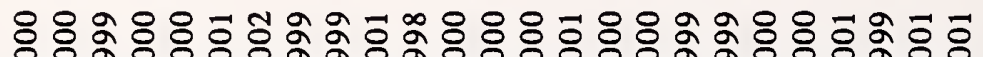

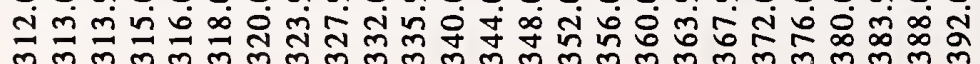

สี $a+\infty \infty$ a $a \sigma a$

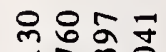
조ำ ธิธ त्ल స్లై స్ల 


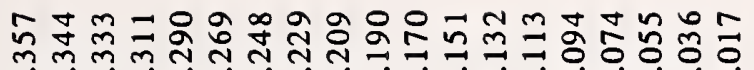

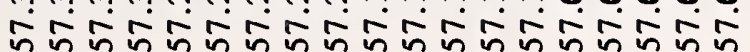

응

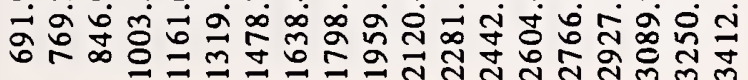

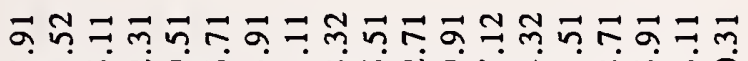

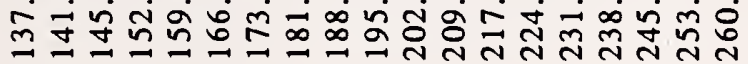

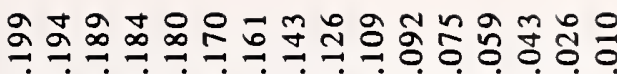

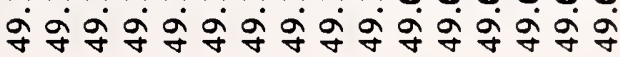

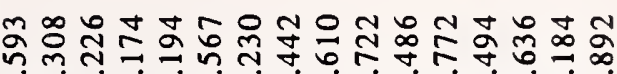

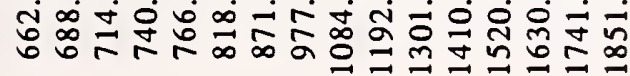

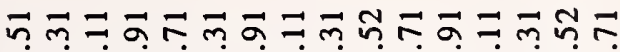

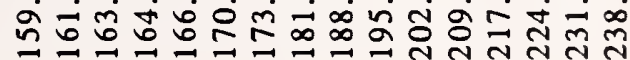

ㄱำ

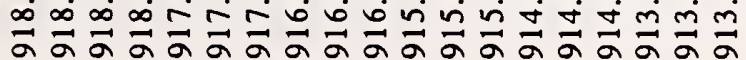

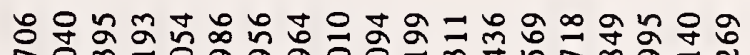
강 क ナn்

웡 mं

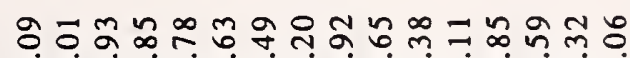

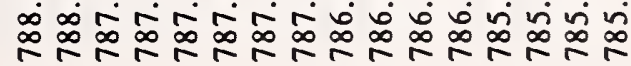

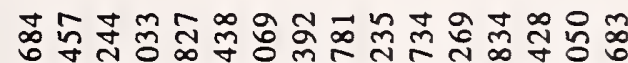

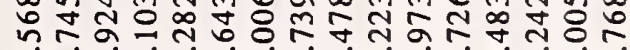

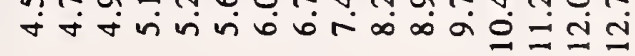

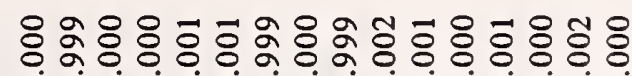

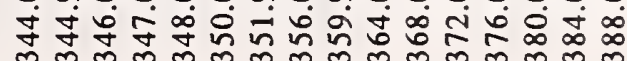




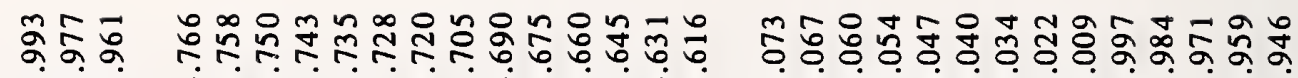

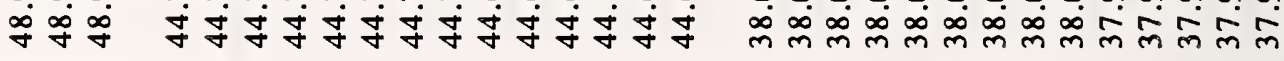

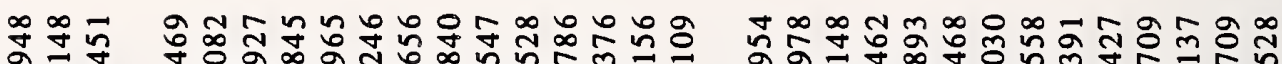

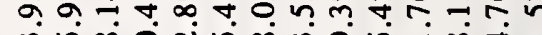

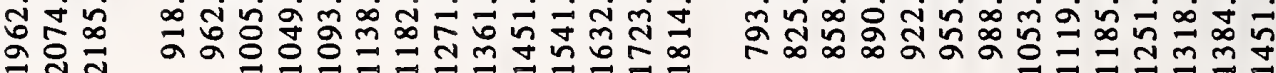

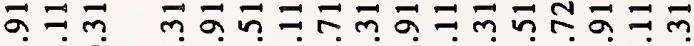

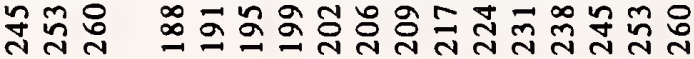

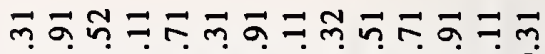

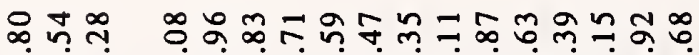

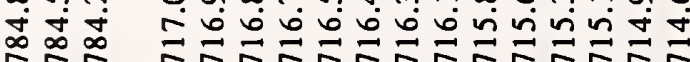

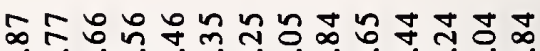

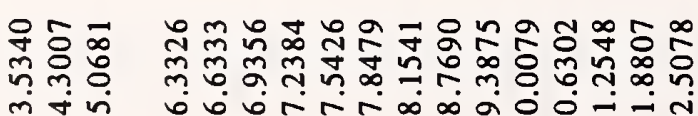

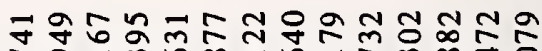

형ㅇㅇㅇㅎㅇㅇㅇㅇㅇㅇㅇㅇㅇㅇㅇㅇㅕ 命

îं î́ 


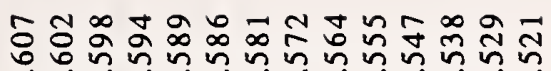

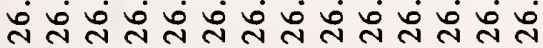

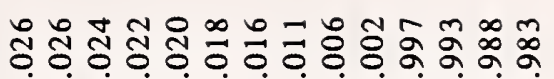

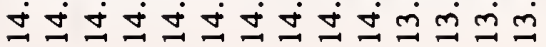

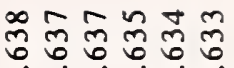

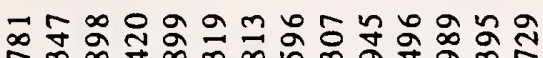

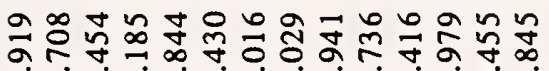

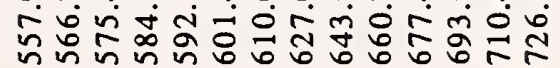

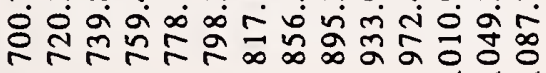

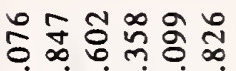

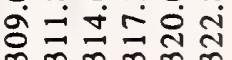

m

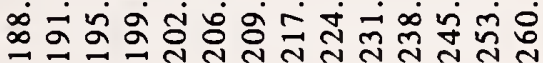

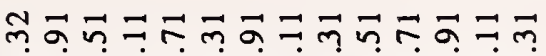

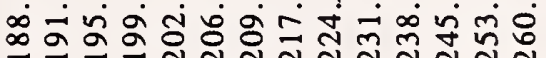

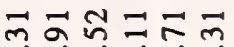

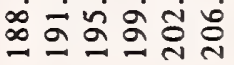

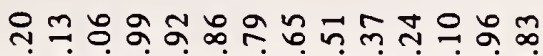

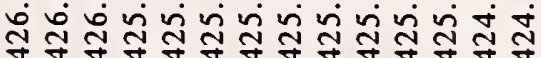

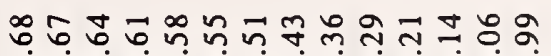
ำํำส สิ

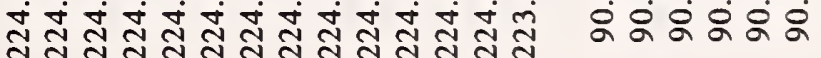

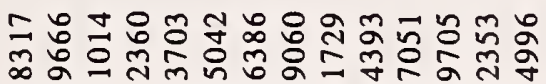
苂守

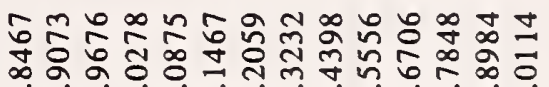
$\dot{m} \dot{m} \dot{m} \dot{\nabla} \dot{\nabla} \dot{\nabla} \dot{\nabla} \dot{\nabla} \dot{\nabla} \dot{\nabla} \dot{\nabla} \dot{q} \dot{q}$

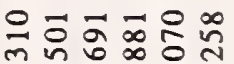
$=0$ 4in 4 is

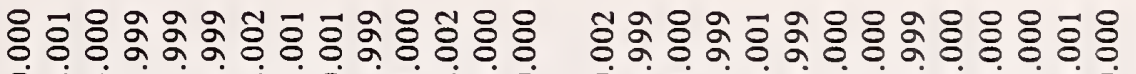

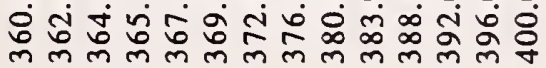

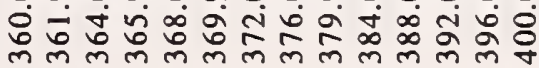

ลूे ㅇํㅇ용

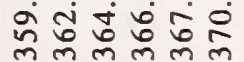




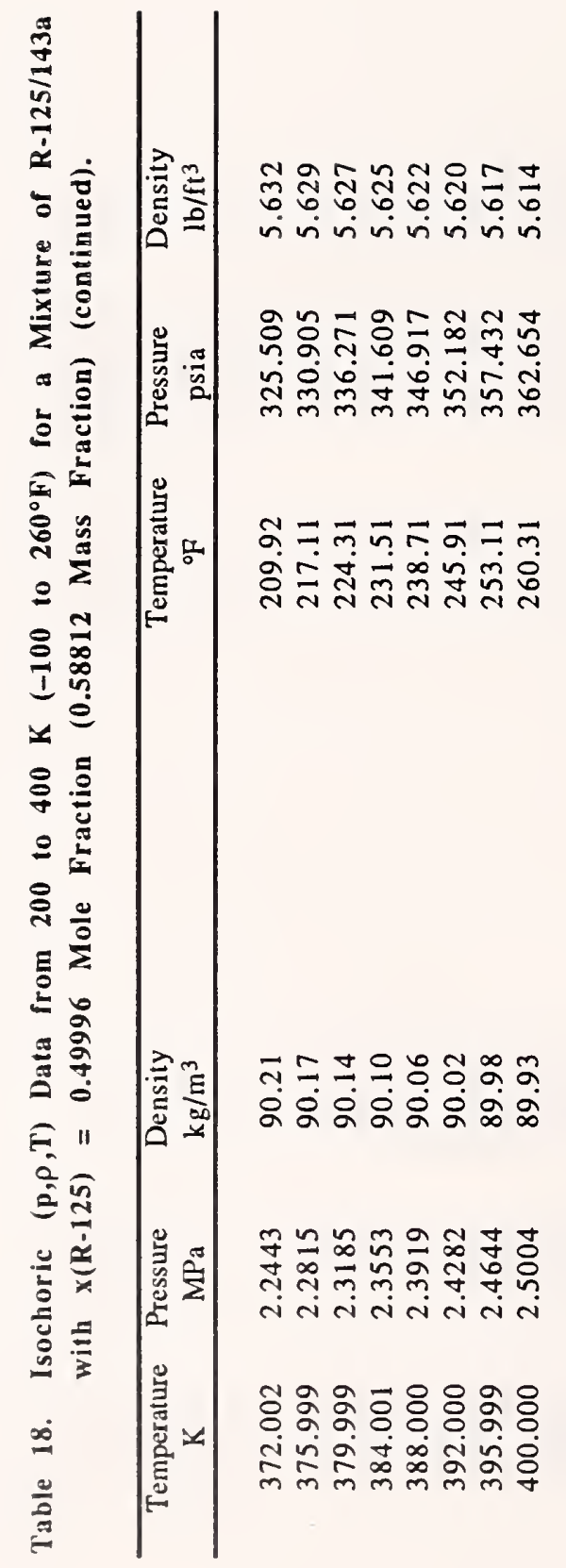




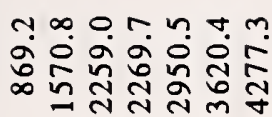

$\infty 0 .-a+70$

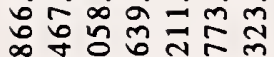

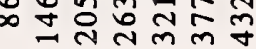

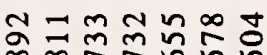
$\infty \infty$

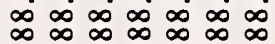

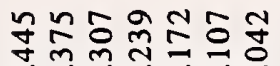
ที丶 ผ่

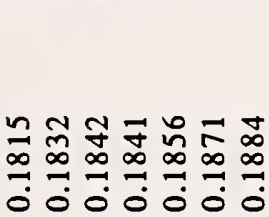

โำ

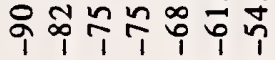

ㄴํำㅇำำㅇำ

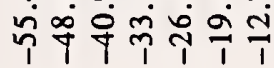
눙

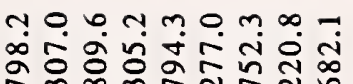

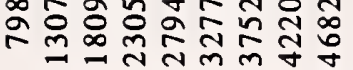

पa $0, \infty$ a 0.7 . กำ

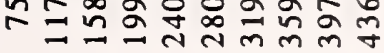

เ

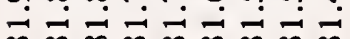

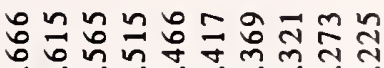

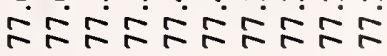

ติ वे n

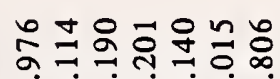

ํํํ궁 மํำ மํㅓㅇㅝ ก

윙

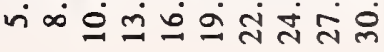

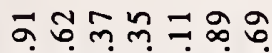
ขึ ปิ 导导筫寻寻

ใูำ 它

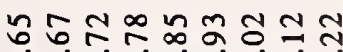
를

웅 궁

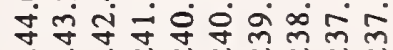

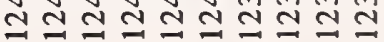

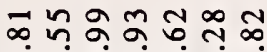
ㅇํำำกำ 용ㅇㅇ

元 过宓 $\infty \dot{\infty} \infty \infty \infty \infty$

nู

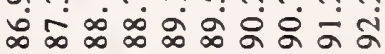

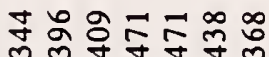

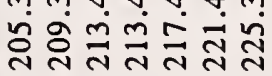

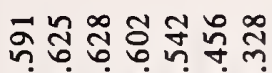
ปั่

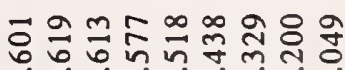

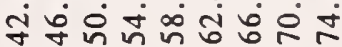

쓸

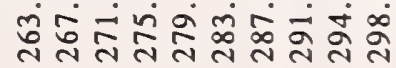




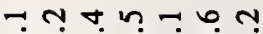

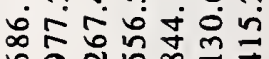
คด

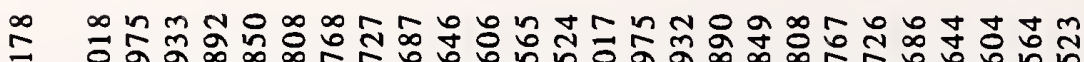

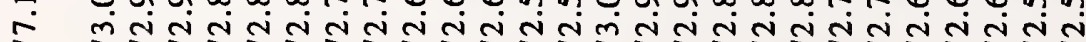

moำ

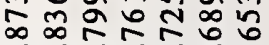
g่

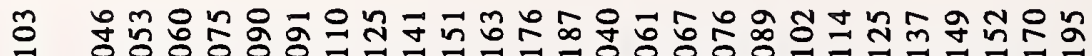

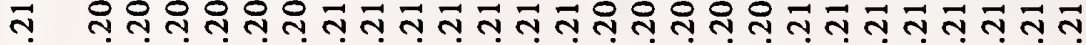
- 00000000000000000000000000

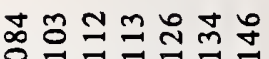

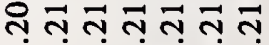
0000000

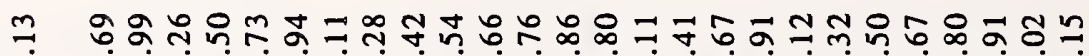
n

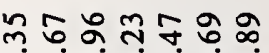
융ํㅇ응

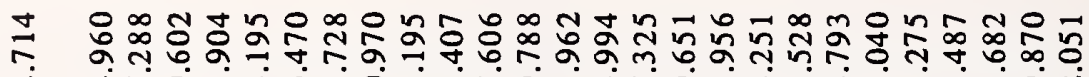
लं अ

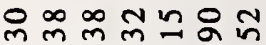
ก. $\dot{\sim} \dot{0} \dot{0} \dot{0} \dot{\Xi}$

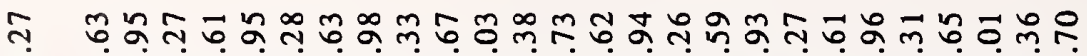
ல ல்

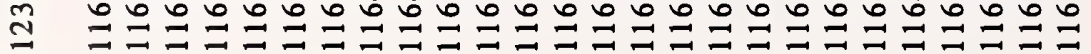

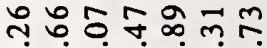
$2 \infty \infty=0$ $\exists \equiv \Xi \Xi \Xi \Xi$

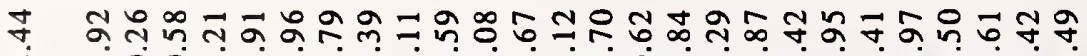

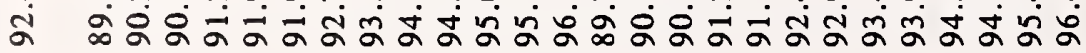

망

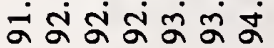

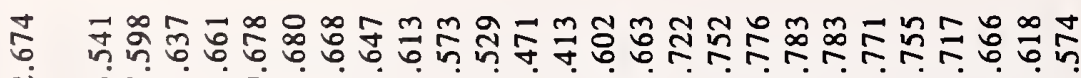
क्ष क्र

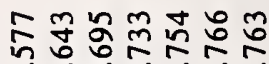
ลूं 
o.

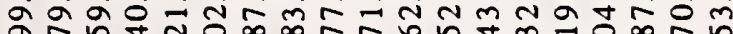

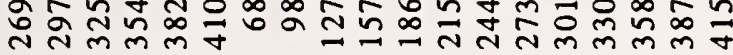

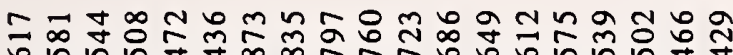
ดे

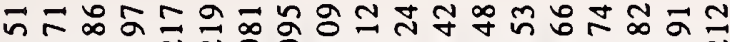

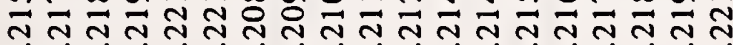

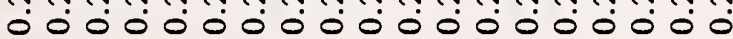

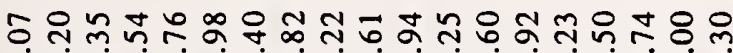

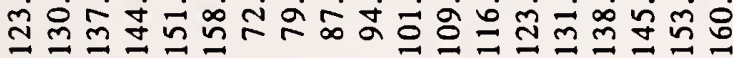

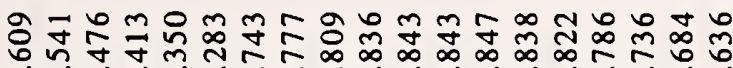
向

๓ก

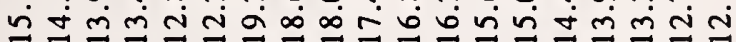

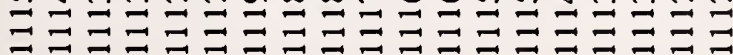

입으요

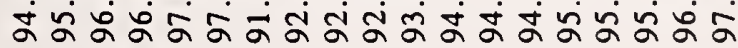

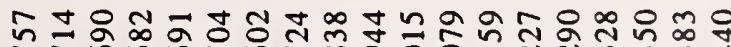
ๆ స్ స̂ल m

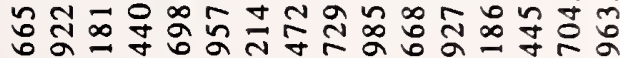
o

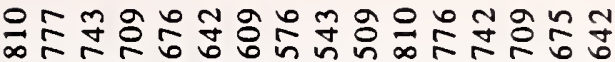
b

ปั่

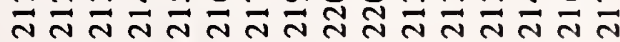
0000000000000000

సิำกำ

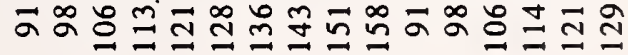

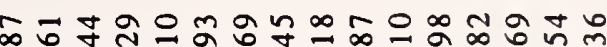

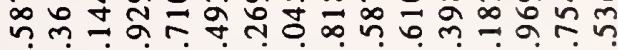

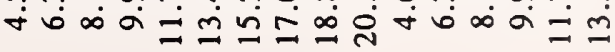

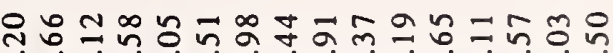
ㅇํㅇ

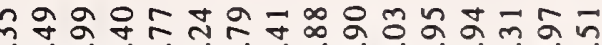
ஸ்

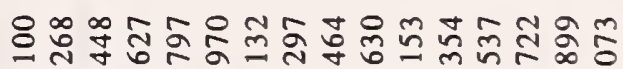

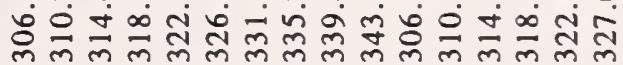




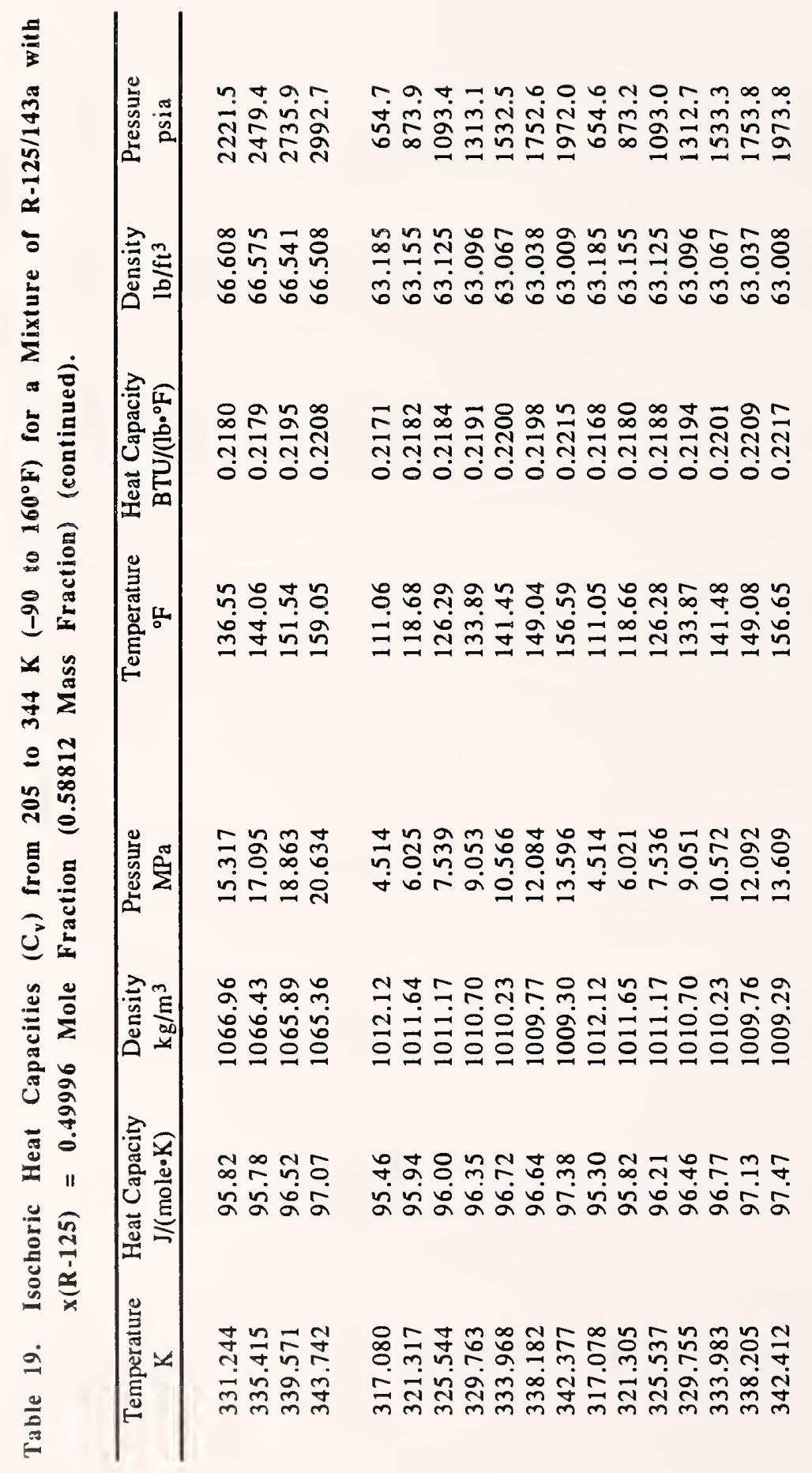




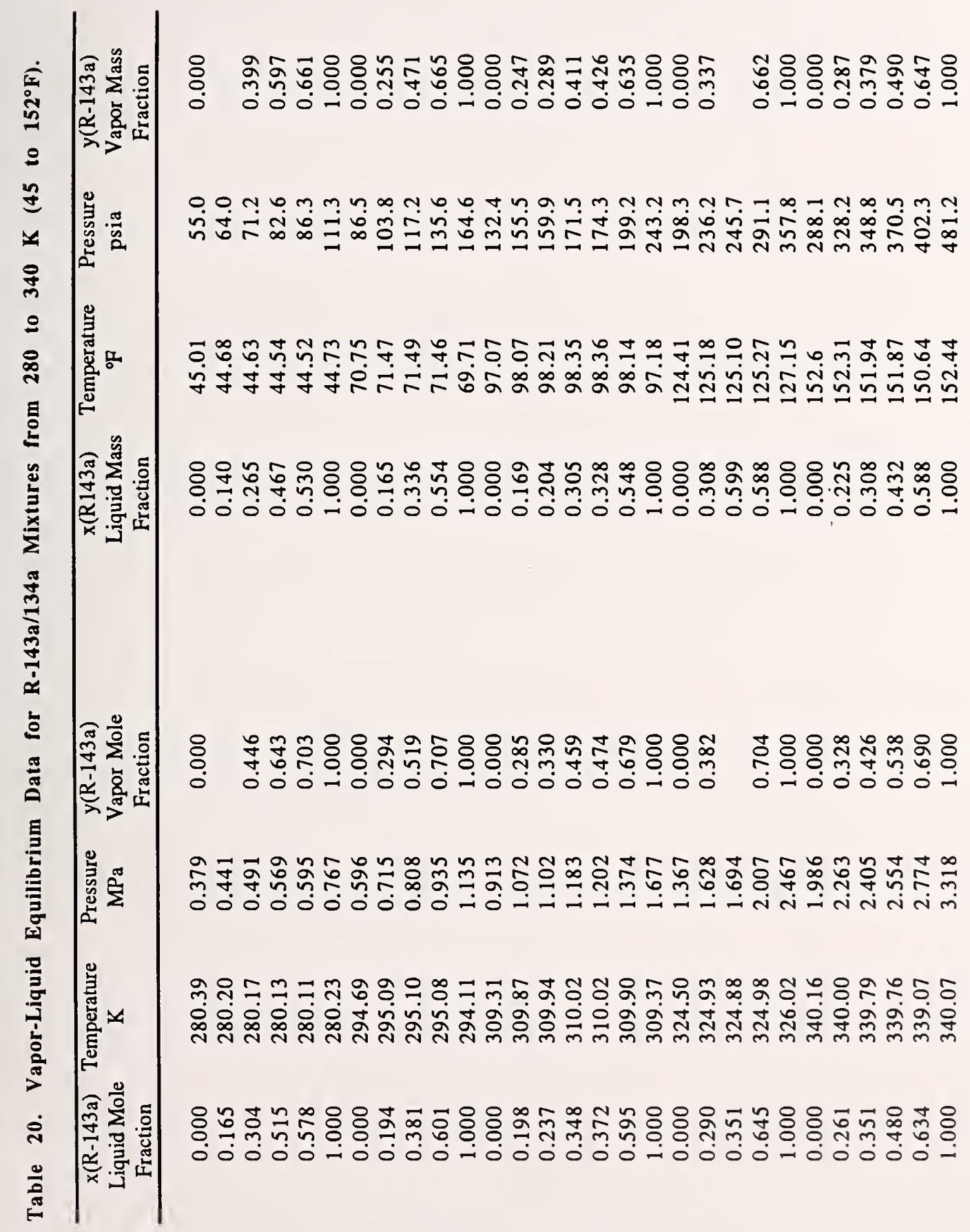




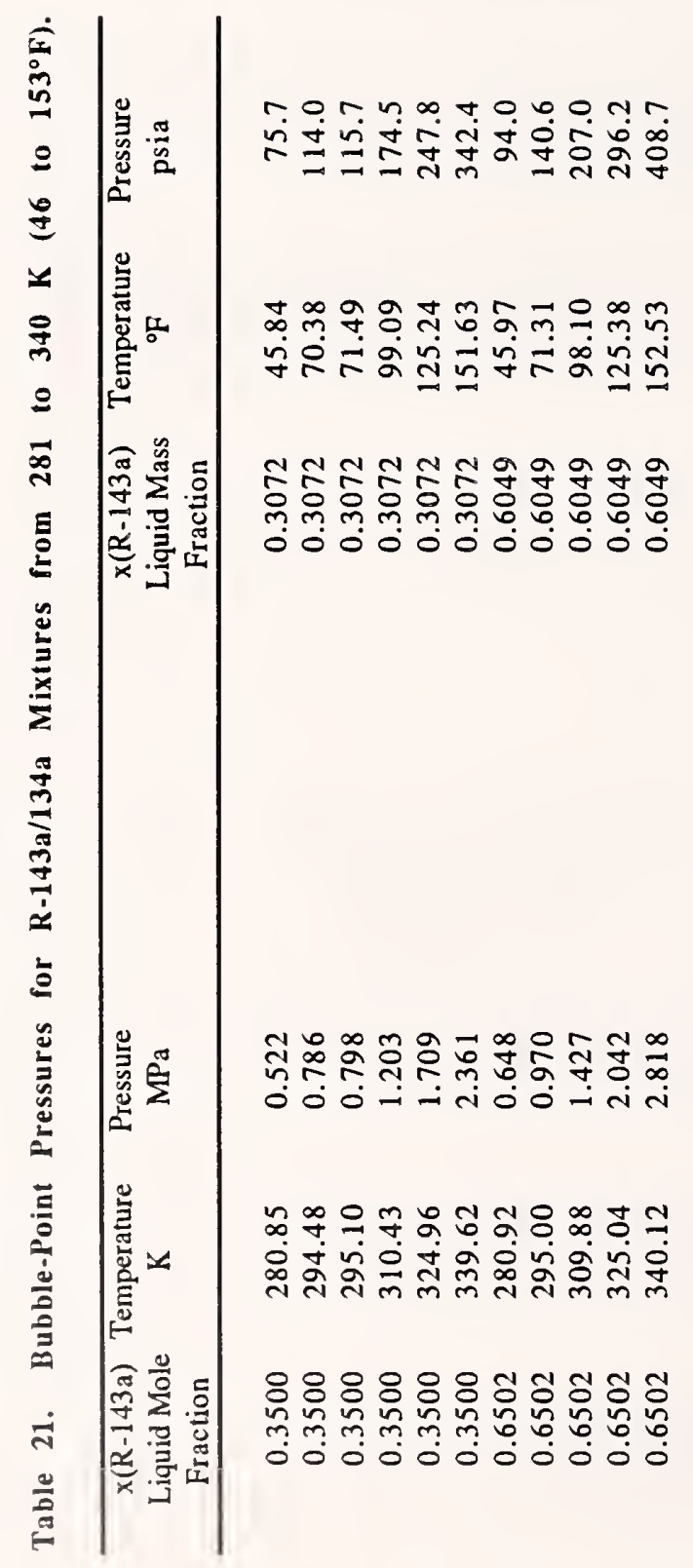




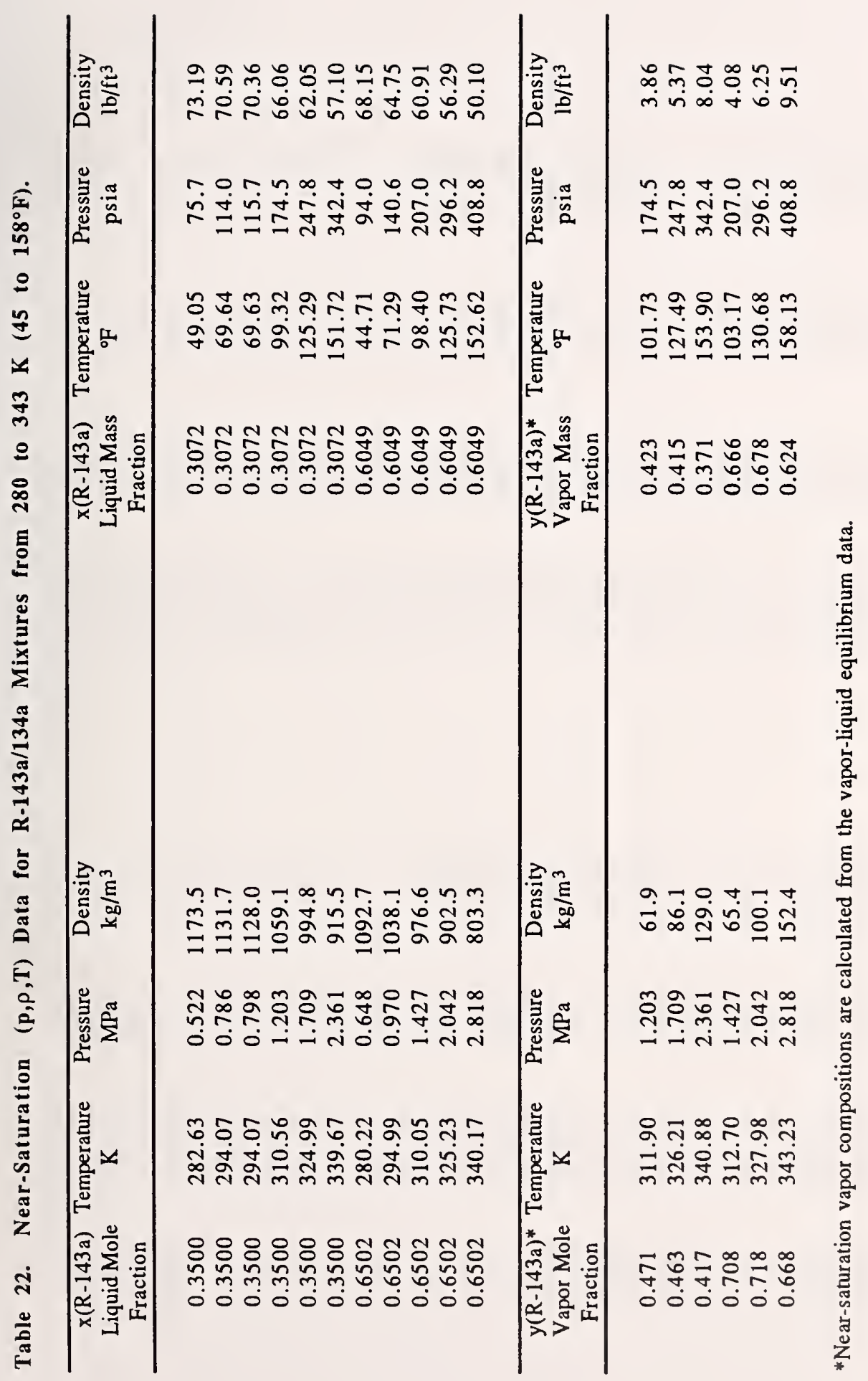




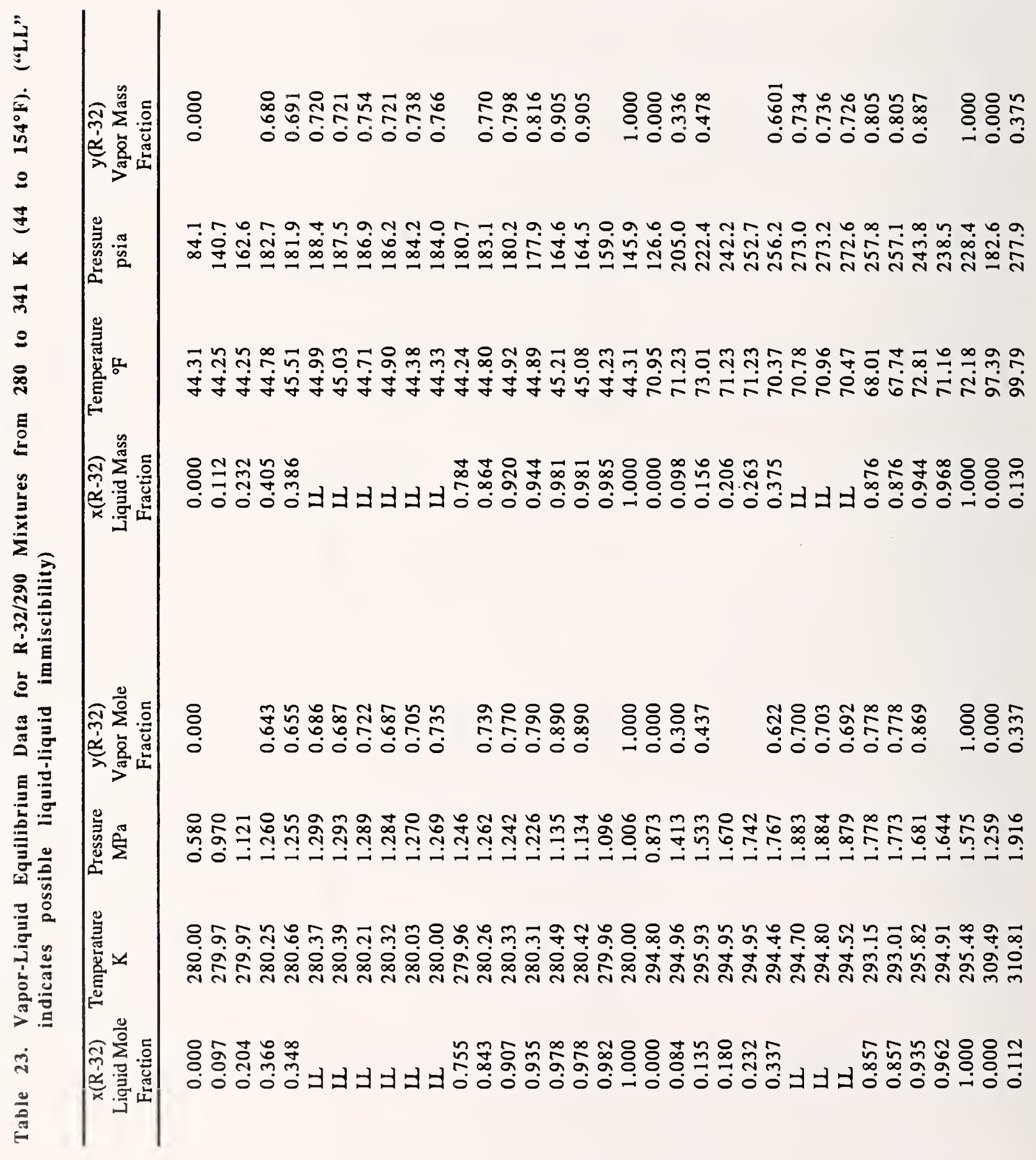




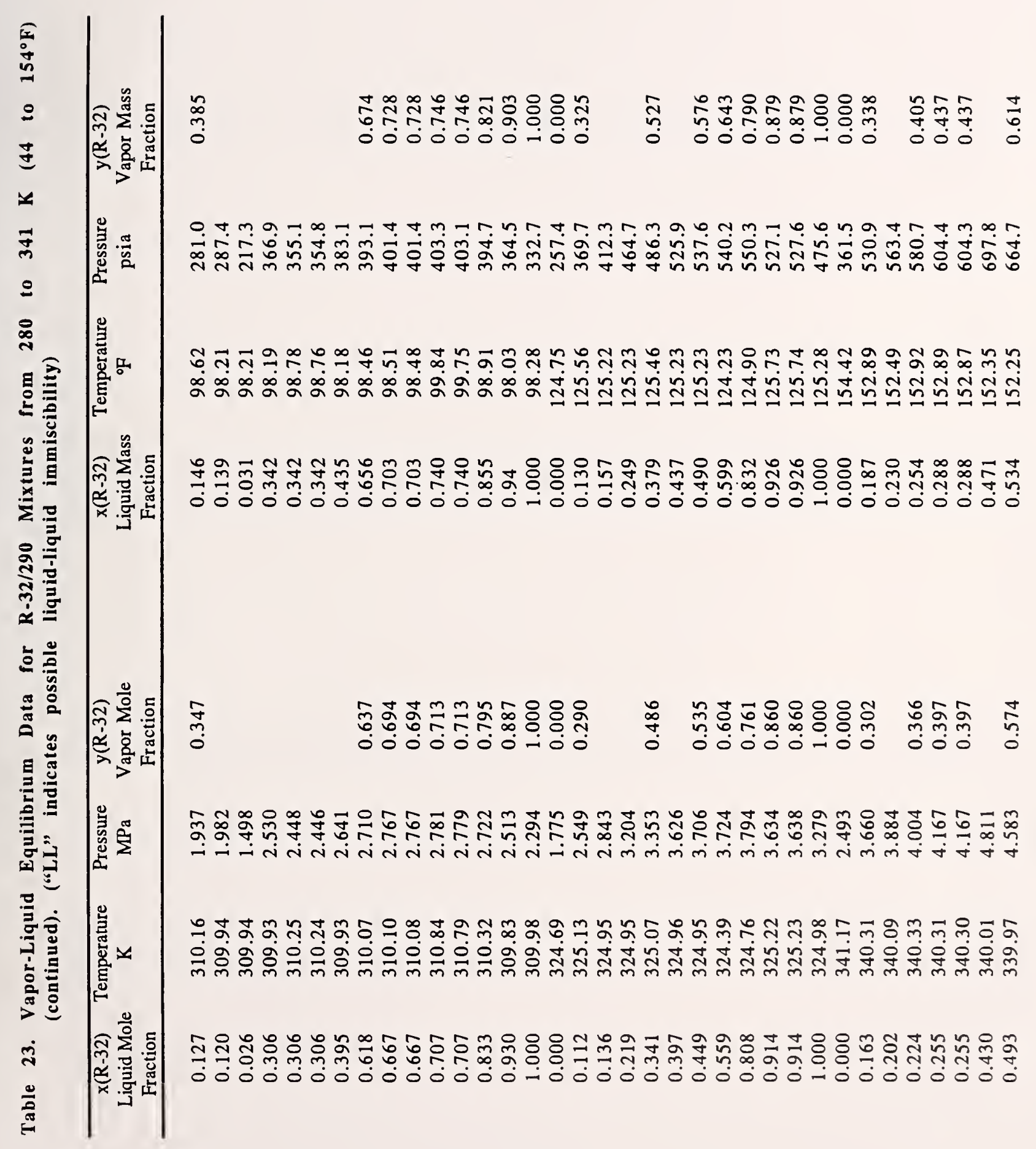




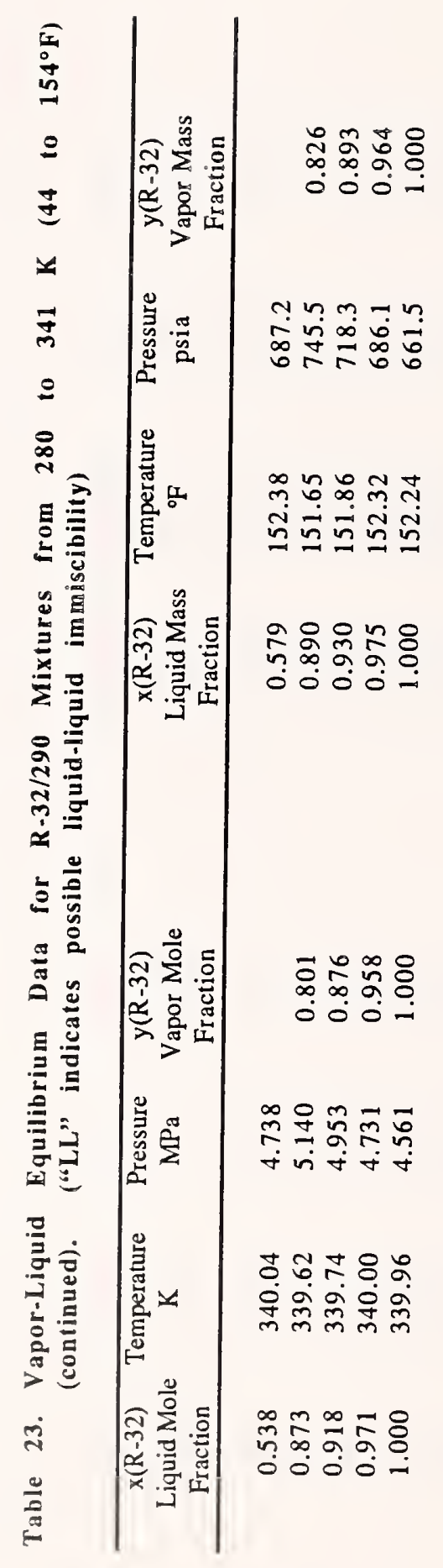




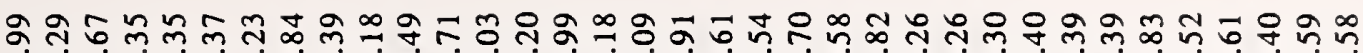

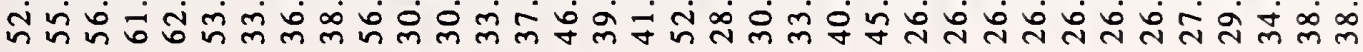

ఈ

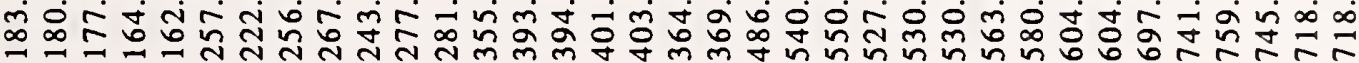

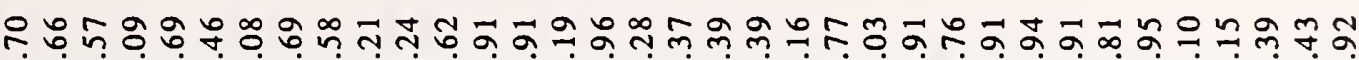

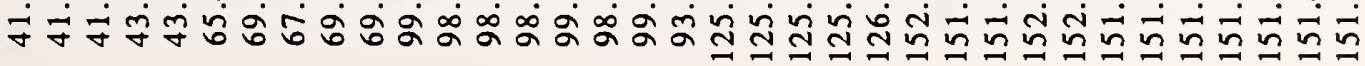

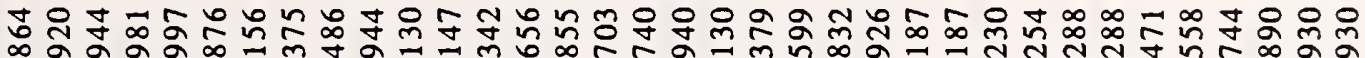

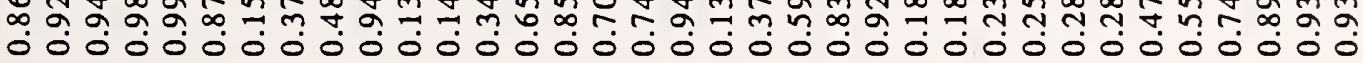

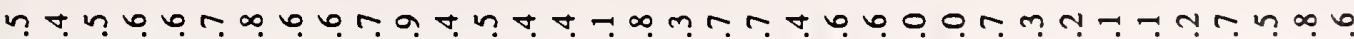
ఫे

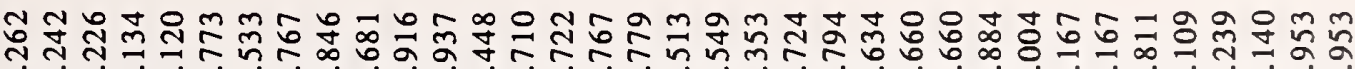

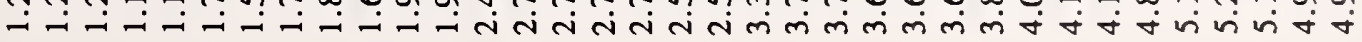

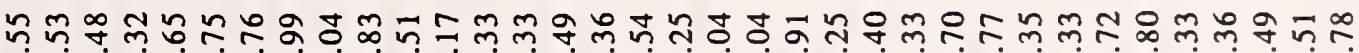

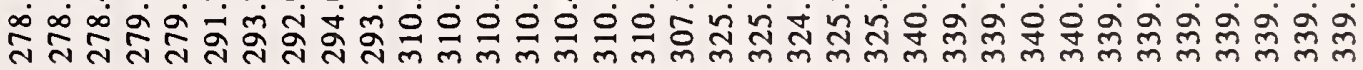

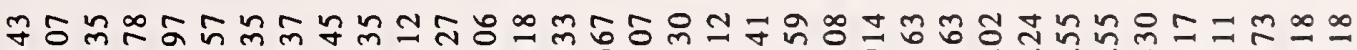

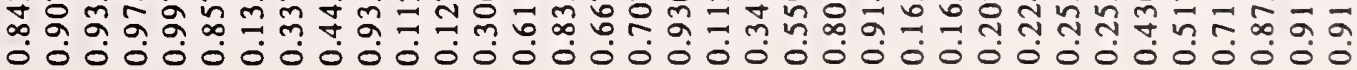




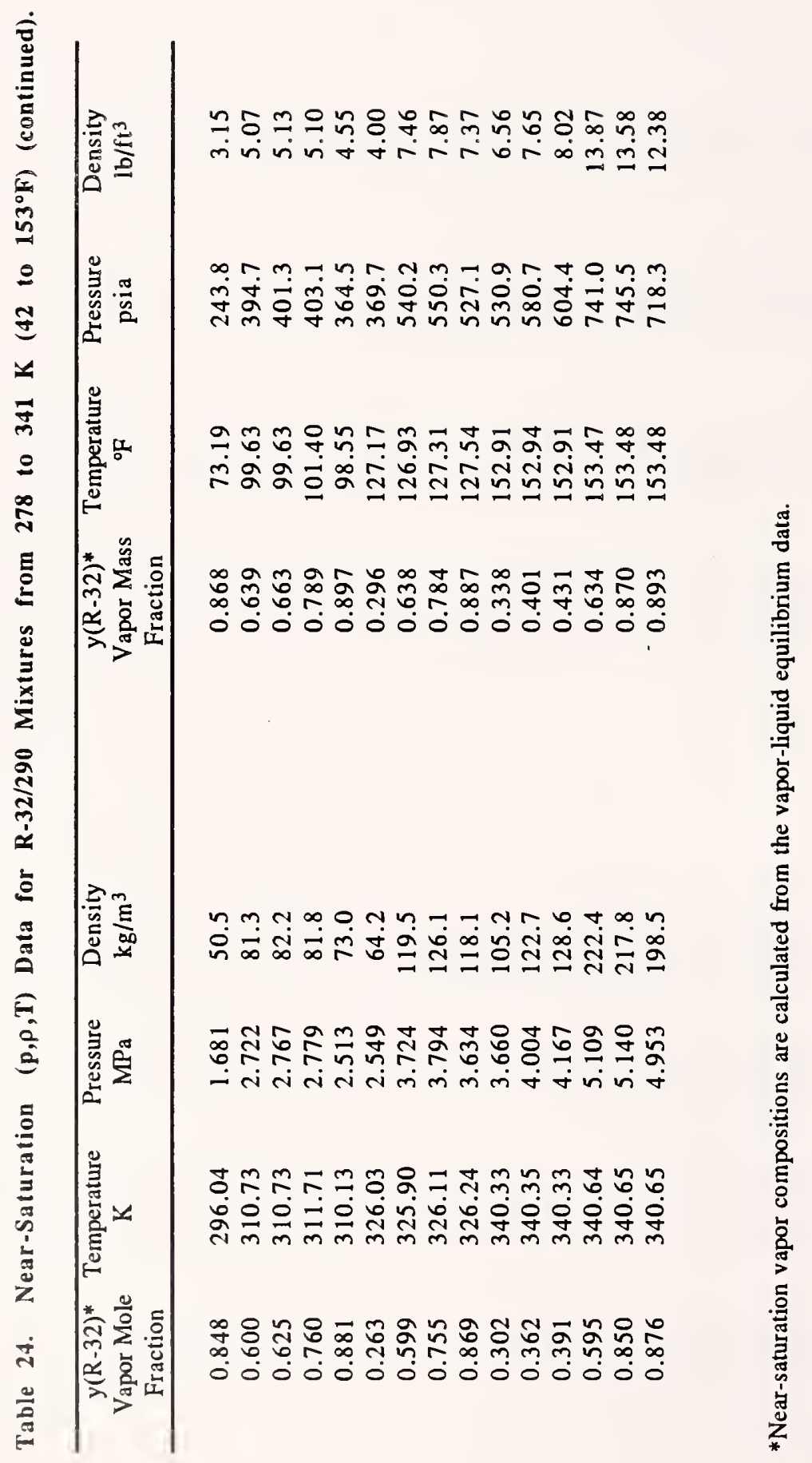




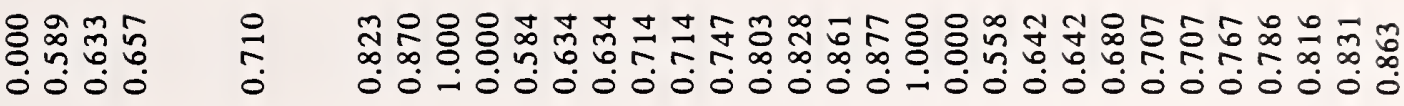

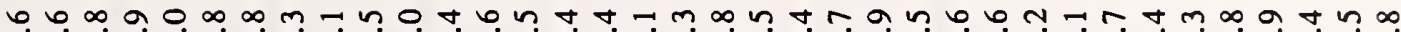
ڤ

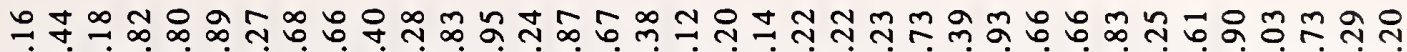

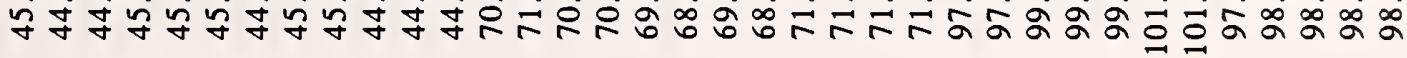

吅

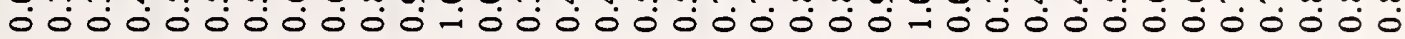

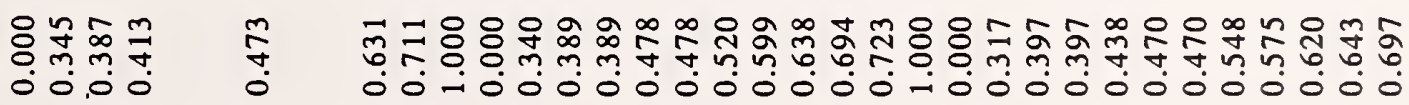

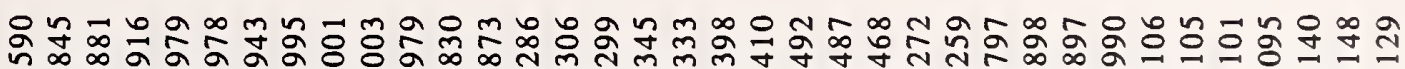

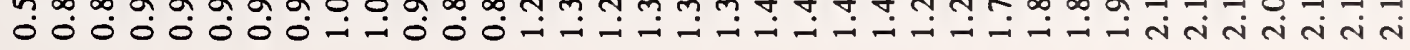

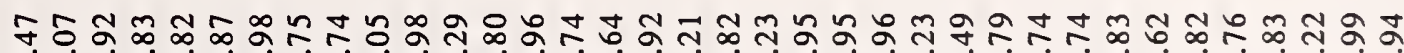

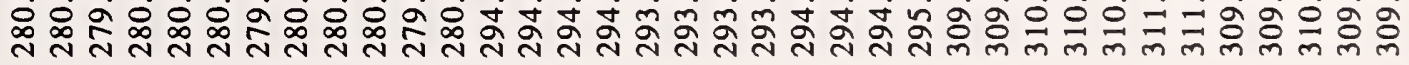

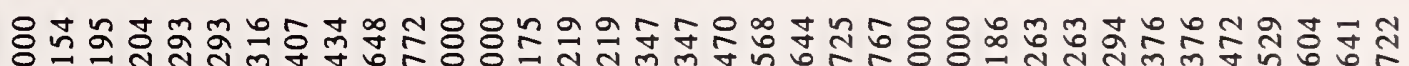

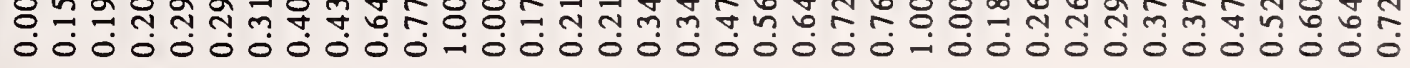




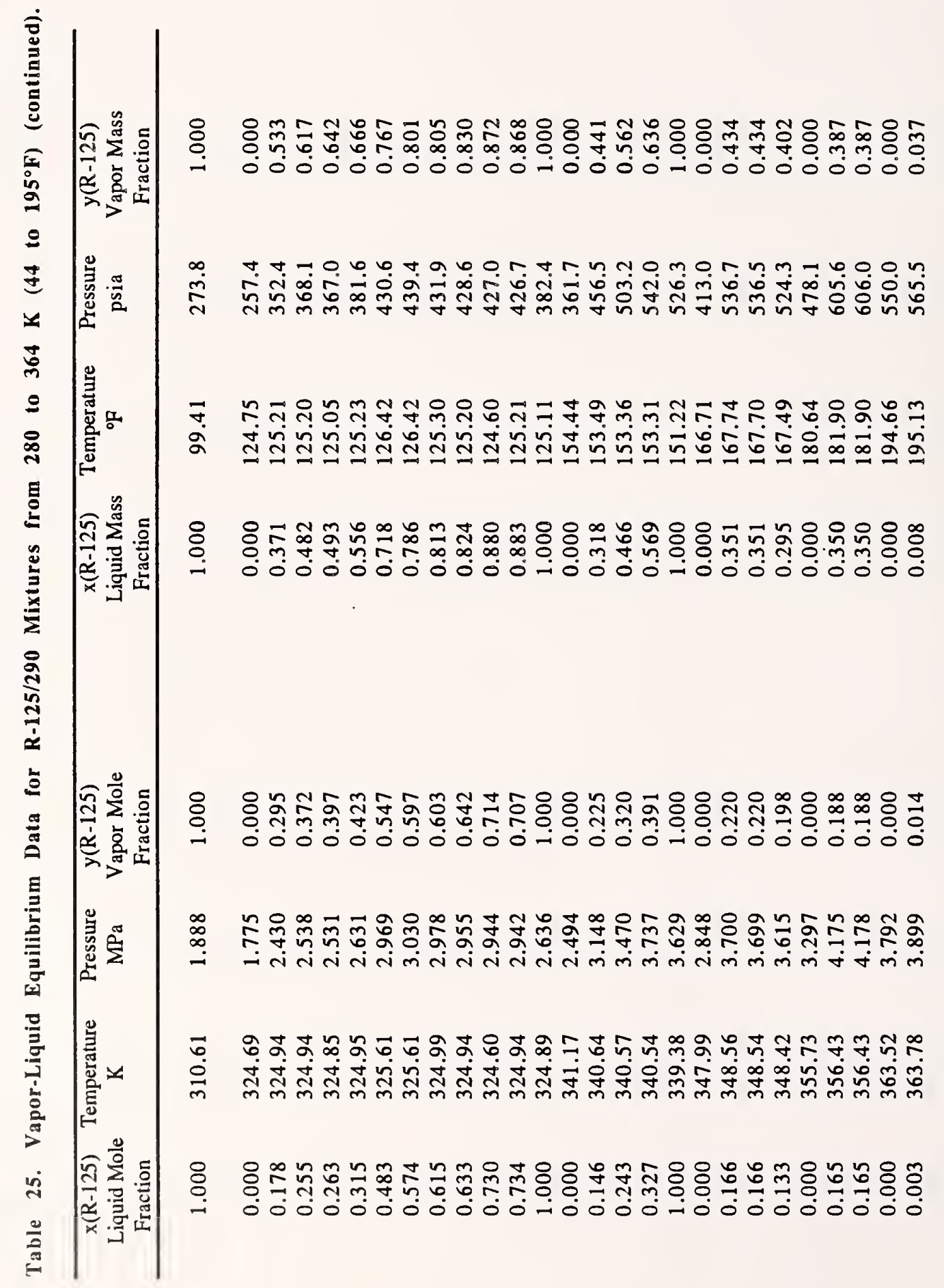




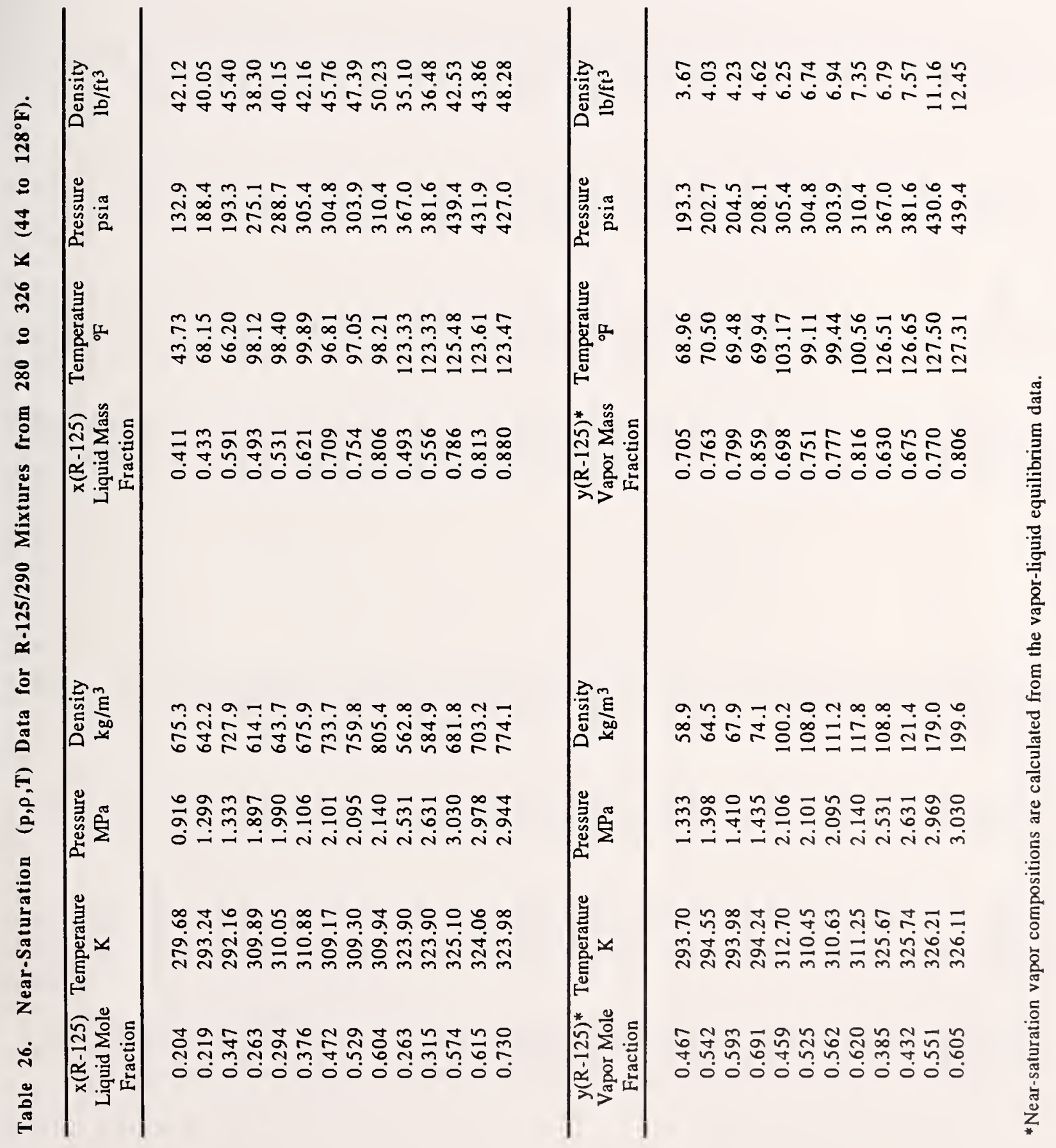




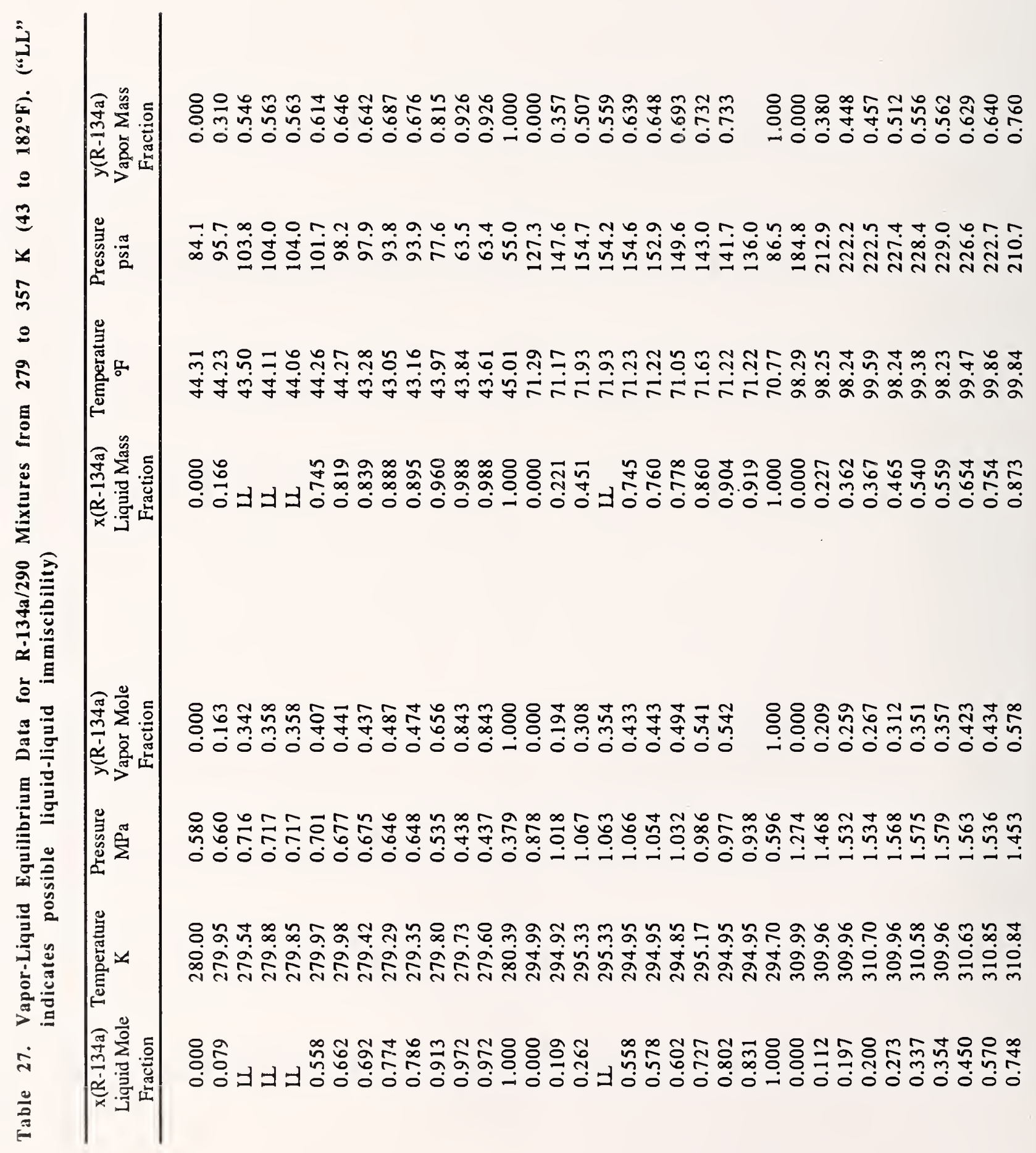




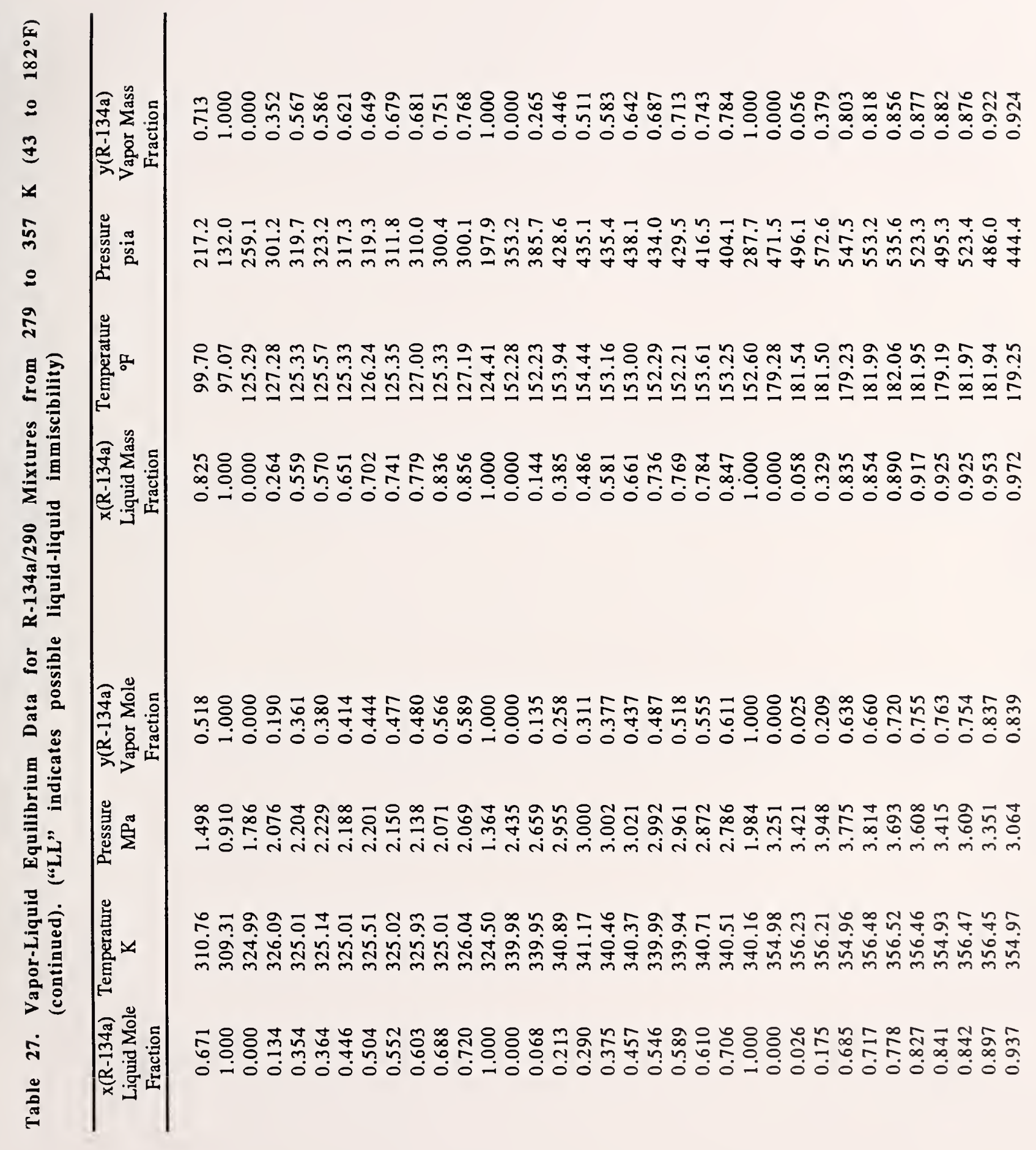




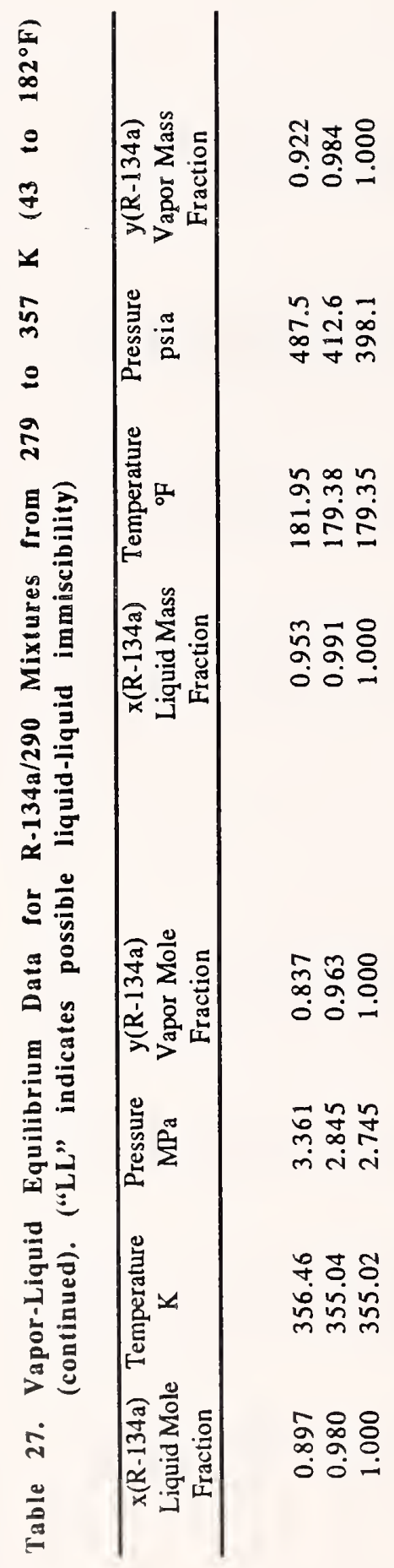


ఫำ

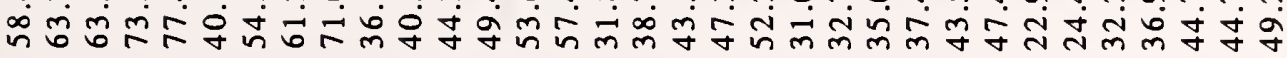

a 0 a on

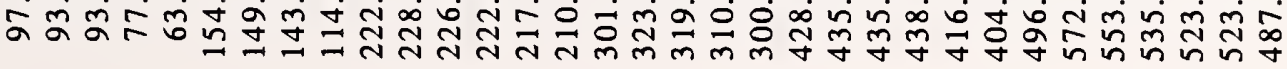

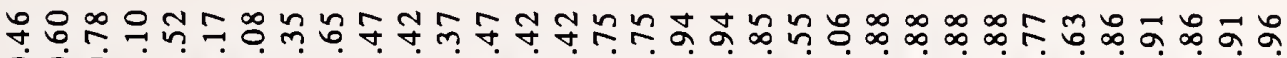

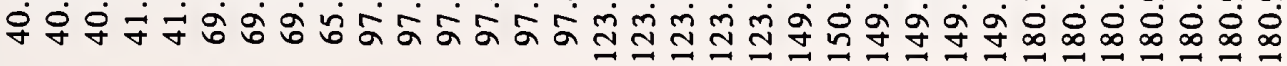

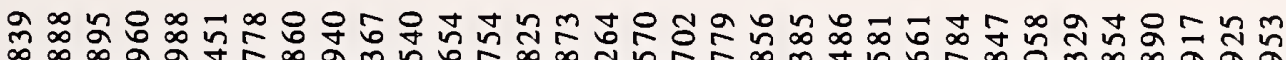

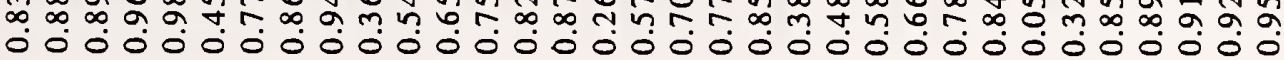

r.

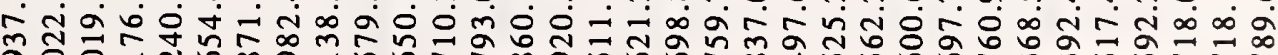

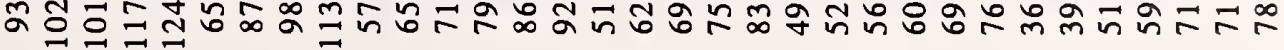

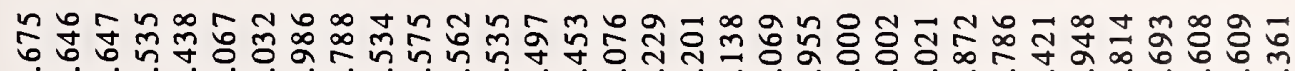

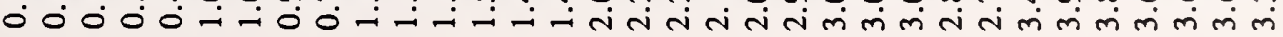

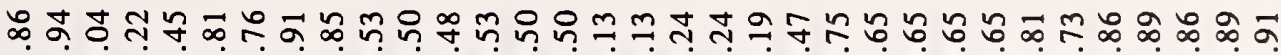

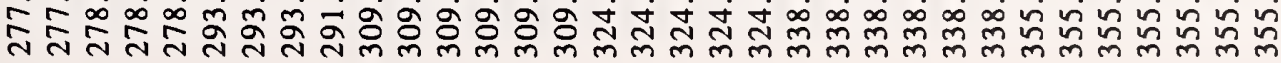

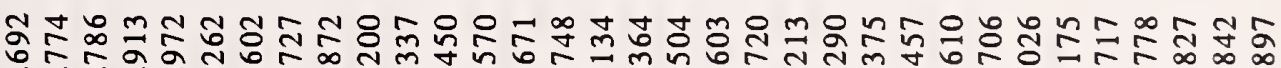

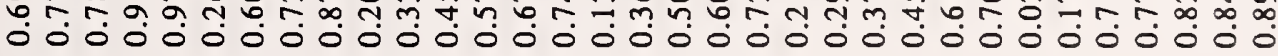




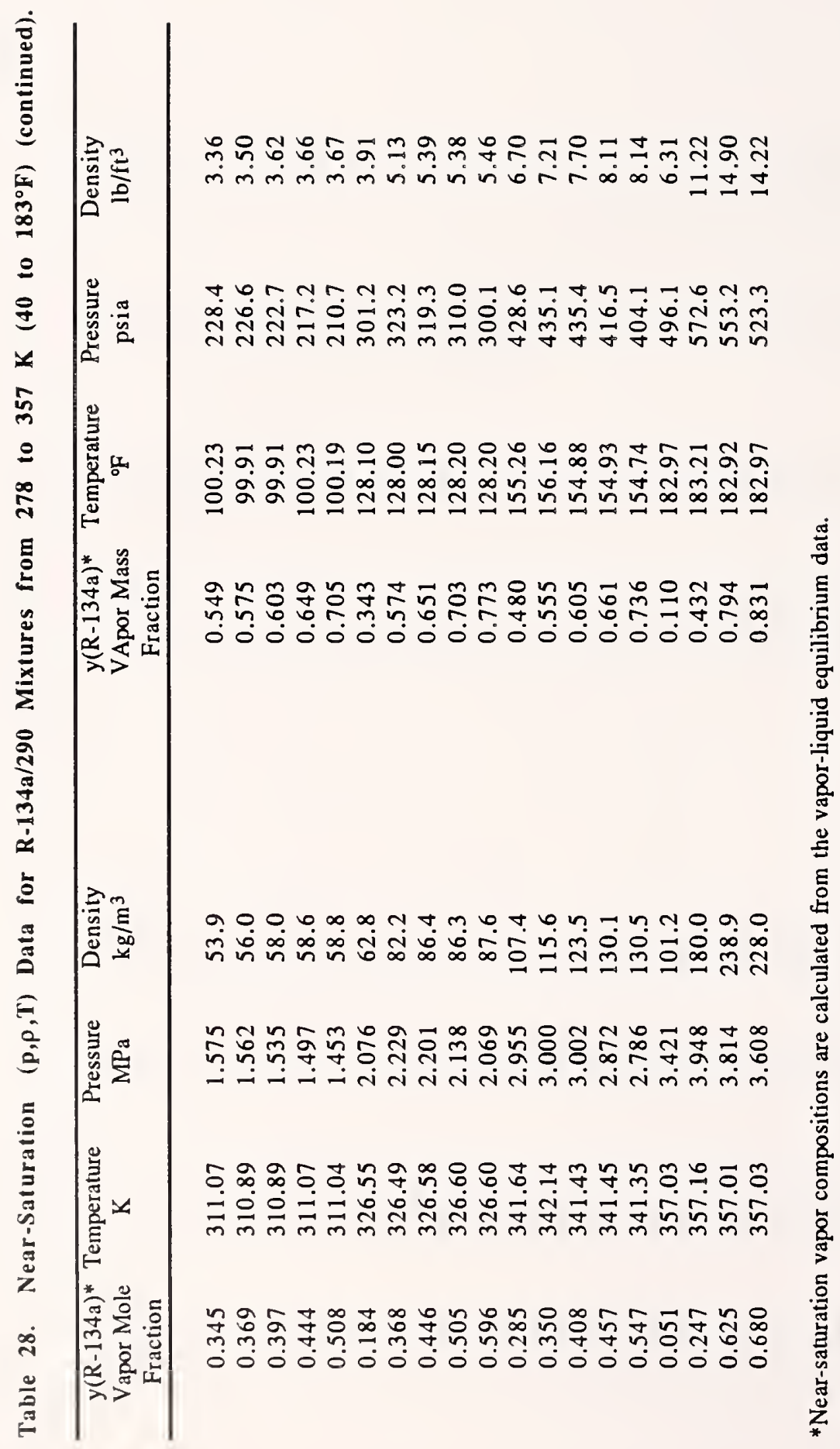




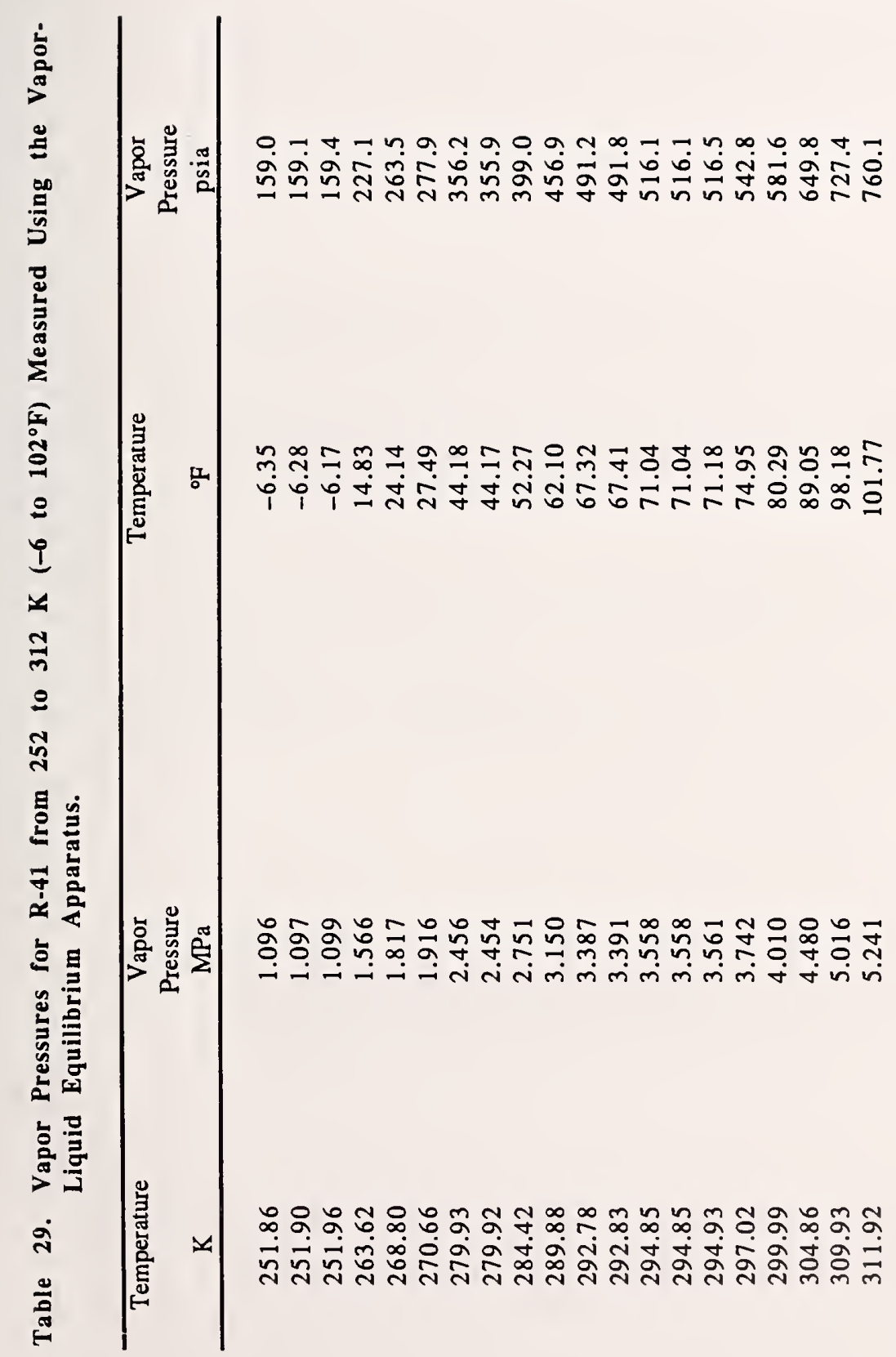




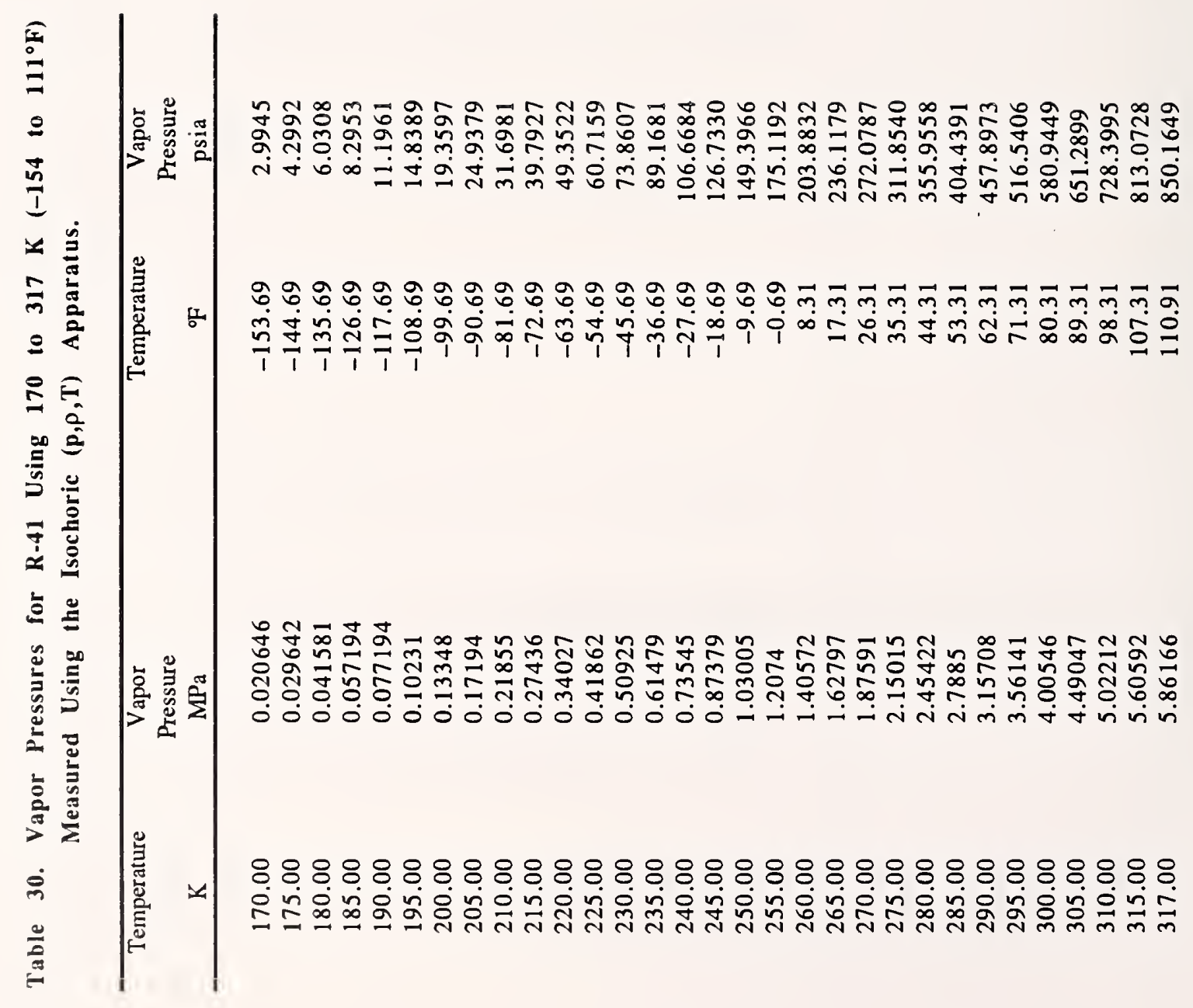




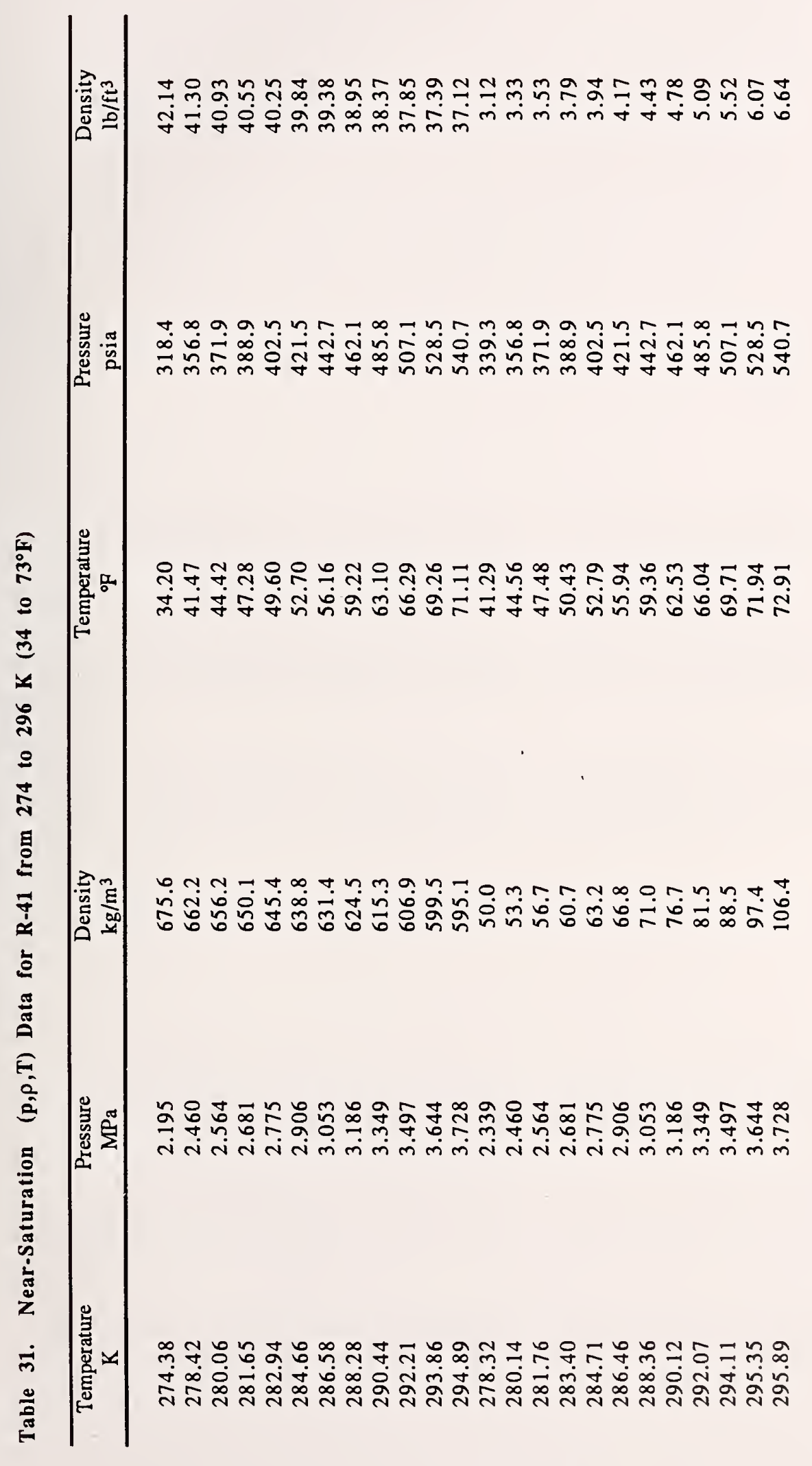




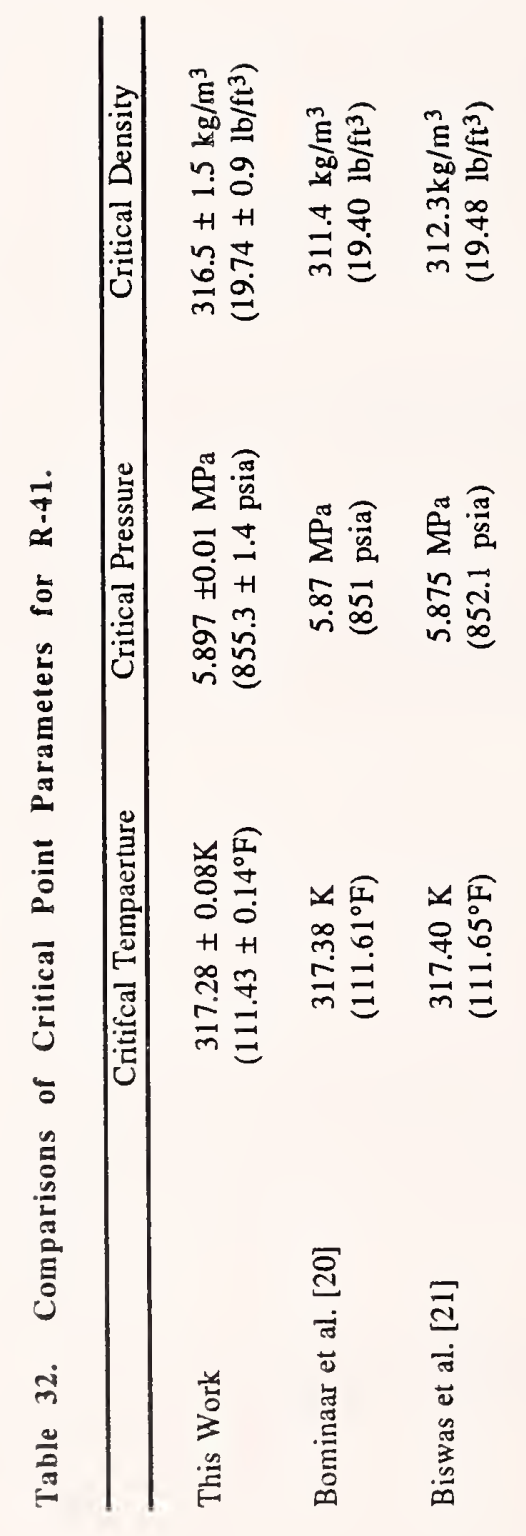




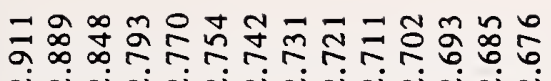
สู่

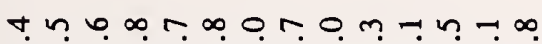
Иี่ ñ

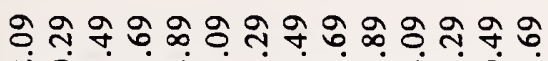

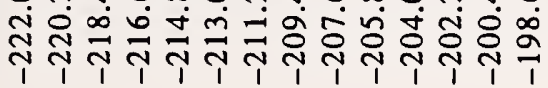

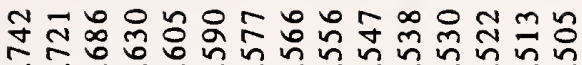

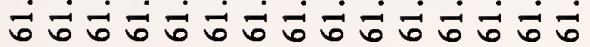

กูํำกำำ : 8 is

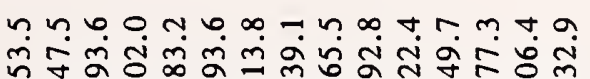
ที่

anor.r.

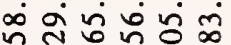
กั

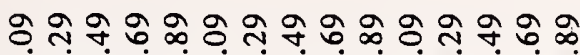
ப் ठ் 궁유
웡영워 तi $\infty \dot{i} \dot{m}$ $\infty 2=\pi=$

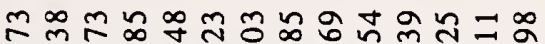

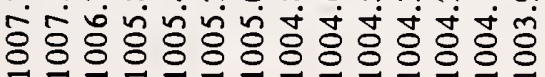

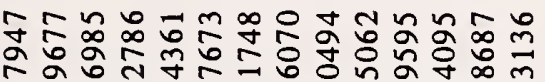
mं

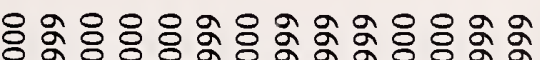

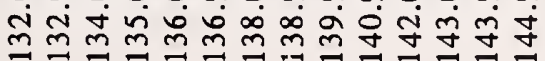

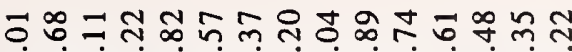

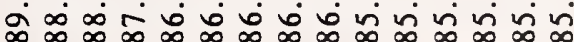
å

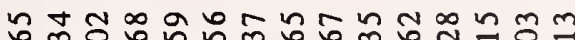

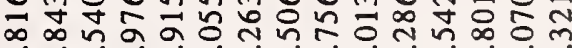

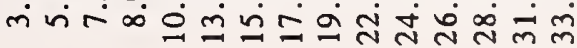

영영ㅇㅎㅇㅇㅇㅇㅇㅇㅇ응

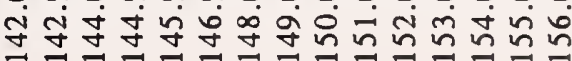

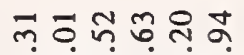

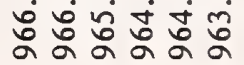

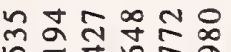

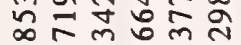
mini⿻

융영형

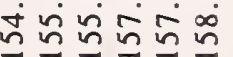




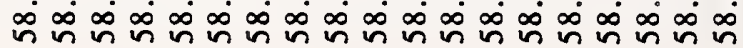

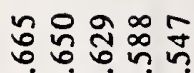
ที่

-arorra-ana

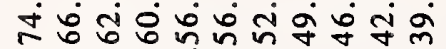

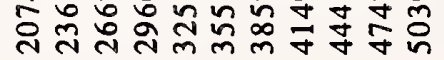

4

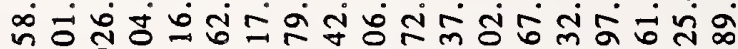

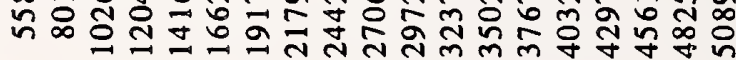

a $0 \div \operatorname{man}$ กิฺ๊ำ

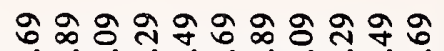

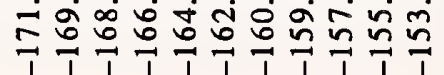

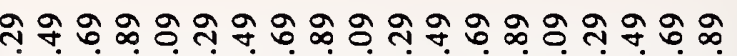

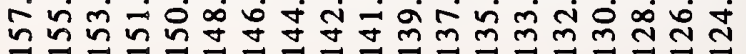

ㅇํㅇํㅇำ

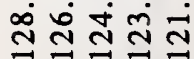

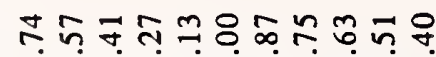

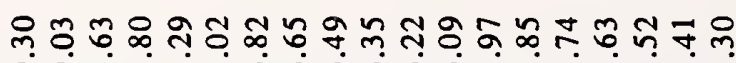

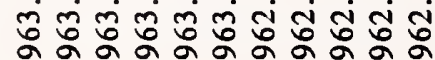

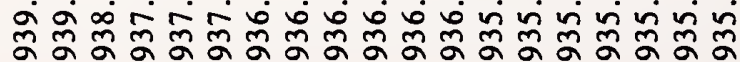

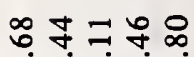
ㄷㅇㅇㅇㅇㅇㅇㅇㅇㅇ

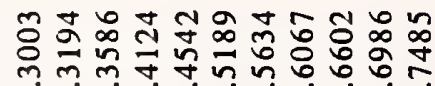
ปे

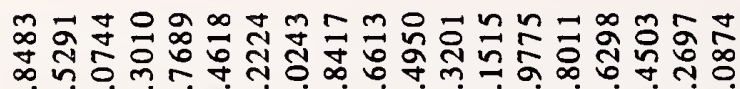
m

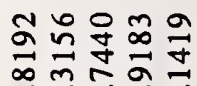

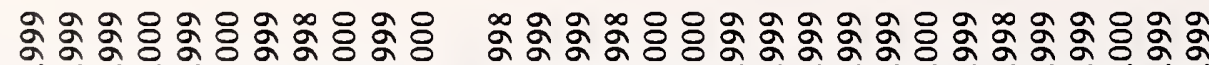
กิ: 万ั

88885

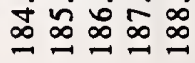




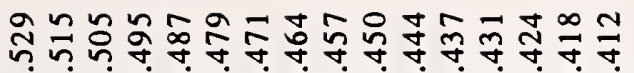


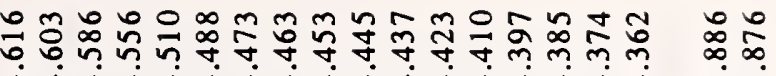

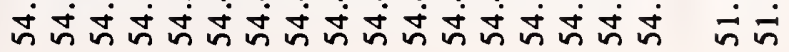

mกm mஸ்

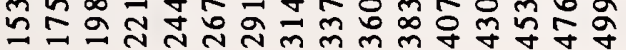

nก

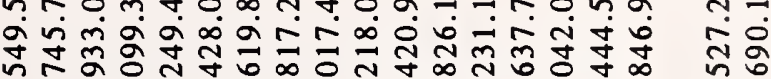

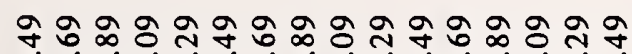

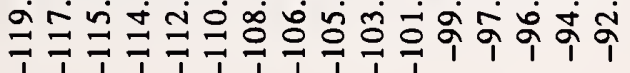

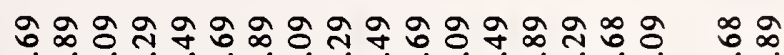
gi å

육ำ

๙

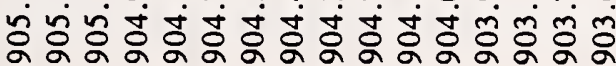

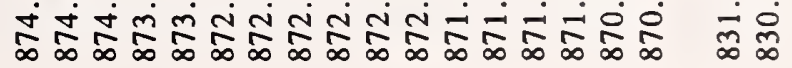

윰

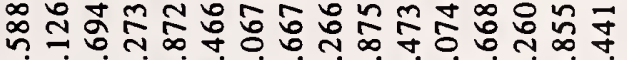
임

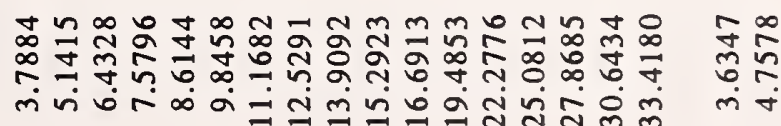

흥ㅎㅇㅇㅇㅇㅇㅇㅇㅇㅇㅇㅇㅇㅇㅇㅇㅇㅇㅇㅇㅇㅇㅇㅇㅇㅇ

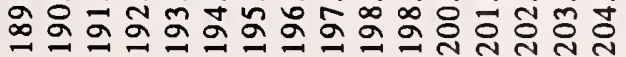

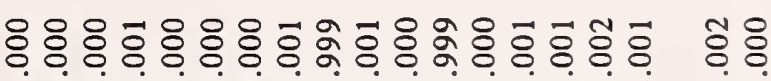

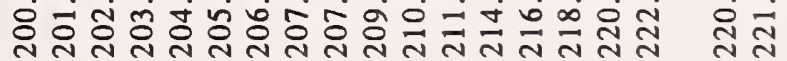




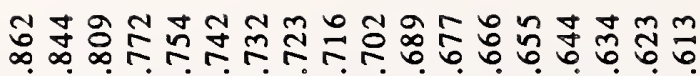

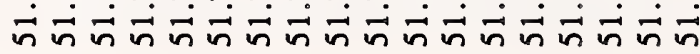

m. n m ஸ் ல்

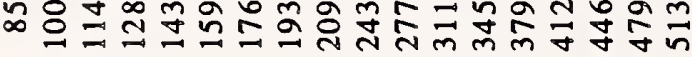

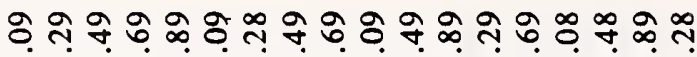

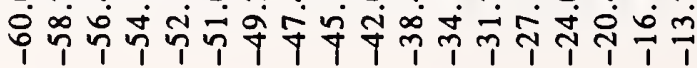

ㄴํㅇำ

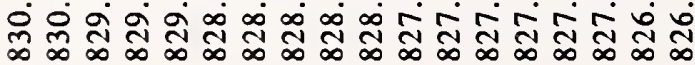

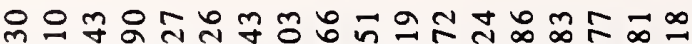

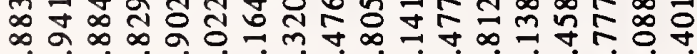

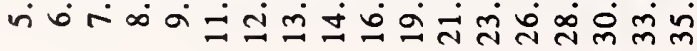

б.

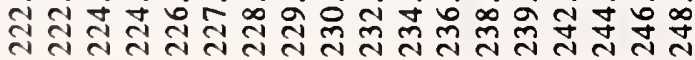

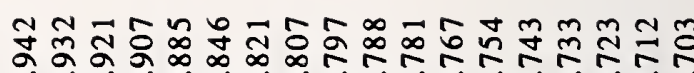

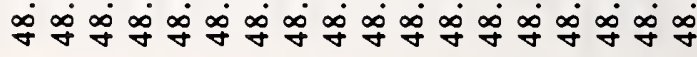

4 กี

항 읭 읭 तิণ

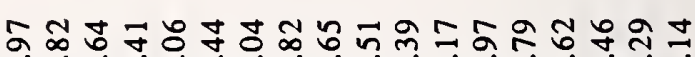
ஸ்

용요 $\infty r 0 n$ f

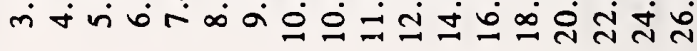

응ㅎㅇㅇㅇㅇㅇㅇㅇㅇㅇㅇㅇㅇㅇㅇㅇㅎㅇㅇㅇㅇㅇㅇㅇㅇㅇㅇ

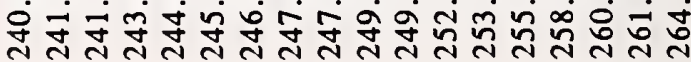




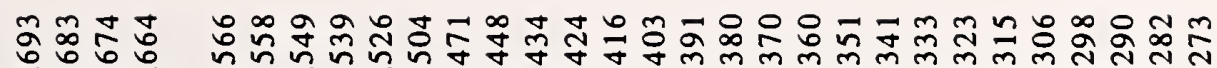

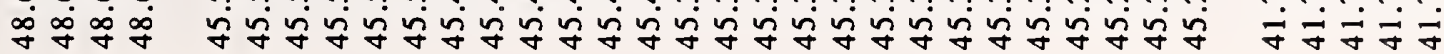

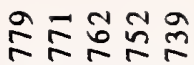

ntবn 0.

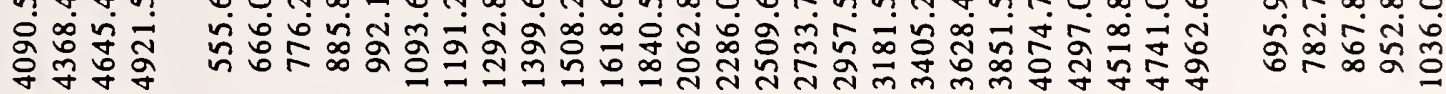

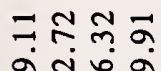

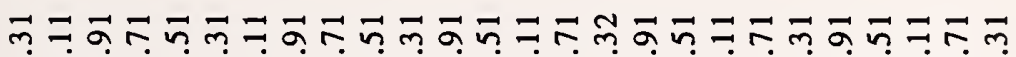

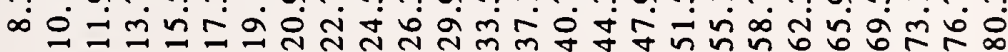

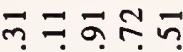
ำ ำ

$a \infty \infty$

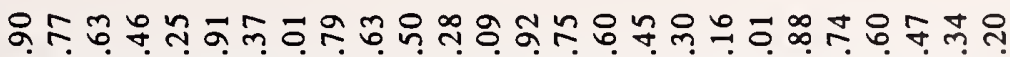
유용

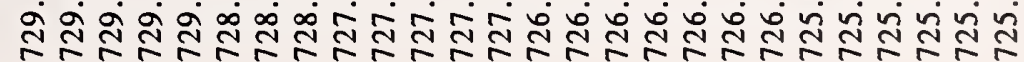

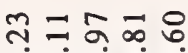
î

ิํㅇㅇำ ๙

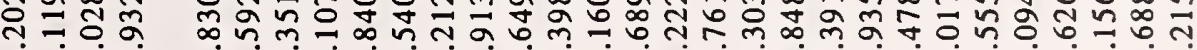

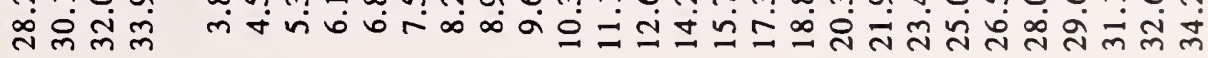

은

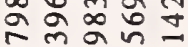

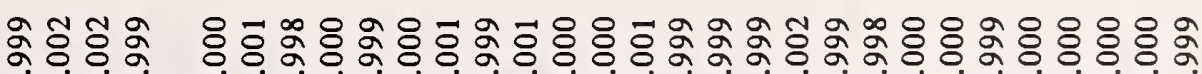

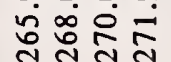
迥

용 i $\bar{\infty}$ i 


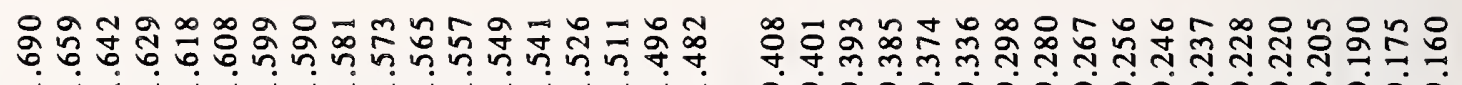

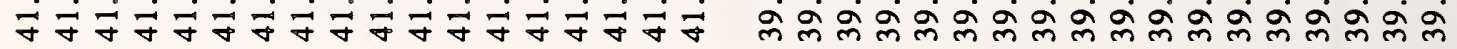

a

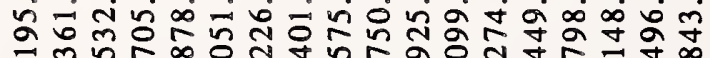

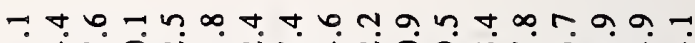

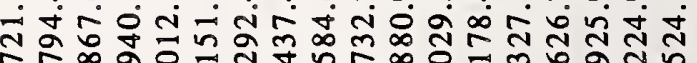
च

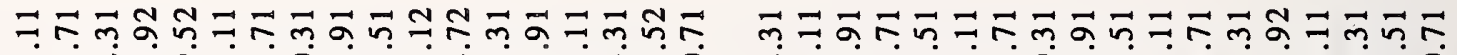

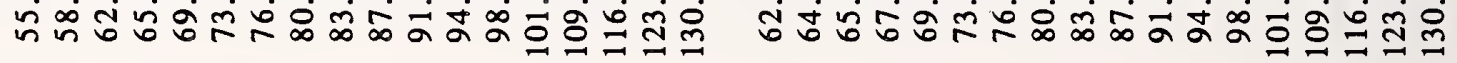

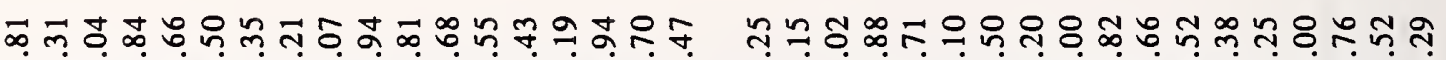

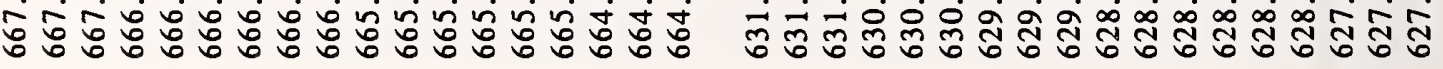

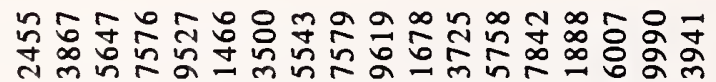
$\infty$ åำ

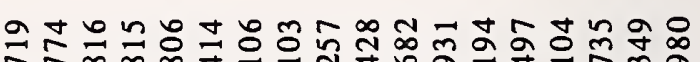

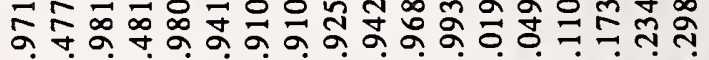
अ

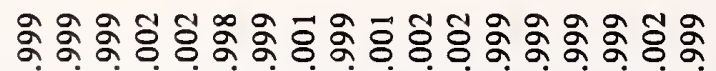

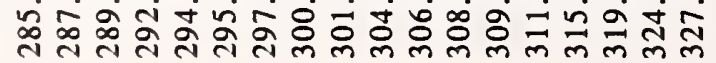

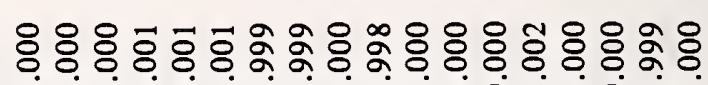

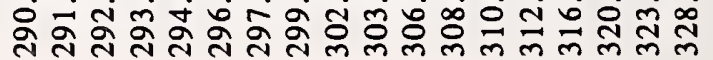




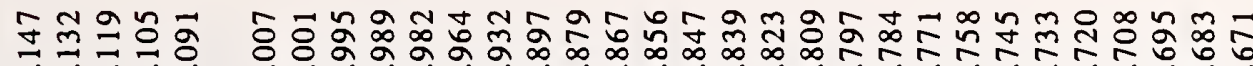
iे $\dot{m}$ i

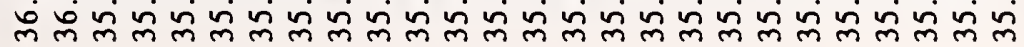

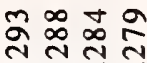

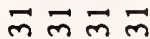

H

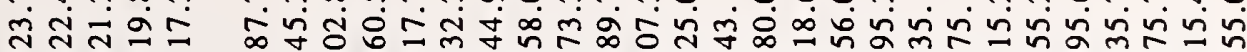

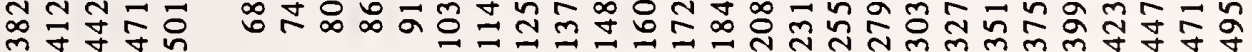

ro.

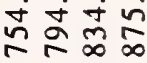

ตุำ

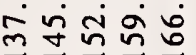

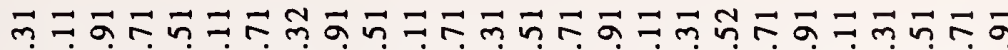
வ

$\vec{n}=\vec{\sigma}=$ a

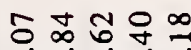

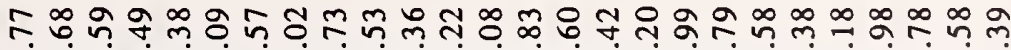
तิ மீம்

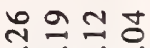

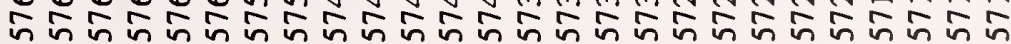

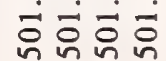

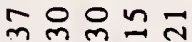

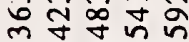

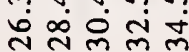

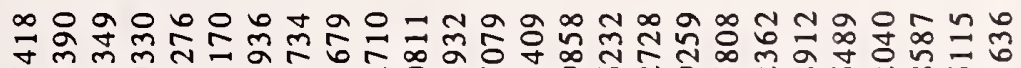

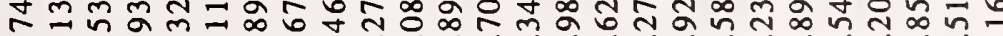

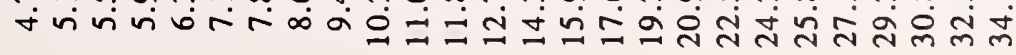

전용요 중 ต่

융용요

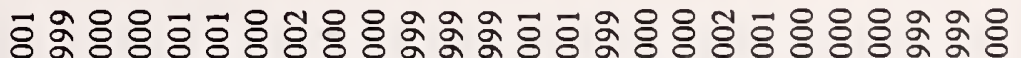
ले

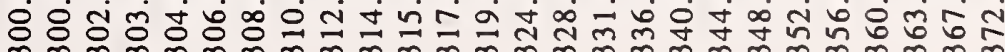

ஓㅇํㅇㅇㅇㅇ $\stackrel{0}{0} \equiv \dot{m}$ 


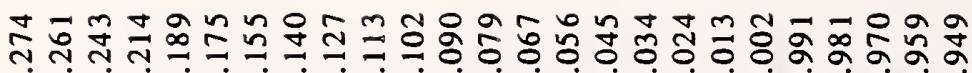

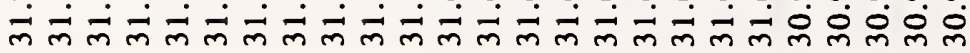

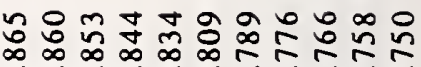

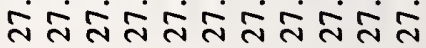

m ต เ எં

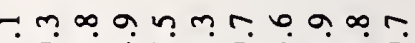

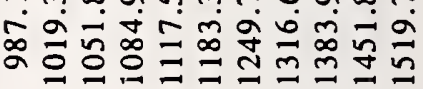

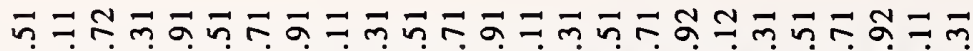
ஜ்

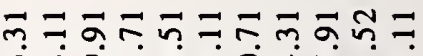

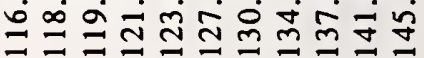

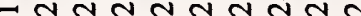

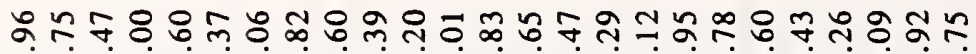

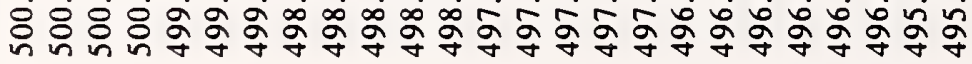

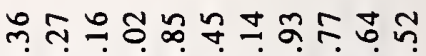

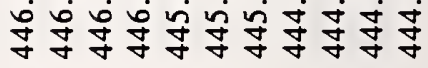

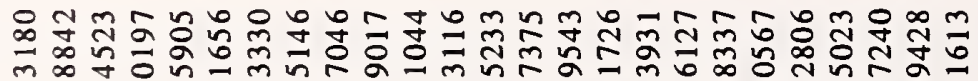

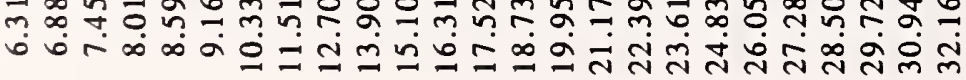

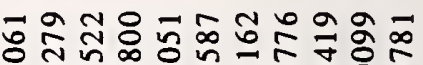

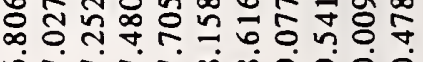
urriris a

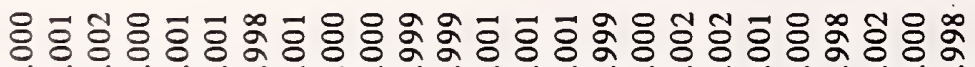
隹市

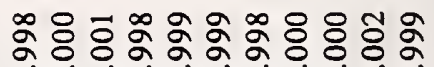

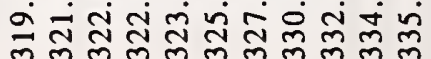




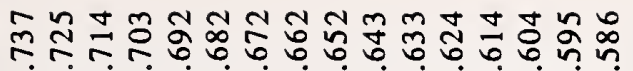

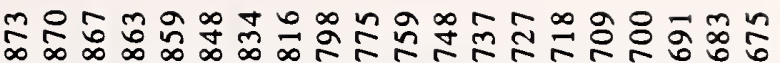

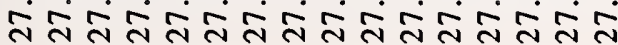

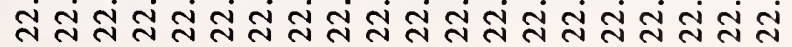

ด 9 \% ம்

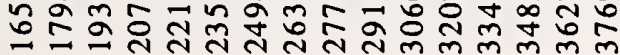

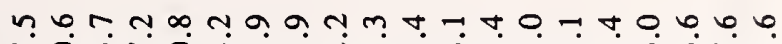
웅

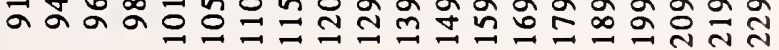

$\vec{m} \vec{n} \vec{\sigma} \exists \vec{m} \vec{n} \vec{a} \exists \vec{m} \vec{n} \vec{\sigma} \exists \vec{m}$ तं

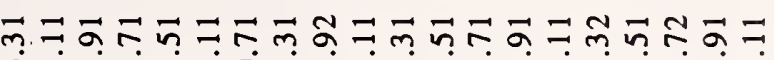

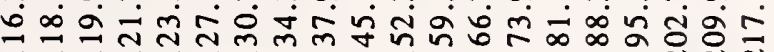

윸ำำำ ำ

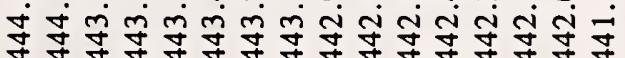

판 ำ 덤

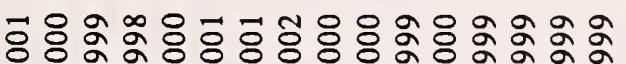

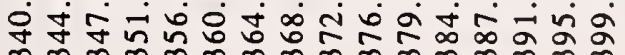

ติ 它

은 సै b ம b

항

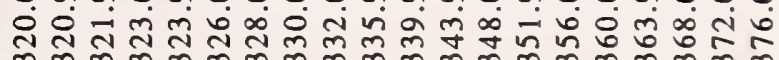




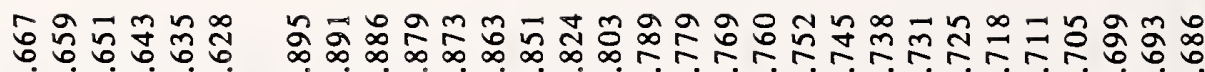
สี่ส่ส

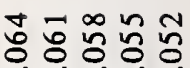
İ $\underset{\mathcal{I}}{ } \underline{\mathrm{I}}$

ก ๆ হं்

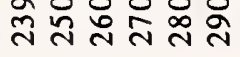
ด̆

mตฺ $ฺ$

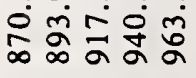

mேี ปี

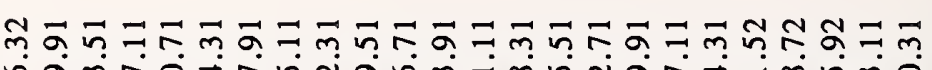
웟ํำ

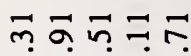

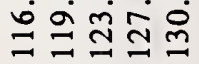

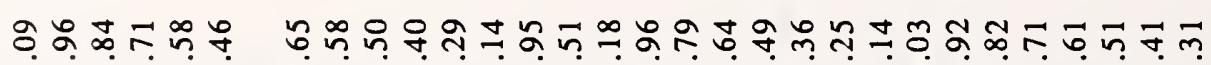
लिं

논ำ은 ติ

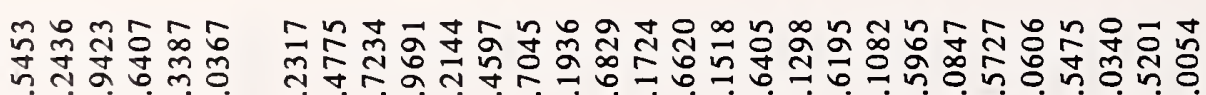
등ㅇㅇ

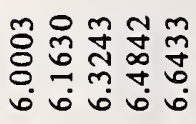

2ু

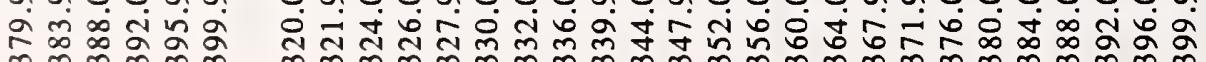

รั

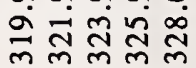




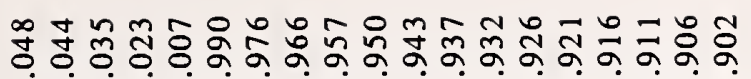

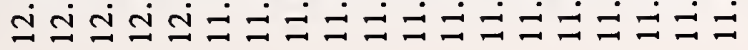

-

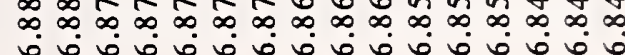

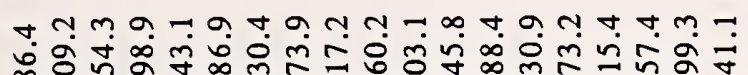

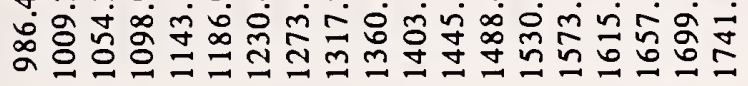

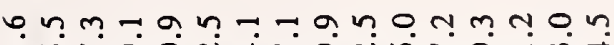

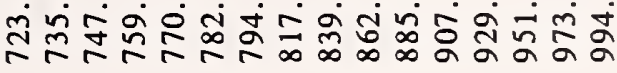

ตั

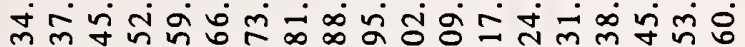

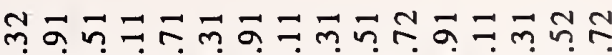

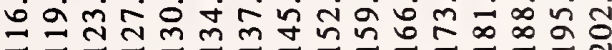

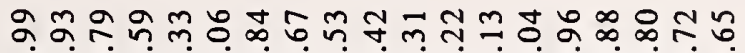

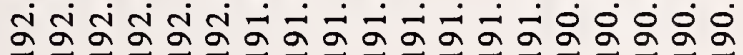

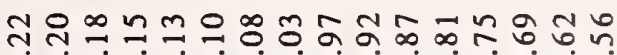

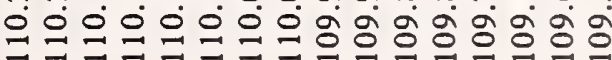

ఫิ

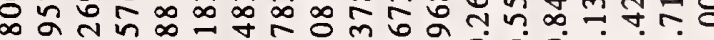

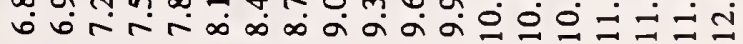

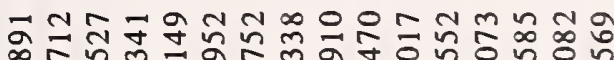

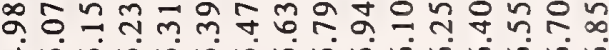

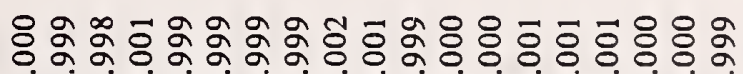

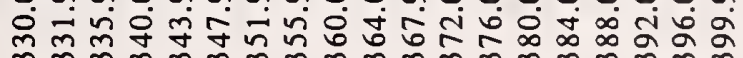

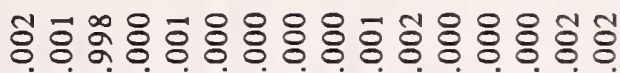

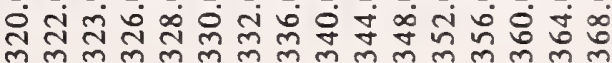




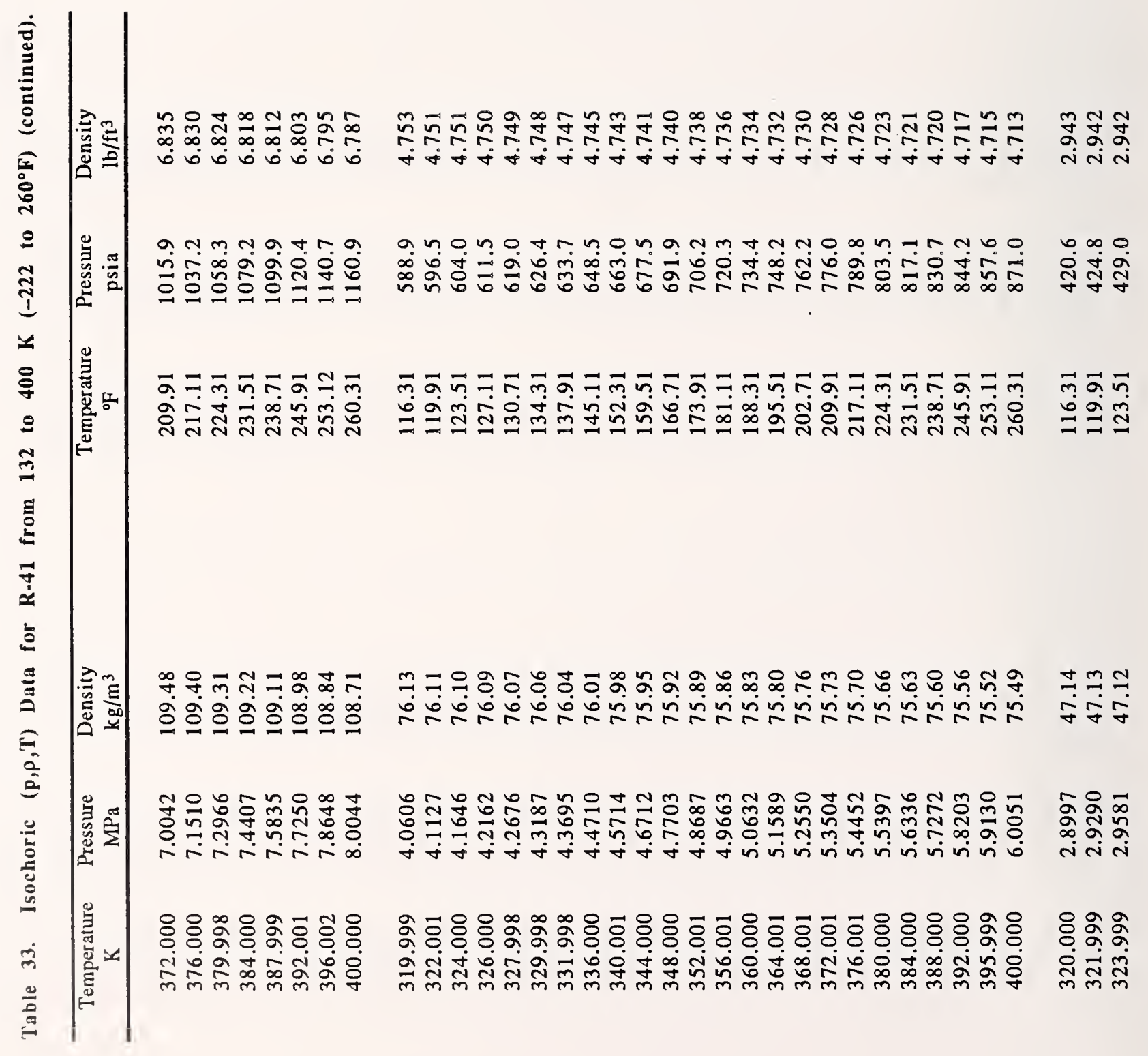




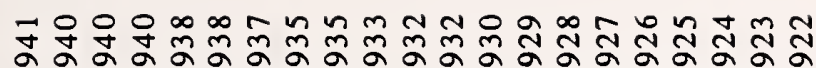

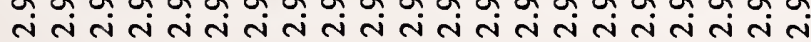

ง ษ

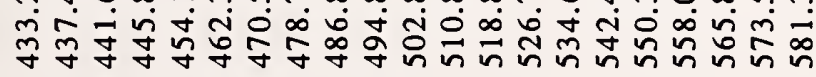

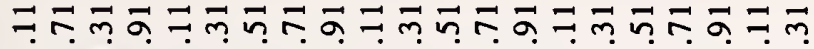

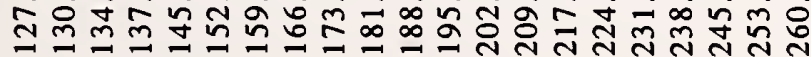

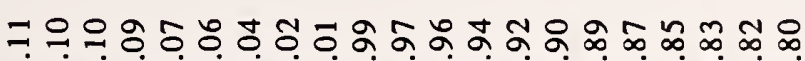

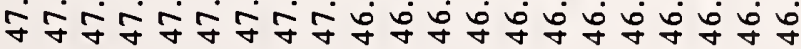

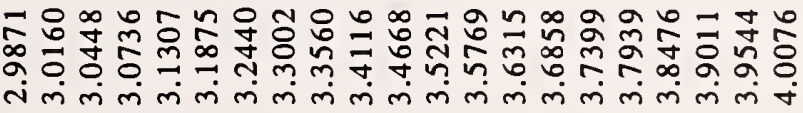

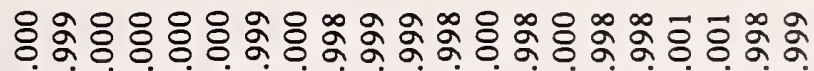

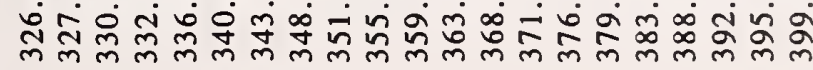




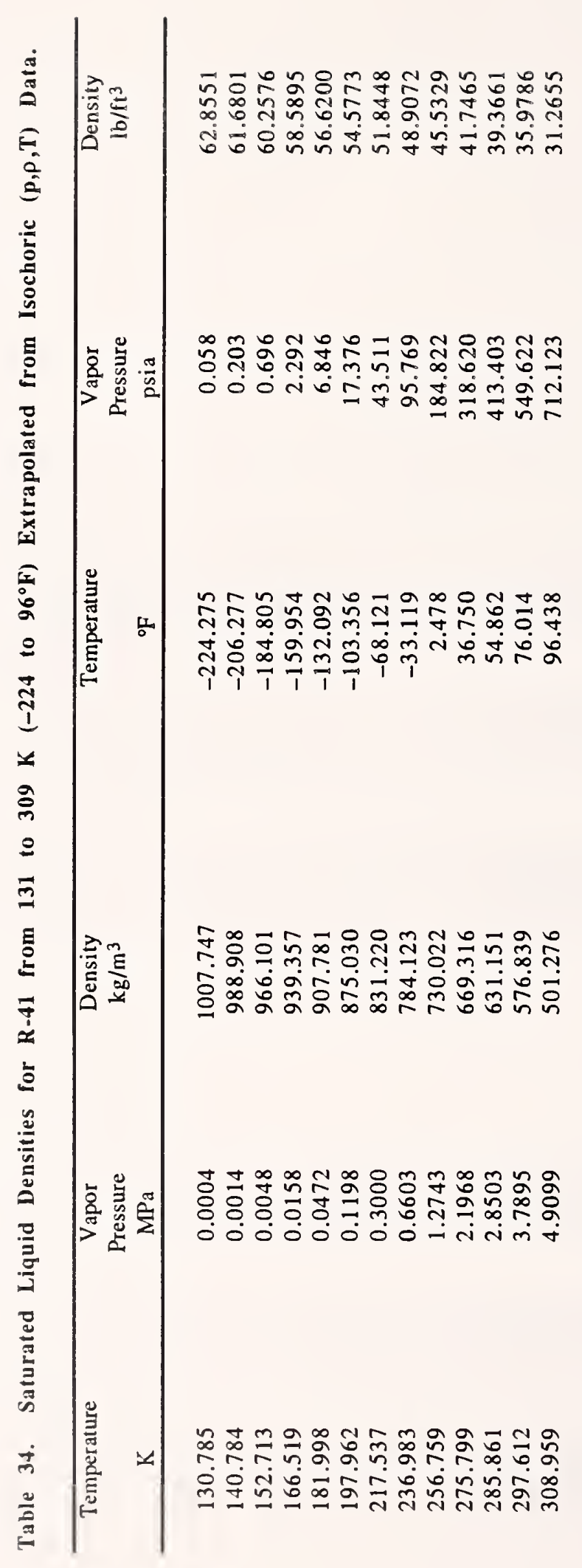




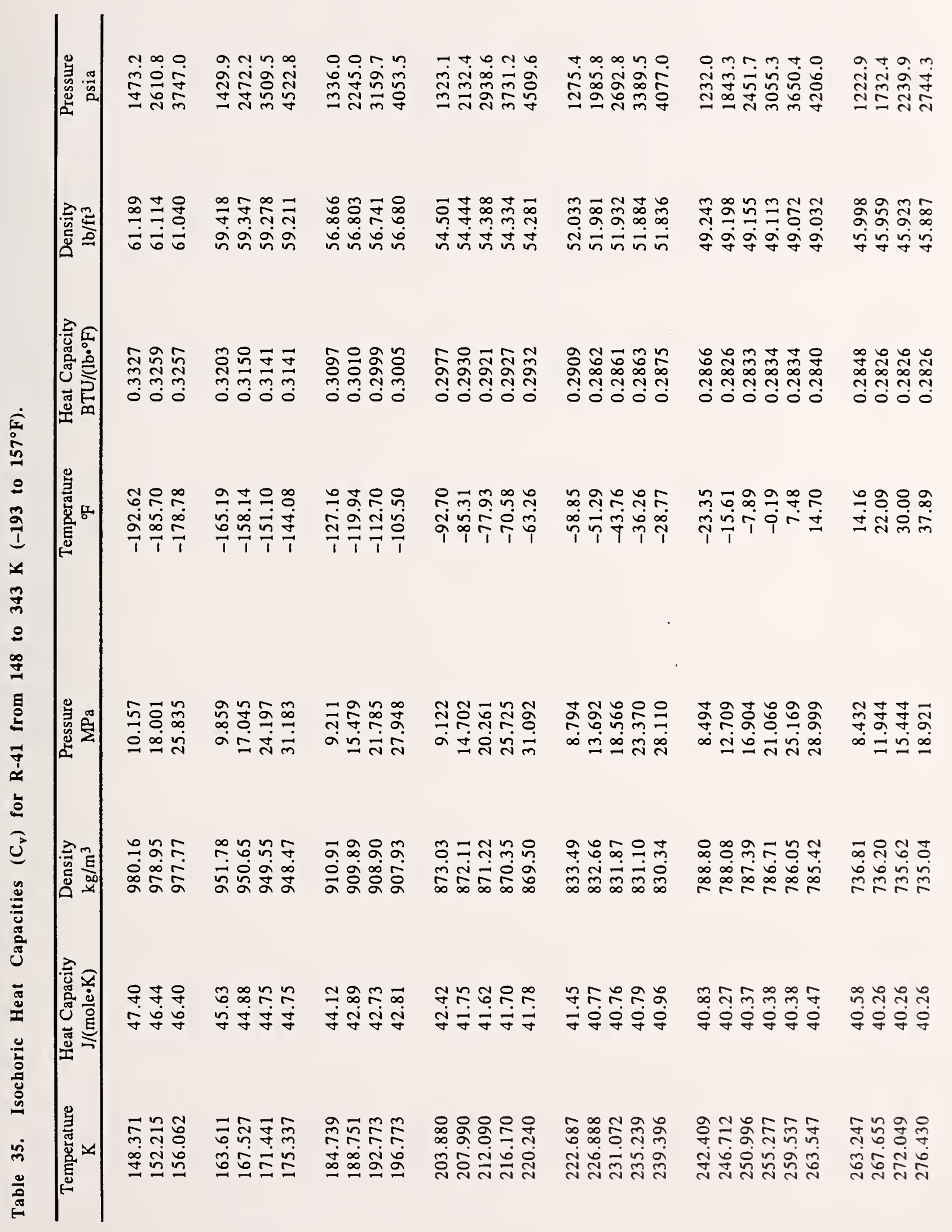




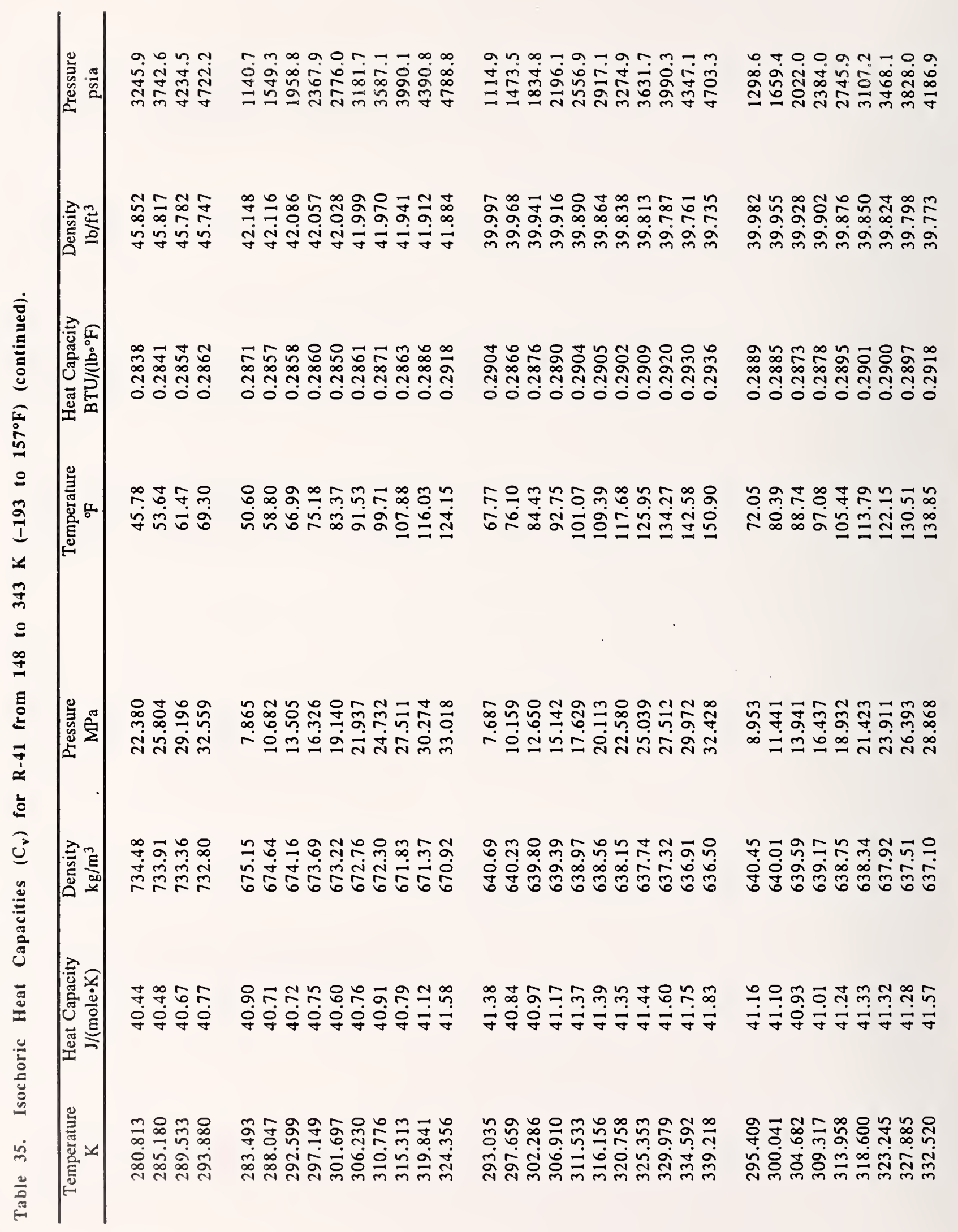




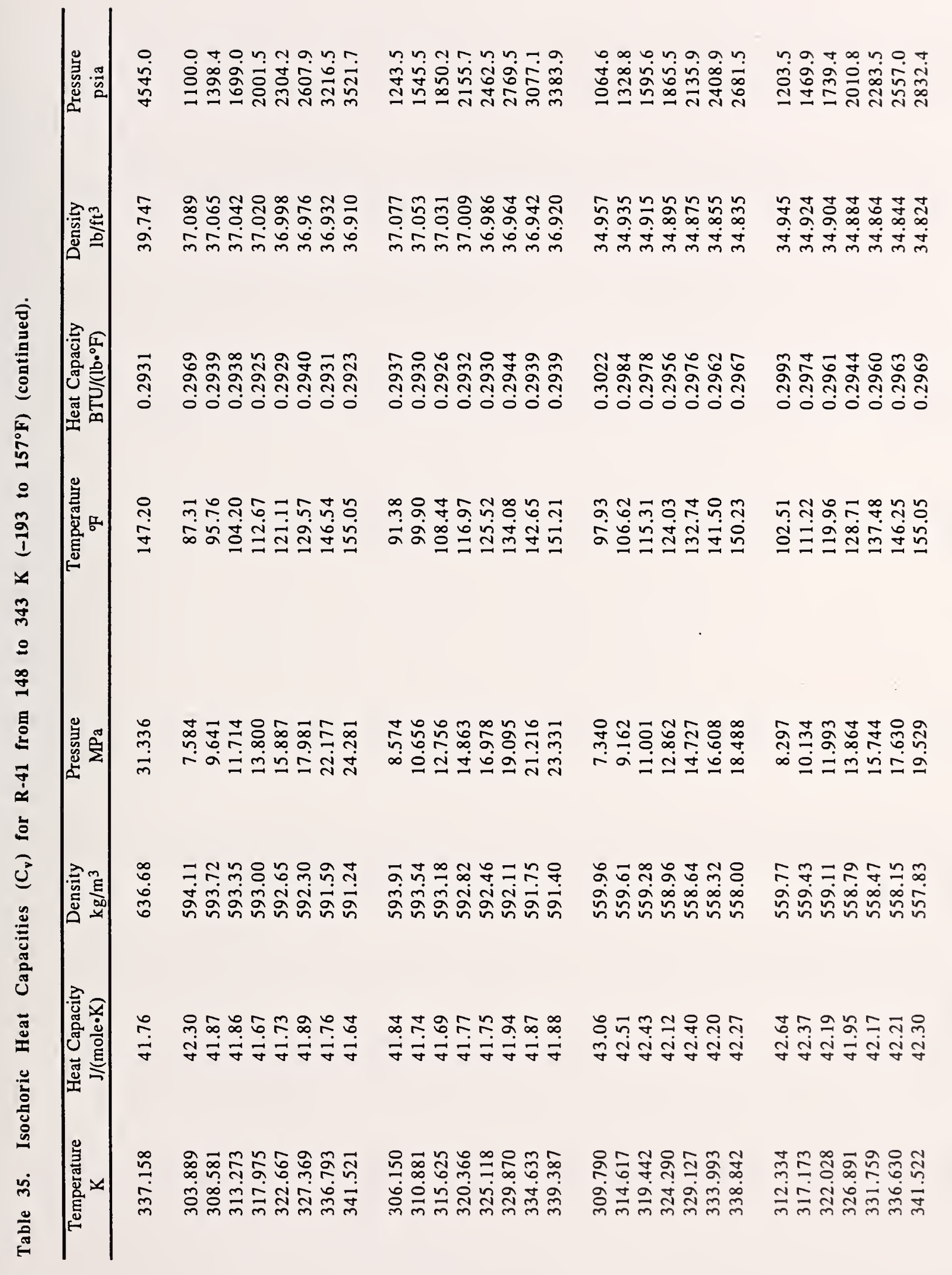




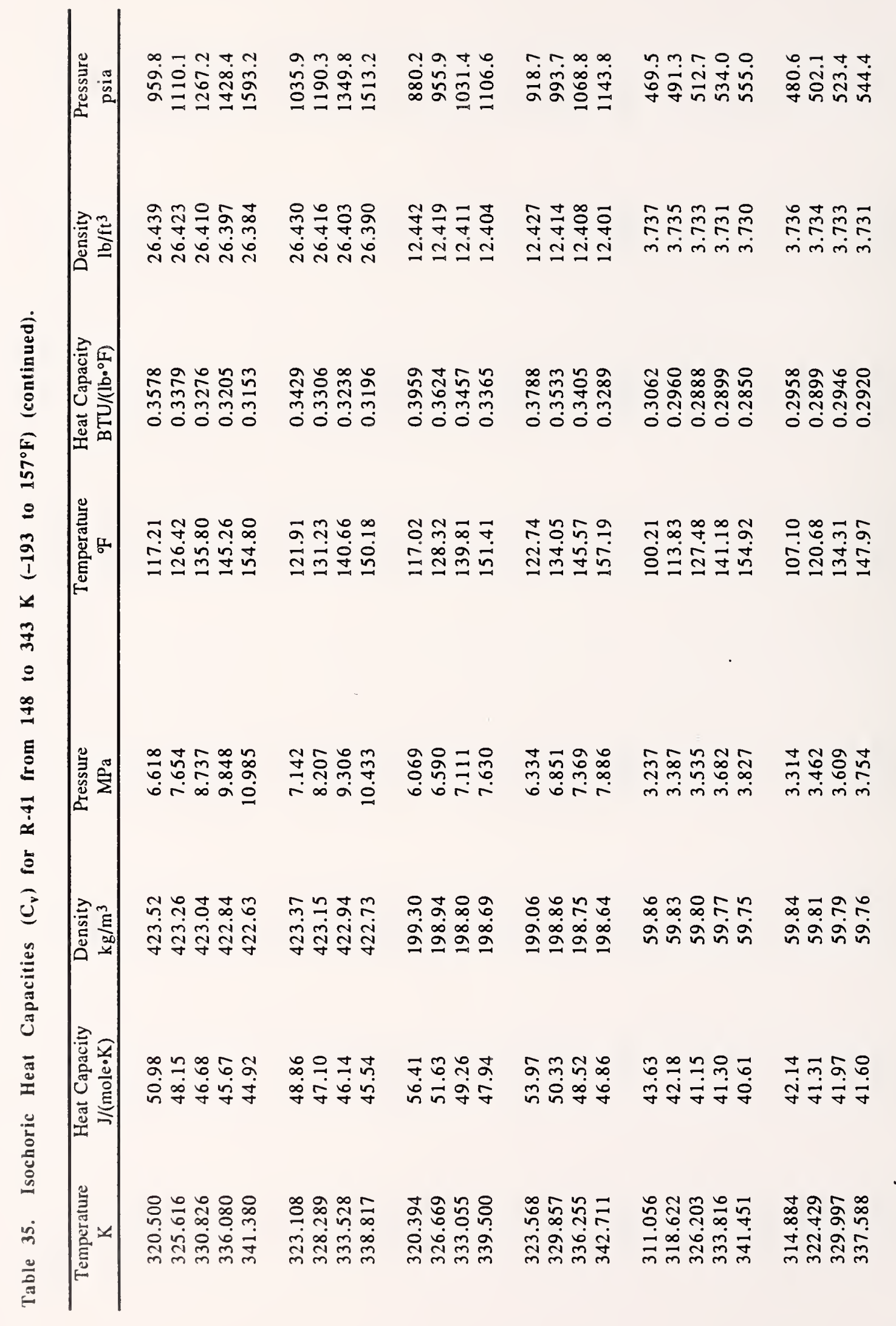




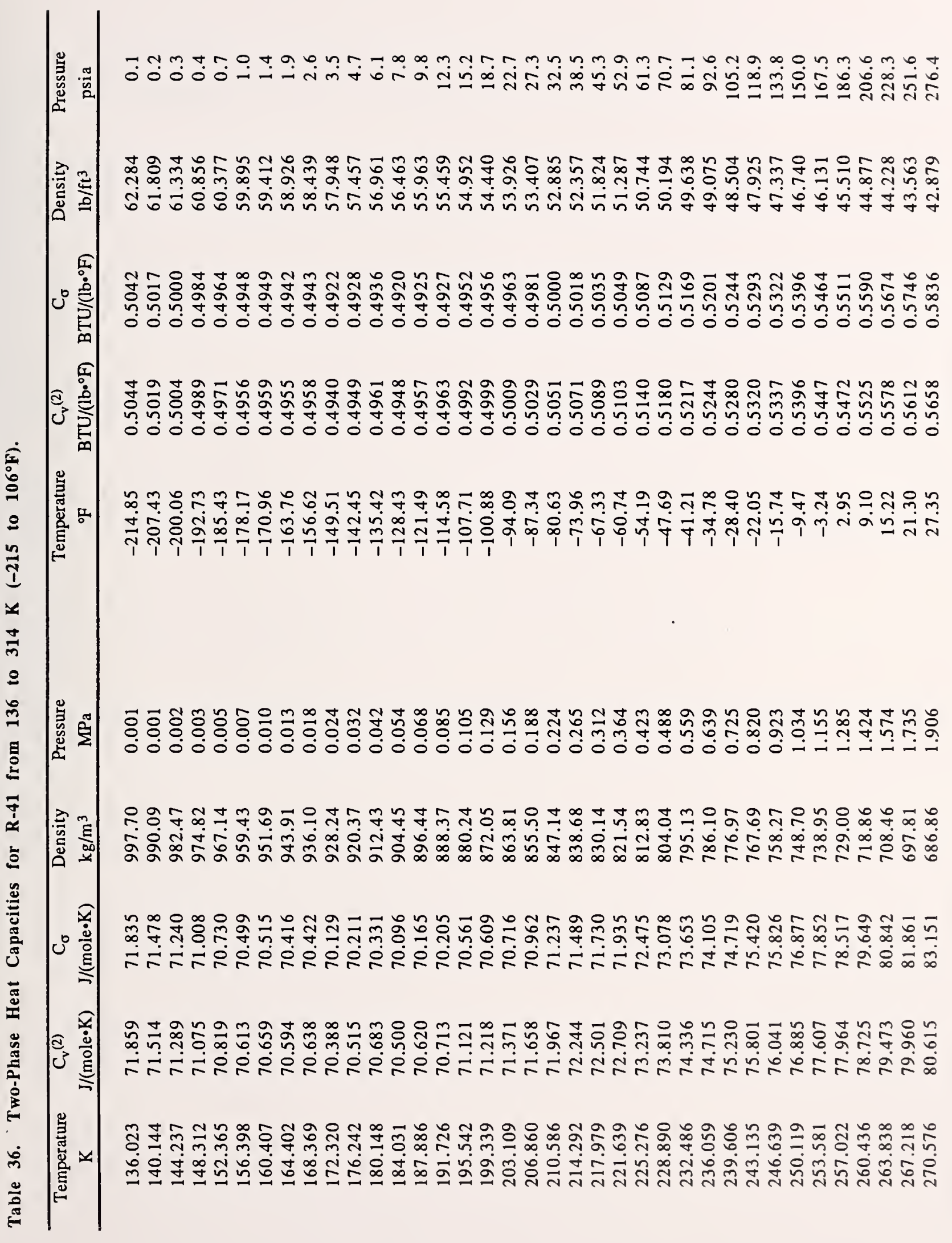




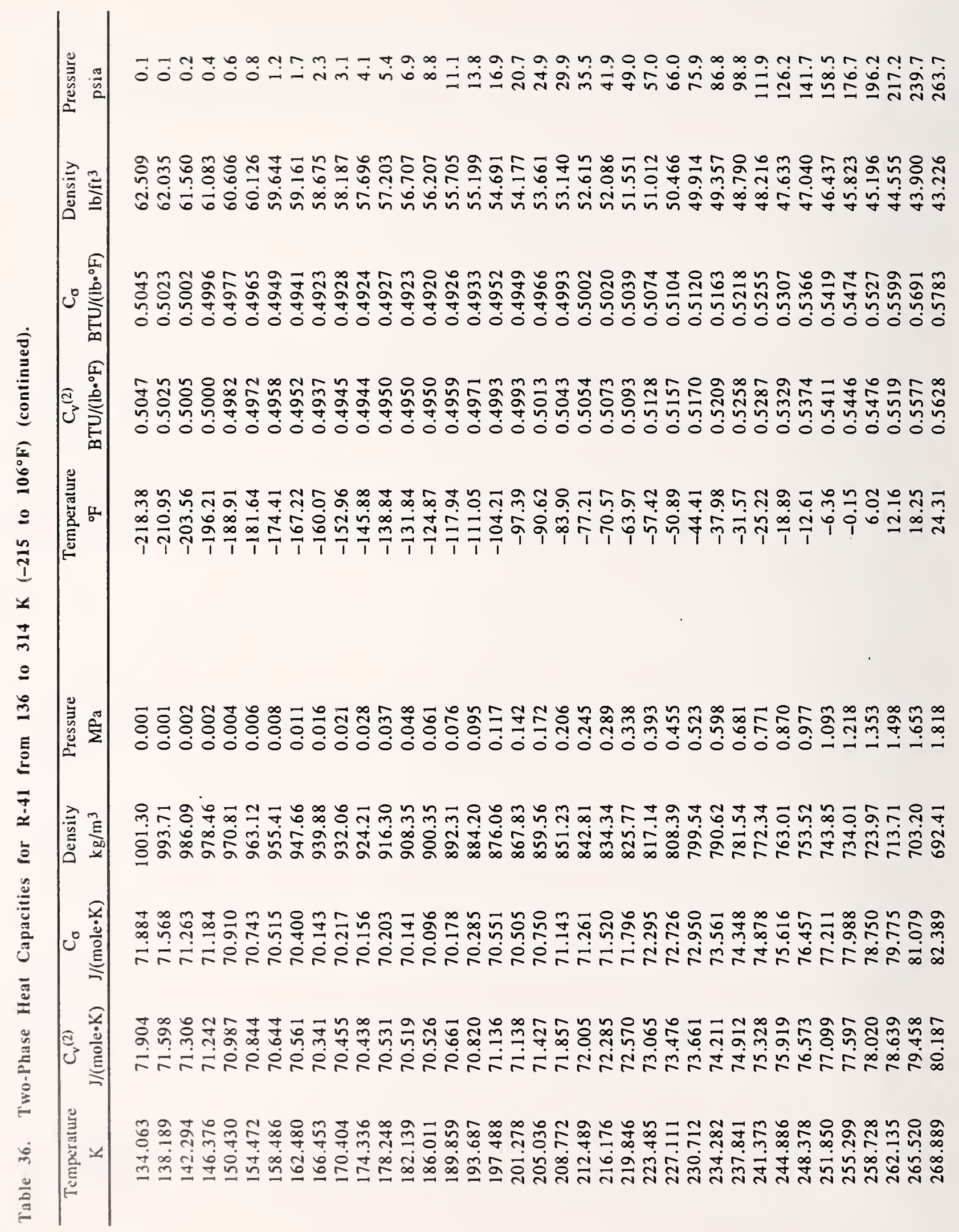




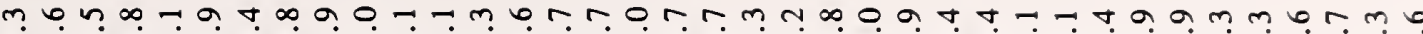

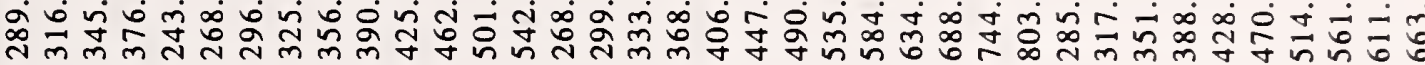

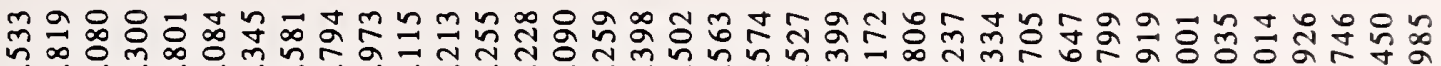

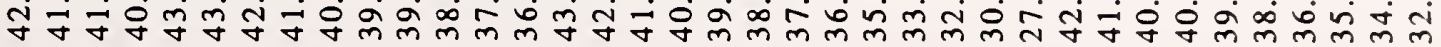

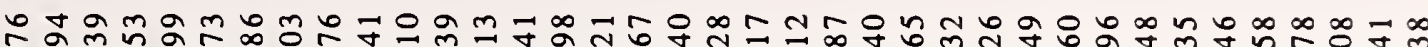

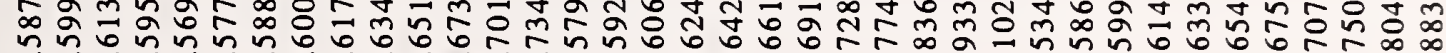

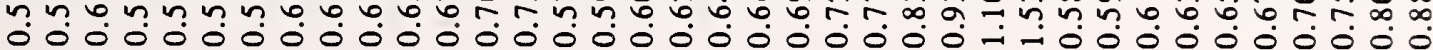

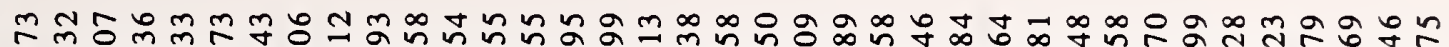

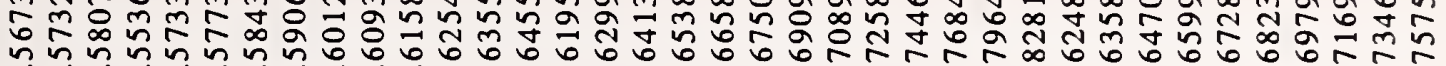
o

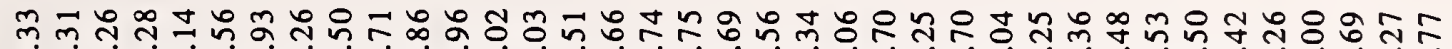

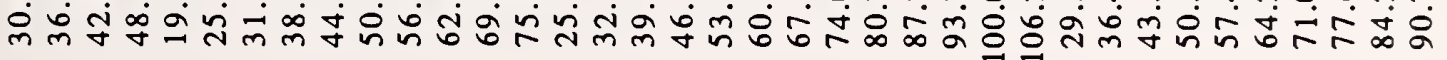

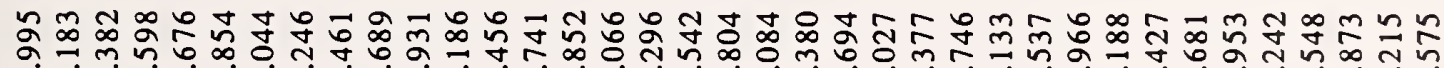

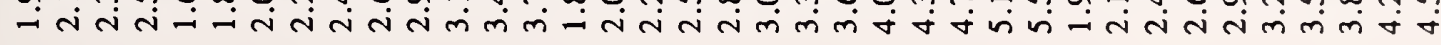

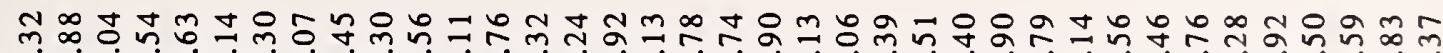

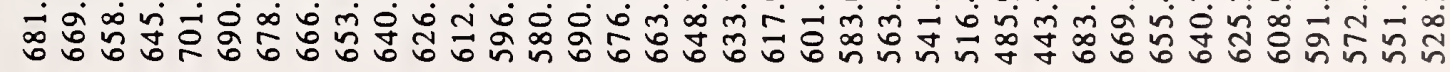

귝유 ஸि

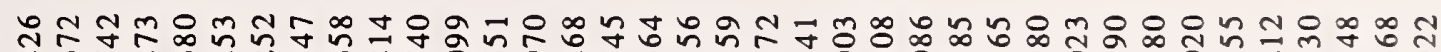
क வ கள் வ வ

ஸิ

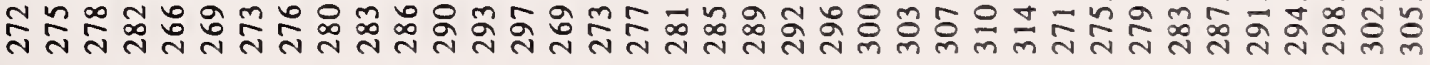




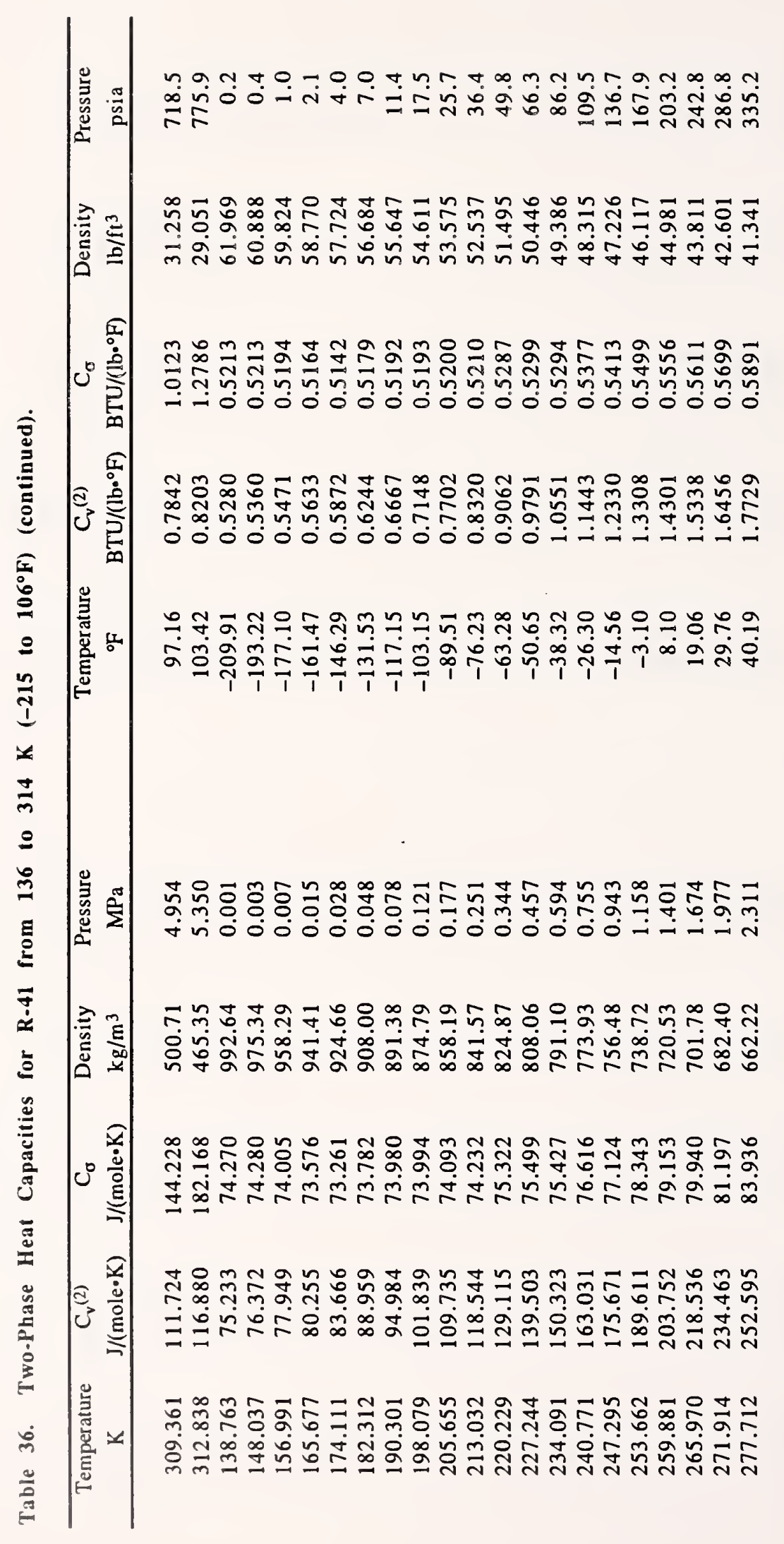




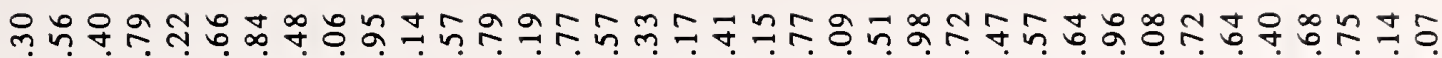
১

m-n по m m

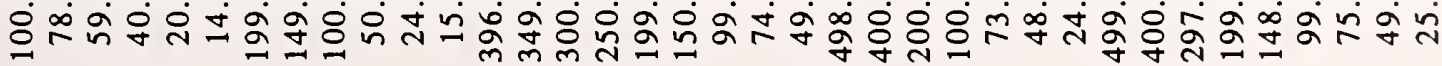

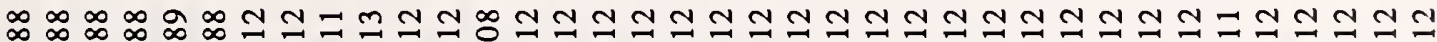

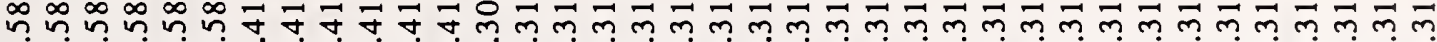

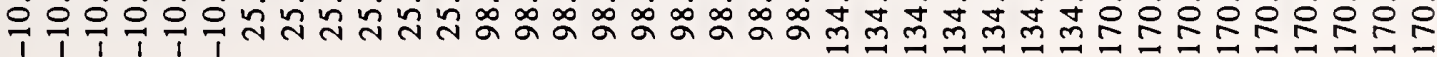

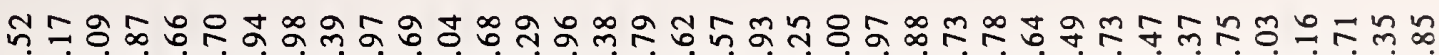

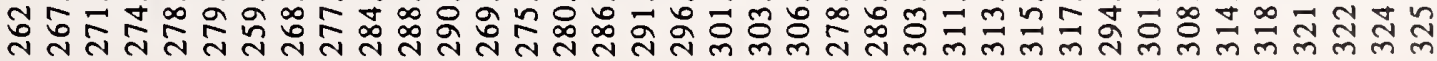

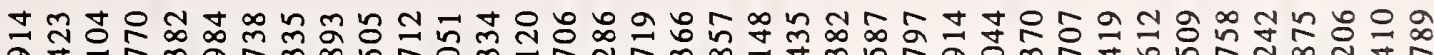

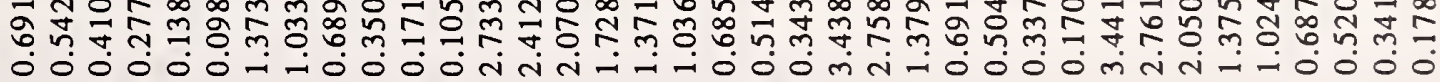

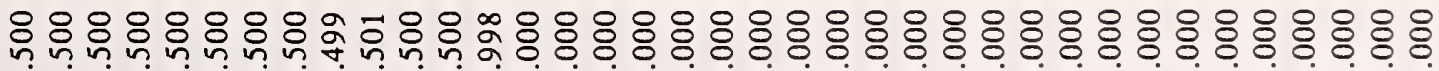

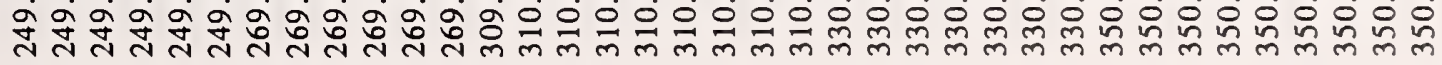




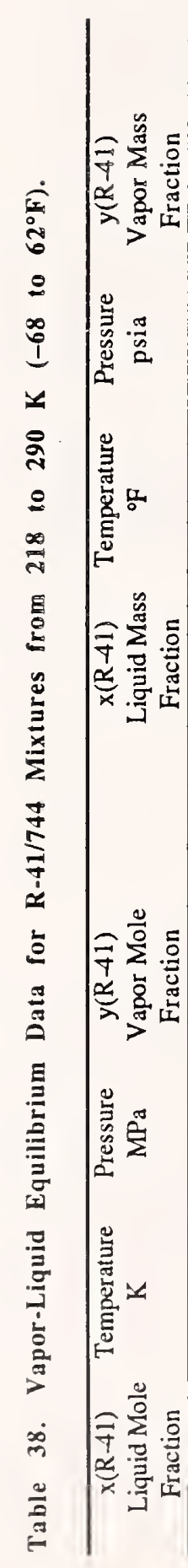

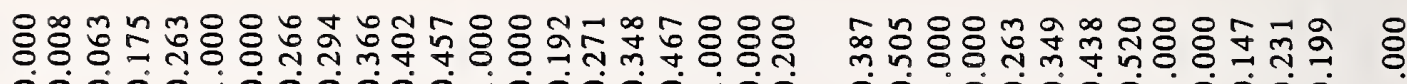
ல் $\dot{0} 0 \dot{0} \dot{0} \dot{0} 0 \dot{0} \dot{0} \dot{0} \dot{0} \dot{0} \dot{0} \dot{0} \dot{0} \dot{0}$ ó

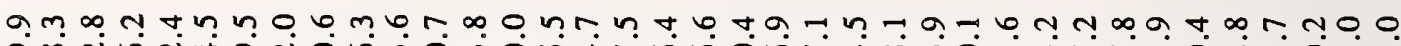
ค.

ํำ бí

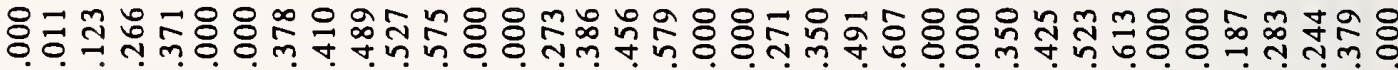
0엄

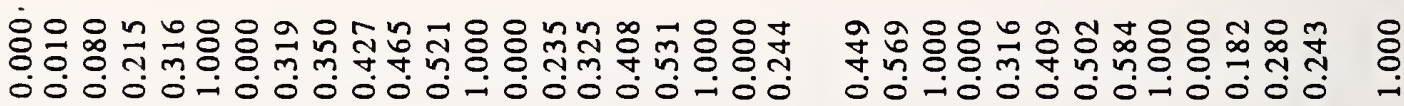

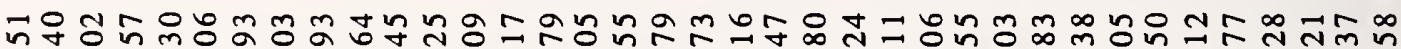

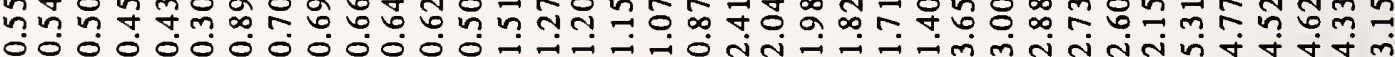

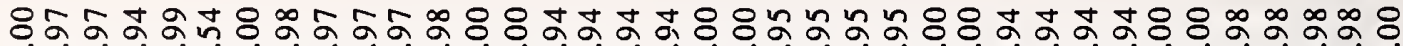

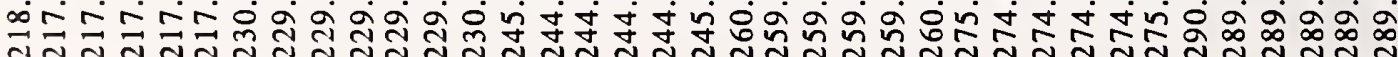

영글 过 


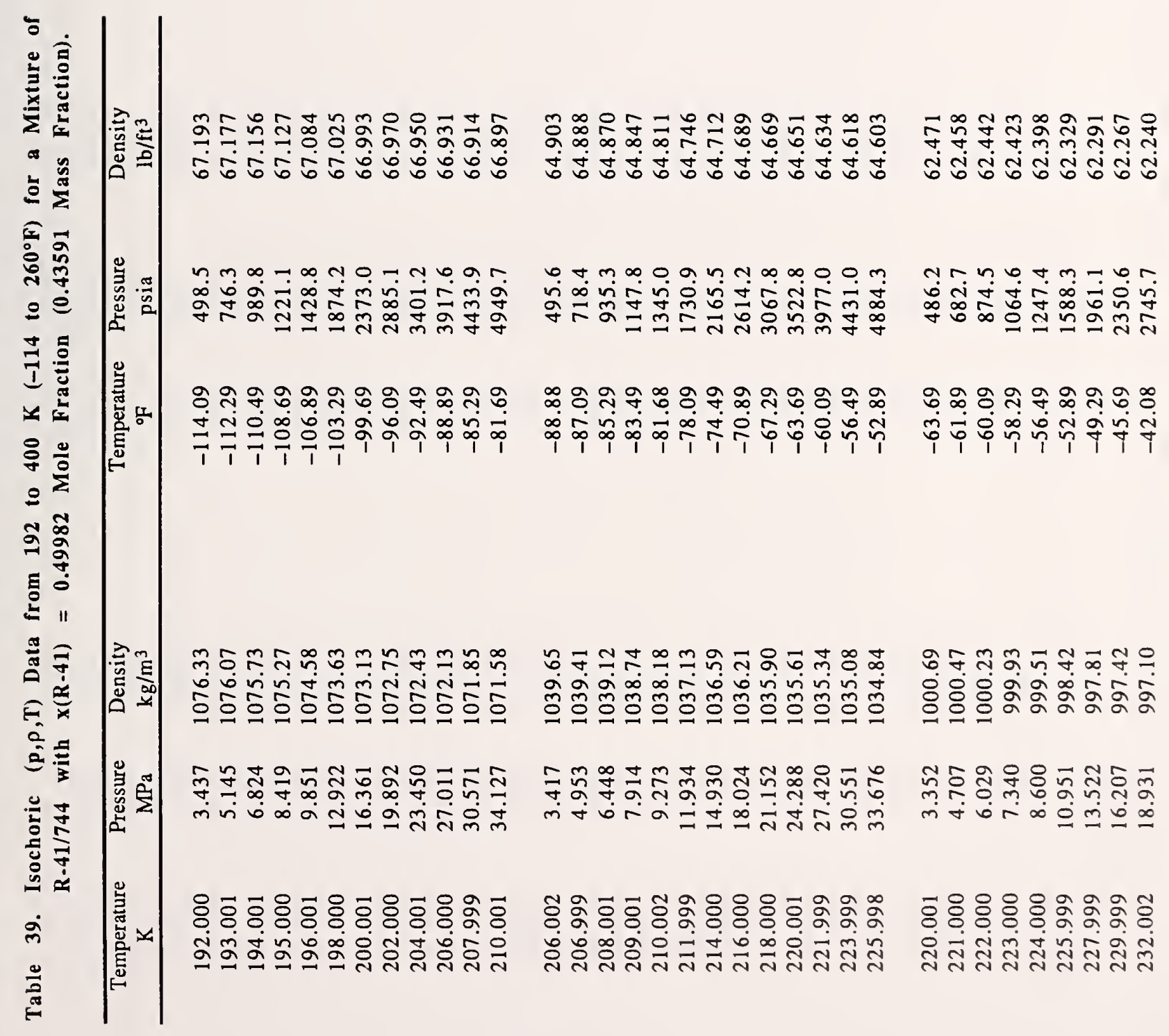




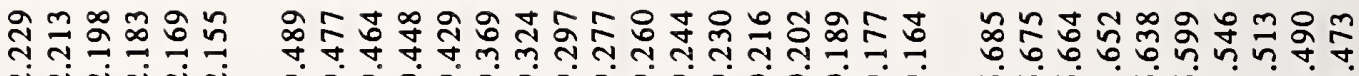

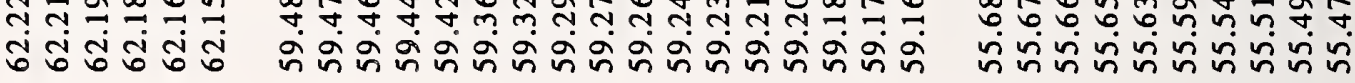

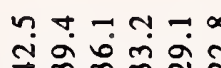

o onn t ar t o o g o - m m t

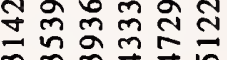

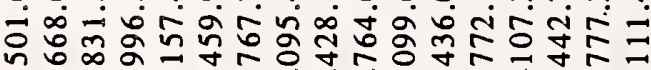

$\infty 0, \infty \sim 0, \infty \infty .0$ ம்ர் ம்ப்

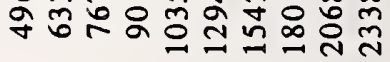

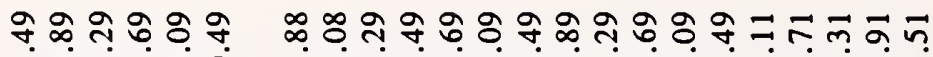

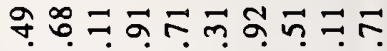

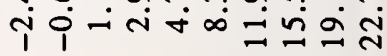

ஸี ஸீ:

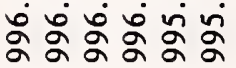

E.

i.

ธิธ์ㅇํㅇํㅇㅇㅛ

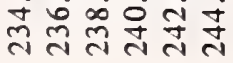

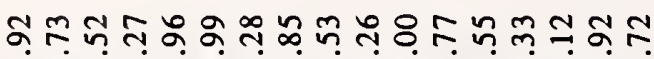

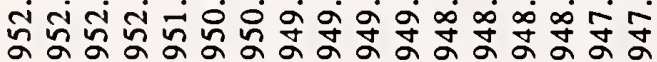
तं तं

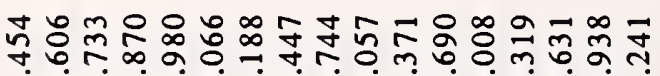

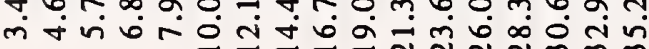

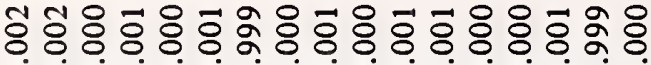

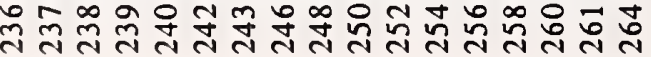

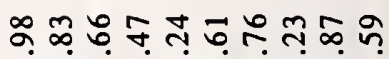

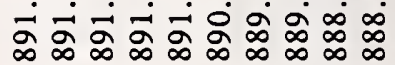

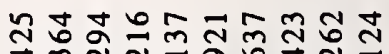

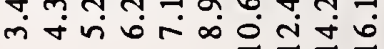

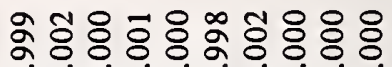

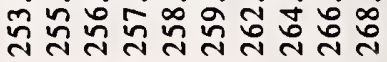




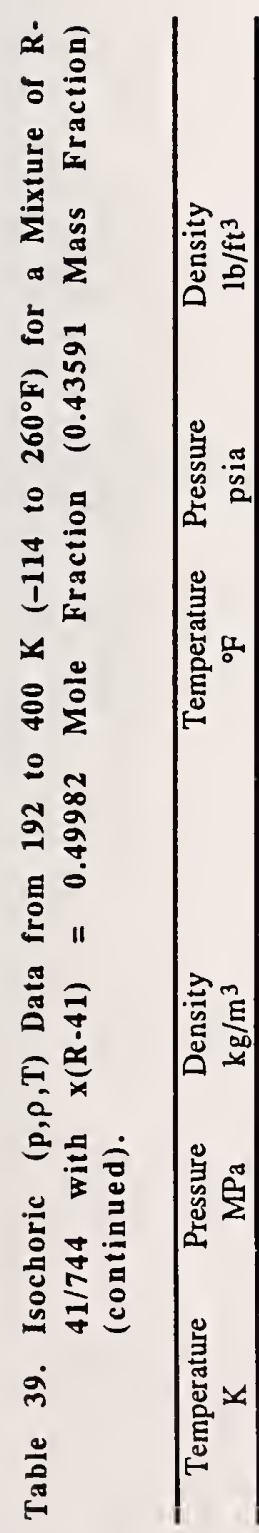

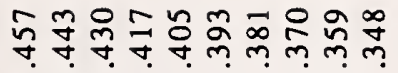

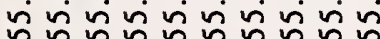

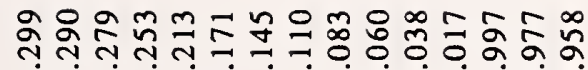

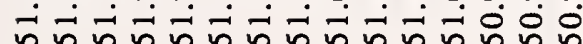

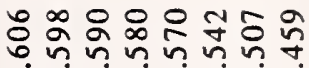

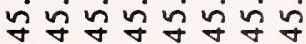

m 0 m t 0 o 0 m 9 윳ำ

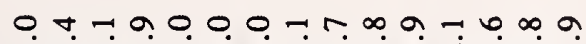

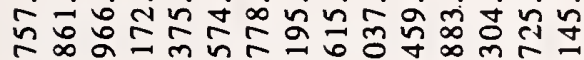

t. $\rightarrow \infty \sim 0,0.0$

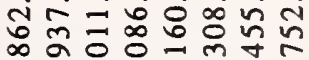

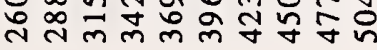
政 으으는

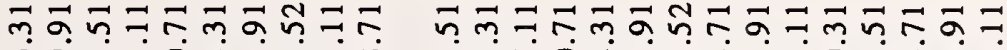

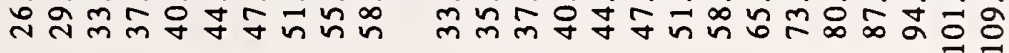

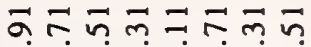
ที่์ฺำ

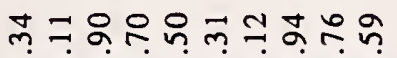

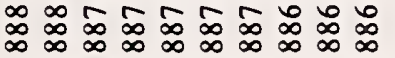

ๆ

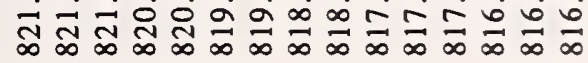

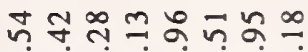
ㅇํㅇㅇำ

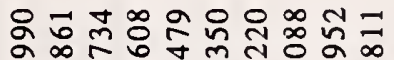
İं

సิ

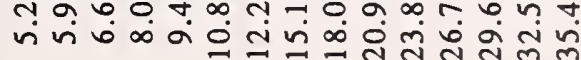

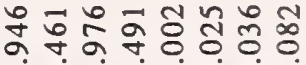

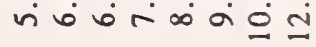

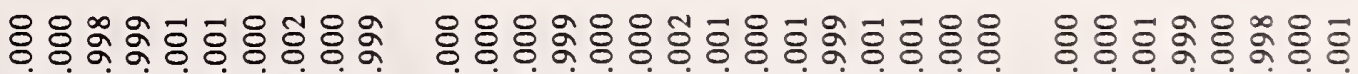

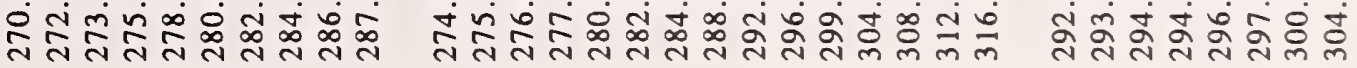




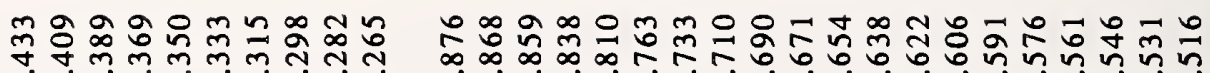

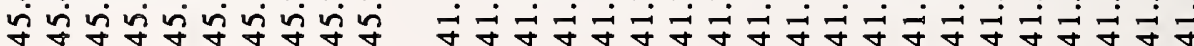

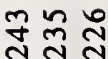
จิจ

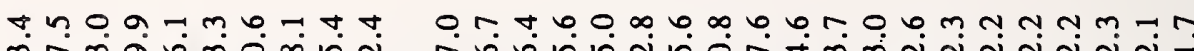

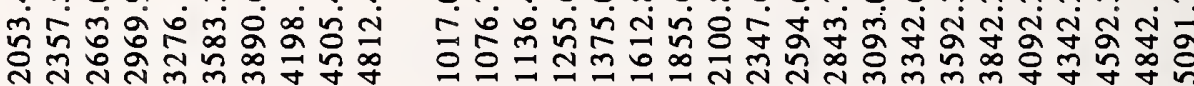

ก $ข$ ำำ

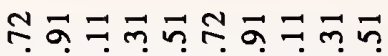

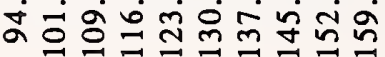

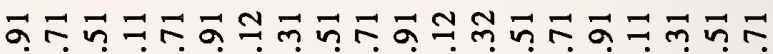
ஸ்

$\vec{a} \bar{n}=$ ㅇํㅇ

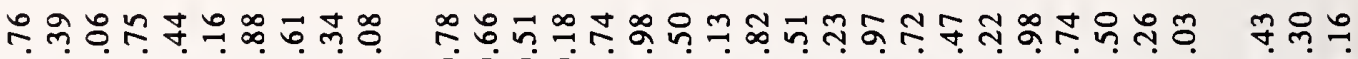

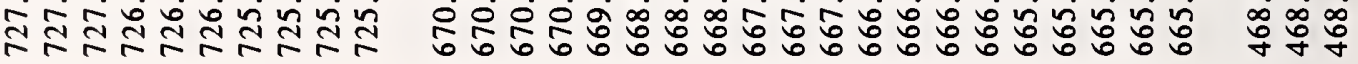

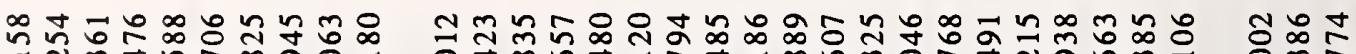
$\vec{\square}$

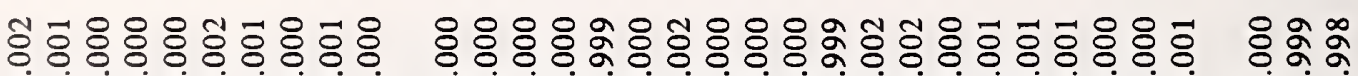
官 


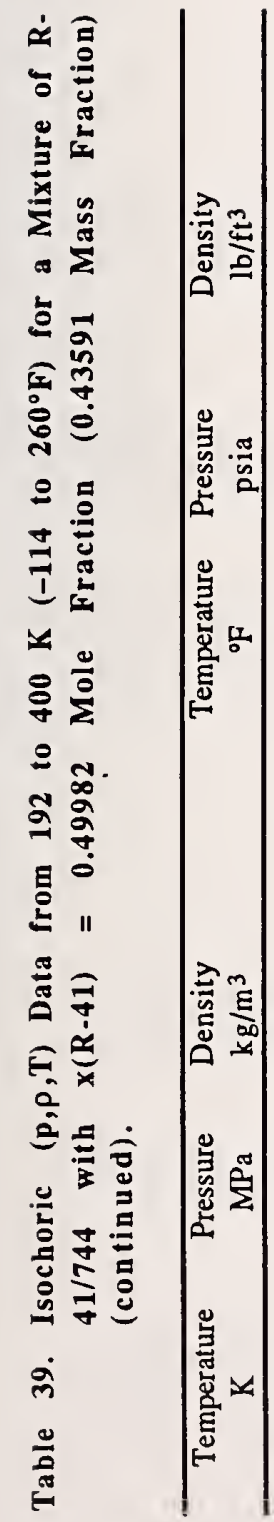

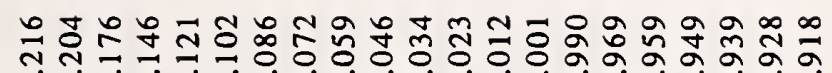

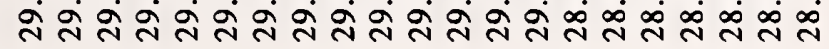

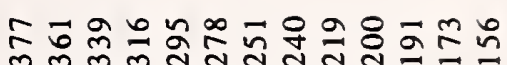

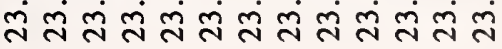

4⿻ mน a a ஸे

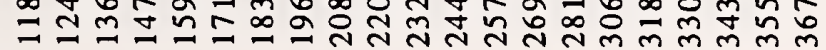

들 I

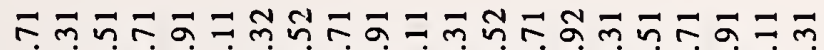
늘ำ

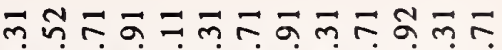

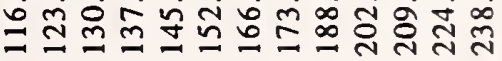

후 mீ 우유 官

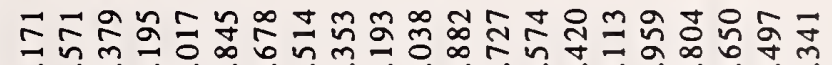

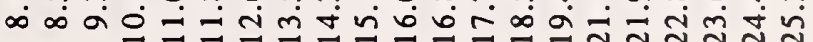

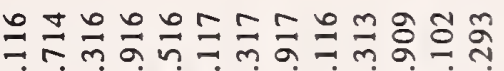
$\infty \infty$ a

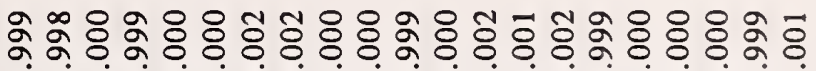

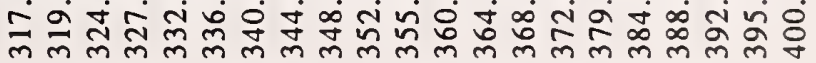

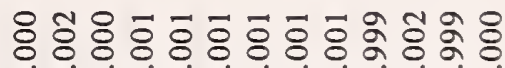

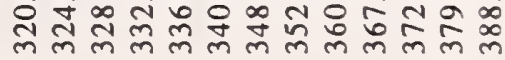


㐫

लें

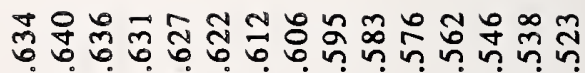

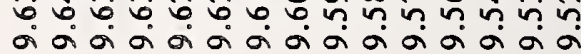

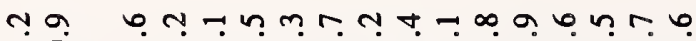
वं०

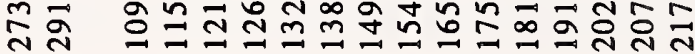

ष.7n

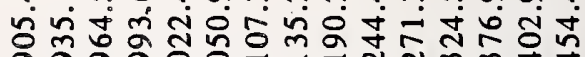

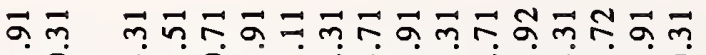

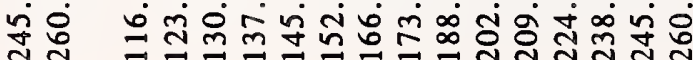

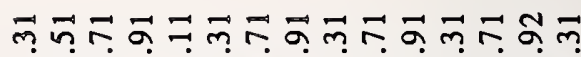

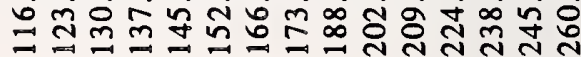

ำก ๆ

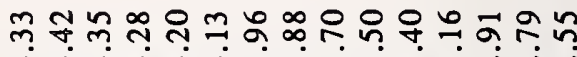

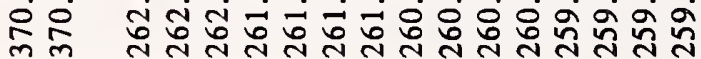

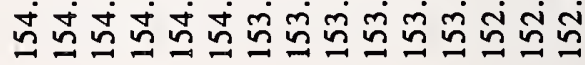

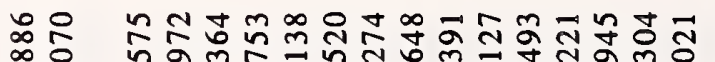

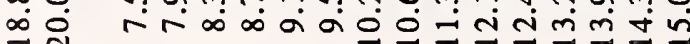

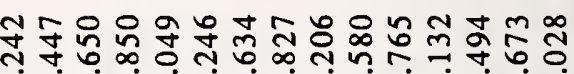

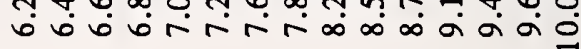

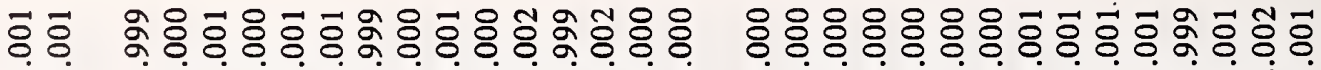
旃 


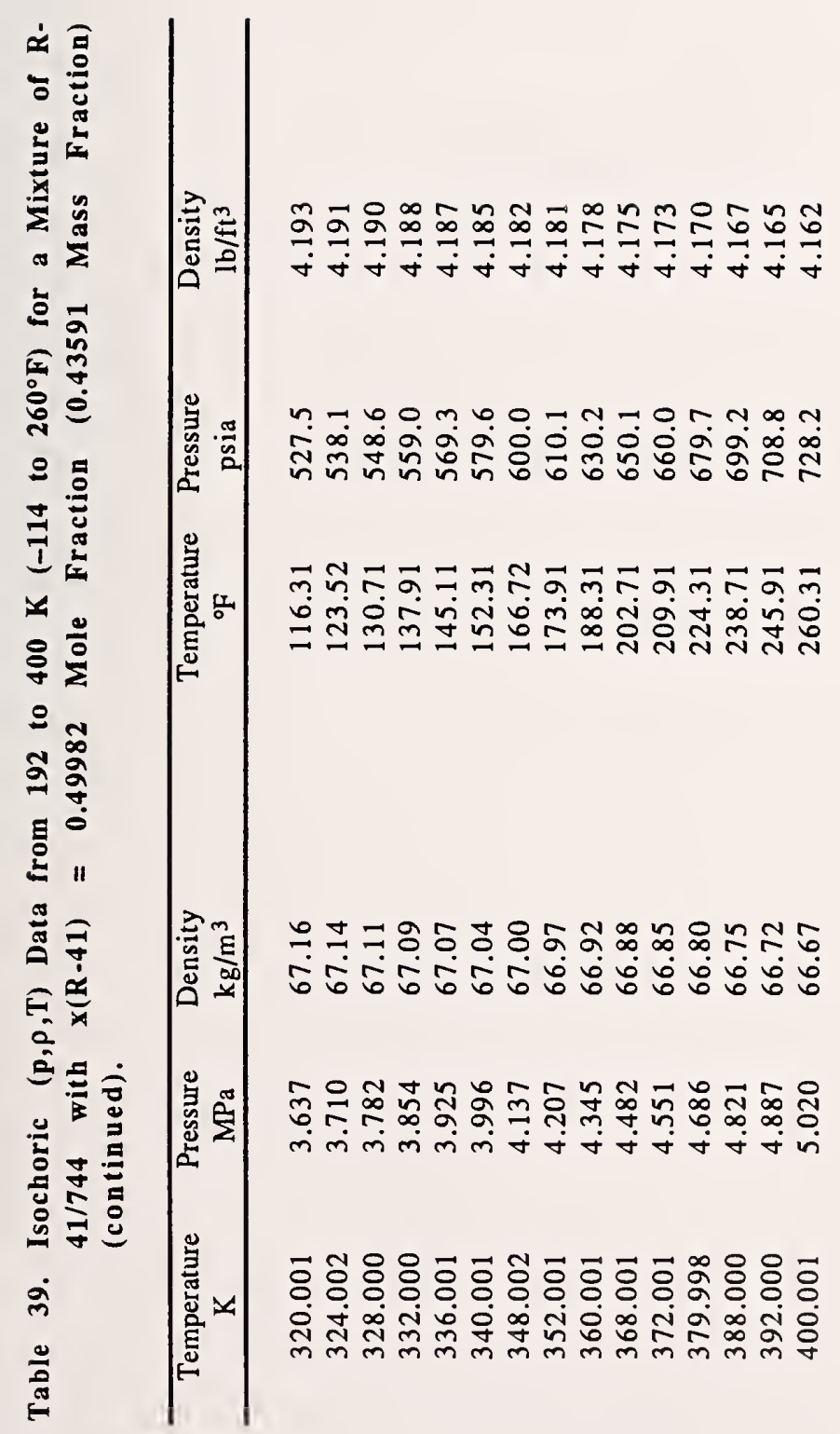



APPENDIX B:

EXPERIMENTAL APPARATUS 
Five apparatus were used to acquire the data for this project. These apparatus will be described in this section.

\section{B.1 Vapor-Liquid Equilibrium Apparatus}

A schematic diagram of the vapor-liquid equilibrium apparatus used in this project is presented in Figure B1. The apparatus is designed to allow the liquid and vapor of a fluid to come to equilibrium. Then the equilibrium pressure and temperature are measured. Also, the liquid and vapor phase compositions are measured by flashing a small sample of either the liquid or the vapor into a low pressure helium carrier gas and using a gas chromatograph to analyze the sample. The main part of the apparatus consists of an equilibrium cell, two recirculating pumps, and a platinum resistance thermometer that are contained in a Dewar filled with silicone oil. The platinum resistance thermometer has been calibrated on the ITS-90. The pressure transducer and feed system are contained in an insulated box with an independent temperature control system to maintain it at a temperature above the temperature of the Dewar. The pressure transducer is an oscillating quartz crystal pressure transducer calibrated in our laboratory.

One or more mixture components are introduced into the system using the feed system. The liquid and the vapor are continuously circulated to ensure that the system is well mixed. The liquid and vapor samples are withdrawn through capillary tubing to gas chromatograph sampling valves that are used to inject a small quantity of the sample into a helium stream. The helium stream carries the sample to the gas chromatograph where the mixture components are separated. The procedure for calibrating the gas chromatograph is outlined in Appendix C.

\section{B.2 Bubble-Point and Near-Saturation $(p, p, T)$ Apparatus}

The apparatus used to measure the bubble-point pressures and near-saturation $(p, \rho, T)$ data is similar to the vapor-liquid equilibrium apparatus described above. The main part of the apparatus consists of an equilibrium cell, two pumps, and two vibrating tube densimeters. These components are housed in an oven which is used to control the temperature of the system. Figure B2 shows a schematic diagram of this system. The liquid pump is located outside of the system and is used when the system is above room temperature.

The system can either be filled with a standard mixture of known composition, or the liquid composition can be measured. The liquid and the vapor are continuously circulated to ensure that the system is well mixed. Once the system is equilibrated, the temperatures of the main cell and both densimeters are measured, the pressure of the system is recorded, and both the liquid and vapor densities are recorded. The composition of the vapor phase is calculated from the vapor-liquid equilibrium data from the VLE apparatus described above. It is assumed that the vapor composition is that of the vapor in equilibrium with the liquid which is at the temperature and pressure of the main cell. The reason the vapor composition is not measured directly is because the temperature gradients in this apparatus adversely affect the vapor composition determination. 


\section{B.3 Isochoric (p,p,T) Apparatus}

An isochoric technique was employed to measure the single-phase densities in this study. In this method, a sample of fixed mass in confined in a container of nearly fixed volume. The volume of the container is accurately known as a function of pressure and temperature. The temperature is changed in selected increments, and the pressure is measured at each temperature, until the upper limit of either temperature $\left(400 \mathrm{~K}\left(260^{\circ} \mathrm{F}\right)\right)$ or pressure $(35 \mathrm{MPa}(5100 \mathrm{psia}))$ was attained. When an isochore is completed, that is, after the upper temperature or pressure limit of the run has been reached, the sample is condensed into a light-weight stainless steel cylinder which is immersed in liquid nitrogen. When the $(p, \rho, T)$ cell and its connecting capillary have been heated to about $20 \mathrm{~K}$ $\left(36^{\circ} \mathrm{F}\right)$ above the critical temperature of the sample, the cylinder is sealed, warmed to ambient temperature, and weighed. The density of the test fluid is then determined from a knowledge of the cell volume and of the mass difference of the steel cylinder before and after trapping the sample. Allowances to account for the noxious volumes in the system, such as those of the capillaries and the pressure gauge, are made for each point. A small adjustment to the apparent sample mass was made to account for the change in the atmospheric buoyant force acting on the steel cylinder. The density of the sample fluid is then the quotient of the mass of the sample and the volume of the cell at each pressure and temperature.

The sample cell, shown in Figure B3, is a cylindrical piece of electrolytic tough pitch copper containing a cavity with a volume of approximately $28.5 \mathrm{~cm}^{3}\left(1.74 \mathrm{in}^{3}\right)$. It is suspended inside an evacuated cryostat from a thin-walled stainless steel tube used for reflux cooling. High resistance wire wound tightly around the cell is used to heat the cell. The cell temperature is determined with a platinum resistance thermometer (calibrated at NIST relative to the IPTS-68, with temperatures converted to the ITS-90) embedded in a small well at the top of the cell. An ultrastable current source supplies the thermometer with a current of $2 \mathrm{~mA}$. Errors caused by steady-state thermal and contact EMF's are minimized by averaging voltages measured for opposite directions of current flow. The temperatures were controlled and reproduced within $1 \mathrm{mK}\left(0.0018^{\circ} \mathrm{F}\right)$. The total uncertainty in the temperature ranged from $10 \mathrm{mK}$ at $100 \mathrm{~K}$ to $30 \mathrm{mK}$ at $400 \mathrm{~K}\left(0.018^{\circ} \mathrm{F}\right.$ at $-279.7^{\circ} \mathrm{F}$ to $0.054^{\circ} \mathrm{F}$ at $\left.260^{\circ} \mathrm{F}\right)$.

Pressures are measured by reading the period of vibration, averaged over $10 \mathrm{~s}$, of an oscillating quartz crystal transducer which is connected to the sample cell through a fine diameter $(0.2 \mathrm{~mm}$ i.d. (0.008 in i.d.)) capillary. Since the frequency of the transducer varies with temperature, the transducer has been anchored in an insulated aluminum block controlled at $333.15 \pm 0.05 \mathrm{~K}$ (139.98 $\pm 0.09^{\circ} \mathrm{F}$ ). The transducer has been calibrated with an oil-lubricated piston gauge, accurate within $\pm 0.01 \%$. Calibrations have demonstrated that the transducer is extremely stable over long periods of time. Changes of less than $0.003 \%$ were observed over one year. The expanded uncertainty in the pressure measurements is approximately $0.01 \%$ for pressure greater than $3 \mathrm{MPa}$ (435 psia), but increases to $0.05 \%$ at low pressures ( $1 \mathrm{MPa}$ (145 psia) and lower) as a result of the transducer resolution, of the fluctuations in the temperature of the pressure transducer, and of the occasional hysteresis in the vibrational frequency of the quartz element. 


\section{B.4 Adiabatic Constant Volume Calorimeter}

The principal components of the calorimeter used for these measurements are shown in Figure B4. A spherical bomb contains a sample of well-established mass. The volume of the bomb, approximately $73 \mathrm{~cm}^{3}\left(4.6 \mathrm{in}^{3}\right)$, is known as a function of temperature and pressure. A platinum resistance thermometer is attached to the bomb for the temperature measurement. Temperatures are reported on the ITS-90, after conversions from the original calibration on the IPTS-68. Pressures are measured with an oscillating quartz crystal pressure transducer with a 0 to $70 \mathrm{MPa}$ (0 to $10000 \mathrm{psia})$ range. Adiabatic conditions are ensured by a high vacuum $\left(3 \times 10^{-3} \mathrm{~Pa}\left(4.4 \times 10^{-4} \mathrm{psia}\right)\right)$ in the can surrounding the bomb, by a temperature-controlled radiation shield, and by a temperature-controlled guard ring which thermally anchors the filling capillary and the lead wires to the bomb.

For heat capacity measurement, a precisely determined electrical energy $(Q)$ is applied and the resulting temperature rise $\left(\Delta T=T_{2}-T_{1}\right)$ is measured. We obtain the heat capacity from

$$
C_{v}=\left(\frac{\delta U}{\delta T}\right)_{v} \cong \frac{Q-Q_{0}-W_{p v}}{n \Delta T}
$$

where $U$ is the internal energy, $Q_{0}$ is the energy required to heat the empty calorimeter, $W_{p v}$ is the change-of-volume work due to the slight dilation of the bomb, and $\mathbf{n}$ is the number of moles contained in the bomb. In this work, the bomb was charged with sample up to the (p,T) conditions of the highest-density isochore. The bomb and its contents were cooled to a starting temperature in the single-phase liquid region. The measurements were performed with increasing temperature until either the upper temperature $\left(345 \mathrm{~K}\left(161^{\circ} \mathrm{F}\right)\right.$ ) or pressure limit (35 MPa (5076 psia)) was attained. At the completion of a run, a small part of the sample was cryopumped into a lightweight cylinder for weighing. The next run was started with a smaller density. A maximum of eight runs was measured with one filling of the bomb. When the runs were completed, the remaining sample was discharged and weighed. A series of such runs from different fillings completes the investigation of the (p,T, $\left.C_{v}\right)$ surface.

\section{B.5 Spherical Resonator Speed of Sound Apparatus}

Accurate data of the speed of sound of a gas are obtained from measurements of the resonant frequencies produced in a stainless steel spherical cavity containing the gas. Measurements of several radial modes are taken at a very stable temperature and pressure. The speed of sound is computed from the frequency at each of the modes, and an average is taken. The sphere radius used in the computation of the speed of sound is found from similar measurements of the radial modes using argon. Highly accurate properties of argon gas, including the speed of sound, are found in the work of M. R. Moldover, et al. [Moldover, M.R.; Mehl, J.B.; Greenspan, M.J. Accoust. Soc. Am. 79: 2; 
1986]. Also included in this reference is a detailed description of the theory of operation of the spherical resonator.

The spherical steel cavity is mounted in a pressure vessel which also contains the gas. This vessel is surrounded by a temperature shield and is housed in a cryostat which provides cooling for lower temperatures. The pressure vessel has been designed for operation at pressures up to $7 \mathrm{MPa}$ (1000 psia) and temperatures from $249 \mathrm{~K}$ to $350 \mathrm{~K}\left(-11.5\right.$ to $\left.170.3^{\circ} \mathrm{F}\right)$. Figure B5 shows a schematic diagram of this apparatus. 


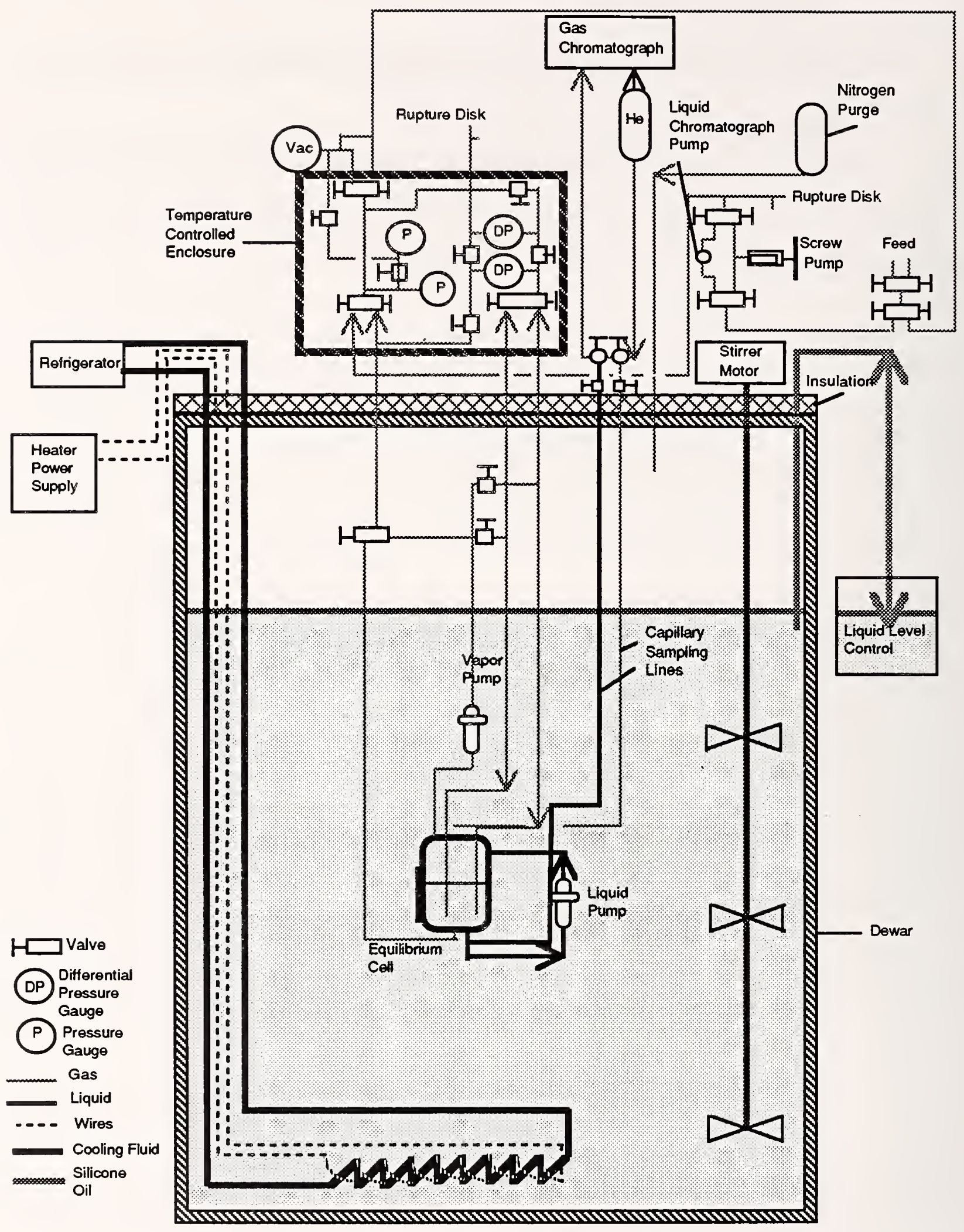

Figure B1. Schematic Diagram of the Dynamic Phase Equilibrium Apparatus. 


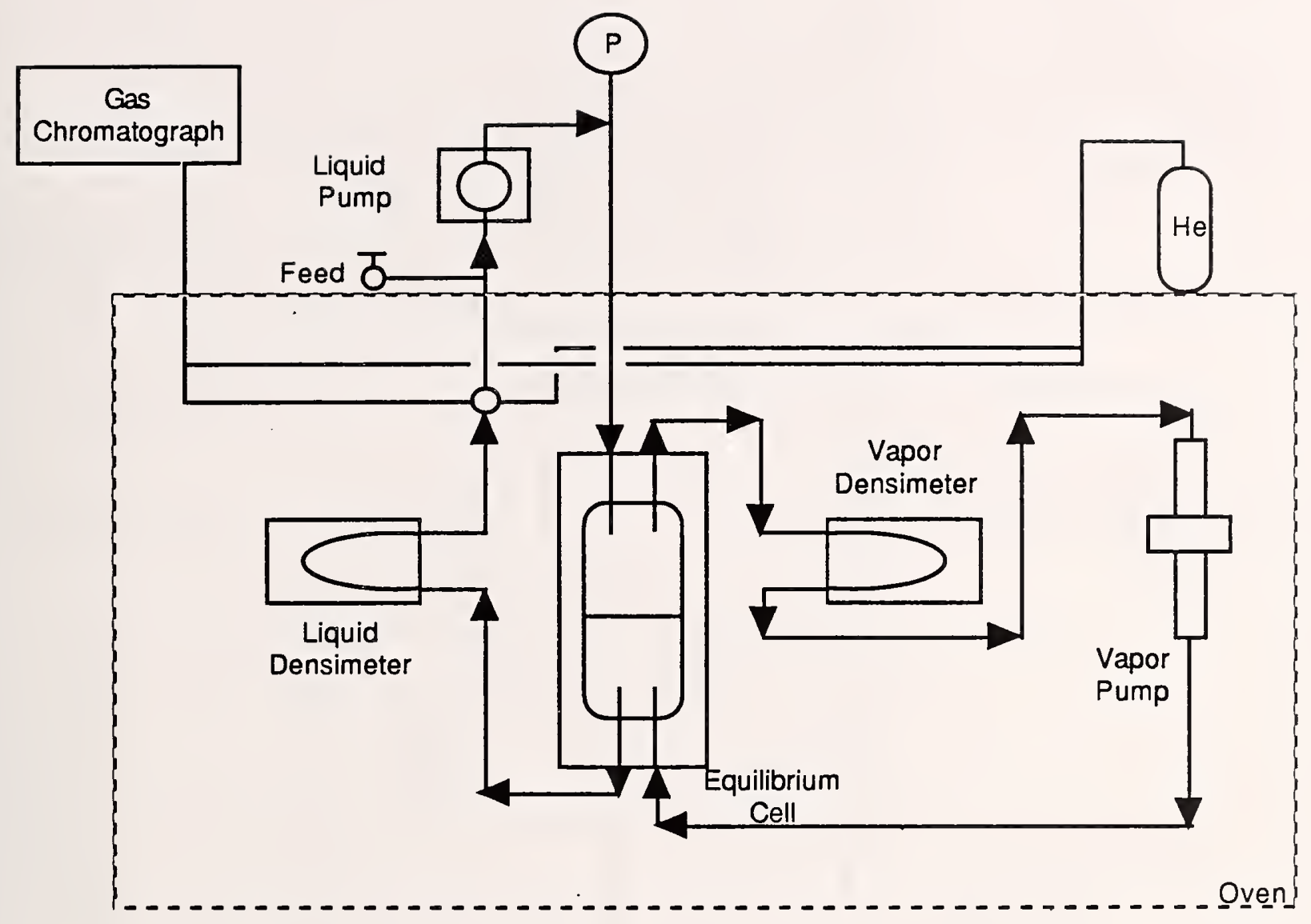

Figure B2. Schematic Diagram of Bubble-Point and Near-Saturation $(p, p, T)$ Apparatus. 


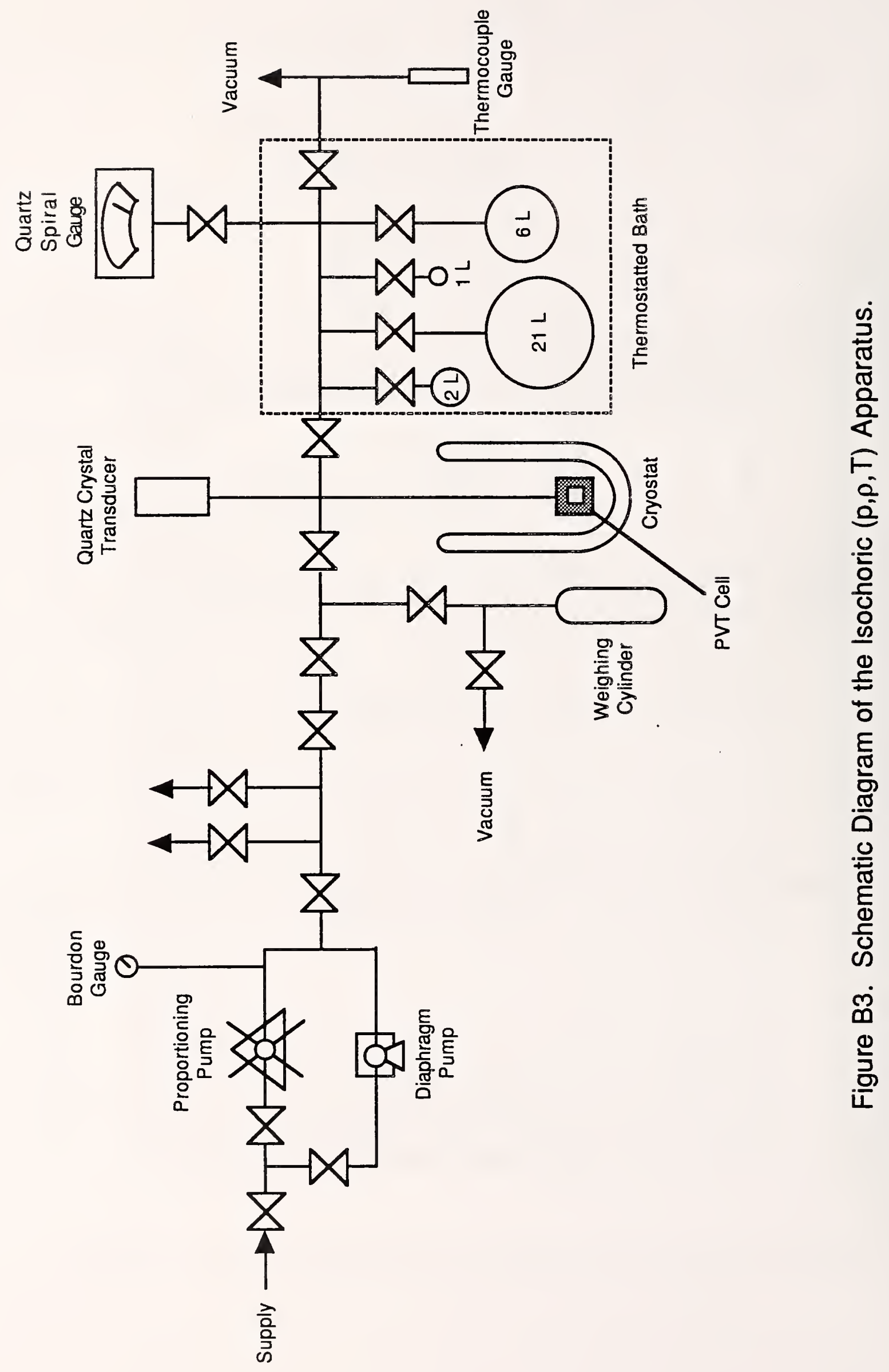




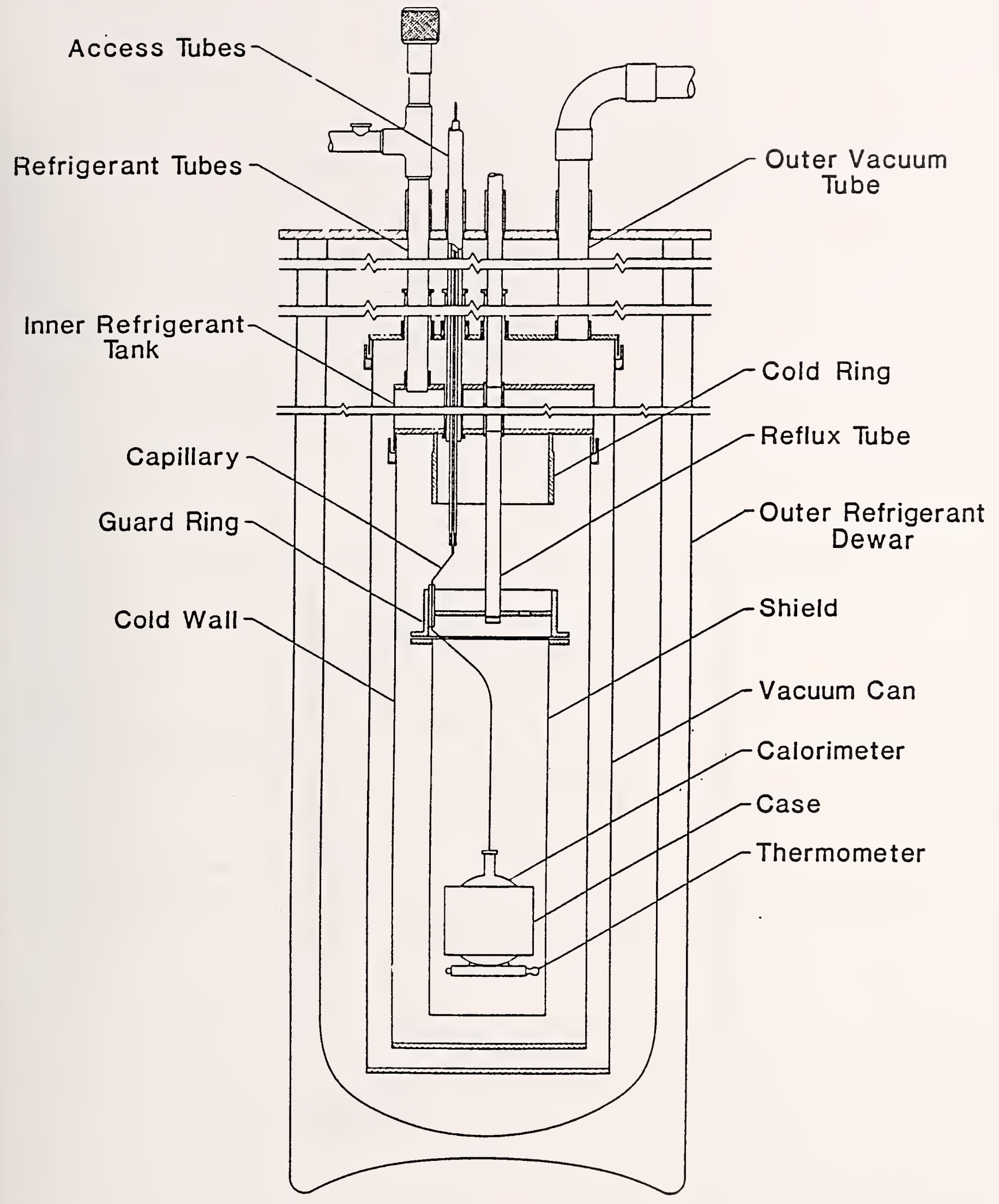

Figure B4. Schematic Diagram of the Calorimeter. 


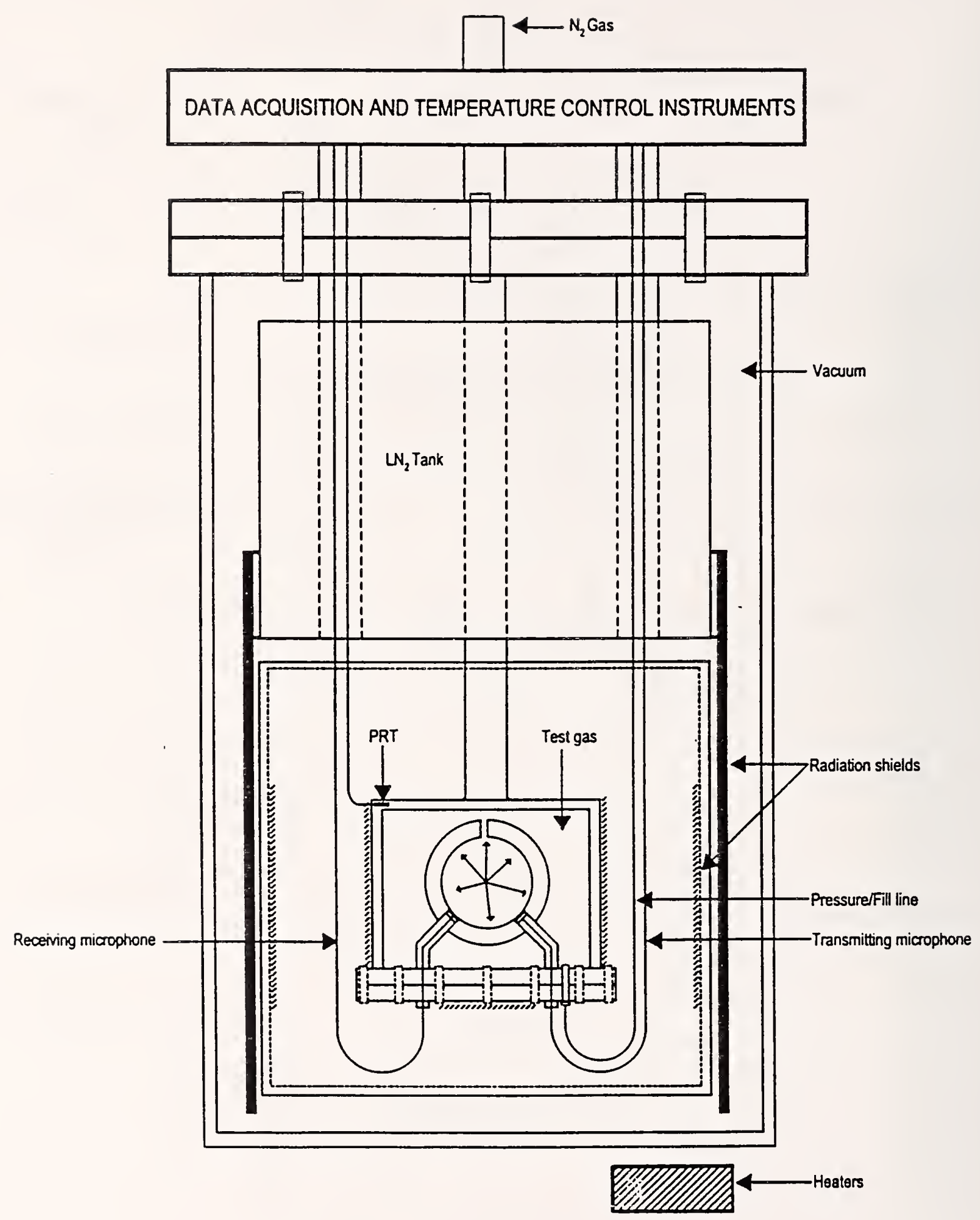

Figure B5. Schematic Diagram of Spherical Resonator Speed of Sound Apparatus. 


\section{APPENDIX C:}

\section{ESTIMATES OF STATE-POINT UNCERTAINTIES}


A state point is a group of parameters that uniquely specifies a point in a system such that there are no degrees of freedom. For a binary system, if there are two phases in equilibrium and the temperature and liquid composition (the independent parameters) are known, the state point is specified. The bubble-point pressure, vapor composition, densities, viscosity, surface tension, and many other dependent properties are functions only of the temperature and liquid composition along the two-phase boundary. Therefore, any uncertainties in the temperature and liquid composition directly affect the uncertainty of the dependent properties. Unlike the measurement of an individual parameter where the uncertainty is a function of only the calibration and measurement technique, the state-point uncertainty also depends on the relations among the measured parameters.

The bubble-point pressure state-point uncertainty is defined as the uncertainty of the bubblepoint pressure given the uncertainty of the liquid composition measurement, the uncertainty of the temperature measurement, the change of the bubble-point pressure with temperature and composition, and the uncertainty in the pressure measurement. The bubble-point pressure state-point uncertainty can be estimated using eq. (Cl).

$$
\pm \Delta \mathrm{P}_{\sigma}= \pm\left[\left|\left(\frac{\delta \mathrm{P}_{\mathrm{o}}}{\delta \mathrm{x}}\right)_{\mathrm{T}} \cdot \Delta \mathrm{x}\right|+\left|\left(\frac{\delta \mathrm{P}_{\sigma}}{\delta \mathrm{T}}\right)_{\mathrm{x}} \cdot \Delta \mathrm{T}\right|+|\Delta \mathrm{P}|\right] \cdot \frac{100}{\mathrm{P}}
$$

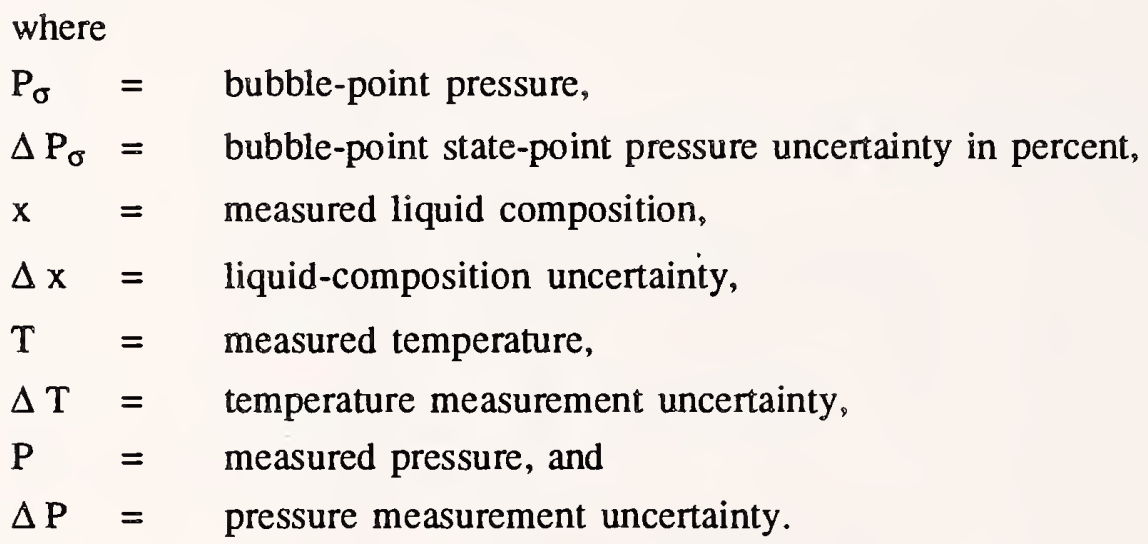

The partial derivatives can be calculated using either the experimental data or an equation of state.

The uncertainty of the vapor-composition state point is a function of temperature, liquid composition, and the interdependence of the parameters. It can be determined with a calculation similar to that of the bubble-point pressure state-point uncertainty. The expression for the vaporcomposition state-point uncertainty is shown in eq. (C2).

$$
\pm \Delta \mathrm{y}_{\sigma}= \pm\left[\left|\left(\frac{\delta \mathrm{y}_{\sigma}}{\delta \mathrm{x}}\right)_{\mathrm{T}} \cdot \Delta \mathrm{x}\right|+\left|\left(\frac{\delta \mathrm{y}_{\sigma}}{\delta \mathrm{T}}\right)_{\mathrm{x}} \cdot \Delta \mathrm{T}\right|+|\Delta \mathrm{y}|\right]
$$


where

$\mathrm{y}_{\sigma}=$ equilibrium vapor composition,

$\Delta y_{\sigma}=\quad$ vapor-composition state-point pressure uncertainty,

$\mathrm{x}=$ measured liquid composition,

$\Delta \mathrm{x}=$ liquid-composition uncertainty,

$\mathrm{T}=$ measured temperature,

$\Delta \mathrm{T}=$ temperature measurement uncertainty,

$\mathrm{y}=$ measured vapor composition, and

$\Delta \mathrm{y}=$ vapor-composition measurement uncertainty.

The uncertainty of the density state point is a function of temperature, composition, and the interdependence of the parameters. It can be determined with a calculation similar to that of the bubble-point pressure state-point uncertainty. The expression for the density state-point uncertainty is shown in eq. (C3).

$\pm \Delta \rho_{\sigma}= \pm\left[\left|\left(\frac{\delta \rho_{\sigma}}{\delta c}\right)_{T} \cdot \Delta \mathrm{c}\right|+\left|\left(\frac{\delta \rho_{\sigma}}{\delta \mathrm{T}}\right)_{\mathrm{c}} \cdot \Delta \mathrm{T}\right|+|\Delta \rho|\right] \cdot \frac{100}{\rho}$,

where

$\rho_{\sigma} \quad=\quad$ state-point density,

$\Delta \rho_{\sigma}=$ density state-point pressure uncertainty in percent,

$\mathrm{c}=$ measured liquid or vapor composition,

$\Delta \mathrm{c}=$ liquid or vapor composition measurement uncertainty,

$\mathrm{T}=$ measured temperature,

$\Delta \mathrm{T}=$ temperature measurement uncertainty,

$\rho=$ measured density, and

$\Delta \rho=$ density measurement uncertainty. 

APPENDIX D:

GAS CHROMATOGRAPH CALIBRATION PROCEDURES 
The gas chromatograph calibration procedure involves six steps. The first step is the preparation of two or three standard mixtures for each system. These mixtures are used to determine which GC column to use, to refine the calibration, and to check the sampling system for adsorption or mixing problems. The number of mixtures needed is dependent on the type of GC column used to separate the two components. A short-packed column usually requires two standard mixtures. A capillary column or long-packed column requires three or more mixtures due to the complex behavior of adsorption and desorption along the length of the column.

In the second step, the standard mixtures are used to determine which GC column best separates the two components and what are the appropriate settings on the GC. Table Dl summarizes the GC columns and settings used for each of the systems in this report.

In the third step of the procedure, density-versus-area data are obtained for the pure components from the GC. A specific volume is chosen for injection of the sample into the GC. This volume is filled at different pressures of the pure fluid in a region where the virial equation for the pure fluid can accurately predict the density. The pressure and temperature of the standard volume are recorded before each injection. The density of the injected gas is calculated from the virial equation of state.

The fourth step of the procedure characterizes any peak interaction or sample size dependence by injecting different quantities of the standard mixtures into the GC. The same sample volume used for the pure fluids is filled to different pressures with the standard mixtures. The area-percent-versussample-size data are recorded.

The fifth step is determining the correct calibration equation to use with the calibration data. For short-packed columns the area percent of the GC peaks should be independent of the amount of the standard mixture injected. The calibration equation for this type of column is based on combining the area-versus-density data of the two pure components. Usually the area-versus-density relationships for each of the pure components can be represented by a simple quadratic equation. The standard mixture data is used to optimize the fit and to check the accuracy of the equation.

A capillary column or long-packed column shows a dependence of area percent on the sample size injected. The calibration equations for these systems are more complicated than for short-packed columns because they include a size dependence as well as a composition dependence that requires all of the mixture and pure component data to be used in the fit. The procedure is more complicated than the procedure for a short-packed column, but is necessary in order to obtain accurate results.

The final step checks the sampling system for losses due to adsorption or inhomogeneous sampling. The apparatus is filled with one of the standard mixtures, and several samples are analyzed using the sampling system. The composition calculated from the GC should be the same as the composition of the standard mixture. If the composition is not the same as the standard mixture, one of the components may be adsorbing to the walls of the sampling system or the sample is not well mixed before it reaches the GC.

The GC calibration is only accurate within the peak area range of its calibration. If the samples withdrawn from the system are too large or too small, the calculated compositions will be in error. 
The size of the sample withdrawn from the apparatus must be adjusted to stay within the limits of the calibration. 


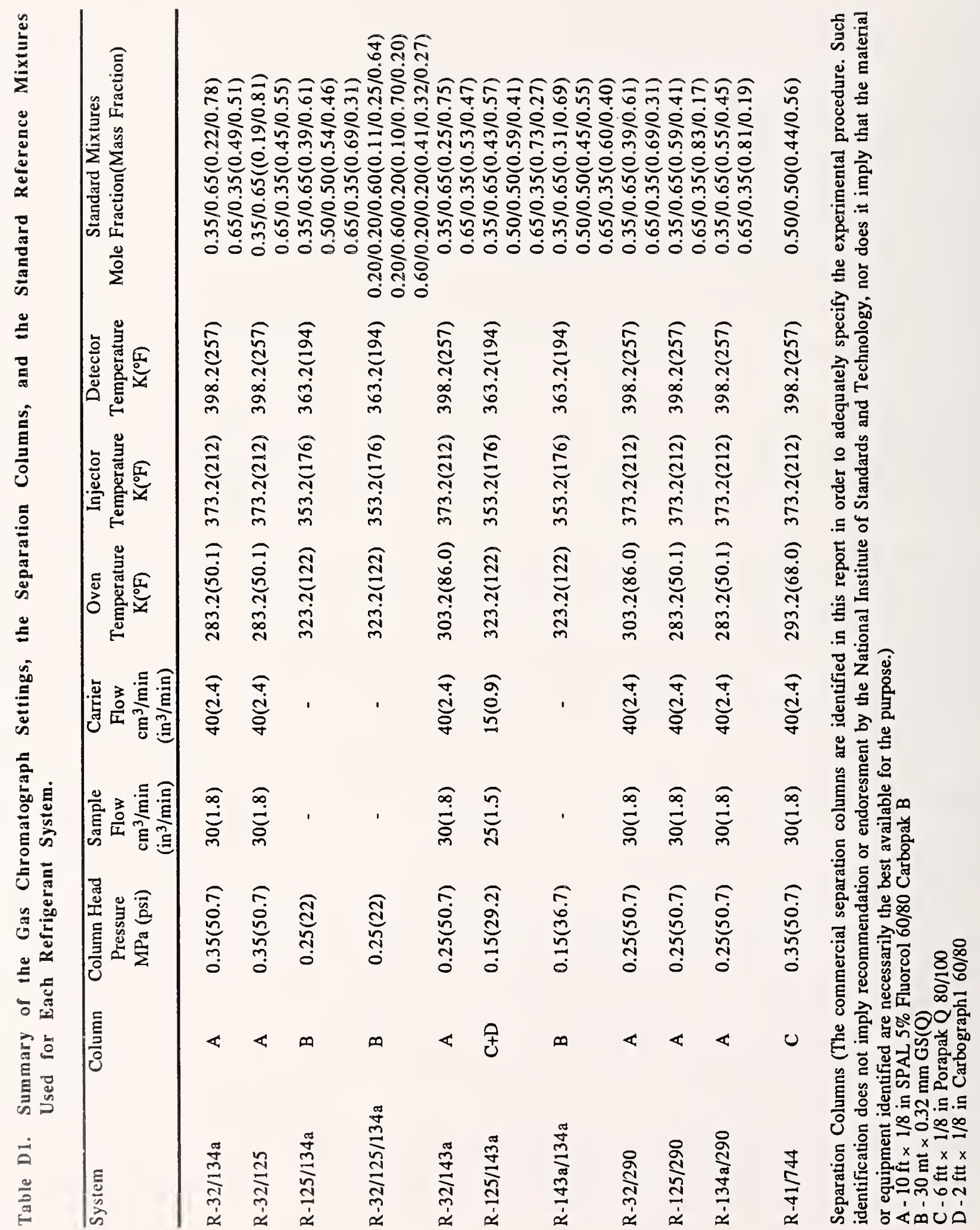




\section{APPENDIX E:}

REPRINTS OF PAPERS RELATED TO THE LEMMON-JACOBSEN MODEL [1] AND REFPROP 6.0 [2] 
Thermodynamic Properties of Mixtures of

Refrigerants R-32, R-125, R-134a, and R-152a1

E.W. Lemmon2,3,4 and R.T Jacobsen2

1 Paper presented at the Thirteenth Symposium on Thermophysical Properties, June 22-27, 1997 , Boulder, Colorado, U.S.A.

2 Center for Applied Thermodynamic Studies, University of Idaho, Moscow, ID 83844-1011

3 Current Address: Physical and Chemical Properties Division, National Institute of Standards and Technology, 325 Broadway, Boulder, CO 80303

4 To whom correspondence should be addressed. 


\section{ABSTRACT}

A mixture model explicit in Helmholtz energy has been developed which is capable of predicting thermodynamic properties of refrigerant mixtures containing R-32, R-125, R-134a, or R-152a. The Helmholtz energy of the mixture is the sum of the ideal gas contribution, the compressibility (or real gas) contribution, and the contribution from mixing. The contribution from mixing is given by a single equation which is applied to all mixtures used in this work. The independent variables are the reduced density and reduced temperature. The model may be used to calculate thermodynamic properties of mixtures at various compositions including dew- and bubble- point properties and critical points. It incorporates the most accurate published equation of state for each pure fluid. The model may be used to calculate the properties of mixtures generally within the experimental accuracies of the available measured properties. The estimated accuracy of calculated properties is $\pm 0.1 \%$ in density, $\pm 0.5 \%$ in the speed of sound, and $\pm 1 \%$ in heat capacities. Calculated bubble-point pressures are generally accurate to within $1 \%$.

KEY WORDS: equation of state; mixtures; R-32; R-125; R-134a; R-152a; thermodynamic properties. 


\section{INTRODUCTION}

Applications requiring the use of equations of state capable of accurate prediction of thermodynamic properties of environmentally-safe refrigerant mixtures are increasing. New refrigerants and mixtures of refrigerants are used as environmentally acceptable replacements for chlorofluorocarbons and hydrochlorofluorocarbons in refrigeration, heat pumps, foam-blowing, and other applications. Mixture equations are required to evaluate the performance of possible alternatives to the fully halogenated chlorofluorocarbons as working fluids. Many of the refrigerant mixtures form azeotropes. This is often desirable in vapor compression cycles because the mixture behaves as a pure fluid during phase changes.

The model presented here for mixtures of refrigerants is part of a more generalized model reported by Lemmon and Jacobsen [1] for mixtures of cryogens, hydrocarbons, and refrigerants. This model was initially reported by Lemmon [2] in a slightly different format. The model is based on corresponding states theory. Reducing parameters which are dependent on the mole fraction are used to modify absolute values of density and temperature. The Helmholtz energy for an ideal solution is determined at the reduced density and temperature of the mixture using accurate pure fluid equations of state for the mixture components.

The portion of the model describing the Helmholtz energy contribution from mixing is nearly the same for all binary mixtures, and relatively simple scaling factors are used to determine its magnitude for a particular application. Experimental data from many different mixtures were used to determine the function. The model is capable of predicting mixture properties for fluids with limited experimental databases. In addition, all vapor and liquid thermodynamic properties, including density, energy, entropy, heat capacity, sound speed, vapor-liquid equilibrium, and the mixture critical temperature, pressure, and density, can be calculated accurately using this approach.

The mixtures studied in this work are:

- R-32/R-125

- R-32/R-134a 
- R-125/R-134a

- R-32/R-125/R-134a

- R-134a/R-152a

Data for these mixtures were used to evaluate the behavior of the model, to calculate the coefficients of the generalized refrigerant mixture equation and to calculate the individual parameters for each binary mixture. Table I lists the pure fluid equations of state used in this work. All equations were converted for convenience from the published format to a fundamental form widely used in system analysis and design.

\section{THE MIXTURE EQUATION FOR ENVIRONMENTALLY-SAFE}

\section{REFRIGERANTS}

The Helmholtz energy for mixtures of refrigerants can be calculated using

$$
\alpha_{m}(\delta, \tau, \mathrm{x})=\alpha_{m}^{i}(\delta, \tau, \mathrm{x})+\alpha^{E}(\delta, \tau, \mathrm{x})
$$

The Helmholtz energy for the ideal solution is

$$
\alpha_{m}^{i}(\delta, \tau, \mathrm{x})=\sum_{i=1}^{r} x_{i}\left[\alpha_{i}^{0}(\delta, \tau)+\alpha_{i}^{r}(\delta, \tau)+\ln x_{i}\right]
$$

where $\mathrm{r}$ is the number of fluids in the mixture, $\alpha_{l}^{0}$ is the ideal gas Helmholtz energy of component

$i$, and $\alpha_{i}^{r}$ is the residual Helmholtz energy of component $i$. Equations for the ideal gas Helmholtz energy and residual Helmholtz energy for the pure fluids are given in the references shown in Table I.

The contribution to the Helmholtz energy from mixing used in this work is

$$
\alpha^{E}=\sum_{p=1}^{r} \sum_{q=p+1}^{r} x_{p} x_{q} F_{p q} \sum_{k=1}^{10} N_{k} \delta^{i} \tau^{j}+x_{\mathrm{R}-32} x_{\mathrm{R}-125}\left(N_{11} \delta \tau+N_{12} \delta\right)+x_{\mathrm{R}-32} x_{\mathrm{R}-125} N_{13} \delta,
$$

where the $N_{k}, i_{k}$, and $j_{k}$ are coefficients and exponents obtained from linear regression of experimental mixture data. The coefficients, $N_{k}$, of the equation are determined using a stepwise least-squares technique with a search and selection procedure which selects an optimum group of terms from a large comprehensive function based on statistical evaluation of the significance of 
individual terms. All thermodynamic properties can be calculated from the Helmholtz energy using differentiation with respect to density or temperature as described by Lemmon et al. [3].

The independent parameters of the equation for the contribution to the Helmholtz energy from mixing given in this work are reduced density and temperature and mixture composition. In addition, one other parameter, $F_{p q}$, is required which relates the excess-like properties of one binary mixture to those of another. This value is determined with a nonlinear fitting procedure that minimizes the sum of squares of the deviations between the equation and the data for a small select set of measurements.

The reduced density and temperature of the mixture are

$$
\begin{aligned}
& \delta=\rho / \rho_{j} \text { and } \\
& \tau=T_{j} / T,
\end{aligned}
$$

where $T_{j}$ and $\rho_{j}$ are the reducing values,

$$
\begin{aligned}
& T_{j}=\sum_{p=1}^{r} x_{p} T_{c_{p}}+\sum_{p=1}^{r} \sum_{q=p+1}^{r} x_{p} x_{q} \zeta_{p q} \\
& \rho_{j}=\left[\sum_{p=1}^{r} \frac{x_{p}}{\rho_{c_{p}}}+\sum_{p=1}^{r} \sum_{q=p+1}^{r} x_{p} x_{q} \xi_{p q}\right]^{-1},
\end{aligned}
$$

and where $\zeta_{p q}$ and $\xi_{p q}$ are used to define the shapes of the reducing parameter lines. The units for temperature and density are kelvins and mol.dm ${ }^{-3}$. These reducing parameters are not the same as the critical parameters of the mixture and the use of these parameters allows the calculation of VLE properties above the reducing temperature. These parameters define the relationship between the critical lines of different binary mixtures and are determined simultaneously in the nonlinear fit with the generalized factor. Details of the fitting procedures to determine the generalized factors and mixture parameters are given by Lemmon [2] and are not repeated here. The values of the coefficients and exponents in Eq. (3) are given in Table II. The generalized factors and mixture parameters are given in Table III. 


\section{COMPARISONS OF CALCULATED REFRIGERANT MIXTUREPROPERTIES}

\section{TO EXPERIMENTAL DATA}

Summary comparisons of values calculated using the mixture equation to $P-\rho-T$ data, isochoric heat capacity data, sound speed data and VLE data for refrigerant mixtures are given in Table IV, as well as the temperature and composition range for the first component listed. Details of the property calculation methods including those for VLE states are given by Lemmon [2].

The accuracies of calculated values of various properties are determined by comparing them to measured values. Statistical analyses are used to determine the overall estimated accuracy of the model in representing the data sets used in determining the coefficients of equations of state, and to define the ranges of estimated accuracies for various properties calculated with the formulation.

The statistics used to evaluate the equation are based on the percent deviation for any property, $X$,

$$
\% \Delta X=100\left(\frac{X_{\text {data }}-X_{\text {calc }}}{X_{\text {data }}}\right) \text {. }
$$

Using this definition, the statistics in Table IV are defined as:

$$
\begin{aligned}
& \mathrm{AAD}=\frac{1}{n} \sum_{i=1}^{n}\left|\% \Delta X_{i}\right|, \\
& \mathrm{Bias}=\frac{1}{n} \sum_{i=1}^{n}\left(\% \Delta X_{i}\right) .
\end{aligned}
$$

Two of the terms listed in Eq. (3) are specific to the R-32/R-125 binary mixture and another is specific to the R-32/R-134a binary mixture. The mixture model behavior is sensitive to the accuracy of the pure fluid equations of state. The equation of Outcalt and McLinden [5] for R32 was used in place of the equation from Tillner-Roth and Yokozeki [4] to determine the sensitivity of the deviations of calculated properties to the selection of the R-32 equation. Replacing the equation increased the AAD for the data of Magee [11] by $20 \%$. The deviations for other data in the supercritical region increased as well. The database for mixtures containing R-32 may be more reliable than that for the pure fluid. Additional details of this analysis are given by Lemmon [2]. This issue may be resolved by additional measurements and a revised correlation for R-32. 
Likewise, there are similar deficiencies in the $\mathrm{R}-125$ database in the critical region.

\section{ACCURACY ASSESSMENT}

An assessment has been made to determine the accuracy of the mixture model reported here. Generally, the equation is accurate to $\pm 0.1 \%$ in density, $\pm 1 \%$ in heat capacity, and $\pm 0.5 \%$ for the speed of sound. For binary mixtures, calculated bubble point pressures are generally within $\pm 1 \%$. The model is valid between from 200 to $450 \mathrm{~K}$ up to $60 \mathrm{MPa}$ as verified by experimental data. In regions where there are no binary mixture data, the accuracy is estimated to be of the same magnitude. However, this cannot be verified by the authors until experimental data are available to support these conclusions. Although the equation was developed using mostly binary data, it is accurate in calculating the properties of mixtures with three or more constituents. This conclusion is based upon comparisons of calculated values to the limited data available for multicomponent systems.

Future measurements will confirm whether the equation is valid for other mixtures and in regions not covered by the experimental data used in the development of this model. These data will enable continued evaluation and development of the model.

\section{REFERENCES}

1. E.W. Lemmon and R.T Jacobsen, submitted to Int. J. Thermophys. (1997).

2. E.W. Lemmon, A Generalized Model for the Prediction of the Thermodynamic Properties of Mixtures Including Vapor-Liquid Equilibrium, Ph.D. Dissertation, University of Idaho (1996).

3. E.W. Lemmon, R.T Jacobsen, S.G. Penoncello, and S.W. Beyerlein, Adv. Cryo. Eng. 39:1891 (1994).

4. R. Tillner-Roth and A. Yokozeki, to be submitted to J. Phys. Chem. Ref. Data (1997).

5. S.L. Outcalt and M.O. McLinden, Int. J. Thermophys. 16(1):79 (1995).

6. R. Tillner-Roth and H.D. Baehr, J. Phys. Chem. Ref. Data 23(5):657 (1994).

7. R. Tillner-Roth, Int. J. Thermophys. 16(1):91 (1995). 
8. C.D. Holcomb, VLE data reported in: Haynes, W.M, Thermophysical Properties of HCFC Alternatives, National Institute of Standards and Technology, Boulder, Colorado, Final Report for ARTI MCLR Project Number 660-50800 (1996).

9. H. Kiyoura, J. Takebe, H. Uchida, H. Sato, and K. Watanabe, J. Chem. Eng. Data 41:1409 (1996).

10. M. Kleemiss, Thermodynamic Properties of Binary and Ternary Mixtures of R134a, R32, R125 and R143a - Measurements and Equations of State, Dissertation, University of Hannover, Germany (1996).

11. J.W. Magee, private communication, NIST, Boulder, Colorado, USA (1995).

12. K. Oguchi, T. Takaishi, N. Yada, T. Namiki, and T. Sato, Kanagawa Institute of Technology, Japan (1995).

13. C.-C. Piao, I. Iwata, and M. Noguchi, to be submitted to J. Chem. Eng. Data, Mech. Eng. Lab., Daikin Industries, Ltd., Japan (1996).

14. T. Sato, H. Kiyoura, H. Sato, and K. Watanabe, Int. J. Thermophys. 17:43 (1996).

15. L.A. Weber and D.R. Defibaugh, Int. J. Thermophys. 15(5):863 (1994).

16. H.-L. Zhang, H. Sato, and K. Watanabe, J. Chem. Eng. Data 41:1401 (1996).

17. D.R. Defibaugh and G. Morrison, Int. J. Refrig. 18(8):518 (1995).

18. K. Fujiwara, H. Momota, M. Noguchi, 13th Japan Symp. Thermophys. Prop. A11.6:61 (1992).

19. Y. Higashi, 19th International Congress of Refrigeration, Netherlands IVa:297 (1995).

20. M. Nagel and K. Bier, Int. J. Refrig. 18:534 (1995).

21. J.V. Widiatmo, H. Sato, and K. Watanabe, High Temp.-High Press. 25:677 (1993).

22. T. Sato, H. Kiyoura, H. Sato, and K. Watanabe, J. Chem. Eng. Data 39(4):855 (1994).

23. J.V. Widiatmo, T. Fujimine, H. Sato, and K. Watanabe, to be submitted to J. Chem. Eng. Data (1997).

24. Y. Higashi, Int. J. Thermophys. 16(5):1175 (1995).

25. J.V. Widiatmo, H. Sato, and K. Watanabe, Fluid Phase Equilib. $29: 199$ (1994). 
26. T. Hozumi, H. Sato, and K. Watanabe, 4th Asian Thermophysical Properties Conference, Japan, p. 307 (1995).

27. M. Higuchi and Y. Higashi, Proc. 16th Japan Symp. Thermophys. Prop., Hiroshima, p. 5 (1995).

28. Y. Higashi, private communication, Department of Mechanical Engineering, Iwaki Meisei University, Japan (1996).

29. M. Dressner and K. Bier, Thermodynamic Measurements in Binary Systems of New Refrigerants, Fortschr.-Ber. VDI 3(332) (1993).

30. R. Tillner-Roth, J. Chem. Thermodyn. 25:1419 (1993).

31. A.J. Grebenkov, Yu.G. Kotelevsky, V.V. Saplitza, O.V. Beljaeva, T.A. Zajatz, and B.D. Timofeev, Proc, CFC's: The Day After, IIR Comm. B1, B2, E1, E2; Padova, Italy (1994).

32. M. Kleiber, M., Fluid Phase Equilib., 92:149 (1994).

Table I. Pure Fluid Equations of State for Refrigerants Used in the Mixture Model.

\begin{tabular}{llrc}
\hline Fluid & Author & $\begin{array}{c}\text { Temperature } \\
\text { Range (K) }\end{array}$ & $\begin{array}{c}\text { Maximum } \\
\text { Pressure (MPa) }\end{array}$ \\
\hline R-32 & Tillner-Roth and Yokozeki [4] & $160-500$ & 60 \\
R-125 & Outcalt and McLinden [5] & $174-500$ & 68 \\
R-134a & Tillner-Roth and Baehr [6] & $169.85-500$ & 70 \\
R-152a & Tillner-Roth [7] & $154.65-435$ & 30 \\
\hline
\end{tabular}


Table II. Coefficients and Exponents of the Mixture Equation

\begin{tabular}{cccc}
\hline$k$ & $N_{k}$ & $i_{k}$ & $j_{k}$ \\
\hline 1 & $-0.245476271425 \times 10^{-1}$ & 1 & 2 \\
2 & -0.241206117483 & 1 & 4 \\
3 & $-0.513801950309 \times 10^{-2}$ & 1 & -2 \\
4 & $-0.239824834123 \times 10^{-1}$ & 2 & 1 \\
5 & 0.259772344008 & 3 & 4 \\
6 & -0.172014123104 & 4 & 4 \\
7 & $0.429490028551 \times 10^{-1}$ & 5 & 4 \\
8 & $-0.202108593862 \times 10^{-3}$ & 6 & 0 \\
9 & $-0.382984234857 \times 10^{-2}$ & 6 & 4 \\
10 & $0.262992331354 \times 10^{-5}$ & 8 & -2 \\
11 & $-0.198606229861 \times 10^{-1}$ & 1 & 1 \\
12 & 0.143226453485 & 1 & 0 \\
13 & $0.369107330061 \times 10^{-1}$ & 1 & 0 \\
\hline
\end{tabular}

Table III. Parameters of the Mixture Equation

\begin{tabular}{llll}
\hline Binary Mixture & \multicolumn{1}{c}{$F_{p q}$} & $\xi_{p q}$ & $\zeta_{p q}$ \\
\hline R-32/R-125 & -0.789585 & -0.00530177 & 14.663390 \\
R-32/R-134a & -0.314574 & -0.00392017 & 5.737916 \\
R-125/R-134a & 0.104729 & 0.0 & -2.736948 \\
R-134a/R-152a & 0.125997 & 0.00487924 & -2.041245 \\
\hline
\end{tabular}


Table IV. Comparisons of Mixture Properties Calculated from the Model to Refrigerant Mixture Data

\begin{tabular}{|c|c|c|c|c|c|}
\hline Author & $\begin{array}{l}\text { No. } \\
\text { Points }\end{array}$ & $\begin{array}{l}\text { Temp. } \\
\text { Range }\end{array}$ & $\begin{array}{l}\text { Comp. } \\
\text { Range }\end{array}$ & $\mathrm{AAD}$ & Bias \\
\hline \multicolumn{6}{|l|}{$\mathrm{R}-32 / \mathrm{R}-125-P-\rho-T$} \\
\hline Holcomb [8] & 45 & $279-341$ & $0.24-0.96$ & 0.940 & 0.361 \\
\hline Kiyoura et al. [9] & 94 & $330-440$ & $0.37-0.61$ & 0.487 & -0.486 \\
\hline Kleemiss [10] & 415 & $243-413$ & $0.50-0.51$ & 0.187 & -0.035 \\
\hline Magee [11] & 228 & $200-400$ & 0.50 & 0.145 & 0.039 \\
\hline Oguchi et al. [12] & 6 & $355-430$ & 0.87 & 0.275 & -0.138 \\
\hline Piao et al. [13] & 533 & $263-393$ & $0.37-0.90$ & 0.245 & -0.098 \\
\hline Sato et al. [14] & 156 & $320-440$ & $0.70-0.90$ & 0.333 & -0.328 \\
\hline Weber and Defibaugh [15] & 17 & $338-373$ & 0.55 & 0.497 & -0.497 \\
\hline Zhang et al. [16] & 124 & $300-380$ & $0.50-0.70$ & 0.279 & -0.273 \\
\hline Overall & 1618 & $200-440$ & $0.24-0.96$ & 0.263 & -0.112 \\
\hline \multicolumn{6}{|l|}{ R-32/R-125 - VLE } \\
\hline Defibaugh and Morrison [17] & ] 10 & $249-338$ & 0.76 & 0.151 & -0.060 \\
\hline Fujiwara et al. [18] & 8 & 273 & $0.06-0.90$ & 2.060 & 2.060 \\
\hline Higashi [19] & 45 & $283-346$ & $0.23-0.90$ & 0.329 & 0.322 \\
\hline Holcomb [8] & 30 & $280-340$ & $0.34-0.95$ & 0.311 & 0.172 \\
\hline Kleemiss [10] & 23 & $224-333$ & $0.48-0.52$ & 0.364 & -0.227 \\
\hline Nagel and Bier [20] & 34 & $205-345$ & $0.24-0.95$ & 0.504 & 0.019 \\
\hline Oguchi et al. [12] & 11 & $250-350$ & 0.87 & 0.432 & 0.432 \\
\hline Piao et al. [13] & 10 & $263-283$ & $0.37-0.90^{*}$ & 0.665 & -0.648 \\
\hline Widiatmo et al. [21] & 24 & $280-310$ & $0.20-0.90$ & 0.530 & 0.383 \\
\hline Overall & 195 & 205-350 & $0.06-0.95$ & 0.476 & 0.192 \\
\hline
\end{tabular}


Table IV. (Continued)

\begin{tabular}{|c|c|c|c|c|c|}
\hline Author & $\begin{array}{l}\text { No. } \\
\text { Points }\end{array}$ & $\begin{array}{l}\text { Temp. } \\
\text { Range }\end{array}$ & $\begin{array}{l}\text { Comp. } \\
\text { Range }\end{array}$ & $\mathrm{AAD}$ & Bias \\
\hline \multicolumn{6}{|l|}{ R-32/R-134a $-P-\rho-T$} \\
\hline Holcomb $[8]$ & 44 & $279-340$ & $0.13-0.97$ & 1.123 & 0.535 \\
\hline Kleemiss [10] & 390 & $243-413$ & $0.50-0.56$ & 0.090 & 0.001 \\
\hline Magee [11] & 219 & $200-400$ & 0.50 & 0.121 & -0.079 \\
\hline Oguchi et al. [12] & 19 & $363-473$ & 0.39 & 0.426 & 0.407 \\
\hline Piao et al. [13] & 633 & $263-393$ & $0.33-0.89$ & 0.405 & -0.225 \\
\hline Sato et al. [22] & 220 & $320-440$ & $0.33-0.89$ & 0.147 & -0.011 \\
\hline Weber and Defibaugh [15] & 17 & $338-373$ & 0.51 & 1.048 & -1.048 \\
\hline Widiatmo et al. [23] & 22 & $280-330$ & 0.40 & 0.105 & -0.003 \\
\hline Overall & 1564 & $200-473$ & $0.13-0.97$ & 0.274 & -0.095 \\
\hline \multicolumn{6}{|l|}{$\mathrm{R}-32 / \mathrm{R}-134 \mathrm{a}-c_{v}$} \\
\hline Magee [11] & 131 & $205-343$ & 0.50 & 0.373 & 0.294 \\
\hline \multicolumn{6}{|l|}{$\mathbf{R}-32 / \mathbf{R}-134 \mathbf{a}-\omega$} \\
\hline Hozumi et al. [26] & 144 & $303-343$ & $0.16-0.90$ & 0.030 & 0.030 \\
\hline \multicolumn{6}{|l|}{ R-32/R-134a - VLE } \\
\hline Defibaugh and Morrison [17] & 25 & $253-358$ & $0.50-0.55$ & 0.398 & 0.260 \\
\hline Fujiwara et al. [18] & 6 & $273-273$ & $0.20-0.92$ & 3.262 & -3.262 \\
\hline Higashi [24] & 39 & $283-365$ & $0.12-0.67$ & 1.171 & 1.104 \\
\hline Holcomb [8] & 48 & $280-340$ & $0.16-0.78$ & 0.400 & 0.127 \\
\hline Kleemiss [10] & 16 & $223-343$ & $0.42-0.52$ & 0.229 & 0.118 \\
\hline Nagel and Bier [20] & 50 & $203-369$ & $0.21-0.77$ & 0.480 & 0.136 \\
\hline Oguchi et al. [12] & 34 & $238-301$ & $0.27-0.71$ & 0.868 & 0.776 \\
\hline Piao et al. [13] & 10 & $261-283$ & $0.33-0.89^{*}$ & 0.565 & -0.565 \\
\hline Widiatmo et al. [25] & 30 & $280-340$ & $0.33-0.89$ & 1.646 & 1.646 \\
\hline Overall & 258 & 203-369 & $0.12-0.92$ & 0.801 & 0.445 \\
\hline
\end{tabular}


Table IV. (Continued)

\begin{tabular}{|c|c|c|c|c|c|}
\hline Author & $\begin{array}{c}\text { No. } \\
\text { Points }\end{array}$ & $\begin{array}{l}\text { Temp. } \\
\text { Range }\end{array}$ & $\begin{array}{l}\text { Comp. } \\
\text { Range }\end{array}$ & $\mathrm{AAD}$ & Bias \\
\hline \multicolumn{6}{|l|}{$\mathrm{R} \cdot 125 / \mathrm{R}-134 \mathrm{a}-P=\rho=T$} \\
\hline Holcomb [8] & 17 & $280-342$ & $0.35-0.72$ & 0.297 & -0.166 \\
\hline Kleemiss [10] & 407 & $243-413$ & $0.50-0.51$ & 0.125 & -0.103 \\
\hline Magee [11] & 268 & $200-400$ & 0.50 & 0.110 & -0.076 \\
\hline Weber and Defibaugh [15] & 18 & $303-373$ & 0.50 & 0.378 & -0.353 \\
\hline Widiatmo et al. [23] & 110 & $280-350$ & $0.09-0.92$ & 0.112 & -0.093 \\
\hline Overall & 820 & $200-413$ & $0.09-0.92$ & 0.128 & -0.100 \\
\hline \multicolumn{6}{|l|}{$R-125 / R-134 a-V L E$} \\
\hline Higuchi and Higashi [27] & 55 & $283-365$ & $0.18-0.78$ & 0.373 & 0.030 \\
\hline Holcomb [8] & 40 & $280-340$ & $0.26-0.65$ & 0.521 & -0.032 \\
\hline Kleemiss [10] & 24 & $224-343$ & $0.46-0.51$ & 0.432 & -0.326 \\
\hline Nagel and Bier [20] & 31 & $206-365$ & $0.25-0.75$ & 0.541 & 0.219 \\
\hline Widiatmo et al. [23] & 75 & $280-350$ & $0.09-0.92$ & 0.712 & 0.711 \\
\hline Overall & 225 & $206-365$ & $0.09-0.92$ & 0.542 & 0.235 \\
\hline \multicolumn{6}{|c|}{$\mathrm{R}-32 / \mathrm{R}-125 / \mathrm{R}-134 \mathrm{a}-P \cdot \rho-\mathrm{T}$} \\
\hline Holcomb [8] & 42 & 244-346 & $0.20-0.68$ & 0.984 & 0.490 \\
\hline Kiyoura et al. [9] & 105 & $315-440$ & $0.38-0.52$ & 0.481 & 0.254 \\
\hline Kleemiss [10] & 369 & $243-413$ & $0.33-0.35$ & 0.093 & -0.019 \\
\hline Oguchi et al. [12] & 12 & $365-430$ & $0.38-0.47$ & 0.090 & -0.023 \\
\hline Piao et al. [13] & 994 & $263-393$ & $0.19-0.47$ & 0.307 & -0.115 \\
\hline Widiatmo et al. [23] & 53 & $280-340$ & $0.38-0.46$ & 0.185 & -0.181 \\
\hline Overall & 1575 & $243-440$ & $0.19-0.68$ & 0.278 & -0.056 \\
\hline
\end{tabular}




\begin{tabular}{|c|c|c|c|c|c|}
\hline Author & $\begin{array}{l}\text { No. } \\
\text { Points }\end{array}$ & $\begin{array}{l}\text { Temp. } \\
\text { Range }\end{array}$ & $\begin{array}{l}\text { Comp. } \\
\text { Range }\end{array}$ & $\mathrm{AAD}$ & Bias \\
\hline \multicolumn{6}{|c|}{ R-32/R-125/R-134a - VLE } \\
\hline Higashi [28] & 52 & $273-359$ & $0.17-0.54$ & 0.624 & -0.235 \\
\hline Holcomb [8] & 58 & $221-345$ & $0.05-0.60$ & 0.901 & 0.030 \\
\hline Kleemiss [10] & 44 & $222-353$ & $0.14-0.66$ & 0.372 & -0.306 \\
\hline Nagel and Bier [20] & 29 & $205-362$ & $0.19-0.43$ & 0.601 & -0.160 \\
\hline Piao et al. [13] & 31 & $270-326$ & $0.32-0.38$ & 0.664 & 0.165 \\
\hline Widiatmo et al. [23] & 43 & $280-340$ & $0.35-0.46$ & 0.504 & 0.500 \\
\hline Overall & 257 & $205-362$ & $0.05-0.66$ & 0.625 & -0.007 \\
\hline \multicolumn{6}{|l|}{ R-134a/R-152a $-P-\rho-T$} \\
\hline Dressner and Bier [29] & 139 & $333-423$ & $0.49-0.54$ & 0.225 & -0.076 \\
\hline Tillner-Roth [30] & 1679 & $243-433$ & $0.25-0.75$ & 0.073 & 0.034 \\
\hline Weber and Defibaugh [15] & 11 & $353-373$ & 0.50 & 0.042 & 0.017 \\
\hline Overall & 1829 & $243-433$ & $0.25-0.75$ & 0.085 & 0.025 \\
\hline \multicolumn{6}{|l|}{ R-134a/R-152a - $\omega$} \\
\hline Grebenkov et al. [31] & 120 & $230-336$ & 0.69 & 0.466 & -0.446 \\
\hline \multicolumn{6}{|l|}{ R-134a/R-152a - VLE } \\
\hline Defibaugh and Morrison [17] & ] 13 & $248-368$ & 0.78 & 0.284 & 0.009 \\
\hline Kleiber [32] & 25 & $255-298$ & $0.31-0.98$ & 0.146 & -0.134 \\
\hline Tillner-Roth [30] & 65 & $243-378$ & $0.23-0.75$ & 0.071 & -0.035 \\
\hline Overall & 103 & $243-378$ & $0.12-0.98$ & 0.116 & -0.054 \\
\hline
\end{tabular}

*Dew point compositions 


\title{
A NEXT GENERATION REFRIGERANT PROPERTIES DATABASE
}

\author{
Mark O. McLinden and Sanford A. Klein² \\ Physical and Chemical Properties Division \\ National Institute of Standards and Technology \\ Boulder, Colorado 80303 USA
}

\begin{abstract}
A completely revised version of the REFPROP refrigerant properties database is described. This program is based on the most accurate pure fluid and mixture models currently available. It implements three models for the thermodynamic properties of pure fluids: the modified Benedict-Webb-Rubin (MBWR) and Helmholtz equations of state, and an extended corresponding states (ECS) model. Mixture calculations employ a new model which applies mixing rules to the pure-fluid Helmholtz energies. Viscosity and thermal conductivity are modeled with either fluid-specific correlations or a new variation on the ECS method. These models are implemented in a suite of subroutines written in standard FORTRAN. A separate graphical user interface provides a convenient means of accessing the models. It will generate tables and/or plots for any user-specified mixture. Numerous options to customize the output are available as well as copy and paste capabilities to and from other applications.
\end{abstract}

\section{INTRODUCTION}

Knowledge of the thermophysical properties is essential for the evaluation of alternative refrigerants and the design of equipment using them. The REFPROP computer database from the National Institute of Standards and Technology (NIST) (Huber et al. 1995) has been one of the more widely used tools designed to provide these data. In the initial versions of REFPROP (Gallagher et al. 1993), the intent was to provide data on a wide variety of fluids to allow screening studies of possible replacements for the CFC or HCFC refrigerants. For many of these fluids, only sparse data were available, and, consequently, the database relied primarily on a simple model with few adjustable parameters-the Carnahan-Starling-DeSantis (CSD) equation of state. As the alternative refrigerants move from the laboratory to use in commercial equipment, highly accurate properties are required for a more limited set of fluids. We describe a completely revised REFPROP program (designated as Version 6) based on the most accurate pure fluid and mixture models currently available.

\section{THERMODYNAMIC MODELS}

REFPROP 6 calculates the thermodynamic properties using comprehensive equations of state. This approach ensures thermodynamic consistency and allows calculations at all conditions. Other approaches, such as the combination of a vaporphase model with vapor pressure and liquid density equations may not be applicable in the compressed liquid and supercritical regions and do not always give reliable results for derived properties such as heat capacity and speed of sound.

\section{Pure Fluid Models}

Three models are used for the thermodynamic properties of pure components, depending on the availability of data. The first is the modified Benedict-Webb-Rubin (MBWR) equation of state. This model was first proposed by Jacobsen and Stewart (1973) and has been applied to a wide variety of fluids, including hydrocarbons, cryogenic fluids, and refrigerants. It is capable of accurately representing the properties of a fluid over wide ranges of temperature, pressure, and density. The MBWR equation is the basis for the current international standard for the properties of RI23 (Younglove and McLinden, 1994).

The MBWR equation expresses pressure as an explicit function of temperature and molar density and is of the form,

$$
P=\sum_{n=1}^{9} \alpha_{n} \rho^{n}+\exp \left[\left(\rho / \rho^{c r i t}\right)^{2}\right] \sum_{n=10}^{15} \alpha_{n} \rho^{2 n-17},
$$

where the $\alpha_{i}$ are simple functions of temperature resulting in a total of 32 adjustable parameters. For a complete description of the energy quantities (enthalpy, entropy, etc.), the MBWR equation is combined with an expression for the molar heat capacity of the ideal-gas state, that is, vapor in the limit of zero pressure. A form combining polynomial and theoretical terms is used:

$$
C_{p}^{i d}=\sum_{i} c_{i} T^{i_{i}}+\sum_{k} \frac{u_{k}^{2} \exp \left(u_{k}\right)}{\left[\exp \left(u_{k}\right)-1\right]^{2}} \text {, with } \quad u_{k}=\frac{c_{k}}{T} \text {. }
$$

All of the thermodynamic properties can be computed from Eqs. (1-3), as detailed by Younglove and McLinden (1994).

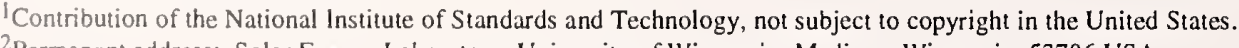

${ }^{2}$ Permanent address: Solar Energy Laboratory, University of Wisconsin, Madison, Wisconsin 53706 USA 
The second high-accuracy pure-fluid equation of state is in terms of reduced molar Helmholtz free energy:

$$
a=\frac{A}{R T}=a^{i d}+a^{r}=\ln \delta+\sum_{i} \alpha_{i} \tau^{t_{i}}+\sum_{k} \alpha_{k} \tau^{t_{k}} \delta^{d_{k}} \exp \left(-\gamma \delta^{l_{k}}\right),
$$

where the first two terms on the right side of Eq. (4) constitute the ideal-gas contribution $a^{i d}$; they are analogous to the combination of the $\alpha_{1}$ term in the MBWR equation of state $\left(\alpha_{1}=R T\right)$ and the ideal-gas heat capacity (Eqs. 2 and 3). The second summation is the residual, or real-fluid, contribution $a^{r}$. The temperature and density are expressed in the dimensionless variables $\tau=T^{*} / T$ and $\delta=\rho / \rho^{*}$, where $T^{*}$ and $\rho^{*}$ are reducing parameters which are of ten, but not always, equal to the critical parameters. The $\alpha_{i}$ and $\alpha_{k}$ are numerical coefficients fitted to experimental data and the exponents $t_{i}, t_{k}, d_{i}$, and $d_{k}$ are typically determined by a selection algorithm starting with a largc bank of terms. The parameter $\gamma$ is equal to 0 for terms with $l_{k}=0$; it is equal to 1 for terms with $l_{k} \neq 0$. This "Helmholtz model" is the basis for the international standard formulation for R134a (Tilner-Roth and Baehr, 1994).

This model is sometimes termed the "fundamental equation" because it gives a complete description of the thermodynamic properties, as discussed by Tillner-Roth and Baehr (1994), but the MBWR equation of state combined with a $C_{p}^{i d}$ equation is entirely equivalent. The sources for the high-accuracy formulations implemented in the database are summarized in Table 1. The accuracy of these formulations vary, but those for $\mathrm{R} 123$ are typical: experimental data are reproduced with average absolute deviations of $0.04 \%$ for densities, $0.05 \%$ for vapor pressures, and $0.75 \%$ for heat capacities.

The third pure-fluid model is the extended corresponding states (ECS) model of Huber and Ely (1994). It is used for fluids with limited experimental data. Simple corresponding states is based on the assumption that different fluids obey, in reduced coordinates, the same intermolecular force law. This assumption leads to the conclusion that, with the appropriate scaling of temperature and density, the reduced residual Helmholtz energies and compressibilities $(Z=p / R T \rho)$ of the unknown fluid " $j$ " and a reference fluid " 0 " (for which an accurate, wide-ranging equation of state is available) are equal:

$$
a_{j}^{r}\left(T_{j}, \rho_{j}\right)=a_{0}^{r}\left(T_{0}, \rho_{0}\right), \text { and } \quad Z_{j}\left(T_{j}, \rho_{j}\right)=Z_{0}\left(T_{0}, \rho_{0}\right)
$$

When combined with an expression for the ideal gas heat capacity (such as Eqs. 2 and 3), all other thermodynamic properties can be calculated. The reference fluid is evaluated at a "conformal" temperature and density:

$$
T_{0}=\frac{T_{j}}{f_{j}}=T_{j} \frac{T_{0}^{\text {crit }}}{T_{j}^{\text {crit }} \theta(T)} \text {, and } \quad \rho_{0}=\rho_{j} h_{j}=\rho_{j} \frac{\rho_{0}^{\text {crit }}}{\rho_{j}^{\text {crit }}} \phi(T) .
$$

where the multipliers $1 / f_{j}$ and $h_{j}$ are termed reducing ratios; they are composed of ratios of the critical parameters. Simple corresponding states was developed for spherically symmetric molecules. The ECS model extends the method to other types of molecules by the introduction of the "shape factors" $\theta$ and $\phi$. These shape factors are taken here to be functions only of temperature. (If data sufficient to fit the density dependence were available, it would be preferable to develop a full equation of state.) The shape factors are fitted to experimental data, typically vapor pressures and saturated liquid densities. The reference

\begin{tabular}{|c|c|c|c|c|c|}
\hline Fluid & Model & $\underline{\text { Source }}$ & \multicolumn{3}{|c|}{ Limits of Application } \\
\hline Rll & Helmholtz & Jacobsen et al. (1992) & $162.68\left(T_{1 p}\right)-625$ & $0-30$ & $0-1768$ \\
\hline $\mathrm{R} 12$ & Helmholtz & Marx et al. (1992) & $116.10\left(T_{t p}\right)-525$ & $0-200$ & 1830 \\
\hline $\mathrm{R} 22$ & Helmholtz & Kamei et al. (1995) & $115.73\left(\mathrm{~T}_{1 \mathrm{p}}\right)-550$ & $0-60$ & $0-1721$ \\
\hline R32 & MBWR & Outcalt and McLinden (1995) & $136.34\left(\mathrm{~T}_{1 \mathrm{p}}\right)-500$ & $0-60$ & $0-1429$ \\
\hline R 113 & Helmholtz & Marx et al. (1992) & $236.93\left(\mathrm{~T}_{\mathrm{tp}}\right)-525$ & $0-200$ & $0-1705$ \\
\hline R 123 & MBWR & Younglove and McLinden (1994) & $166\left(T_{t p}\right)-500$ & $0-40$ & 774 \\
\hline $\mathrm{R} 124$ & Helmholtz & de Vries et al. (1995) & $100-400$ & $0-40$ & $0-1903$ \\
\hline $\mathrm{R} 125$ & MBWR & Outcalt and McLinden (1995) & $172.52\left(T_{1 p}\right)-500$ & $0-60$ & 691 \\
\hline $\mathrm{R} 134 \mathrm{a}$ & Helmholtz & Tillner-Roth and Baehr (1994) & $169.85\left(T_{1 p}\right)-460$ & $0-70$ & 591 \\
\hline $\mathrm{R} 143 \mathrm{a}$ & MBWR & Outcalt and McLinden (1994) & $161.34\left(T_{1 p}\right)-500$ & $0-40$ & 329 \\
\hline $\mathrm{R} 152 \mathrm{a}$ & MBWR & Outcalt and McLinden (1996) & $154.56\left(T_{1 p}\right)-500$ & $0-60$ & 193 \\
\hline R170 (ethane) & MBWR & Younglove and Ely (1987) & $90.35\left(T_{t p}\right)-600$ & $0-70$ & $0-664$ \\
\hline R290 (propane) & MBWR & Younglove and Ely (1987) & $85.87\left(T_{1 p}\right)-600$ & $0-100$ & $0-$ \\
\hline R600 (butane) & MBWR & Younglove and Ely (1987) & $134.86\left(T_{t p}\right)-500$ & $0-70$ & $0-$ \\
\hline R600a (isobutane) & MBWR & Younglove and Ely (1987) & $113.55\left(\mathrm{~T}_{1 \mathrm{p}}\right)-600$ & $0-35$ & $0-7$ \\
\hline R717 (ammonia) & Helmholtz & Tillner-Roth et al. (1993) & $195.49\left(\mathrm{~T}_{1 \mathrm{p}}\right)-700$ & $0-1000$ & $0-900$ \\
\hline $\mathrm{R} 744\left(\mathrm{CO}_{2}\right)$ & MBWR & Ely et al. (1987) & $216.58\left(\mathrm{~T}_{\mathrm{tp}}\right)-500$ & $0-40$ & $0-1178$ \\
\hline
\end{tabular}
fluid is chosen to be chemically similar to the fluid of interest. The fluids represented with the ECS model are listed in Table 2.

Table 1-High-accuracy pure-fluid equations of state currently implemented in REFPROP 6 
Table 2-Fluids currently represented with the extended corresponding states (ECS) model in REFPROP 6

\begin{tabular}{|c|c|c|c|c|c|c|c|}
\hline \multicolumn{2}{|c|}{ Fluid Reference Fluid } & \multicolumn{2}{|c|}{ Fluid Reference Fluid } & \multicolumn{2}{|c|}{ Fluid Reference Fluid } & \multicolumn{2}{|c|}{ Fluid Reference Fluic } \\
\hline $\mathrm{R} 13$ & $\mathrm{R} 12$ & RI15 & $\mathrm{R} 12$ & $\mathrm{R} / 42 \mathrm{~b}$ & R22 & $\mathrm{RC} 270$ & propane \\
\hline $\mathrm{R} 14$ & $\mathrm{R} 12$ & RI16 & R12 & R227ea & R134a & RC318 & propane \\
\hline R23 & R134a & RI34 & R134a & $\mathrm{R} 236 \mathrm{fa}$ & R134a & $\mathrm{R} 1270$ & propane \\
\hline R114 & $\mathrm{R} 12$ & Rl4lb & R22 & $\mathrm{R} 245 \mathrm{ca}$ & RI34a & RE 170 & propane \\
\hline
\end{tabular}

Mixture Model

The thermodynamic properties of mixtures are calculated with a new model which was developed, in slightly different forms, independently by Tillner-Roth (1993) and Lemmon (1996). It applies mixing rules to the Helmholtz energy of the mixture components:

$$
a_{\text {mix }}=\frac{A_{\text {mix }}}{R T}=\sum_{j=1}^{n} x_{j}\left(a_{j}^{i d}+a_{j}^{r}\right)+x_{j} \ln x_{j}+\sum_{p=1}^{n-1} \sum_{q=p+1}^{n} x_{p} x_{q} F_{p q} a_{p q}^{\text {excess }} .
$$

This mixing formula may be applied directly to the Helmholtz equation of state. Application to the MBWR equation of state and the ideal gas heat capacity expression used with the MBWR and ECS models requires transformations:

$$
\begin{aligned}
& a^{r}=\frac{1}{R T} \int_{V}^{\infty}(P-R T \rho) d V, \text { and } \\
& a^{i d}=\frac{h_{r e f}}{R T}-\frac{s_{r e f}}{R}-1+\ln \left(\frac{T \rho}{T_{r e f} \rho_{r e f}}\right)+\frac{1}{R T} \int_{T_{r e f}}^{T} C_{p}^{i d} d T-\frac{1}{R} \int_{T_{r e f}}^{T} \frac{C_{p}^{i d}}{T} d T,
\end{aligned}
$$

where $h_{\text {ref }}$ and $s_{\text {ref }}$ are an arbitrary reference enthalpy and entropy at the reference state specified by $T_{\text {ref }}$ and $\rho_{\text {ref }}$.

The first summation in Eq. (9) represents the ideal solution; it consists of ideal gas (superscript $i d$ ) and residual or real fluid (superscript $r$ ) terms for each of the pure fluids in the $n$ component mixture. The $x_{j} \ln x_{j}$ terms arise from the entropy of mixing of ideal gases where $x_{j}$ is the mole fraction of component $j$. The double summation accounts for the "excess" free energy or "departure" from ideal solution. The $F_{p q}$ are generalizing parameters which relate the behavior of one binary pair with another; $F_{p q}$ multiplies the $a_{p y}^{\text {excess }}$ term(s), which are empirical functions fitted to experimental binary mixture data. The $a^{r}$ and $a_{p y}^{\text {excess }}$ functions in Eqs ( 9 and 10) are not evaluated at the temperature and density of the mixture $T_{m i x}$ and $\rho_{m i x}$ but, rather, at a reduced temperature and density $\tau$ and $\delta$. These $\tau$ and $\delta$ are very much in the spirit of the conformal temperature and density of the ECS method and are a key innovation in this model. Several mixing rules for the reducing parameters are used, including

$$
\begin{aligned}
& \tau=\frac{T^{*}}{T_{m i x}}, \quad \text { with } \quad T^{*}=\sum_{p=1}^{n} \sum_{q=1}^{n} k_{T, p q} x_{p} x_{q}\left(T_{p}^{\text {crit }} T_{q}^{\text {crit }}\right)^{1 / 2}, \text { and } \\
& \delta=\frac{\rho_{\text {mix }}}{\rho^{*}}, \quad \text { with } \quad \frac{1}{\rho^{*}}=\sum_{p=1}^{n} \sum_{q=1}^{n} k_{V, p q} x_{p} x_{4} \frac{1}{8}\left[\left(V_{p}^{\text {crit }}\right)^{1 / 3}+\left(V_{q}^{c r i t}\right)^{1 / 3}\right]^{3} .
\end{aligned}
$$

If only limited vapor-liquid equilibrium (VLE) data are available the $a_{p q}^{\text {excess }}$ term is taken to be zero, and only the $k_{T, p q}$ and/or $k_{V, p q}$ parameters are fitted. The $k_{T, p q}$ parameter is most closely associated with bubble point pressures, and it is necessary to reproduce azeotropic behavior. The $k_{V, p q}$ parameter is associated with volume changes on mixing. (Ternary and higher order mixtures are modeled in terms of their constituent binary pairs: $k_{T, p q}=1$ and $k_{V, p q}=1$ for $p=q$.) If extensive data, including single-phase pressure-volume-temperature (PVT) and heat capacity data, are avallable, the $a_{p y}^{\text {excess }}$ function can be determined. The $F_{p q}$ parameter is used (either alone or in combination with $k_{T, p q}$ and $k_{V, p q}$ ) to generalize the detailed mixture behavior described by the $a_{p y}^{\text {excess }}$ function to other, similar, binary pairs. Lemmon (1996) has determined an $a_{p y}^{\text {excess }}$ function based on data for 28 binary pairs of hydrocarbons, inorganics, and HFC's (but using different mixing rules than Eqs. 12 and 13).

This "mixture Helmholtz model" provides a number of advantages. By applying mixing rules to the Helmholtz energy of the mixture components, it allows the use of high-accuracy equations of state for the components, and the properties of the mixture will reduce exactly to the pure components as the composition approaches a mole fraction of 1 . Different components in a mixture may be modeled with different forms; for example, a MBWR equation may be mixed with a Helmholtz equation of state. If the components are modeled with the ECS method, this mixture model allows the use of a different reference fluid for each component. The mixture is modeled in a fundamental way, and thus the departure function is a relatively small contribution to the total Helmholtz energy for most refrigerant mixtures. The great flexibility of the adjustable parameters in this model allows an accurate representation of a wide variety of mixtures, provided sufficient experimental data are available. 


\section{TRANSPORT PROPERTY MODELS}

\section{Pure Fluid Models}

The transport properties of viscosity and thermal conductivity are modeled with the residual concept. In this representation, the property $\chi$ (representing either viscosity $\eta$ or thermal conductivity $\lambda$ ) is composed of three contributions:

$$
\chi=\chi^{i d}(T)+\Delta \chi^{r}(T, \rho)+\Delta \chi^{c}(T, \rho) .
$$

$\chi^{i d}$ is a dilute gas term which is a function only of temperature, and $\Delta \chi^{r}$ is a residual term accounting for the behavior at higher densities, including liquid densities. $\Delta \chi^{r}$ is primarily a function of density, but it may also be a function of temperature and density. The thermal conductivity approaches infinity at the critical point, and this critical enhancement is expressed by $\Delta \chi^{c}$. This term is significant for thermal conductivity even quite far from the critical point. For viscosity the enhancement is small except extremely close to the critical point and may be safely ignored in all practical applications. A variety of fluid-specific correlations for viscosity and thermal conductivity, based on the residual concept, have been implemented in the database.

Where fluid-specific correlations are not available, the transport properties are modeled with the extended corresponding states method of Klein et al. (1996). This method is a modification of the ECS model of Huber et al. (1992a, 1992b) and shares many of the concepts of the ECS model for the thermodynamic properties described above. The dilute gas term is modeled using kinetic theory (Hirschfelder et al. 1954). The residual term is scaled to the properties of a reference fluid:

$$
\Delta \chi_{j}^{r}(T, \rho)=\Delta \chi_{0}^{r}\left(T_{0}, \rho_{0}\right) f_{j}^{1 / 2} h_{j}^{-2 / 3}\left[\frac{M_{j}}{M_{0}}\right]^{1 / 2},
$$

where $M$ is molar mass. The determination of the reducing ratios involves an iterative procedure. Eqs. (5) and (6) are iterated to find the $f_{j}$ and $h_{j}$ satisfying those two conformal relations. The conformal temperature $T_{0}$ is defined in Eq. (7). The conformal density $\rho_{0}$ in the residual term (but not the critical enhancement) is further modified from that in the thermodynamic ECS method (Eq. 8) by the introduction of a third shape factor $\Psi$ :

$$
\rho_{0}=\rho_{j} \frac{\rho_{0}^{\text {crit }}}{\rho_{j}^{\text {crit }}} \phi(T) \Psi(\rho) .
$$

The shape factor $\Psi$ is a linear function of density and is determined by a least-squares fit to experimental data. Separate $\Psi$ functions are determined for viscosity and thermal conductivity.

\section{Mixture Model}

The viscosity of a mixture is calculated with the extended corresponding states method of Klein et al. (1996):

$$
\eta(T, \rho, x)=\eta^{i d}(T, x)+\Delta \eta_{0}\left(T / f_{x}, \rho h_{x}\right) F_{\eta}+\Delta \eta^{*}(\rho, x) \text {, with } \quad F_{\eta}=f_{x}^{1 / 2} h_{x}^{-2 / 3} g_{x}^{1 / 2}
$$

The low-density contribution $\eta^{\text {id }}$ is calculated with kinetic theory (Hirschfelder et al. 1954) and $\Delta \eta^{*}$ is an Enskog-theory hardsphere correction for size and mass differences given by Ely (1981). The reducing ratios $f_{x}$ and $h_{x}$ are determined by applying Eqs. (5) and (6) to the mixture. The "mass shape factor" for the mixture, $g_{x}$, is determined by mixing rules applied to the component mass shape factors, defined as

$$
g_{j}^{1 / 2}=\frac{\Delta \eta_{j}\left(T_{j}, \rho_{j}\right)}{\Delta \eta_{0}\left(T / f_{j}, \rho h_{j}\right)} f_{j}^{-1 / 2} h_{j}^{2 / 3} .
$$

The residual viscosity of component $j$ in Eq. (19) is evaluated, using either a fluid-specific correlation or the pure-fluid ECS model described above, at the conformal conditions

$$
T_{j}=\frac{T_{m i x} f_{j}}{f_{x}} \text { and } \quad \rho_{j}=\frac{\rho_{m i x} h_{x}}{h_{j}} .
$$

This formulation yields the pure-fluid values exactly as the composition approaches a mole fraction of 1. A analogous method is used for thermal conductivity. For the transport properties, R134a is used as the reference fluid for all mixture components.

\section{PROPERTY SUBROUTINES}

The property models described above are implemented as a suite of FORTRAN subroutines. These routines have been completely rewritten from earlier versions of REFPROP. Source code is provided with the database so that users may link the property routines with their own application. ("Translation" routines will allow applications written using the subroutine calls 
of earlier versions of REFPROP to use the new subroutines.) The routines are written in ANSI-standard FORTRAN 77 and are compatible with FORTRAN 90. They are written in a structured format, are internally documented with extensive comments, and have been tested on a variety of compilers.

The fluid or mixture of interest is specified with a (required) call to the subroutine "SETUP." This routine reads the coefficients to the NIST-recommended models for that fluid. Alternative property models and/or nonstandard reference states may be specified by calls to additional (optional) setup routines. Routines are provided to calculate thermodynamic and transport properties and surface tension at a given $(T, \rho, x)$ state. Iterative routines provide saturation properties at a specified $(T, x)$ or $(P, x)$ state. Flash calculations calculate single- or two-phase states at specified $(P, h, x),(P, T, x)$, etc.

The routines mentioned above are independent of the model. Underlying these routines are sets of "core" routines for each of the models implemented in the database. Each such set is highly modular and is contained in a separate file. Coefficients nceded for a particular model are stored in common blocks, but these commons are referenced only by routines in the same file. These sets of subroutines, thus, resemble "units" in the Pascal language with clearly demarcated "interface" and "local" declarations. This structure is intended to simplify the addition of future models to the database and will make such additions almost totally transparent to the user.

Numerical coefficients to the property models are stored in text files. There is one file per fluid and one file containing coefficients for the mixture departure functions. These files are read (once) upon the call to SETUP. Fluids can be added to or deleted from the database without recompilation.

\section{USER INTERFACE}

A graphical user interface has been developed for REFPROP 6 independent of the code implementing the algorithms. The interface provides a convenient means to calculate and display thermodynamic and transport properties. It is written for the Windows ${ }^{\mathrm{TM}}$ operating system. (Mention of commercial products is to fully specify the database and does not constitute endorsement by NIST or imply that they are necessarily the best suited for the purpose.) The interface is written in Pascal; it accesses the FORTRAN property subroutines via a dynamic link library. Screen shots of the interface program are shown in Figures 1 and 2. The program is controlled through the use of the following pull-down menus (visible at the top of Figure 1):

File provides commands to save and print generated tables and plots. Individual items or entire sessions with multiple windows may be saved or recalled. The standard "print setup" and "quit" commands are also present.

The Edit menu provides copy and paste commands which allow selected data to be exchanged with other applications.

The Options menu provides commands for selecting the unit system, properties of interest, and the reference state. These options may be stored for recall at a later time. A user-defined set of preferences is loaded upon program startup.

The pure fluid or mixture of interest is specified with commands in the Substance menu. Most of the refrigerant mixtures of current commercial interest (those having an ASHRAE R400 or R500-series designation) are predefined. In addition, new mixtures can be specified and saved by combining up to five of the pure components listed in Tables 1 and 2 .

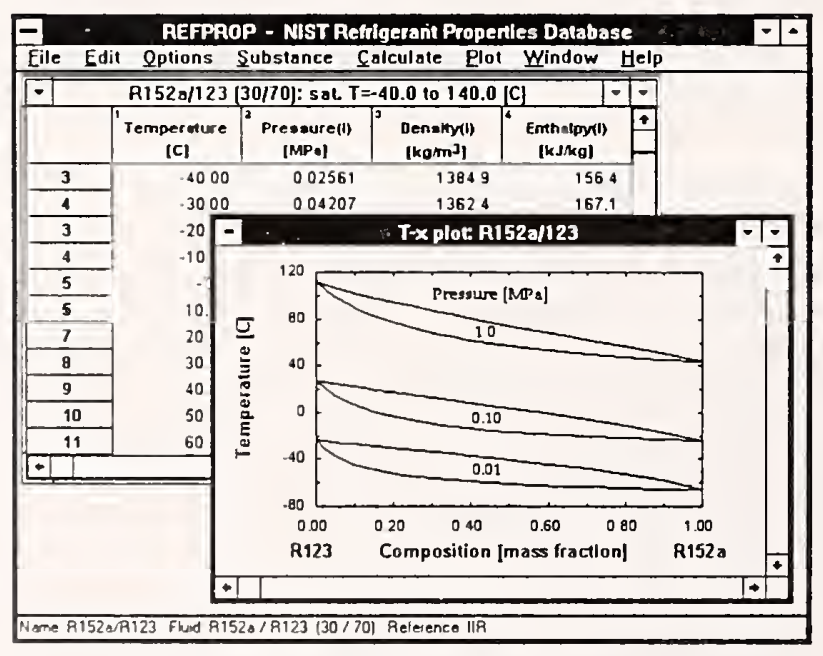

Figure 1. Screen shot of interface showing a typical data table and temperature-composition diagram.

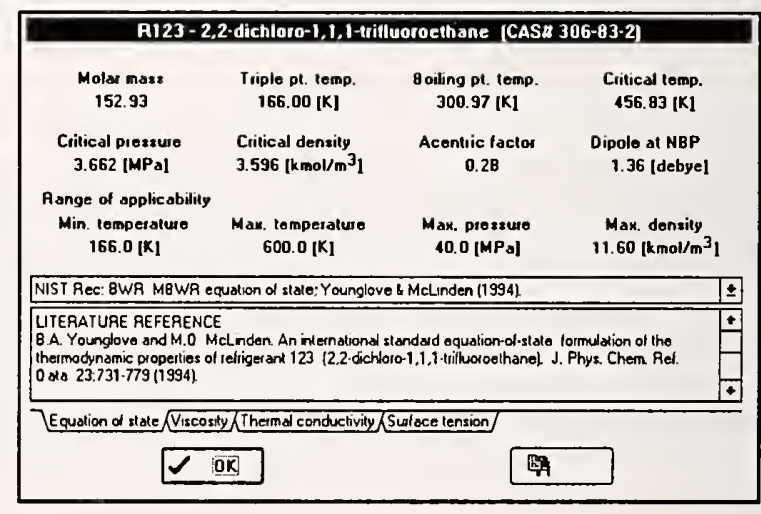

Figure 2. Pure-component information screen available from the interface. 
The Calculate menu initiates the calculations that generate a property table. Each property selected for display is shown in a separate column of the table. Two types of tables are provided. The first type, such as that shown in Figure I, provides properties at saturation or with a property (such as temperature or pressure) held constant with another selected property varying over a specified range. The second type allows the user to select the independent variables. Values of the independent variables may then be entered with the keyboard, read from a file, or pasted from another application.

The Plot menu provides publication-quality $x-y$ plots of any variables appearing in a table. In addition, temperatureentropy, pressure-enthalpy, temperature-composition and pressure-composition diagrams may be generated automatically Controls are provided to modify the plot size, axis scaling, plot symbols, line type, legend, and other plot features.

Each table or plot appears in a separate window and can be accessed, resized, or retitled with commands in the Window menu. The number of windows is limited only by available memory.

A complete online-help system can be accessed through the Help menu.

A status line at the bottom of the screen displays the currently specified mixture, composition, and reference state. Clicking on the status line will call up a screen for each of the components providing documentation for fluid constants, the source of the models, and their range of applicability, as shown in Figure 2.

\section{CONCLUSIONS}

The new REFPROP 6 database implements a variety of high-accuracy models for the thermodynamic and transport properties of refrigerants and their mixtures. These models are implemented as a suite of FORTRAN 77 subroutines written in a modular fashion; this structure will facilitate the incorporation of additional fluids and future models. A graphical user interface provides a convenient means of accessing the models and producing tables and plots of any specified mixture.

\section{ACKNOWLEDGEMENTS}

We gratefully acknowledge many helpful discussions with D. Friend, M. Huber, A. Laesecke, and R. Perkins. The stay of S.A. Klein at NIST was funded, in part, by the University of Wisconsin and by a grant from the National Science Foundation under Agreement No. 9527385. Any opinions, findings, and conclusions or recommendations expressed in this publication are those of the authors and do not necessarily reflect the views of the National Science Foundation.

\section{REFERENCES}

de Vries, B., Tillner-Roth, R. and Baehr, H.D. (1995). 19th International Congress of Refrigeration, IVa: $582-589$.

Ely, J.F. (1981). J. Res. NBS 86: 597-604.

Ely, J.F., Magee, J.W. and Haynes, W.M. (1987). Research Report RR-110, Gas Processors Association, Tulsa, OK.

Gallagher, J., Huber, M., Morrison, G. and McLinden, M. (1993). NIST Standard Reference Database 23, version 4.0. Standard Reference Data Program, National Institute of Standards and Technology, Gaithersburg, MD.

Hirschfelder, J.O., Curtiss, C.F. and Bird, R.B. (1954). Molecular Theory of Gases and Liquids, John Wiley and Sons, Inc. Huber, M.L. and Ely, J.F. (1992a). Fluid Phase Equilibria 80: 239-248.

Huber, M.L., Friend, D.G. and Ely, J.F. (1992b). Fluid Phase Equilibria 80: 249-261.

Huber, M.L. and Ely, J.F. (1994). Int. J. Refrigeration 17: 18-31.

Huber, M., Gallagher, J., McLinden, M. and Morrison, G. (1995). NIST Standard Reference Database 23, version 5.0. Standard Reference Data Program, National Institute of Standards and Technology, Gaithersburg, MD.

Jacobsen, R.T. and Stewart, R.B. (1973). J. Phys. Chem. Ref. Data 2: 757-922.

Jacobsen, R.T., Penoncello, S.G. and Lemmon, E.W. (1992). Fluid Phase Equilibria 80: 45-56.

Kamei, A., Beyerlein, S.W. and Jacobsen, R.T. (1995). Int. J. Thermophysics 16: 1155-1164.

Klein, S.A., McLinden, M.O. and Laesecke, A. (1996). An improved extended corresponding states method for estimation of viscosity of pure refrigerants and mixtures. Int. J. Refrigeration (submitted).

Lemmon, E.W. (1996). PhD Thesis, Mechanical Engineering, University of Idaho, Moscow, ID.

Marx, V., Pruß, A. and Wagner, W. (1992). Neue Zustandsgleichungen für R 12, R 22, R 11 und R 113 . Beschreibung des thermodynamishchen Zustandsverhaltens bei Temperaturen bis $525 \mathrm{~K}$ und Drücken bis $200 \mathrm{MPa}$, VDI Verlag.

Outcalt, S.L. and McLinden, M.O. (1995). Int. J. Thermophysics 16: 79-89.

Outcalt, S.L. and McLinden, M.O. (1996). J. Phys. Chem. Ref. Data 25: 605-636.

Outcalt, S.L. and McLinden, M.O. (1994). In: Thermophysical Properties of HFC-143a and HFC-152a, final report to the AirConditioning and Refrigeration Technology Institute, Arlington, VA, report no. DOE/CE/23810-39.

Tillner-Roth, R. (1993). Dr.-Ing. Thesis, Institut für Thermodynamik, Universität Hannover, Germany.

Tillner-Roth, R. and Baehr, H.D. (1994). J. Phys. Chem. Ref. Data 23: 657-729.

Tillner-Roth, R., Harms-Watzenberg, F. and Baehr, H.D. (1993). DKV-Tagungsbericht 20, II: $167-181$.

Younglove, B.A. and Ely, J.F. (1987). J. Phys. Chem. Ref. Data 16: 577-798.

Younglove, B.A. and McLinden, M.O. (1994). J. Phys. Chem. Ref. Data 23: 731-779. 




\section{NIST Technical Publications}

\section{Periodical}

Journal of Research of the National Institute of Standards and Technology-Reports NIST research and development in those disciplines of the physical and engineering sciences in which the Institute is active. These include physics, chemistry, engineering, mathematics, and computer sciences. Papers cover a broad range of subjects, with major emphasis on measurement methodology and the basic technology underlying standardization. Also included from time to time are survey articles on topics closely related to the Institute's technical and scientific programs. Issued six times a year.

\section{Nonperiodicals}

Monographs-Major contributions to the technical literature on various subjects related to the Institute's scientific and technical activities.

Handbooks-Recommended codes of engineering and industrial practice (including safety codes) developed in cooperation with interested industries, professional organizations, and regulatory bodies.

Special Publications-Include proceedings of conferences sponsored by NIST, NIST annual reports, and other special publications appropriate to this grouping such as wall charts, pocket cards, and bibliographies.

Applied Mathematics Series-Mathematical tables, manuals, and studies of special interest to physicists, engineers, chemists, biologists, mathematicians, computer programmers, and others engaged in scientific and technical work.

National Standard Reference Data Series-Provides quantitative data on the physical and chemical properties of materials, compiled from the world's literature and critically evaluated. Developed under a worldwide program coordinated by NIST under the authority of the National Standard Data Act (Public Law 90-396). NOTE: The Journal of Physical and Chemical Reference Data (JPCRD) is published bimonthly for NIST by the American Chemical Society (ACS) and the American Institute of Physics (AIP). Subscriptions, reprints, and supplements are available from ACS, 1155 Sixteenth St., NW, Washington, DC 20056.

Building Science Series-Disseminates technical information developed at the Institute on building materials, components, systems, and whole structures. The series presents research results, test methods, and performance criteria related to the structural and environmental functions and the durability and safety characteristics of building elements and systems.

Technical Notes-Studies or reports which are complete in themselves but restrictive in their treatment of a subject. Analogous to monographs but not so comprehensive in scope or definitive in treatment of the subject area. Often serve as a vehicle for final reports of work performed at NIST under the sponsorship of other government agencies.

Voluntary Product Standards-Developed under procedures published by the Department of Commerce in Part 10, Title 15, of the Code of Federal Regulations. The standards establish nationally recognized requirements for products, and provide all concerned interests with a basis for common understanding of the characteristics of the products. NIST administers this program in support of the efforts of privatesector standardizing organizations.

Consumer Information Series-Practical information, based on NIST research and experience, covering areas of interest to the consumer. Easily understandable language and illustrations provide useful background knowledge for shopping in today's technological marketplace.

Order the above NIST publications from: Superintendent of Documents, Government Printing Office, Washington, DC 20402.

Order the following NIST publications-FIPS and NISTIRs-from the National Technical Information Service, Springfield, VA 22161.

Federal Information Processing Standards Publications (FIPS PUB)-Publications in this series collectively constitute the Federal Information Processing Standards Register. The Register serves as the official source of information in the Federal Government regarding standards issued by N1ST pursuant to the Federal Property and Administrative Services Act of 1949 as amended, Public Law 89-306 (79 Stat. 1127), and as implemented by Executive Order 11717 (38 FR 12315, dated May 11, 1973) and Part 6 of Title 15 CFR (Code of Federal Regulations).

NIST Interagency Reports (NISTIR)-A special series of interim or final reports on work performed by NIST for outside sponsors (both government and non-government). In general, initial distribution is handled by the sponsor; public distribution is by the National Technical Information Service. Springfield, VA 22161, in paper copy or microfiche form. 
U.S. Department of Commerce

National Institute of Standards and Technology 325 Broadway

Boulder, Colorado 80303-3328

Official Business

Penalty for Private Use, $\$ \mathbf{3 0 0}$ 